
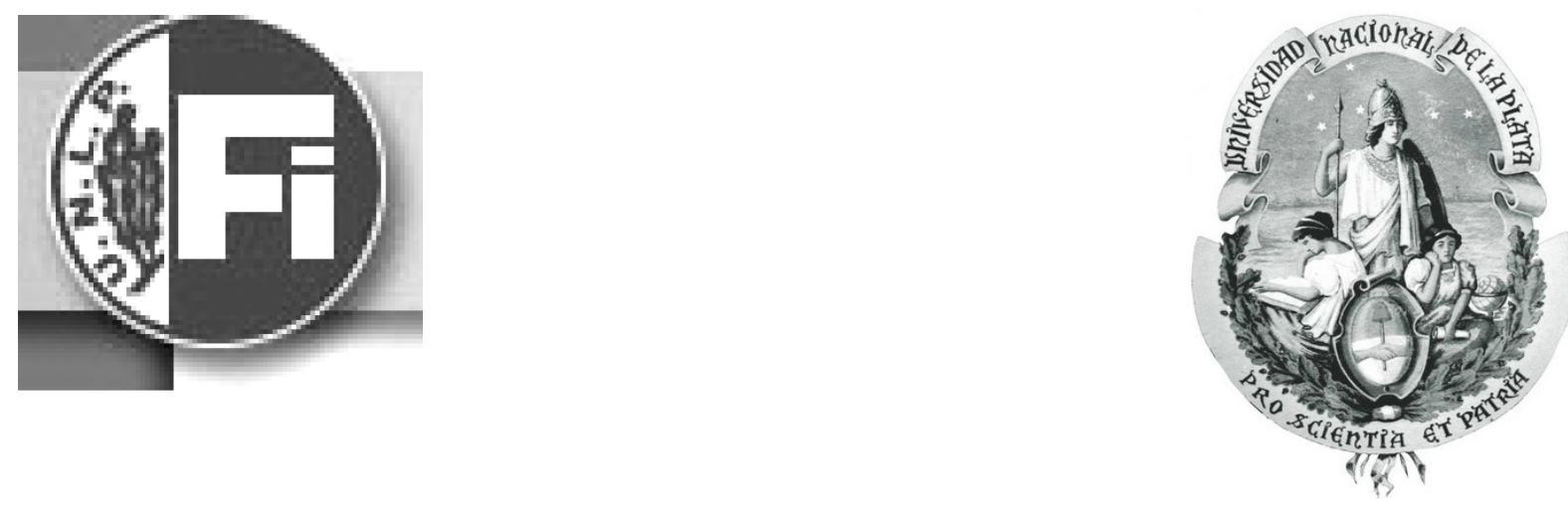

\title{
"Evaluación sobre el uso de arcillas para la adsorción de colorantes utilizados en la industria textil"
}

\author{
Tesis de Doctorado \\ Susana Yamila Martinez Stagnaro \\ Presentada ante la Facultad de Ingeniería \\ Universidad Nacional de La Plata \\ Para acceder al grado académico de \\ DOCTOR EN INGENIERÍA
}

Dirección de Tesis

Dra Ing. Cristina Volzone

\author{
Jurado de Tesis \\ Dra Alejandra Giaveno Dr Ricardo Etcheverry Ing. Mónica A. Trezza
}




\title{
"Evaluación sobre el uso de arcillas para la adsorción de colorantes utilizados en la industria textil"
}

\author{
Tesis Doctoral presentada por \\ Susana Yamila Martinez Stagnaro \\ ante la \\ Facultad de Ingeniería de la \\ Universidad Nacional de La Plata \\ para acceder al grado académico de
}

\section{DOCTOR EN INGENIERÍA}

\author{
Dirección de Tesis \\ Dra Ing. Cristina Volzone \\ Representate Departamental \\ Ing. Norma Gallegos
}

La Plata, Marzo 2017 


\section{ÍNDICE DE CONTENIDOS}

Nomenclatura.

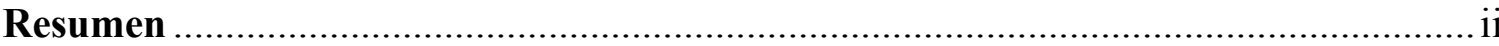

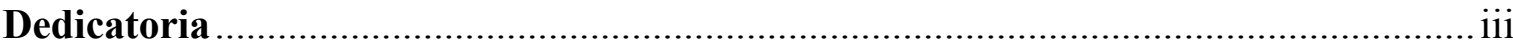

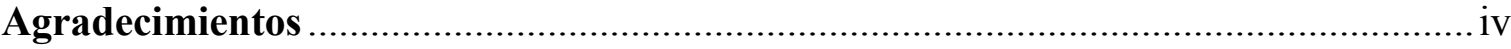

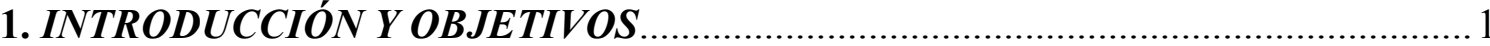

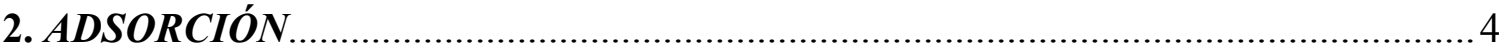

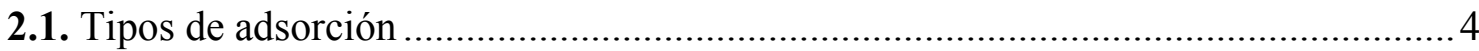

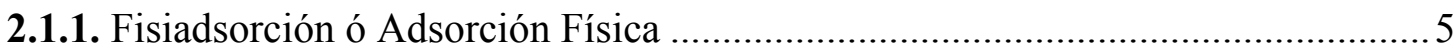

2.1.2. Quimiadsorción ó Adsorción Química ……......................................................

2.1.3. Diferencias entre Adsorción Física y Química......................................................5

2.2. Factores que intervienen en los mecanismos de adsorción en fase líquida ...............6

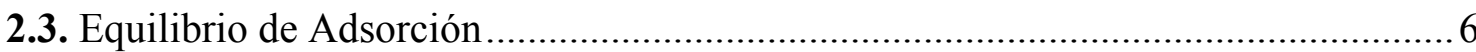

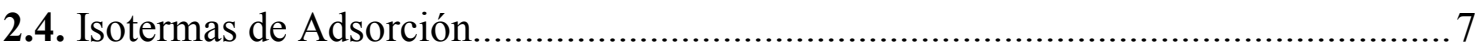

2.4.1. Modelo de Isoterma de Langmuir .............................................................

2.4.2. Modelo de Isoterma de Freundlich ................................................................

2.4.3. Modelo de Isoterma de Brunauer, Emmet y Teller (BET) ..................................9

2.4.4. Modelo de isoterma Lineal o de Henry …........................................................ 10

2.4.5. Clasificación de Isotermas de Adsorción de compuestos en solución ................... 11

3. ARCILLAS

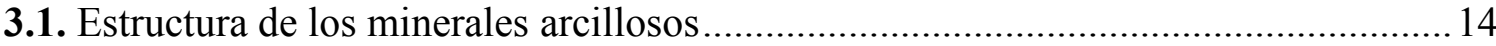

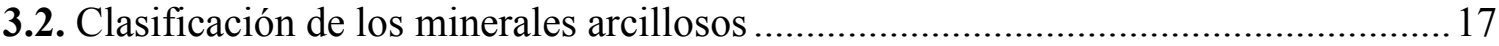

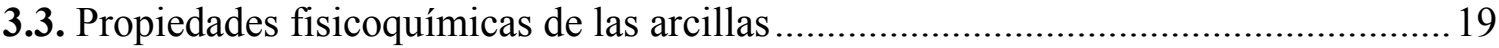

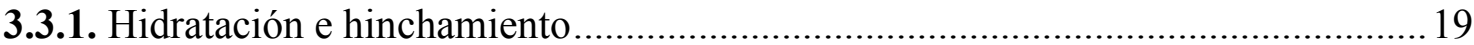

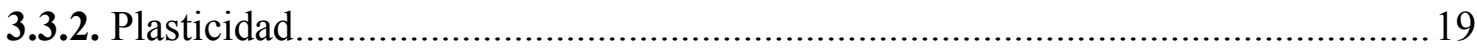

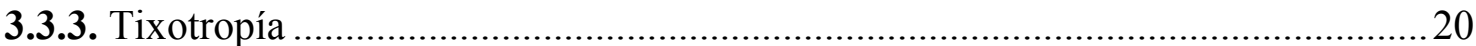




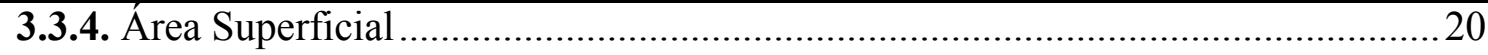

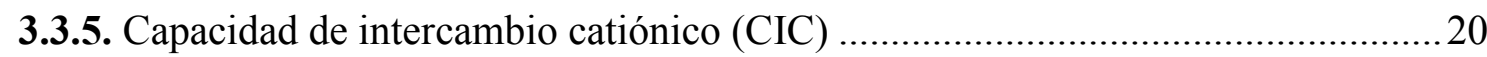

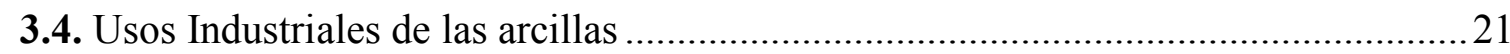

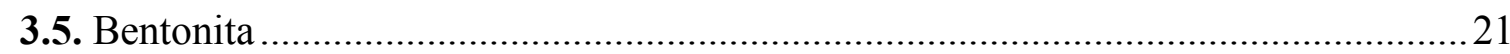

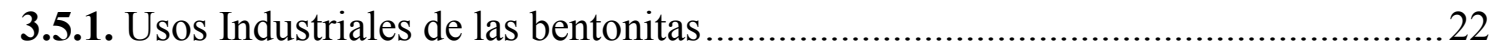

3.5.2. Bentonitas como adsorbentes de contaminantes acuosos ..................................22

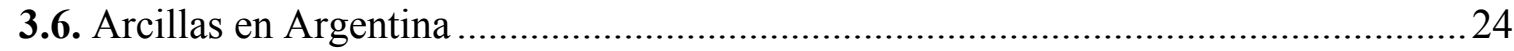

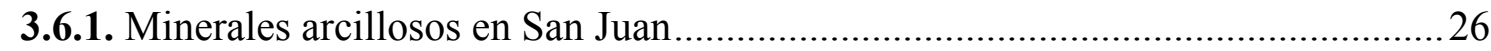

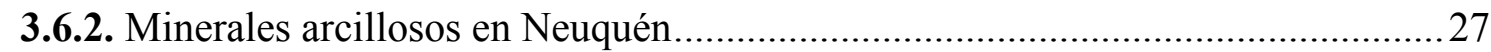

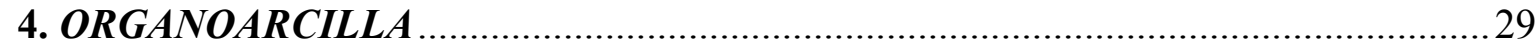

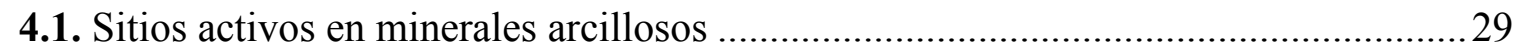

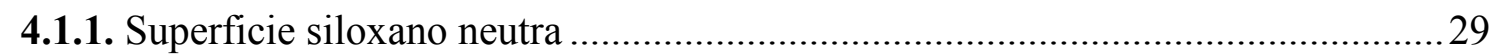

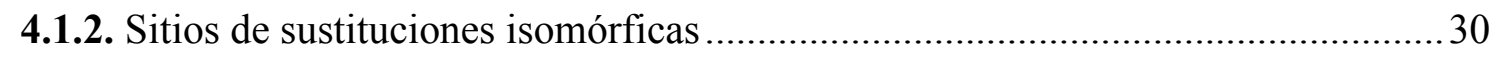

4.1.3. Cationes metálicos ocupando sitios de cationes de intercambio ......................... 30

4.1.4. Moléculas de agua alrededor de los cationes de intercambio................................ 31

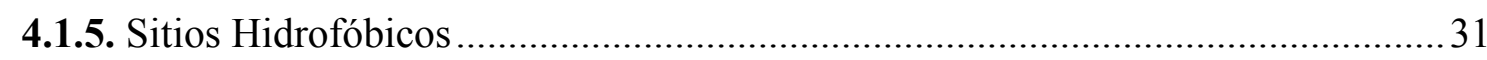

4.1.6. Sitios de bordes rotos y superficie expuesta de grupos silicio y aluminio ............31

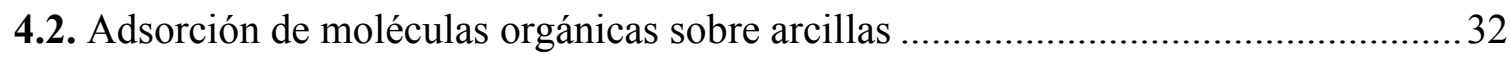

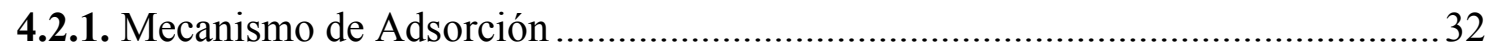

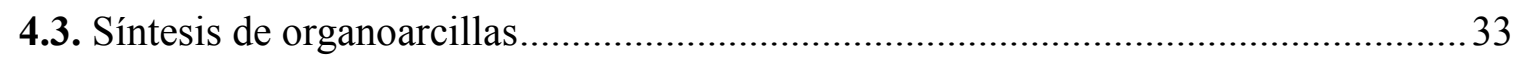

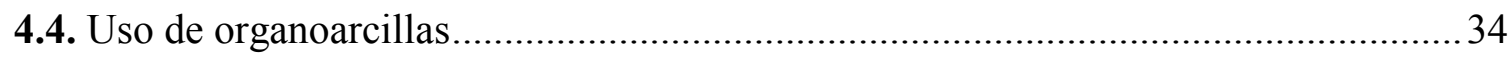

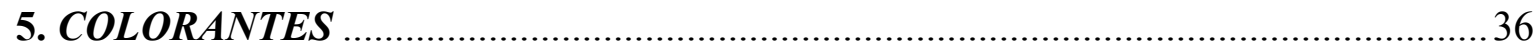

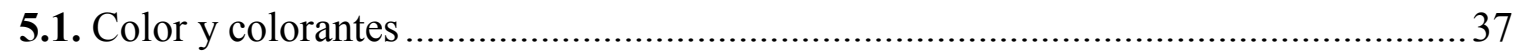

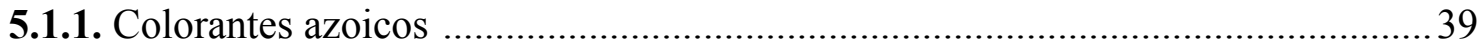

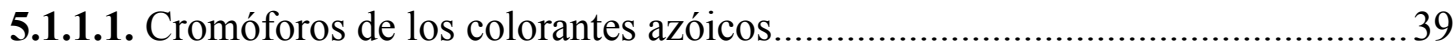

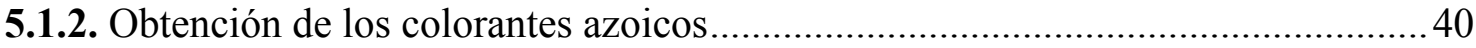


5.3.1. Red Allura AC 42

5.3.1.1. Toxicidad. 42

5.3.1.2. Estructura Química .43

5.3.1.3. Propiedades y Usos .43

5.3.2. Orange $G$ .44

5.3.2.1. Toxicidad .44

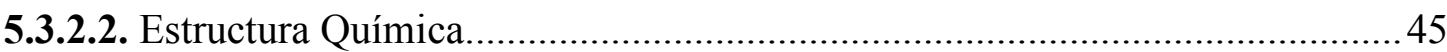

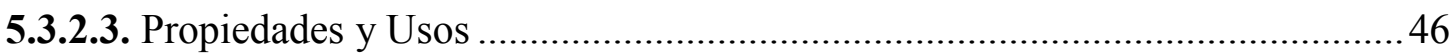

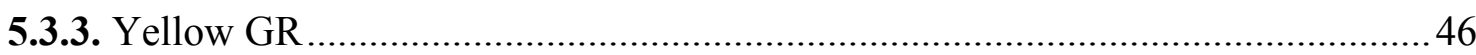

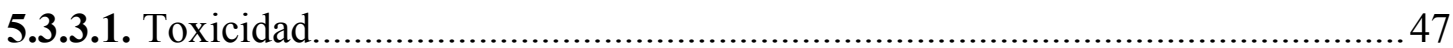

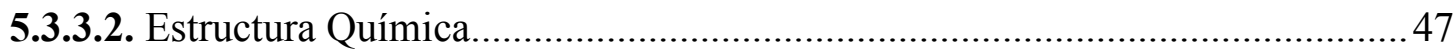

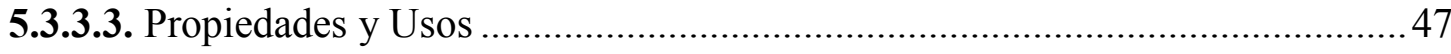

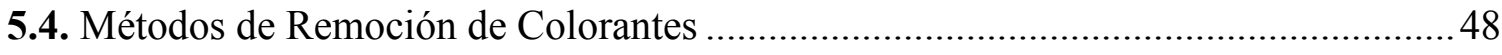

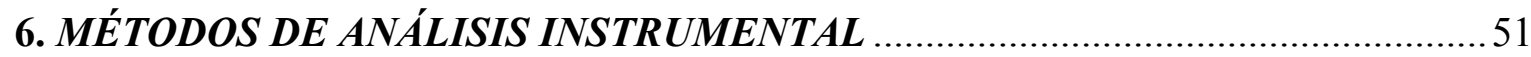

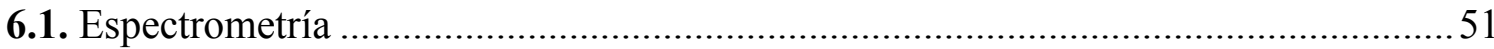

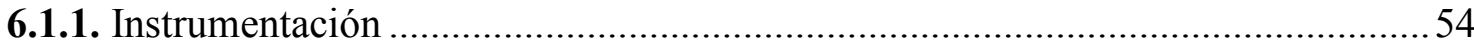

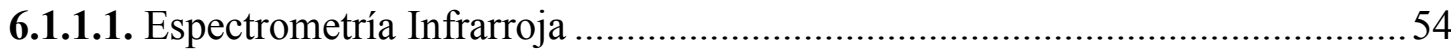

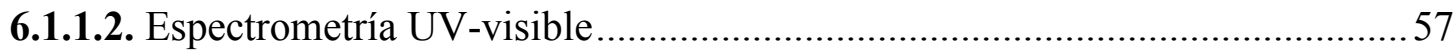

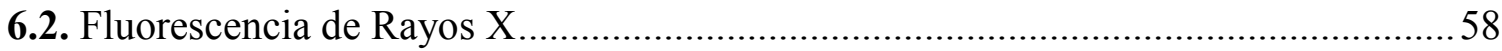

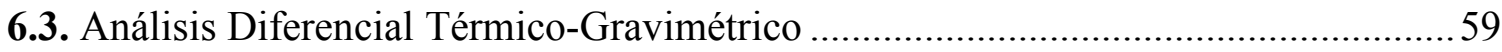

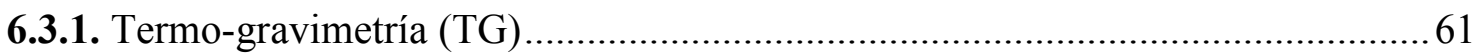

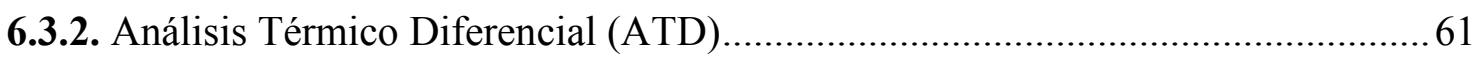

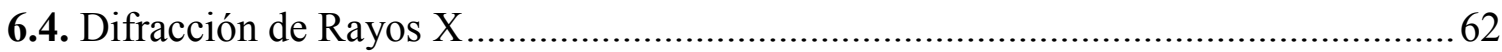

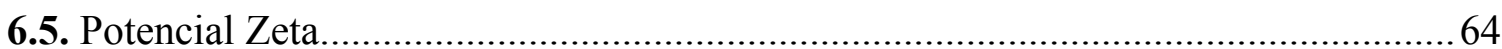




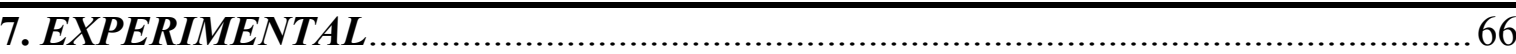

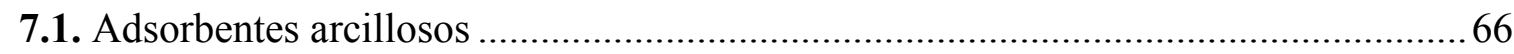

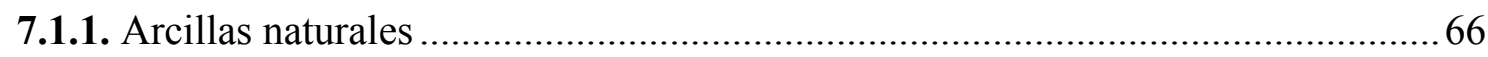

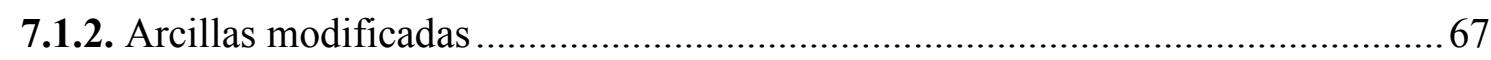

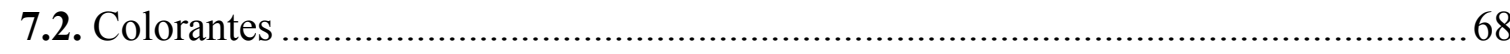

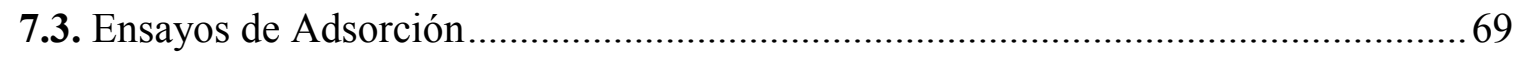

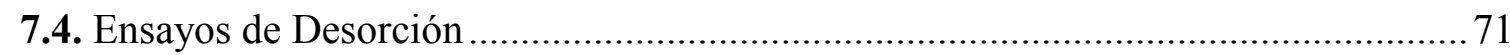

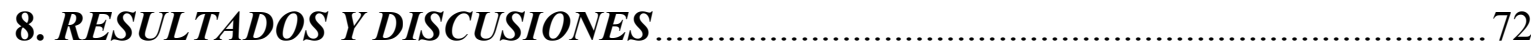

8.1. Composición estructural de los colorantes estudiados - Análisis comparativo .......... 72

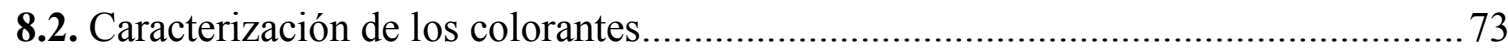

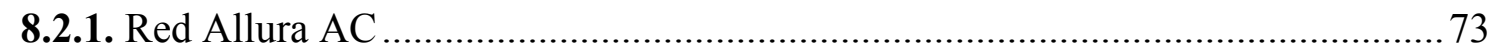

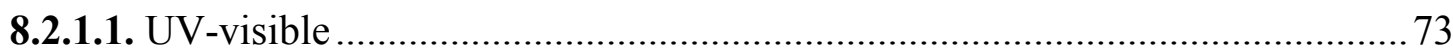

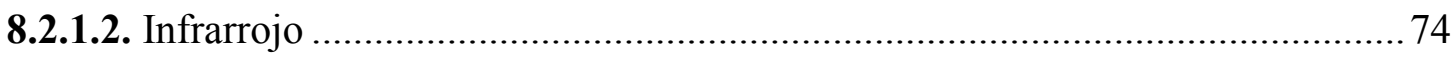

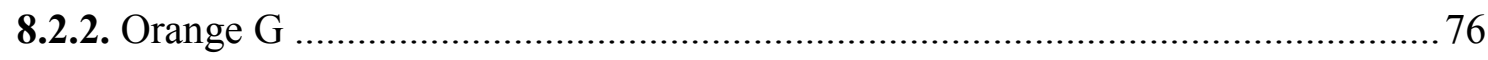

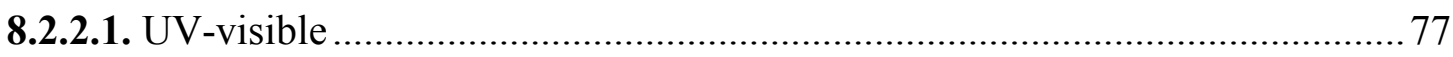

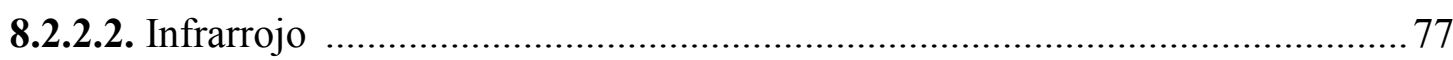

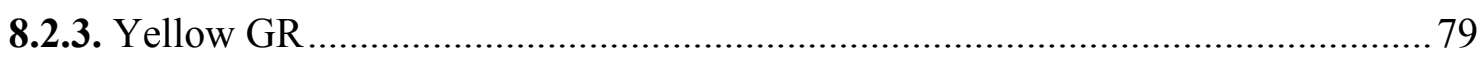

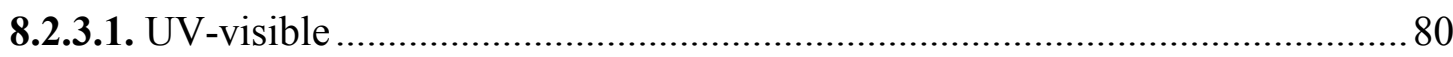

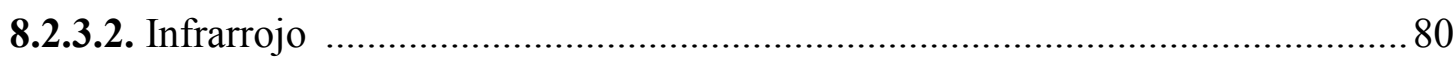

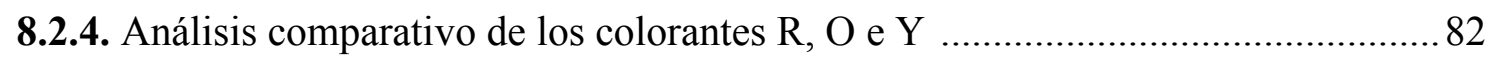

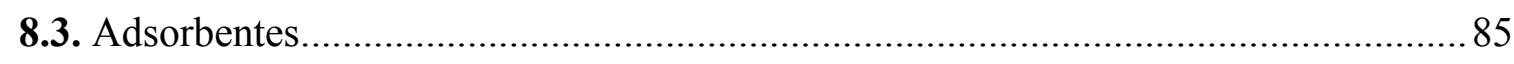

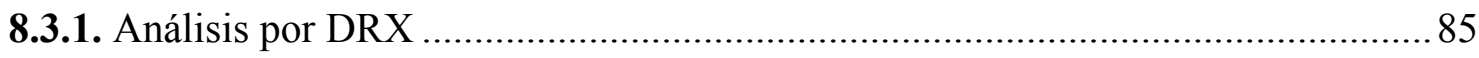

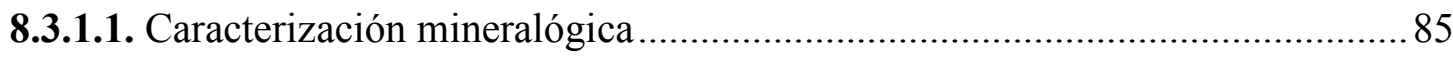

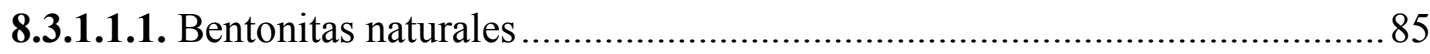

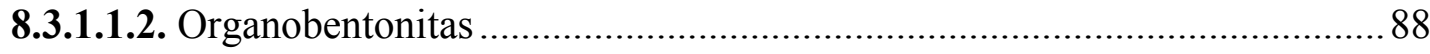

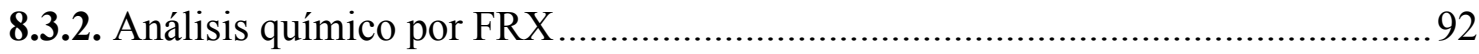


8.3.3. Análisis ATD-TG .................................................................................... 94

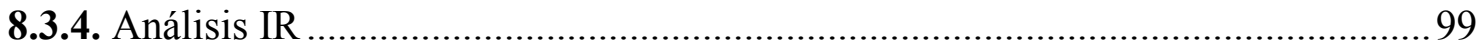

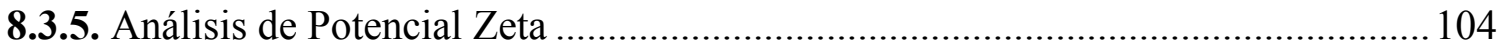

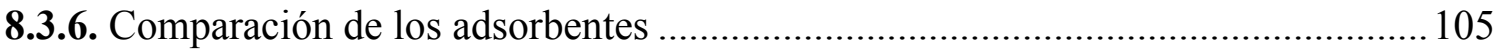

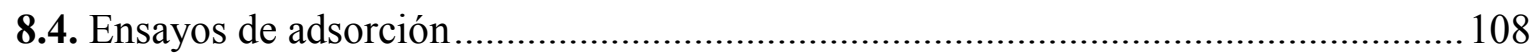

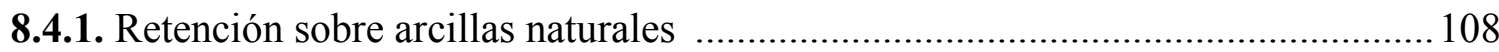

8.4.1.1. Análisis por UV-visible de suspensiones centrifugadas del sistema

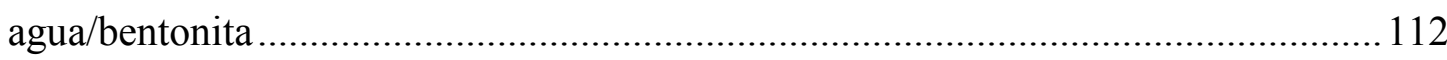

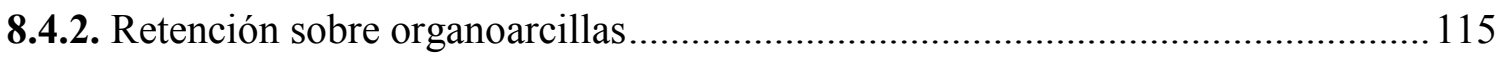

8.4.2.1. Análisis de la cantidad agregada del adsorbente por volumen de colorante $(\mathrm{mg} / \mathrm{mL})$ versus retención de colorante $(\%)$............................................................ 118

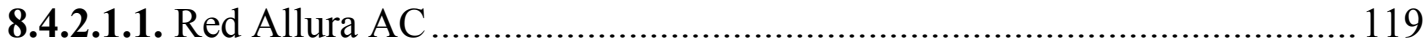

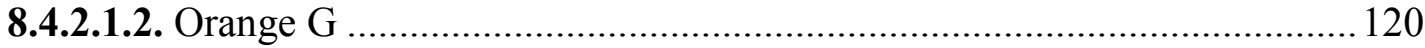

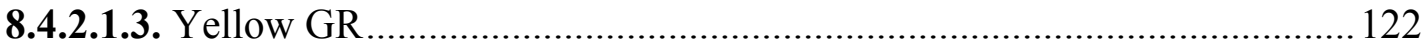

8.4.2.1.4. Comparación de retenciones de los tres colorantes $\mathrm{R}, \mathrm{O}$ e $\mathrm{Y}$, por las organobentonitas considerando cantidad agregada de sólido

8.4.2.2. Isotermas de adsorción

8.4.2.2.1. Isotermas de adsorción grupo cromóforo azo de los colorantes $\mathrm{Y}, \mathrm{O}$ y $\mathrm{R}$

8.4.2.2. Isotermas de adsorción grupo cromóforo naftaleno de los colorantes $\mathrm{O}$ y $\mathrm{R}$

8.4.2.2.3. Isotermas de adsorción grupo cromóforo benceno del colorante $\mathrm{O}$

8.4.5. Comparación en la adsorción de los tintes $\mathrm{R}, \mathrm{O}$ e $\mathrm{Y}$

8.5. Caracterización de los productos de adsorción

8.5.1. Análisis por DRX. Espaciado interlaminar (d001).

8.5.2. Análisis por ATD-TG

8.5.3. Análisis por IR 
8.5.4. Ensayos de Desorción..................................................................................... 150

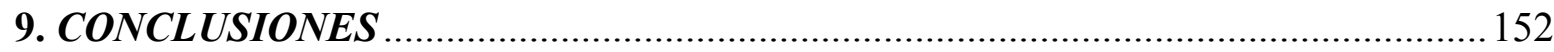

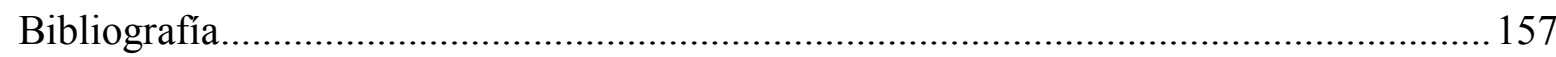

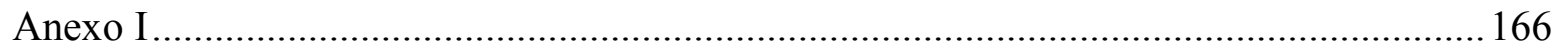

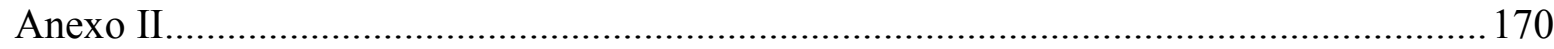




\section{ÍNDICE DE FIGURAS}

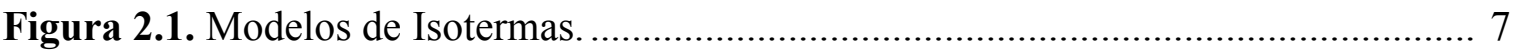

Figura 2.2. Clasificación de Isotermas de Giles et. al. 1960........................................... 11

Figura 3.1. a) Estructura de la capa tetraédrica (T). b) Estructura de la capa octaédrica (O).

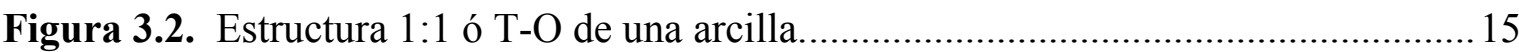

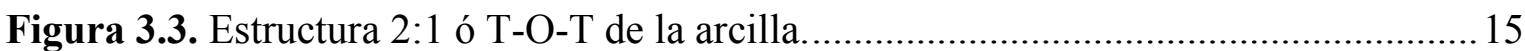

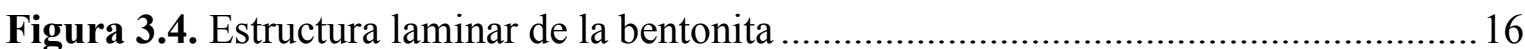

Figura 3.5. Producción mineral de la provincia de San Juan del año 2013 .......................27

Figura 3.6. Producción mineral de la provincia de Neuquén del año 2015 ......................27

Figura 5.1. Región visible del espectro electromagnético. .............................................36

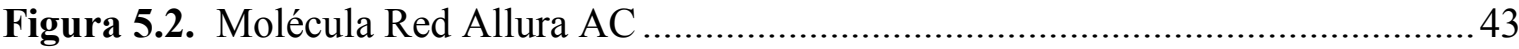

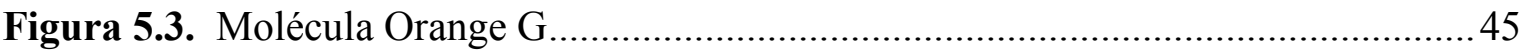

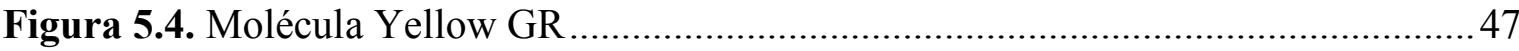

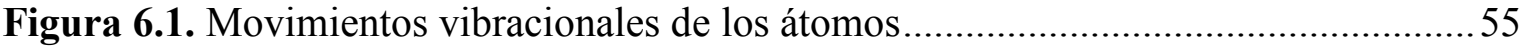

Figura 6.2. Espectometro IR Spectrum One Perkin Elmer ..........................................57

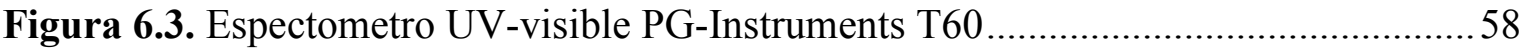

Figura 6.4. Equipo de Fluorescencia de Rayos X Shimadzu EDX-800HS .......................59

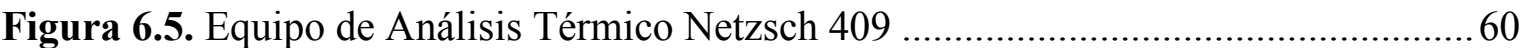

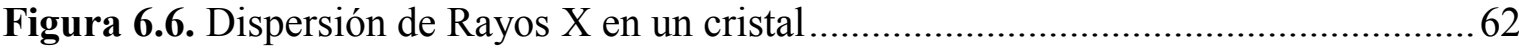

Figura 6.7. Equipo de Difracción de Rayos X Bruker D8 Advance ...................................64

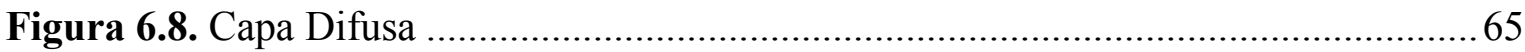

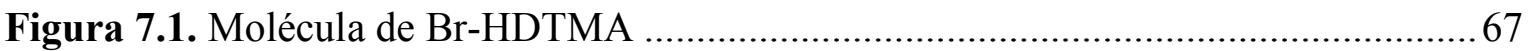

Figura 7.2. Preparación de los sólidos adsorbentes So y Zo ...............................................68

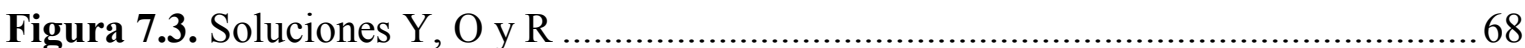

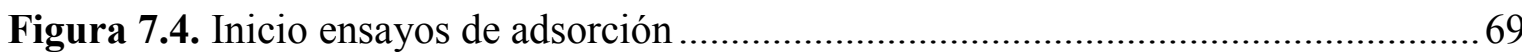


Figura 7.5. Finalización de los ensayos de adsorción

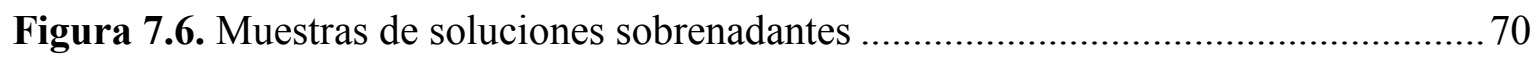

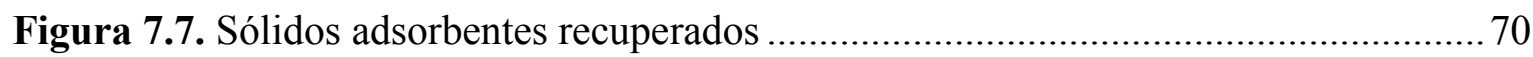

Figura 7.8. Esquema de adsorción de colorantes ...................................................... 71

Figura 7.9. a) Ensayos de desorción So; b) Ensayos de desorción Zo ..............................71

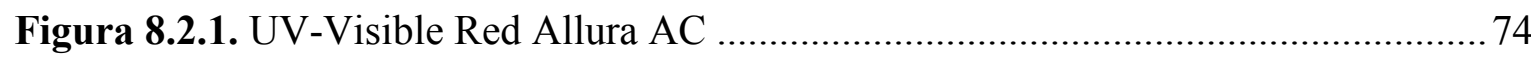

Figura 8.2.2. IR (3600-2600 $\left.\mathrm{cm}^{-1}\right)$ del colorante Red Allura AC .................................... 74

Figura 8.2.3. IR $\left(1700-700 \mathrm{~cm}^{-1}\right)$ del colorante Red Allura AC ...................................... 75

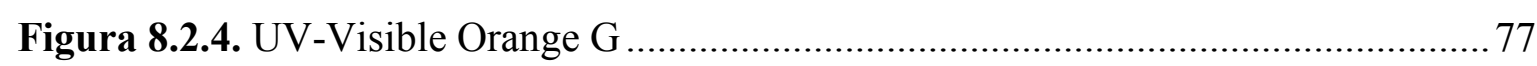

Figura 8.2.5. IR $\left(3600-2600 \mathrm{~cm}^{-1}\right)$ del colorante Orange G......................................... 78

Figura 8.2.6. IR $\left(1700-700 \mathrm{~cm}^{-1}\right)$ del colorante Orange G.............................................. 78

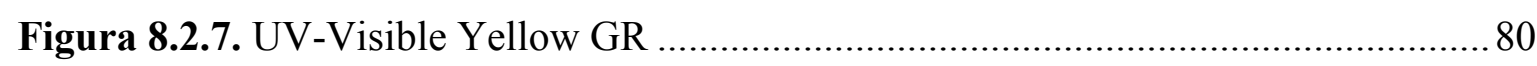

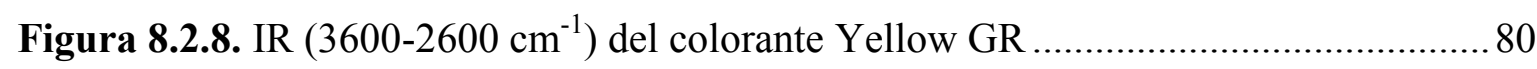

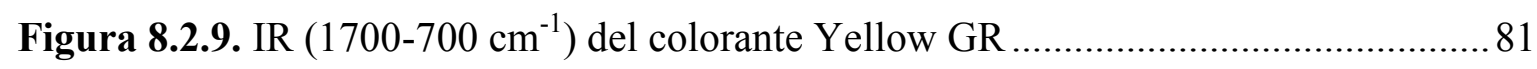

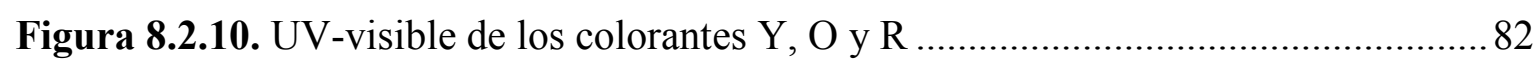

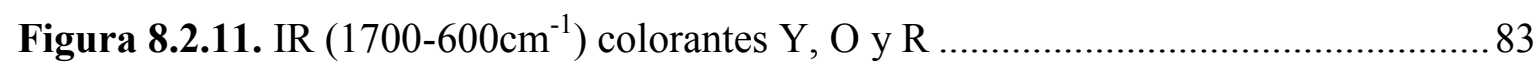

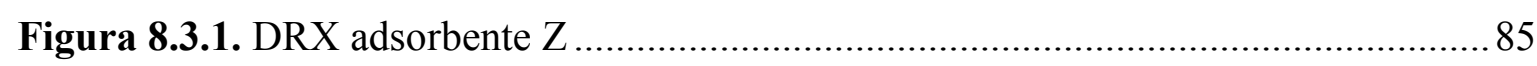

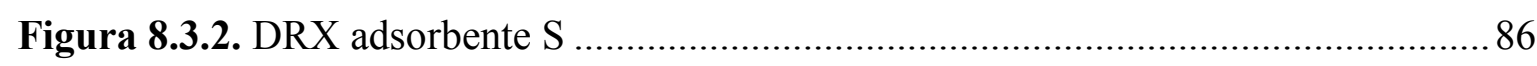

Figura 8.3.3. DRX de la bentonita $Z$ natural Z-n, glicolada Z-g y calcinada Z-c.............87

Figura 8.3.4. DRX de la bentonite S natural S-n, glicolada S-g y calcinada S-c..............87

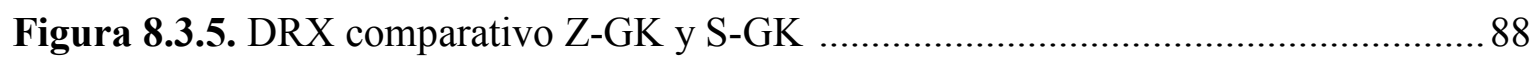

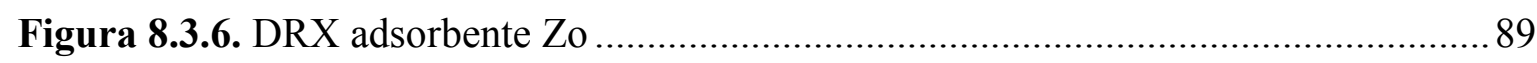

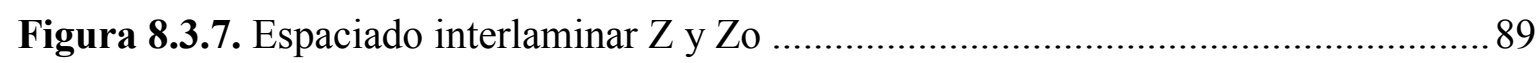

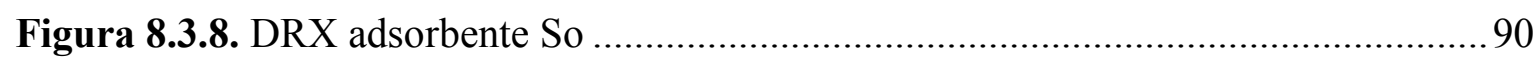

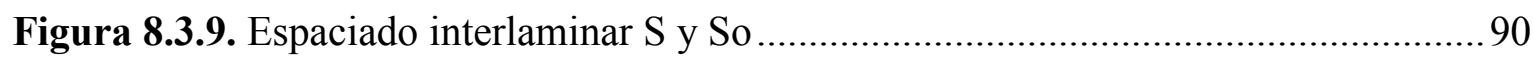


Figura 8.3.10. Orientación de los cationes orgánicos entre las láminas del mineral arcilloso

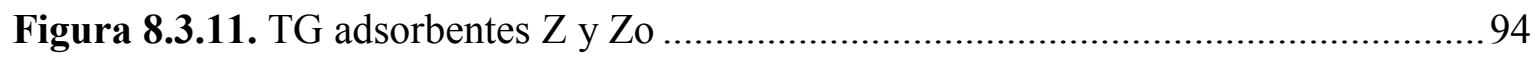

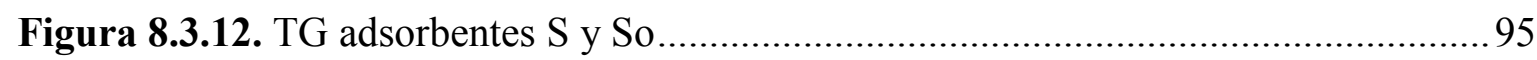

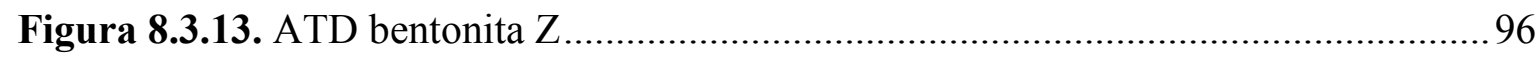

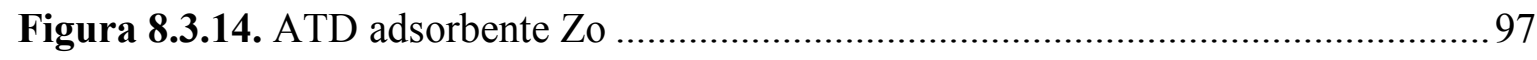

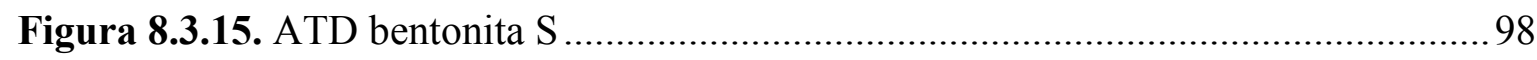

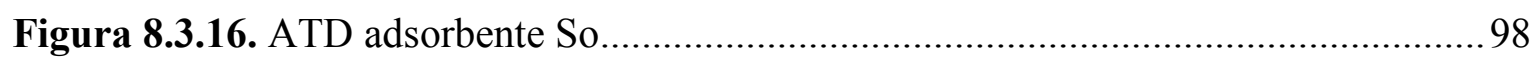

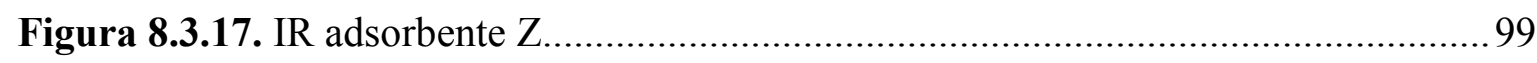

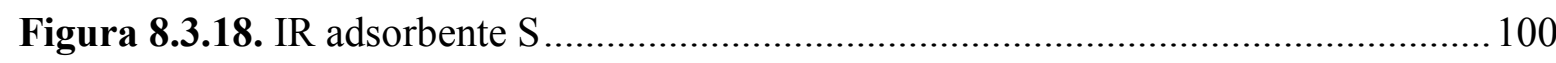

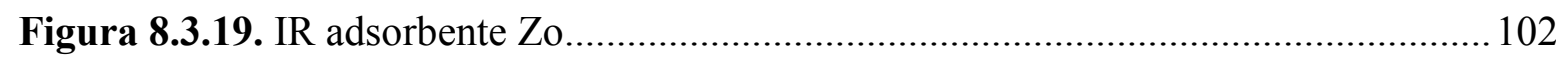

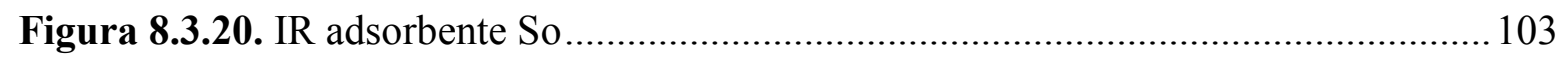

Figura 8.4.1. Ensayos UV-visible de las soluciones sobrenadantes resultantes de los ensayos sobre el adsorbente natural S y el colorante R................................................ 108

Figura 8.4.2. Ensayos UV-visible de las soluciones sobrenadantes resultantes de los ensayos sobre el adsorbente natural $\mathrm{Z}$ y el colorante $\mathrm{R}$

Figura 8.4.3. Ensayos UV-visible de las soluciones sobrenadantes resultantes de los ensayos sobre el adsorbente natural $\mathrm{S}$ y el colorante $\mathrm{O}$

Figura 8.4.4. Ensayos UV-visible de las soluciones sobrenadantes resultantes de los ensayos sobre el adsorbente natural $\mathrm{Z}$ y el colorante $\mathrm{O}$

Figura 8.4.5. Ensayos UV-visible de las soluciones sobrenadantes resultantes de los ensayos sobre el adsorbente natural $\mathrm{S}$ y el colorante $\mathrm{Y}$.

Figura 8.4.6. Ensayos UV-visible de las soluciones sobrenadantes resultantes de los ensayos sobre el adsorbente natural $\mathrm{Z}$ y el colorante $\mathrm{Y}$.....

Figura 8.4.7. Finalización de ensayo S24h y Z24h

Figura 8.4.8. Análisis UV-visible de los sobrenadantes del sistema bentonita/agua S24h. 
Figura 8.4.9. Análisis UV-visible de los sobrenadantes del sistema bentonita/agua $\mathrm{Z} 24 \mathrm{~h}$ 113

Figura 8.4.10. Ensayos UV-visible de las soluciones sobrenadantes resultantes de las experiencias sobre el adsorbente So y el colorante $\mathrm{R}$

Figura 8.4.11. Ensayos UV-visible de las soluciones sobrenadantes resultantes de las experiencias sobre el adsorbente So y el colorante $\mathrm{O}$

Figura 8.4.12. Ensayos UV-visible de las soluciones sobrenadantes resultantes de las experiencias sobre el adsorbente So y el colorante Y

Figura 8.4.13. Ensayos UV-visible de las soluciones sobrenadantes resultantes de las experiencias sobre el adsorbente Zo y el colorante R

Figura 8.4.14. Ensayos UV-visible de las soluciones sobrenadantes resultantes de las experiencias sobre el adsorbente Zo y el colorante $\mathrm{O}$

Figura 8.4.15. Ensayos UV-visible de las soluciones sobrenadantes resultantes de las experiencias sobre el adsorbente Zo y el colorante $\mathrm{Y}$

Figura 8.4.16. Ensayos de retención So-R(azo) y So-R(naftaleno)

Figura 8.4.17. Ensayos de retención Zo-R(azo) y Zo-R(naftaleno)

Figura 8.4.18. Ensayos de retención So-O(azo), So-O(naftaleno) y So-O(benceno)........ 120

Figura 8.4.19. Ensayos de retención Zo-O(azo), Zo-O(naftaleno) y Zo-O(benceno)........ 121

Figura 8.4.20. Ensayos de retención So-Y(azo)

Figura 8.4.21. Ensayos de retención Zo-Y(azo)

Figura 8.4.22. Comparación de retención del grupo azoico en $\mathrm{R}, \mathrm{O}$ e $\mathrm{Y}$ sobre los adsorbentes So y Zo

Figura 8.4.23. Comparación de retención del grupo naftaleno en $\mathrm{R}$ y $\mathrm{O}$ sobre los adsorbentes So y Zo

Figura 8.4.24. Comparación de retención del grupo bencénico en $\mathrm{O}$ sobre los adsorbentes So y Zo

Figura 8.4.25. Isotermas de adsorción del grupo azo en $\mathrm{Y}, \mathrm{O}$ y R sobre So 126

Figura 8.4.26. Isotermas de adsorción del grupo azo en Y, O y R sobre Zo 127 
Figura 8.4.27. Isotermas de adsorción del grupo naftaleno en O y R sobre So .................128

Figura 8.4.28. Isotermas de adsorción del grupo naftaleno en $\mathrm{O}$ y R sobre Zo.................129

Figura 8.4.29. Isotermas de adsorción del grupo bencénico en O para So y Zo................ 130

Figura 8.5.1. Espacio interlaminar organoarcilla So y So-R/Y/O.................................136

Figura 8.5.2. Espacio interlaminar organoarcilla So y So-R/Y/O ..................................137

Figura 8.5.3. TG muestras Zo y Zo-R/Y/O ............................................................. 138

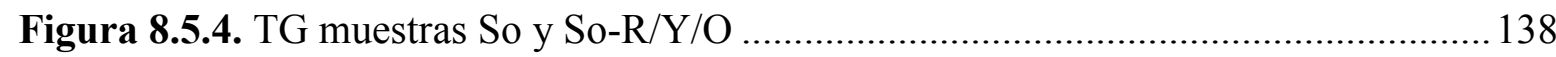

Figura 8.5.5. ATD muestras Zo y Zo-R/O/Y .......................................................... 140

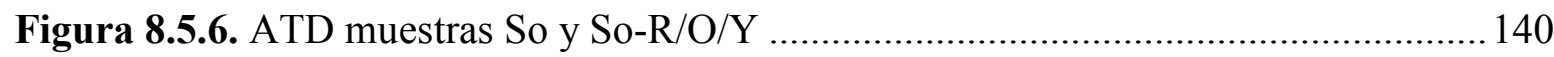

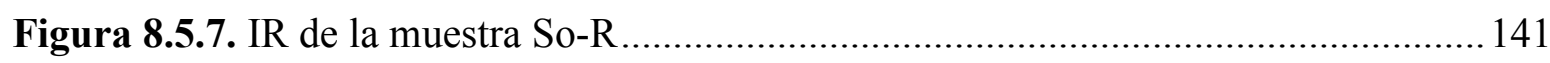

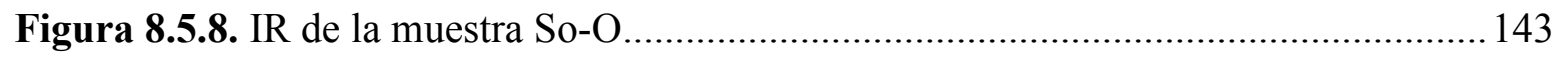

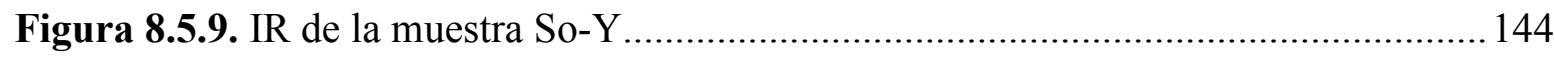

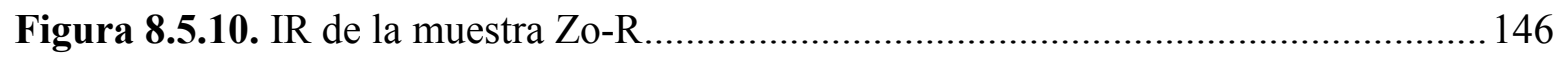

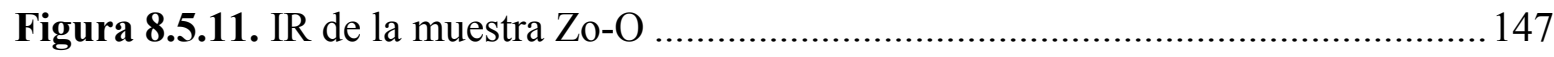

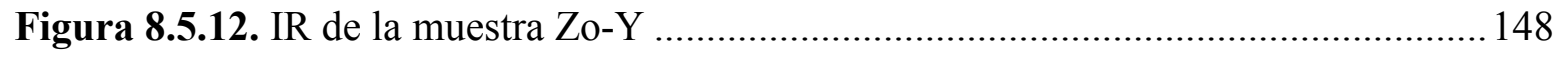

Figura 8.5.13. UV-visible ensayos de desorción So-R/O/Y ......................................... 150

Figura 8.5.14. UV-visible ensayos de desorción Zo-R/O/Y ......................................... 151 


\section{ÍNDICE DE TABLAS}

Tabla 2.1. Diferencias entre Fiasiadsorción y Quimiadsorción ...................................... 6

Tabla 3.1. Distribución de cargas de una montmorillonita ........................................... 16

Tabla 3.2. Características estructurales de los principales grupos de minerales

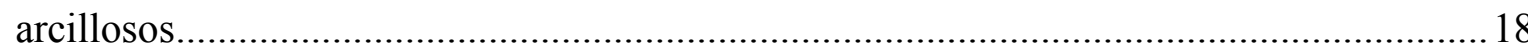

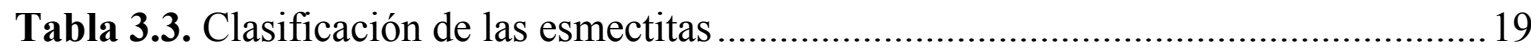

Tabla 3.4. Distribución de cargas de una montmorillonita ...............................................20

Tabla 3.5. Capacidad de intercambio catiónico de minerales arcillosos............................21

Tabla 5.1. Relación entre la luz absorbida y el color observado .........................................36

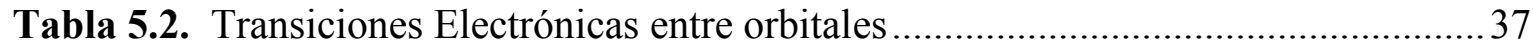

Tabla 5.3. Longitud de Onda absorbida en el espectro UV-Visible por polienos

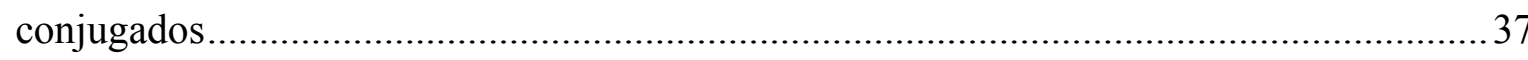

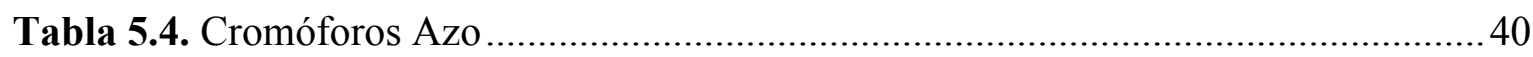

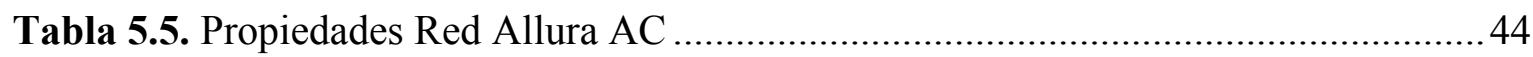

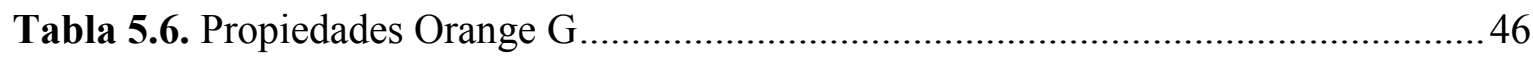

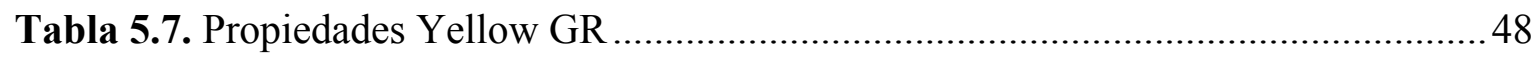

Tabla 8.1.1. Comparación estructural colorantes R, O e Y …......................................... 72

Tabla 8.2.1. Bandas de absorción y grupos asociados Red Allura ....................................76

Tabla 8.2.2. Bandas de absorción y grupos asociados Orange ........................................ 79

Tabla 8.2.3. Bandas de absorción y grupos asociados Yellow........................................... 81

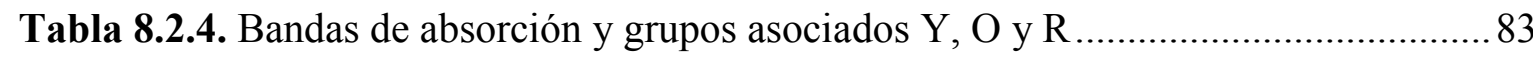

Tabla 8.3.1. Análisis químico por FRX de los adsorbentes ............................................92

Tabla 8.3.2. Fase mineralógica de las muestras $\mathrm{S} y \mathrm{Z}$.........................................................93

Tabla 8.3.3. Pérdidas de masa de los adsorbentes S, So, Z y Zo .....................................95

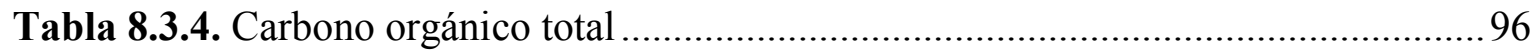


Tabla 8.3.5. Temperatura de picos endo/exo-térmicos establecidos de los espectros

ATD de las bentonitas naturales $\mathrm{S}$ y $\mathrm{Z}$ .99

Tabla 8.3.6. Bandas de absorción y grupos asociados del adsorbente Z........................... 100

Tabla 8.3.7. Bandas de absorción y grupos asociados del adsorbente $\mathrm{S} \ldots \ldots \ldots \ldots \ldots \ldots \ldots \ldots \ldots . . . . . . . . . . .101$

Tabla 8.3.8. Bandas de absorción y grupos asociados del adsorbente Zo.......................... 102

Tabla 8.3.9. Bandas de absorción y grupos asociados del adsorbente So .......................... 104

Tabla 8.3.10. Potencial zeta de los adsorbentes naturales (S y Z) y orgánicas (So y Zo).. 105

Tabla 8.4.1. Parámetros de Langmuir del cromóforo azo ............................................. 127

Tabla 8.4.2. Parámetros de Langmuir del cromóforo naftaleno..................................... 129

Tabla 8.4.3. Parámetros de Langmuir del cromóforo benceno ..................................... 130

Tabla 8.4.4. Comparación $\mathrm{Xm}$ de los ensayos So-R/O/Y y Zo-R/O/Y en los grupos azo

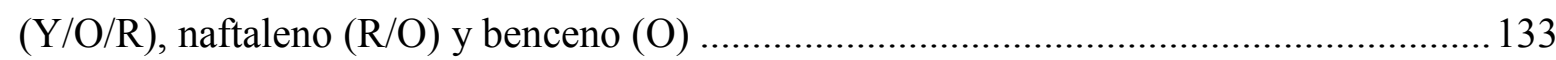

Tabla 8.4.5. Cantidad de átomos presentes en las estructura de los tintes Y, R y O......... 134

Tabla 8.5.1. Pérdidas de masa de los adsorbentes So-R/O/Y y Zo-R/O/Y ...................... 139

Tabla 8.5.2. Bandas de absorción y grupos asociados de la muestra So-R ....................... 142

Tabla 8.5.3. Bandas de absorción y grupos asociados de la muestra So-O....................... 143

Tabla 8.5.4. Bandas de absorción y grupos asociados de la muestra So-Y........................ 145

Tabla 8.5.5. Bandas de absorción y grupos asociados de la muestra Zo-R........................ 146

Tabla 8.5.6. Bandas de absorción y grupos asociados de la muestra Zo-O ...................... 148

Tabla 8.5.7. Bandas de absorción y grupos asociados de la muestra Zo-Y .......................149 



\section{NOMENCLATURA}

HDTMA-Br: Bromuro de hexadecil-trimetil-amonio

HDTMA $^{+}$: Catión hexadecil-trimetil-amonio

CIC: Capacidad de Intercambio Catiónico

COT: Carbono Orgánico Total

ATD: Análisis Térmico Diferencial

TG: Análisis Termo-Gravimétrico

FRX: Espectrometría de Fluorescencia de Rayos X

IR: Espectrometría Infrarrojo

UV-vis.: Espectrometría Ultravioleta-visible

DRX: Análisis por Difracción de Rayos X

GK: Ensayo de Greene-Kelly

PPC: Pérdida por calcinación

d: Espaciado basal (nm) 



\section{RESUMEN}

En la actualidad, una de las industrias que se encuentra en creciente auge y representa un importante sector económico a nivel mundial, debido a la gran demanda de sus productos, es la industria textil. En ella son utilizados diversos colorantes, los que después de un proceso de teñido, permanecen junto a una gran variedad de sustancias químicas que no se fijan en las fibras y son desechados. El comportamiento malicioso de éstos materiales se debe a que, parte de ellos, en solución acuosa, producen aminas secundarias, sustancias aromáticas, metales pesados, cloruros, etc.; propios de su estructura molecular, que pueden ser transportados por los sistemas fluviales, representando un potencial riesgo. Las arcillas son minerales naturales y abundantes en la naturaleza, constituidas fundamentalmente por aluminosilicatos laminares. En esta Tesis Doctoral, se estudió el proceso de adsorción de tres colorantes azo aniónicos textiles: Yellow GR (Y), Orange G (O) y Red Allura (R), empleando como adsorbentes dos materiales arcillosos conocidos como bentonitas, procedentes de las provincias de Neuquén (Z) y San Juan (S). Las bentonitas naturales (hidrofílicas por naturaleza) fueron transformadas en organofilicas (órgano-bentonitas) posterior al tratamiento con el catión hexadecil-trimetil-amonio para facilitar una mayor retención de los colorantes. Los sólidos fueron caracterizados por difracción de rayos X, espectroscopia infrarroja, análisis químicos, análisis térmicos diferencial y gravimétrico, y potencial zeta; los colorantes por infrarrojo y análisis en el UV-visible, en tanto que, las cantidades retenidas de los tintes fueron analizadas por isotermas de adsorción utilizando espectroscopia UV-visible. La disposición del catión orgánico en el mineral arcilloso de la bentonita, en forma de parafina o pseudotrilámina fue dependiente de la estructura interna del mineral e influyo en la capacidad de retención de los tintes. En ambos tipos de órganobentonita la retención del colorante Yellow fue mayor que el colorante Red y Orange, debido a la presencia de mayor contenido en grupos azo. Los grupos cromóforos naftaleno (presente en el $\mathrm{R}$ y O) y benceno (presente en $\mathrm{O}$ ) también fueron retenidos por las órganobentonitas. 

Dedicado a Chale...

Ea razón de todo, mi vida... 

A Cristina Volzone, por haber confiado en mi capacidad, su guía y continua enseñanza, $y$ principalmente por su gran amistad. A Jorge Venaruzzo, por iniciarme en la investigación y contagiarme su pasión por ella, siempre estaré muy agradecida querido amigo.

A Norma Gallegos, por brindarme su apoyo como representante departamental en la carrera doctoral, además de su aporte en la realización de los ensayos IR. A Ana María Casé, por confiar en mí y brindarme su apoyo desinteresado, como codirectora de beca de finalización doctoral. A la Facultad de Ingeniería de la Universidad Nacional de La Plata, por darme la oportunidad de realizar mi doctorado en tan prestigiosa casa de estudios. Al Consejo Nacional de Investigaciones Científicas y Técnicas (CONICET), por haberme permitido dedicarme exclusivamente a lo que tanto me apasiona. Al personal científico y técnico del Centro de Tecnología de Recursos Minerales y Cerámica (CETMIC), por los aportes realizados, y por permitirme utilizar el instrumental disponible.

Al personal del Instituto de Investigación y Desarrollo en Ingeniería de Procesos, Biotecnología y Energías Alternativas (PROBIEN-CONICET-UNCo), por permitirme el empleo del Espectrómetro UV-vis.

A Gastón Fouga de la División Cinética Química de la Comisión Nacional de Energía Atómica, del Centro Atómico Bariloche (CONEA-CAB), por la realización de parte de los ensayos IR y DRX. A Joaquín Cornejo y Alejandra Fuentes, por su aporte y gran ayuda en la realización de ensayos de laboratorio. A mis amigos hermanos, por acompañarme en las buenas y en las malas, siempre con alegría y mucho amor. A mis padres, hermanos y sobrinos, ;mi gran familia! por su incondicionalidad, acompañamiento y principalmente por los valores inculcados. A mi familia, Male y Pablo, por su inmenso y eterno amor, sin ustedes nada tendría sentido, gracias infinitas. 

..."Aprende como si fueras a vivir toda la vida, $y$ vive como si fueras a morir mañana”...

Charles Chaplin

(1887-1977) 


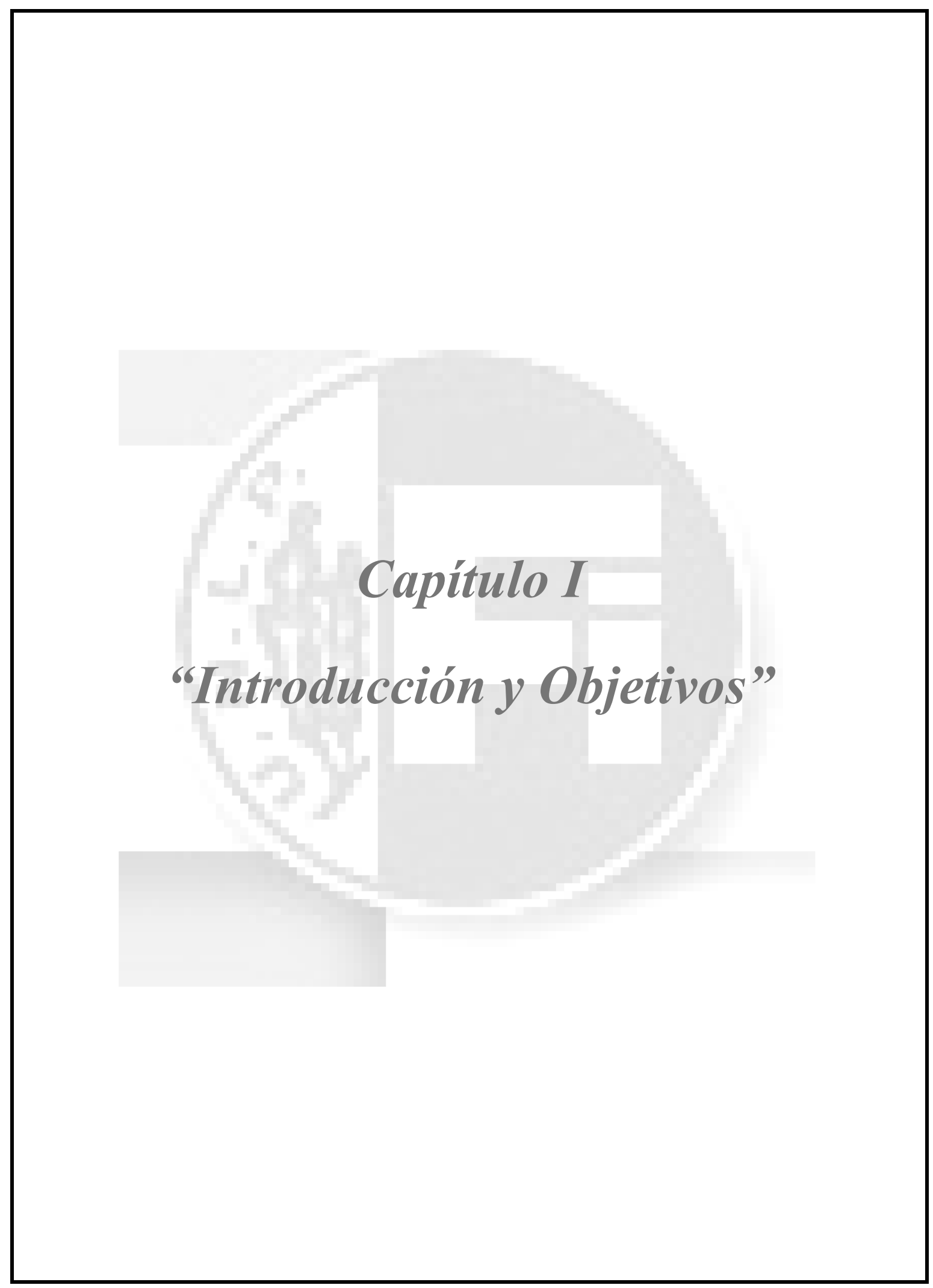




\section{INTRODUCCIÓN Y OBJETIVOS}

Como consecuencia de los numerosos problemas ambientales provocados por actividades antropogénicas, que dañan tanto el medio ambiente como a los seres vivos, es necesario estudiar y modificar aquellos procedimientos inadecuados para menguar los efectos nocivos de las actividades humanas.

En la industria textil son utilizados grandes volúmenes de colorantes, 10.000 variedades de colorantes textiles con una producción anual de $7 \times 10^{5}$ toneladas métricas están disponibles alrededor del mundo; $30 \%$ de éstos colorantes son usados en exceso de aproximadamente 1.000 toneladas por año, y $90 \%$ de los productos textiles son usados a niveles de hasta 100 toneladas anuales. Luego del proceso de tinción de las fibras entre $10 \%$ a $25 \%$ de ellos son perdidos durante ésta etapa y de $2 \%$ al $20 \%$ son descargados directamente a efluentes acuosos junto a una gran variedad de sustancias químicas que no se fijan en las fibras, llegando a producir en los lechos fluviales productos muy tóxicos, carcinogénicos y mutagénicos de diversas formas, compuestos tales como bencidina, naftaleno entre otros aromáticos (Baban y col. 2010; Robinson y col. 2001; Soloman y col. 2009). Al llegar éstos residuos a los cursos de aguas para consumo humano, producen efectos dañinos en órganos tales como: riñones, cerebro e hígado, generando el mal funcionamiento del sistema nervioso central, sistema reproductor, entre otros. Además son capaces de interferir directamente con algunas plantas acuáticas, afectando su actividad fotosintética. El comportamiento malicioso de éstos materiales se debe a que algunos de ellos tienen la capacidad de producir aminas en presencia de agua, y también pueden contener otras sustancias peligrosas como metales pesados, cloruros, etc. Cabe destacar que no solo la industria textil hace uso de colorantes, sino también las papeleras, cosméticos, impresiones, tapices y aquellas industrias que producen plásticos (Dawood y col. 2014).

Con el objetivo de disminuir el contenido de colorantes en los cuerpos de agua se han desarrollado diversas técnicas de eliminación o incluso recuperación. Los tratamientos de los efluentes de desechos de éste tipo, pueden ser químicos, físicos o biológicos; sin embargo ninguno de estos métodos por si solo logra extraer el $100 \%$ de los contaminantes, con lo cual es conveniente combinar los métodos para alcanzar mejores resultados; además en muchos de los casos, se trata sólo de tratamientos de decoloración, tales como procesos electroquímicos, procesos específicos mecánicofísicos, químicos, y en ocasiones biológicos (Suteu y col. 2009; Zaharia y col. 2006; 
Zaharia y col. 2009) que no llegan a eliminar las sustancias dañinas de los cuerpos de agua.

Los métodos de tratamiento de efluentes mediante la adsorción han sido estudiados e incluso puestos en práctica en los países más industrializados. Ayala y col. (2006), utilizaron membranas de nanofiltración, llegando a obtener resultados de hasta un $97 \%$ de recuperación de colorantes, éste procedimiento puede ser viable en la industria solo en el caso de ser justificado, por lo que puede ser, un costo alto del colorante, o bien, se encuentre en concentraciones que lleguen a justificar la inversión. Otros investigadores como Morales-Guzmán y Melgoza-Alemán (2009), combinaron técnicas de adsorción con mecanismos de reducción para la transformación y posterior eliminación de los compuestos tóxicos, en un sistema de dos reactores con lecho de carbón activado, que actúo como agente redox, aumentando la velocidad de reducción del colorante, y un lecho de biomasa que fue quien permitió, por medio de la acción de microorganismos, la eliminación del colorante. Si bien las investigaciones citadas arrojaron resultados positivos en cuanto a la remediación de aguas contaminadas con tintes, el llevar a la práctica estas tecnologías requiere de un gran costo, y suelen ser inalcanzables para pequeñas y medianas industrias. Por esto es importante realizar estudios empleando materiales menos costosos y con los cuales se obtengan resultados satisfactorios.

Una revisión de la literatura indica que la capacidad de adsorción de las arcillas naturales, activadas o modificadas puede ser muy elevada, con un costo mucho menor a los que implicaría un tratamiento como los mencionados con anterioridad. A lo largo y ancho de nuestro país podemos encontrar diversas rocas compuestas por una gran gama de minerales arcillosos. Los argilominerales reúnen propiedades naturales destacables para su empleo como adsorbente, propiedades que provienen de su reducido tamaño de partícula, estructura laminar y capacidad de intercambio catiónico. Una caracterización exhaustiva del mineral arcilloso: composición química, mineralógica, comportamiento térmico, morfología, etc., permitirá evaluar las propiedades que presenta y junto a ensayos de adsorción de laboratorio, bajo condiciones específicas, se determinará su potencial uso como adsorbentes de los tintes.

De acuerdo a datos bibliográficos la retención de colorantes orgánicos presentes en medios acuosos dependerá no solo de sus propiedades fisicoquímicas sino también de las propiedades de quien actúa como adsorbente. En el caso particular de esta tesis en donde 
se seleccionan tres colorantes azoicos (Yellow GR, Red Allura y Orange G) con cierto aporte en propiedades aniónicas, fue necesario evaluar con mayor detalle las propiedades del adsorbente para que posean requerimientos adecuados para dicha retención. Es por ello que siendo las arcillas naturalmente hidrofilica, se debió efectuar un tratamiento previo para modificar su afinidad hacia compuestos orgánicos, con lo cual los ensayos fueron realizados no solo sobre los materiales arcillosos seleccionados, sino modificados con un catión orgánico.

El objetivo general del trabajo de tesis fue evaluar el aprovechamiento de recursos arcillosos (bentonitas) para la obtención de adsorbentes, capaces de ser empleados en la retención de tres tintes azoicos textiles (Yellow GR, Red Allura y Orange G).

Por otro lado, los objetivos específicos del trabajo de Tesis Doctoral fueron: a) estudiar las propiedades físicas y químicas de las arcillas; b) aplicar técnicas adecuadas para su caracterización; c) tomar conocimiento sobre la capacidad de adsorción de las arcillas para evaluar la retención de tintes textiles; d) estudiar el comportamiento de los minerales arcillosos con el objetivo de incrementar la capacidad de adsorción de tres tintes azoicos en solución acuosa, evaluando posibles interacciones entre el adsorbato y el adsorbente; e) hacer extensivos los resultados obtenidos con aquellos tintes que posean los grupos funcionales, en especial los tipo azo. 



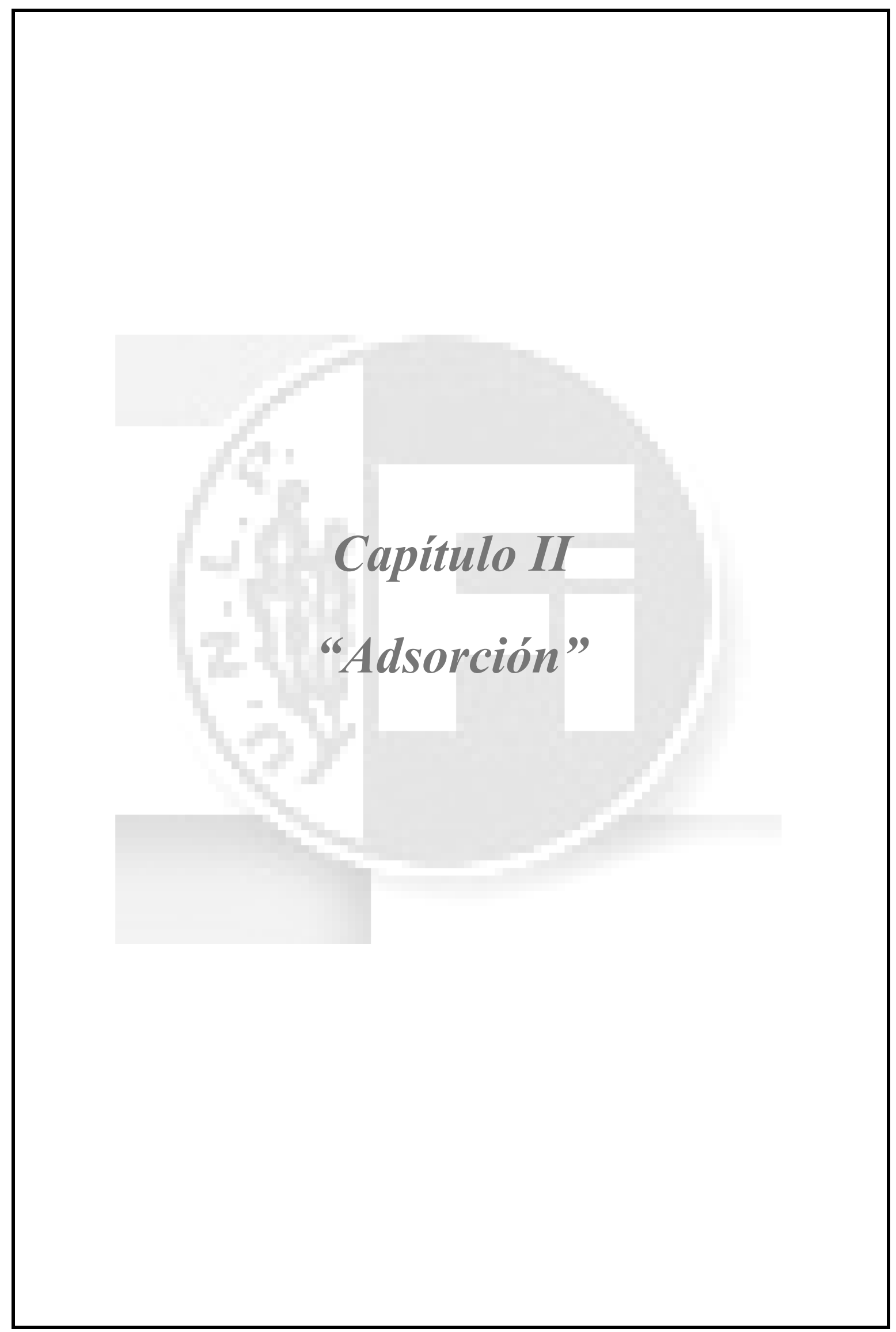




\section{ADSORCIÓN}

De acuerdo a la Unión Internacional de Química Pura y Aplicada (IUPAC) es posible definir el término adsorción como el enriquecimiento, en uno o más componentes, de la región entre dos fases, conocida como interfase o superficie interfasial (IUPAC, 1997). Este proceso puede tener lugar en una interfase gas-sólido o líquido-sólido.

El fenómeno de adsorción surge como resultado de la presencia de fuerzas moleculares en la superficie de los sólidos. Así, cuando un sólido se pone en contacto con un gas o un líquido, se produce una interacción con la superficie del mismo que tiende a compensar las fuerzas residuales, provocadas por la atracción y retención sobre su superficie, de las moléculas del gas o del líquido. Como resultado se observa una mayor concentración del gas o del líquido, denominado adsorbato, en la superficie del sólido o adsorbente, que en el seno de la fase gaseosa o líquida que contenía el adsorbato. La fase fluida, disolución o mezcla de gases, puede estar constituida por más de un componente.

Las fuerzas intermoleculares implicadas en el proceso de adsorción son de la misma naturaleza que las fuerzas existentes en el seno de un líquido o de un sólido. En el interior de una fase, las fuerzas que mantienen unidas las diferentes partes de la misma se encuentran compensadas en todas direcciones, excepto en la superficie, donde aparece una fuerza atractiva neta, normal a la superficie. Esta fuerza es responsable del acercamiento de las moléculas del adsorbato, produciéndose el fenómeno de adsorción.

\subsection{Tipos de adsorción}

El enlace de adsorción puede ser de diferente naturaleza; naturaleza física, donde las moléculas está unidas por medio de fuerzas físicas o de dispersión, sobre la superficie del adsorbente; o bien, de naturaleza química, donde las fuerzas de atracción son de naturaleza netamente químicas. 


\subsubsection{Fisiadsorción o Adsorción Física}

En la fisiadsorción (adsorción física), se produce una interacción de Van der Waals (por ejemplo una adsorción de dispersión o dipolar) entre el adsorbato y el sustrato. Se trata de una interacción de largo alcance, pero débil, y la energía desprendida cuando se adsorbe una partícula físicamente es del mismo orden de magnitud que la entalpía de condensación. Esta energía puede ser adsorbida en forma de vibraciones de red y disipada como calor, de modo que la partícula que rebota a través de la superficie, perderá gradualmente su energía y se unirá finalmente a la superficie. La entalpía de fisiadsorción se puede medir observando el aumento de temperatura de una muestra de capacidad calorífica conocida, sus valores típicos son del orden de 20 $\mathrm{kJ} \mathrm{mol}^{-1}$. Esta energía es insuficiente para producir la rotura de un enlace, por lo que una molécula adsorbida físicamente mantiene su identidad, aunque podría estar distorsionada debido a la presencia de la superficie.

\subsubsection{Quimiadsorción o Adsorción Química}

En quimiadsorción (adsorción química) las partículas se unen en las superficies formando un enlace químico (normalmente covalente) y tienden a buscar posiciones que maximicen sus números de coordinación con el sustrato. La entalpía de quimiadsorción es mucho mayor que la de fisiadsorción; los valores típicos están en torno a $200 \mathrm{~kJ} \cdot \mathrm{mol}^{-}$ 1. Una molécula adsorbida químicamente se puede disociar ante la demanda de las valencias no saturadas de los átomos superficiales. La existencia de fragmentos moleculares en la superficie como resultado de la quimiadsorción es una de las razones por las que las superficies catalizan reacciones.

\subsubsection{Diferencias entre Adsorción Física y Química}

Resumiendo, en la adsorción física, las moléculas del adsorbato se mantienen unidas a la superficie del sólido por medio de fuerzas intermoleculares relativamente débiles de tipo Van der Waals. En la quimisorción, se produce una reacción química en la superficie del sólido, y el adsorbato se mantiene unido a la misma a través de enlaces químicos fuertes.

En la Tabla 2.1 se aprecian las principales diferencias entre ambos fenómenos. 
Tabla 2.1. Diferencias entre Fisiadsorción y Quimiadsorción.

\begin{tabular}{|c|c|}
\hline Fisiadsorción & Quimiadsorción \\
\hline Fenómeno no específico & Fenómeno específico \\
Monocapa o multicapas & Monocapa \\
Bajo calor de adsorción & Alto calor de adsorción \\
(2 ó 3 veces el calor latente de vaporización) & (del orden del calor de una reacción química) \\
Significativa a temperaturas relativamente bajas & Posible en un amplio intervalo de temperatura \\
No activada & Activada \\
Reversible & Irreversible \\
No hay transferencia de electrones pero puede & Hay transferencia de electrones con formación de \\
producirse la polarización del adsorbato & enlace entre el adsorbato y el adsorbente
\end{tabular}

En los procesos donde el adsorbato es de origen orgánico, la adsorción se produce como resultado de interacciones específicas entre elementos estructurales identificables del adsorbato y del adsorbente, es así que éste tipo de adsorción, al no ser netamente física o química, se la conoce como adsorción específica (Mattson, 1969; Irwin, 1981).

\subsection{Factores que intervienen en los mecanismos de adsorción en fase líquida}

Si nuestro sistema de adsorción se encuentra en fase líquida, las interacciones que se pueden generar no son sólo aquellas producidas por el adsorbato y el adsorbente, sino también las que provienen de la interacción entre el adsorbato y el adsorbente con el disolvente. Es por lo expuesto que la retención de una sustancia determinada en fase líquida, dependerá del solvente. Sin embargo, no sólo el solvente posee un efecto en el fenómeno de adsorción, ya que también se verá afectada por otros factores tales como: superficie específica del adsorbente, naturaleza del adsorbato el adsorbente y el solvente, $\mathrm{pH}$ de la disolución, temperatura, y en el caso de que la solución, con los componentes a retener, se encuentre conformada por más de un componente, la competencia entre ellos.

\subsection{Equilibrio de Adsorción}

Al realizar ensayos de adsorción la concentración del soluto en la solución disminuye debido a la acumulación de éste en la superficie del adsorbente. Mientras la diferencia en la concentración de ambas fases, líquida en la solución con el adsorbato y sólida para el adsorbente; la velocidad de adsorción aumenta, cuando éstas velocidades 
se igualan y la retención del adsorbato en el adsorbente ya no se produzca, se dice que el sistema ha alcanzado el equilibrio, siendo éste un equilibrio dinámico entre el adsorbato y la solución.

\subsection{Isotermas de Adsorción}

La representación gráfica de la cantidad de soluto adsorbido por unidad de peso del adsorbente, en función de la cantidad de soluto en la solución, a una temperatura constante, se conocen como isoterma.

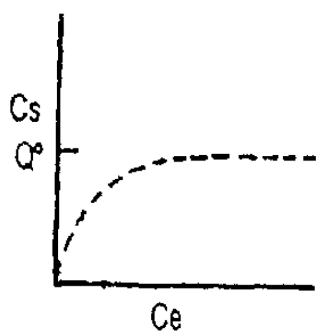

(a) Langmuir

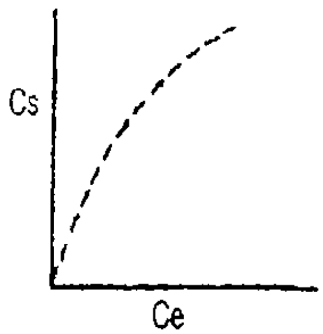

(d) Frecondictith $<1$

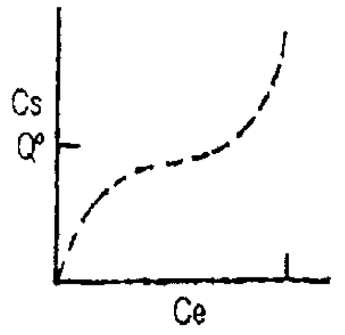

(b) $\mathrm{BET}$

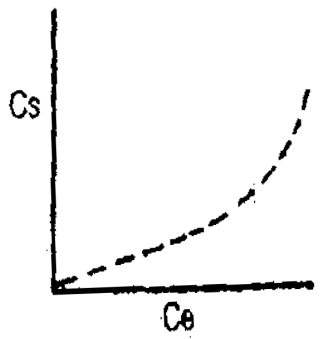

(e) Freundich $1 / n>1$

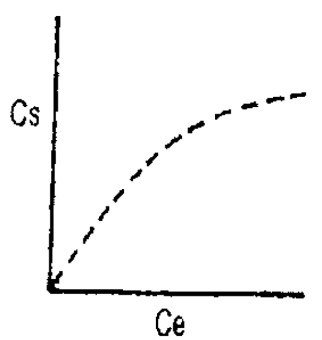

(c) 0 obo

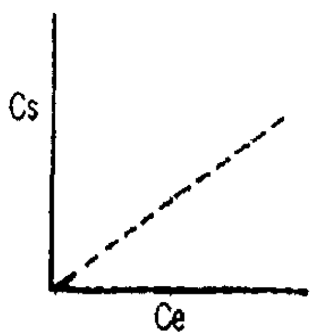

(f) Linear

Figura 2.1. Modelos de Isotermas.

En la Figura 2.1 se observan diferentes modelos de isotermas, que aportan valiosa información de acuerdo a su forma, pendiente y ordenada al origen, lo que ha sido una herramienta valiosa para los investigadores dedicadas a la temática de adsorción, tanto en fase líquida como gaseosa.

\subsubsection{Modelo de Isoterma de Langmuir}

En el modelo isotérmico de Langmuir se asume que la energía de adsorción de cada molécula es la misma y a su vez es independiente de la superficie que cubre, por ende todas las posiciones son equivalentes y la capacidad de una molécula para unirse a 
la superficie es independiente de si hay o no posiciones próximas ocupadas, y no hay una interacción entre las moléculas retenidas.

Es un modelo termodinámico que se basa en las siguientes suposiciones: a) la adsorción máxima corresponde a una monocapa saturada de moléculas de soluto sobre la superficie del adsorbente, b) la energía de activación es constante, c) no existe migración de adsorbato sobre la superficie del adsorbente.

En la Ecuación 2.2., se representa la fórmula que describe el modelo de Langmuir.

$$
\text { Ecuación 2.2. } \quad \mathrm{C}_{\mathrm{S}}=\frac{\mathrm{X}_{\mathrm{m}} \cdot \mathrm{b} \cdot \mathrm{C}_{\mathrm{e}}}{1+\mathrm{b} \cdot \mathrm{C}_{\mathrm{e}}}
$$

Donde:

$$
\begin{aligned}
& \left.\mathrm{C}_{\mathrm{s}}=\text { Cantidad de soluto retenido (mmol.g } \mathrm{g}^{-1}\right) \\
& \mathrm{X}_{\mathrm{m}}=\text { Capacidad de adsorción en equilibrio }\left(\mathrm{mmol} \cdot \mathrm{g}^{-1}\right) \\
& \mathrm{b}=\text { Coeficiente de adsorción }\left(\mathrm{L} \cdot \mathrm{mmol}^{-1}\right) \\
& \mathrm{C}_{\mathrm{e}}=\text { Concentración de soluto en la solución acuosa en equilibrio } \\
& \left(\mathrm{mmol} . \mathrm{L}^{-1}\right) .
\end{aligned}
$$

Los valores de $\mathrm{X}_{\mathrm{m}} \mathrm{y}$ b son obtenidos por medio de la isoterma experimental. A su vez b es una constante de equilibrio que varía con la temperatura de acuerdo a la Ecuación 2.3 de Van't Hoff.

$$
\text { Ecuación .3.2. } \mathrm{b}=\mathrm{k}_{0} \exp \left(\frac{-\Delta \mathrm{H}}{\mathrm{R} \cdot \mathrm{T}}\right)
$$

Donde:

$$
\begin{aligned}
& \mathrm{K}_{0}=\text { Constante relacionada con la Entropía } \mathrm{S} \\
& \Delta \mathrm{H}=\text { Entalpía del sistema de adsorción } \\
& \mathrm{R}=\text { Constante universal de los gases } \\
& \mathrm{T}=\text { Temperatura }
\end{aligned}
$$




\subsubsection{Modelo de Isoterma de Freundlich}

El modelo de Freundlich es el modelo de isoterma no lineal más empleado, siendo un modelo adecuado para la interpretación de los casos de adsorción en superficies heterogéneas, a diferencia de la ecuación de Langmuir que considera la superficie como homogénea.

Al aumentar la energía libre de adsorción el número de centros de adsorción disminuye exponencialmente, y no se desprecia la fuerza de interacción entre las moléculas de adsorbato.

En la Ecuación 2.4, es posible observar la fórmula general de éste modelo.

$$
\text { Ecuación 2.4. } \mathrm{C}_{\mathrm{s}}=\mathrm{K}_{\mathrm{F}} \cdot \mathrm{C}_{\mathrm{e}}^{1 / \mathrm{n}}
$$

Donde:

$$
\begin{aligned}
& \mathrm{C}_{\mathrm{s}}=\text { Cantidad de soluto retenido }\left(\mathrm{mmol} \cdot \mathrm{g}^{-1}\right) \\
& \mathrm{K}_{\mathrm{F}}=\text { Capacidad de adsorción (equivalente al coeficiente de adsorción) } \\
& 1 / \mathrm{n}=\text { Intensidad de adsorción } \\
& \mathrm{C}_{\mathrm{e}}=\text { Concentración de soluto en la solución acuosa en equilibrio } \\
& \left(\mathrm{mmol} . \mathrm{L}^{-1}\right)
\end{aligned}
$$

$\mathrm{K}_{\mathrm{F}}$ y $1 / \mathrm{n}$ son coeficientes obtenidos empíricamente y son constantes características del adsorbente y el soluto.

Esta expresión es utilizada únicamente como expresión empírica para ajustar datos experimentales, debido a que predice adsorción infinita cuando la concentración aumenta y no siempre cumple con la ecuación lineal de Henry, si se extrapola hasta zonas próximas al cero.

\subsubsection{Modelo de Isoterma de Brunauer, Emmet y Teller (BET)}

La isoterma más utilizada para el estudio de adsorción en multicapas para sistemas sólido/gas, se debe a Stephen Brunauer, Paul Emmet y Edward Teller, y se denomina isoterma BET.

En la teoría BET se asumen las siguientes suposiciones: 
- La adsorción en la primera capa tiene lugar sobre una superficie de energía homogénea.

- Las moléculas de la primera capa actúan como sitios de adsorción de la segunda capa, siendo éste comportamiento repetitivo en las capas posteriores. En el caso más simple se aproxima a un espesor infinito conforme la presión de vapor $\left(\mathrm{P}_{\mathrm{v}}\right)$ se aproxima a la presión de vapor de saturación de un líquido, presión de vapor del líquido puro $\left(\mathrm{P}_{0}\right)$.

- La condensación y la evaporación son iguales en todas las capas a excepción de la primera. El calor de adsorción de la segunda capa y las que le siguen a ésta son iguales, siendo equivalente al calor de condensación del gas (DHv).

La expresión matemática para éste modelo se observa en la Ecuación 2.5.

$$
\text { Ecuación 2.5. } \frac{\mathrm{P} / \mathrm{P}_{0}}{\mathrm{C}_{\mathrm{S}} \cdot\left(1-\mathrm{P} / \mathrm{P}_{0}\right)}=\frac{1}{\mathrm{C}_{\mathrm{Sm}} \cdot \mathrm{C}}+\frac{\mathrm{C}-1}{\mathrm{C}_{\mathrm{Sm}} \cdot \mathrm{C}} \cdot \frac{\mathrm{P}}{\mathrm{P}_{0}}
$$

Donde:

$$
\begin{aligned}
& \mathrm{C}_{\mathrm{s}}=\text { Cantidad de soluto adsorbida }\left(\mathrm{mmol} \cdot \mathrm{g}^{-1}\right) \\
& \mathrm{C}_{\mathrm{Sm}}=\text { Adsorción máxima en la monocapa }\left(\mathrm{mmol} \cdot \mathrm{g}^{-1}\right) \\
& \mathrm{C}=\text { Constante que relaciona el calor de adsorción de la primera capa y } \\
& \text { el de las multicapas sucesivas (DHv) }
\end{aligned}
$$

\subsubsection{Modelo de isoterma Lineal o de Henry}

El modelo Lineal o de Henry se basa en que la adsorción en un sistema es directamente proporcional con la concentración del adsorbato en la solución. Asume como condiciones necesarias en la aplicación del mismo, que el sistema se encuentra a temperatura constante, la superficie del adsorbente es lisa, homogénea e infinita y que no existen interacciones entre las moléculas adsorbidas. 
La Ecuación 2.6, representa éste modelo y se presenta a continuación.

$$
\text { Ecuación 2.6. } \mathrm{C}_{\mathrm{S}}=\mathrm{K} \cdot \mathrm{C}_{\mathrm{e}}
$$

Donde:

$$
\begin{aligned}
& \mathrm{C}_{\mathrm{s}}=\text { Cantidad de soluto adsorbida }\left(\mathrm{mmol} \cdot \mathrm{g}^{-1}\right) \\
& \mathrm{K}=\text { Capacidad de adsorción }\left(\mathrm{g} \cdot \mathrm{L}^{-1}\right) \\
& \mathrm{C}_{\mathrm{e}}=\text { Concentración de soluto en la solución acuosa en equilibrio } \\
& \left(\mathrm{mmol} . \mathrm{L}^{-1}\right)
\end{aligned}
$$

\subsubsection{Clasificación de Isotermas de Adsorción de compuestos en solución}

Giles y col. (1960) clasificaron isotermas de adsorción de compuestos en solución en cuatro clases de acuerdo a su forma inicial, definiendo de ésta manera a cada isoterma de acuerdo al comportamiento de adsorción del compuesto en el sólido cuando está en solución. Además, cada una de estas clasificaciones primitivas se las dividió en subgrupos $(1,2,3$ y 4$)$ en relación a la forma en la parte superior de la curva.

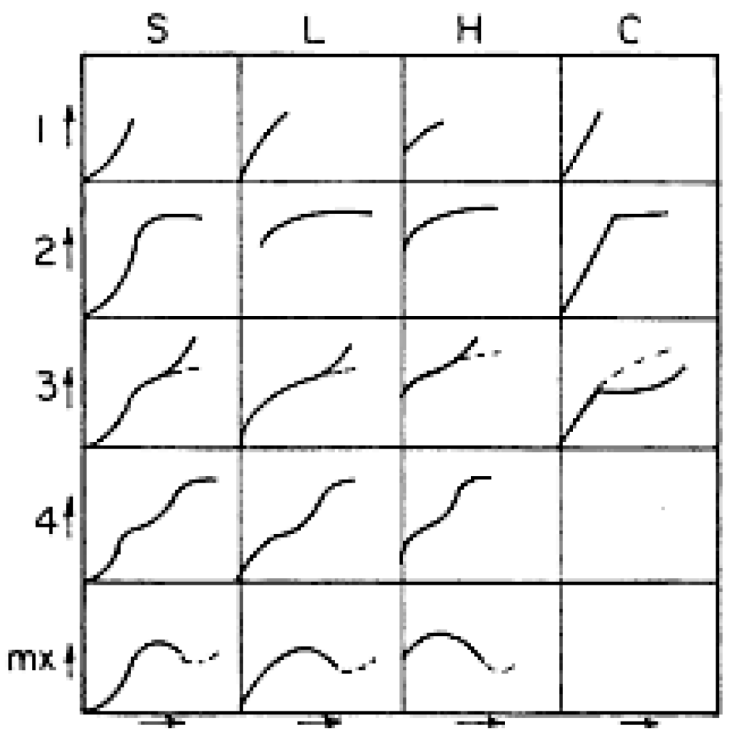

Figura 2.2. Clasificación de Isotermas de Giles y col. 1960.

La Figura 2.2, muestra el sistema de clasificación de Isotermas de Giles y col. (1960). 
Las cuatro clases principales son:

- Curvas tipo S: indican una orientación en las moléculas adsorbidas sobre la superficie.

- Curvas tipo L: también conocida como isoterma de Langmuir, normalmente indican que las moléculas o iones adsorbidos en la superficie con una fuerza de atracción intermolecular particular.

- Curvas Tipo $\mathrm{H}$ : comienzan en un valor positivo sobre el eje $\mathrm{x}$ (concentración de sólido), también conocidas como de alta afinidad, se trata de solutos adsorbidos con iones de alta afinidad, intercambiando iones de baja afinidad.

- Curvas Tipo C: son también conocidas como de partición lineal. Los solutos penetran dentro del sólido más fácilmente que el solvente.

Los subgrupos se diferencian entre ellos por las siguientes características particulares:

Subgrupo 1: Tiene en cuenta la pendiente inicial de la isoterma. Para las curvas L, éste subgrupo se origina debido a que el adsorbente tiene una cantidad de sitios disponibles, y a medida que aumenta la cantidad del compuesto retenido los sitios disminuyen, con lo cual hay menos posibilidades que el adsorbato encuentre sitios disponibles para fijarse. El comportamiento descripto con anterioridad también es válido para los grupos principales $\mathrm{S}$ y $\mathrm{H}$, aunque en la curva $\mathrm{S}$ el soluto es retenido en cantidades adicionales, debido a la interacción del compuesto fijado y las moléculas del adsorbato que se encuentran rodeándolo. La asociación entre las moléculas del adsorbato, también llamada "adsorción cooperativa", ayudándose las moléculas entre sí a soportarse en la superficie del adsorbente. Por último, las curvas tipo C son características de sólidos que poseen siempre sitios disponibles, aun cuando el adsorbato se encuentre en altas concentraciones.

Subgrupo 2: representativa de la formación de una monocapa saturada, con lo cual posee una forma tipo plateau o meseta. 
Subgrupo 3 y 4: estos subgrupos son conformados por las isotermas que se corresponden con una adsorción adicional, en la que la retención de una capa del adsorbato, correspondiente al subgrupo 3, existiendo la posibilidad de apreciar incluso una segunda meseta (subgrupo 4).

- Curvas Tipo mx: la isoterma presenta un máximo a altas concentraciones. Es un caso raro e indica que a altas concentraciones del adsorbato, las interacciones del adsorbato con el adsorbente aumenta mucho más rápidamente de lo que aumentan las atracciones adsorbato-adsorbente. 



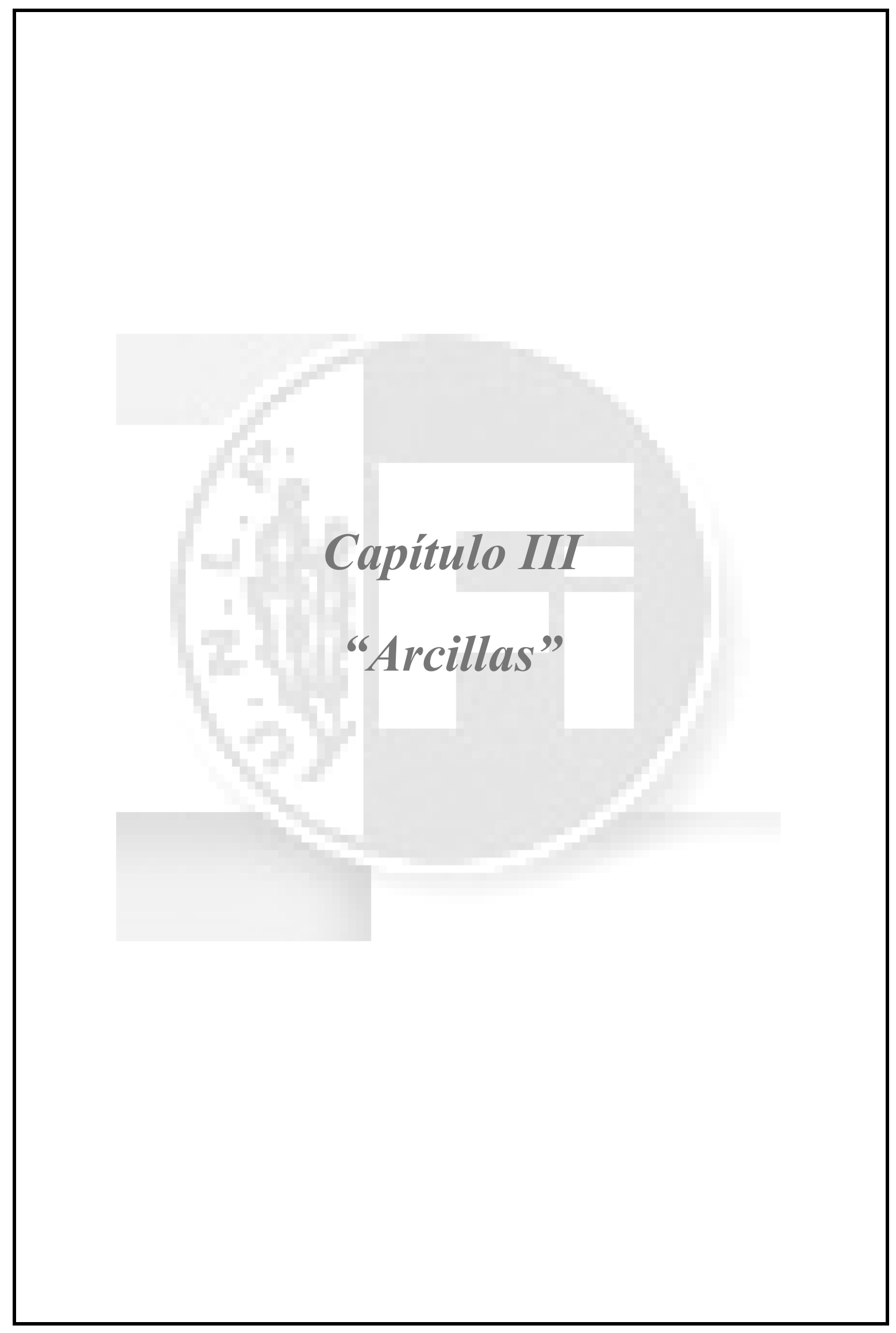




\section{ARCILLAS}

Las arcillas forman parte de una gran familia de minerales constituidas por minerales arcillosos acompañados por impurezas tales como cuarzo, feldespato, y /o yeso, entre otros.

El significado del término "mineral arcilloso" depende de la disciplina de la que se esté tratando, aunque como denominador común podemos clasificar a éstos materiales según su tamaño de partícula, cantidad de fracción arcillosa, constitución química y propiedades específicas. De ésta manera es posible definir arcilla como material natural compuesto por partículas de grano fino con propiedades plásticas, que contienen agua en su estructura y poseen la propiedad de endurecer al ser secadas y/o calcinadas (Guggenheim y Martin, 1995).

\subsection{Estructura de los minerales arcillosos}

Los minerales arcillosos poseen estructura laminar, y es por ésta razón que son incluidos dentro de los denominados "filosilicatos". Estructuralmente las arcillas se encuentran formadas por dos unidades básicas o capas; una de ellas constituida por grupos tetraédricos de $\mathrm{Si}^{+4}$, Figura 3.1.a; cuyos iones pueden ser reemplazados por $\mathrm{Al}^{+3}$, $\mathrm{Fe}^{+3}$ y $\mathrm{Fe}^{+2}$, y otra capa formada por grupos octaédricos, principalmente $\mathrm{Al}^{+3}$, Figura 3.1.b; con un cierto grado de sustitución isomórfica por iones $\mathrm{Mg}^{+2}, \mathrm{Fe}^{+2}, \mathrm{Fe}^{+3}, \mathrm{Cr}^{+3}$, $\mathrm{Mn}^{+2}, \mathrm{Zn}^{+2}$, (Brindley y Brown, 1980).

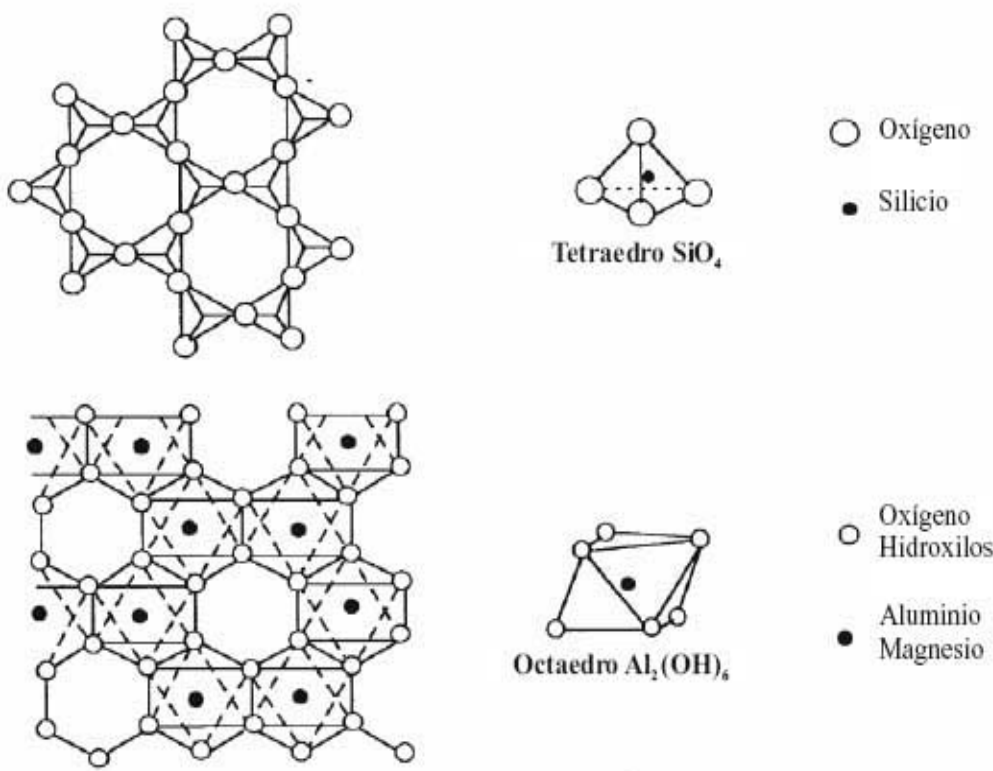

Figura 3.1. a) Estructura de la capa tetraédrica (T). b) Estructura de la capa octaédrica $(O)$. 
Los grupos del mismo tipo están unidos entre sí hexagonalmente formando planos de tetraedros y de octaedros.

La separación entre los iones externos de las láminas tetraédricas y octaédricas es suficiente para que ambas láminas puedan unirse por medio de iones oxígeno $\mathrm{u}$ oxhidrilo mutuamente; esto hace posible la formación de estructuras laminares de dos o de tres láminas. Cuando un mineral de arcilla presenta un empaquetamiento de una capa tetraédrica y una capa octaédrica se conoce como Tipo 1:1 ó T-O, Figura 3.2; mientras que, dos capas tetraédricas separadas por una capa octaédrica se la llama Tipo 2:1 ó TO-T, Figura 3.3.

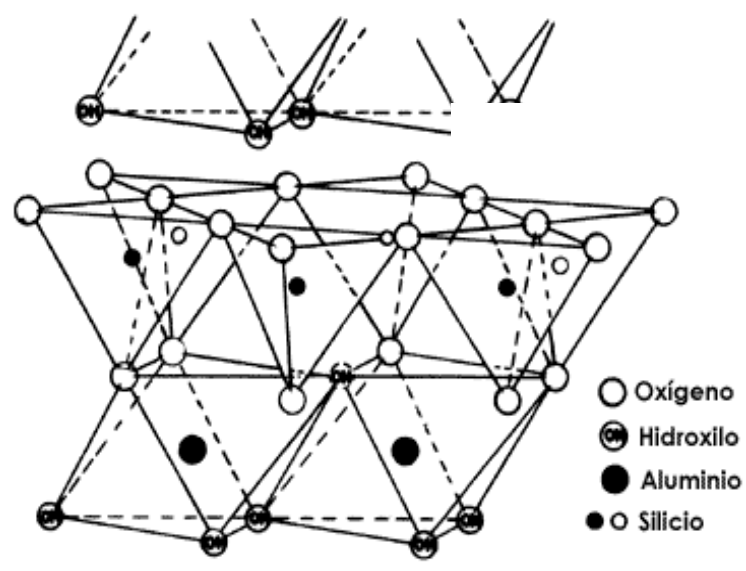

Figura 3.2. Estructura 1:1 ó T-O de una arcilla.

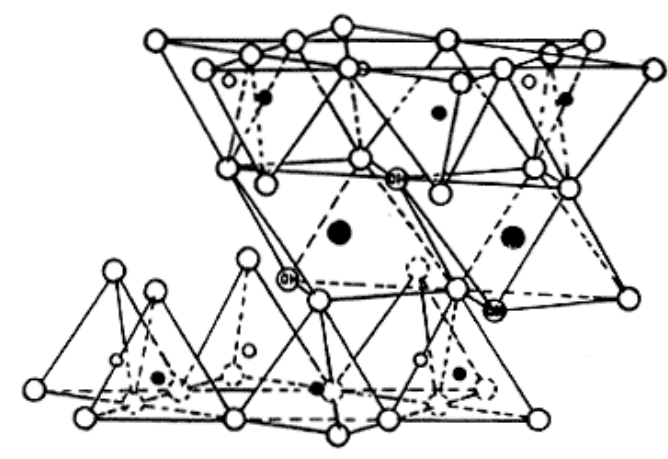

CAIIONES INTERCAMBIABLES Y AGUA INTERLAMINAR

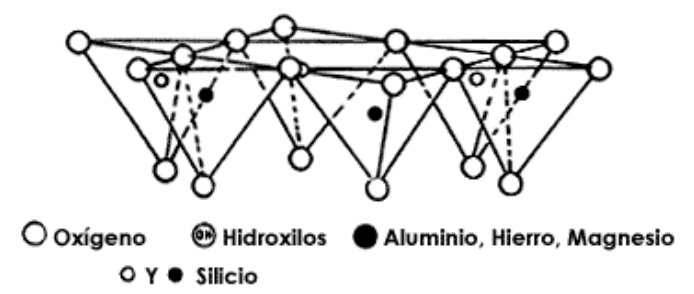

Figura 3.3. Estructura 2:1 ó T-O-T de la arcilla. 
La variedad de los minerales de arcilla, depende de la distribución de apilamiento de estas estructuras laminares, así como del tipo de iones que proveen el enlace de las mismas.

La distribución de los elementos en una estructura tipo 2:1 también pueden representarse como en la Figura 3.4.
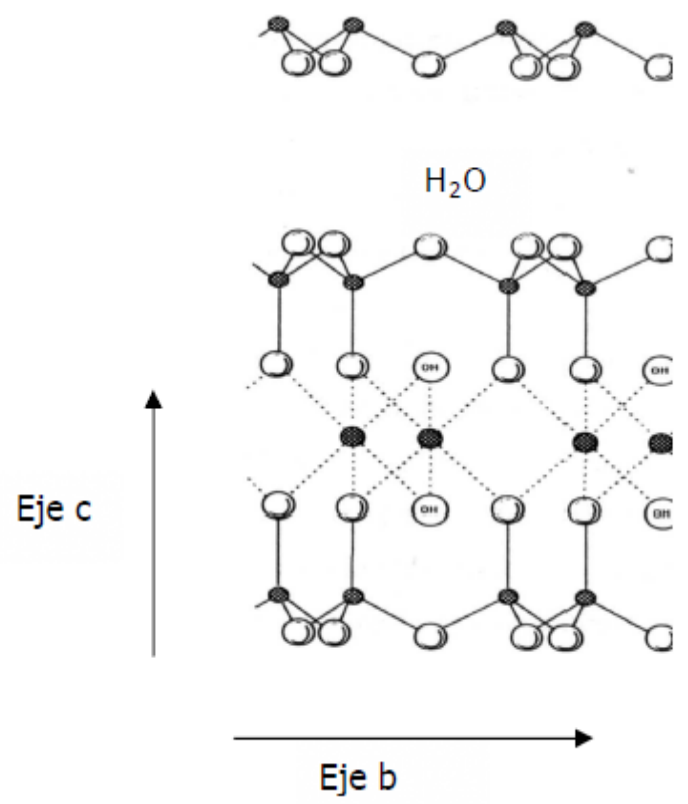

Figura 3.4. Estructura laminar de la bentonita.

La Tabla 3.1, muestra la distribución de cargas y elementos constituyentes de una celda unidad del componente arcilloso tipo esmectita, la cual está formada por 20 oxígenos y 4 grupos oxhidrilos con 8 sitios tetraédricos y 6 sitios octaédricos.

Tabla 3.1. Distribución de cargas de una montmorillonita.

\begin{tabular}{c|c}
$6 \mathrm{O}^{-2}$ & -12 \\
\hline $\mathrm{H}_{2} \mathrm{O}$ y cationes & Espacio interlaminar \\
\hline $6 \mathrm{O}^{-2}$ & -12 \\
$4 \mathrm{Si}^{+4}$ & +16 capa tetraédrica \\
$4 \mathrm{O}^{-2}+2 \mathrm{OH}^{-1}$ & -10 iones comunes a ambas capas \\
$4 \mathrm{Al}^{+3}$ & +12 capa octaédrica \\
$4 \mathrm{O}^{-2}+2 \mathrm{OH}^{-1}$ & -10 iones comunes a ambas capas \\
$4 \mathrm{Si}^{+4}$ & +16 capa tetraédrica \\
$6 \mathrm{O}^{-2}$ & -12 \\
\hline $\mathrm{H}_{2} \mathrm{O} \mathrm{y} \mathrm{cationes}^{-2}$ & Espacio interlaminar \\
\hline $6 \mathrm{O}^{-2}$ & -12
\end{tabular}




\subsection{Clasificación de los minerales arcillosos}

La abundante variedad de minerales arcillosos se encuentran relacionados a la disposición de las estructuras detalladas anteriormente y a los cationes presentes entre las láminas, es así que es posible reconocer cuatro grupos de minerales: Caolinita/Haloisita, Illita, Esmectita y Vermiculita.

- Grupo Caolinita: Se presentan en forma de hojas hexagonales pequeñas distribuidas en dos capas una de sílice y otra gibsita $\left(\mathrm{Al}_{2}(\mathrm{OH})_{4}{ }^{+2}\right)$ fuertemente enlazadas. Son producto de meteorización del feldespato ortoclasa proveniente de granitoides/riolitas y se encuentra frecuentemente en suelos formados por sedimentos. La diquita $\mathrm{y}$ haloisita son minerales arcillosos pertenecientes a éste grupo, la diferencia entre ellas es que la diquita tiene la misma composición que la caolinita pero diferente orden en sus láminas y la haloisita poseen láminas en forma tubular enlazadas por moléculas de agua.

- Grupo Illita: Se presenta en forma de hojas y su estructura se encuentra formada por láminas tipo 2:1, una capa tipo gibsita entre dos de sílice con los iones potasio ubicados entre las láminas. Posee un enlace entre láminas más débil que la caolinita, lo que resulta en partículas más pequeñas y delgadas. Son el resultado de la meteorización de las micas, por ende son similares aunque éstas poseen menos cantidad de potasio y más agua en su composición.

- Grupo de la Esmectita: La estructura fundamental está constituida por láminas tipo 2:1, una capa octaédrica, normalmente gibsita o en algunos casos brucita $\left(\mathrm{Mg}_{3}(\mathrm{OH})_{4}{ }^{+2}\right)$; entre dos capas tetraédricas de sílice. Forma enlaces con metales como potasio, generando enlaces débiles entre las láminas. La capacidad que poseen las esmectitas de adsorber moléculas de agua, hacen que su volumen aumente considerablemente. Éste mineral arcilloso es el constituyente principal de las bentonitas y otras variedades similares, y son el resultado de la meteorización del feldespato plagioclasa en depósitos de cenizas volcánicas. 
- Grupo Vermiculita: La estructura de este mineral de arcilla es muy similar a la estructura de la esmectita, se diferencia de ésta al poseer mayor contenido de magnesio en la estructura. En la Tabla 3.2., se describen las principales características estructurales de cada uno de los grupos de minerales arcillosos mencionados.

Tabla 3.2. Características estructurales de los principales grupos de minerales arcillosos.

\begin{tabular}{|c|c|c|c|c|}
\hline & $\begin{array}{l}\text { CAOLINITA } \\
\text { HALOISITA }\end{array}$ & ILLITA & ESMECTITA & VERMICULITA \\
\hline Formula & $\begin{array}{c}\mathrm{Al}_{2} \mathrm{Si}_{2} \mathrm{O}_{5}(\mathrm{OH})_{4} \\
\mathrm{Al}_{4} \mathrm{Si}_{4} \mathrm{O}_{10}(\mathrm{OH}) \\
{ }_{8} \cdot 4 \mathrm{H}_{2} \mathrm{O}\end{array}$ & $\begin{array}{c}\mathrm{K}_{0,8} \mathrm{Al}_{2}\left(\mathrm{Si}_{3,2} \mathrm{Al}_{0,8}\right) \\
\mathrm{O}_{10}(\mathrm{OH})_{2}\end{array}$ & $\mathrm{Si}_{8} \mathrm{Al}_{4} \mathrm{O}_{20}(\mathrm{OH})_{4} \cdot \mathrm{nH}_{2} \mathrm{O}$ & $\begin{array}{l}(\mathrm{Mg}, \mathrm{Fe}, \mathrm{Mn}, \mathrm{Al})_{12} \\
(\mathrm{Si}, \mathrm{Al})_{8} \mathrm{O}_{20}(\mathrm{OH})_{16}\end{array}$ \\
\hline Estructura & $\begin{array}{c}1: 1 \\
\text { dioctaédrica }\end{array}$ & $\begin{array}{c}2: 1 \\
\text { principalmente } \\
\text { dioctaédrica }\end{array}$ & 2:1 di y trioctaédrica & $2: 1: 1$ trioctaédrica \\
\hline Espaciado (Á) & $\begin{array}{l}7,1 \\
10\end{array}$ & 10 & Variable, mayormente 15 & 14,2 \\
\hline $\begin{array}{c}\text { Cationes } \\
\text { interlaminares }\end{array}$ & Ninguno & $\mathrm{K}$ & $\mathrm{Ca}$ y $\mathrm{Na}$ & Ninguno \\
\hline $\begin{array}{c}\text { Agua } \\
\text { interlaminar }\end{array}$ & $\begin{array}{l}\text { Ninguna para } \\
\text { Caolinita } \\
1 \text { lámina para } \\
\text { Halosita }\end{array}$ & & Variable & Ninguna \\
\hline $\begin{array}{l}\text { Capacidad de } \\
\text { intercambio } \\
\text { catiónico }\end{array}$ & 10 meq. $/ 100 \mathrm{~g}^{-1}$ & $\begin{array}{c}10-40 \\
\text { meq./100g }\end{array}$ & $80-150$ meq. $/ 100 \mathrm{~g}^{-1}$ & \\
\hline
\end{tabular}

En la presente tesis doctoral, al referirnos particularmente al grupo de la esmectita, por ser el mineral arcilloso constituyente de los adsorbentes estudiados, se expone en la Tabla 3.3, una breve clasificación de éste grupo. 
Tabla 3.3. Clasificación de las esmectitas.

\begin{tabular}{c|ccc}
\hline $\begin{array}{c}\text { Estructura } \\
\text { laminar }\end{array}$ & Grupo & Subgrupo & Especies Representativas \\
\hline \multirow{2}{*}{$2: 1$} & Esmectita & Esmectita & Saponita \\
& & Trioctaédrica & Hectorita \\
& & & Sauconita \\
& & Esmectita & Montmorillonita \\
& & Dioctaédrica & Beidellita \\
& & & Nontronita \\
\hline
\end{tabular}

\subsection{Propiedades fisicoquímicas de las arcillas}

Las propiedades fisicoquímicas particulares de los minerales de arcillas, hacen de éstas, materiales sumamente importantes en diferentes industrias. Estas propiedades provienen de su reducido tamaño de partícula (menor a $2 \mu \mathrm{m}$ ), morfología laminar y la capacidad de poseer déficit de cargas producto de las sustituciones isomórficas de cationes interlaminares débilmente ligados. Las propiedades mencionadas dan lugar a un valor elevado de área superficial y sitios activos, los que provocan que éste material posea una gran capacidad de intercambio catiónico, como resultado de tender a compensar el déficit de cargas generadas en el espaciado interlaminar de cationes débilmente ligados, con variado estado de hidratación.

\subsubsection{Hidratación e hinchamiento}

El hinchamiento o hidratación de las arcillas, particularmente aquellas pertenecientes al grupo de las esmectitas, se debe a la incorporación de moléculas de agua en el espaciado interlaminar, lo que produce un aumento del espaciado original, dando lugar al efecto de hinchamiento; por lo tanto éste fenómeno está ligado a la naturaleza del catión interlaminar y a la carga de la lámina.

\subsubsection{Plasticidad}

El agua que se encuentra entre las láminas forma un recubrimiento sobre éstas partículas laminares, lubricándolas y provocando que se deslicen entre ellas, propiedad conocida como plasticidad. Por medio de los índices de límite líquido, límite plástico y 
límite de retracción; es posible cuantificar ésta propiedad. A través de estos límites es posible obtener información sobre la naturaleza del mineral arcilloso. Generalmente las arcillas más plásticas son aquellas que poseen partículas más pequeñas y estructura imperfecta.

\subsubsection{Tixotropía}

La tixotropía en las arcillas en suspensión es una propiedad que consiste en la pérdida de resistencia con la agitación y su posterior recuperación al cesar el movimiento.

\subsubsection{Area Superficial}

El área superficial de una arcilla se expresa en unidad de $\mathrm{m}^{2} \cdot \mathrm{g}^{-1}$, siendo esta área la correspondiente a la suma de la superficie interior y exterior del material. En la Tabla 3.4, se exponen algunos valores de área superficial de diversos minerales arcillosos.

Tabla 3.4. Área superficial

\begin{tabular}{c|c}
\hline Arcilla & $\begin{array}{c}\text { Área Superficial } \\
\left(\boldsymbol{~}^{2} \cdot \mathbf{g}^{-1}\right)\end{array}$ \\
\hline Caolinita de elevada cristalinidad & $<15$ \\
Caolinita de baja cristalinidad & $<50$ \\
Haloisita & $<60$ \\
Illita & $<50$ \\
Montmorillonita & $80-300$ \\
\hline
\end{tabular}

\subsubsection{Capacidad de intercambio catiónico (CIC)}

Se define capacidad de intercambio catiónico a la suma de todos los cationes de intercambio que un mineral puede adsorber a un determinado $\mathrm{pH}$, siendo equivalente a la suma de todas las cargas negativas de la arcilla. La CIC se expresa, en general, en unidades de miliequivalentes (meq) de cationes intercambiables por $100 \mathrm{~g}$ de arcilla, es decir la unidad es meq. $100 \mathrm{~g}^{-1}$.

Ésta propiedad es una de las principales dentro del grupo de las esmectitas, mineral arcilloso constituyente de las bentonitas. 
La Tabla 3.5, exhibe los valores de CIC de algunos de los principales minerales arcillosos.

Tabla 3.5. Capacidad de intercambio catiónico de minerales arcillosos

\begin{tabular}{c|c}
\hline Arcilla & CIC $\left(\right.$ meq. $\left.100 g^{-1}\right)$ \\
\hline Caolinita & $3-5$ \\
Haloisita & $10-40$ \\
Illita & $10-50$ \\
Clorita & $10-50$ \\
Vermiculita & $100-200$ \\
Montmorillonita & $80-200$ \\
\hline
\end{tabular}

Esta propiedad da una idea cuantitativa y cualitativa de la tendencia del mineral a la intercalación, siendo éste factor muy importante en la capacidad de adsorción del mineral.

\subsection{Usos Industriales de las arcillas}

El principal uso de las rocas arcillosas, aproximadamente el $90 \%$ de la extracción total, se da en la construcción, en la fabricación de ladrillos, cerámicos, tejas, baldosas, losas, etc. Se trata de arcillas normalmente formadas por dos o más minerales arcillosos, generalmente caolinita, illita y/o esmectita. El 10\% que resta es empleado en otras industrias tales como: pintura, papel, caucho, productos químicos y farmacéuticos, arenas de moldeo, adsorbentes, etc. Estas últimas son rocas conformadas por un solo tipo de mineral arcilloso y sus características y posibles empleos dependen exclusivamente de las propiedades del mineral arcilloso que las componen.

\subsection{Bentonita}

El término bentonita hace referencia a una roca compuesta esencialmente por minerales del grupo de las esmectitas, con independencia de su génesis y modo de aparición (Grim, 1972). Además de la fracción mayoritaria de mineral arcilloso esmectítico, la bentonita posee como constituyentes minoritarios, en ocasiones denominados impurezas, minerales tales como: yeso, feldespato y cuarzo.

La industria clasifica a las bentonitas teniendo en cuenta la capacidad de hinchamiento en agua, es así entonces que es factible hablar de bentonitas altamente 
hinchables o sódicas, bentonitas poco hinchables o cálcicas $\mathrm{y}$ bentonitas moderadamente hinchables o intermedias.

\subsubsection{Usos Industriales de las bentonitas}

Debido a su gran área superficial, homogeneidad en la distribución de los centros superficiales y su elevada capacidad de adsorción, son materiales muy empleados como catalizadores y adsorbentes, principalmente en la industria del petróleo. Ésta industria emplea las bentonitas para la remoción de impurezas en los productos del proceso de destilación del crudo, además de ser usadas como catalizadores en reacciones de transformación de los derivados del petróleo.

Además son ampliamente utilizadas en la producción o fabricación de detergentes; pinturas; grasas; plásticos; como emulsionante y ablandador de agua, como agente gelificante, tixotrópico o emulsionante cuando se encuentran modificadas orgánicamente; en agricultura activadas con sodio para recubrir ciertas semillas aumentando su tamaño y mejorando así su distribución y a la vez facilitando la germinación de éstas; para mejorar las propiedades de suelos arenosos, como membranas para desalinizar agua; en la fabricación de cosméticos; material de sellado de residuos tóxicos; entre otros empleos.

\subsubsection{Bentonitas como adsorbentes de contaminantes}

Debido a la mayor actividad industrial, producto de la demanda creciente de diversos productos manufacturados, aumenta año a año de manera muy considerablemente, la generación de contaminantes de diferentes orígenes. Es por esto, que se han visto en aumento los estudios referentes al campo ambiental. Las investigaciones referidas al uso de minerales arcillosos como descontaminates, emplean estos materiales como adsorbentes de sustancias nocivas para la salud y el medioambiente; pudiendo clasificar a las mencionadas investigaciones en dos grandes ramas: empleo de arcillas naturales y de arcillas modificadas; independientemente del tipo de contaminante a retener.

Tahir y col. (2004), removieron Fe (II) de los efluentes desechados de la industria del galvanizado, utilizando como adsorbente una bentonita. Los autores evaluaron el efecto de diferentes variables sobre los valores de retención del catión metálico, variables tales como: efecto de la cantidad de arcilla en el sistema, 
concentración del Fe (II) en solución, el tiempo de contacto, $\mathrm{pH}$, mezcla de cationes y el tratamiento del sistema de adsorción para la desorción del metal con diferentes ácidos. Concluyeron que la bentonita es un adsorbente adecuado para retener Fe (II), alcanzando retenciones de hasta un 95\% con el agregado de $2 \mathrm{~g}$ de mineral en soluciones de $100 \mathrm{mg} . \mathrm{L}^{-1}$ de Fe (II), el ácido que actuó con mayor efectividad en la desorción del Fe (II) fue el $\mathrm{HNO}_{3}$, la mezcla de cationes en el sistema actúa de manera desfavorable disminuyendo la retención del Fe (II), observándose un mayor efecto en la disminución de la adsorción cuando se encuentra presente el $\mathrm{Zn}$ en el sistema, a pH 3 se retuvo hasta un 98\% del catión. El estudio de los investigadores permitió montar una planta de tratamiento de residuos de la industria galvánica.

Venaruzzo y col. (2002), utilizaron una bentonita modificada como adsorbente de $\mathrm{CO}, \mathrm{CO}_{2} \mathrm{y} \mathrm{SO}_{2}$. La modificación de la arcilla se efectuó con una solución de $\mathrm{HCl}$ de concentraciones variables entre 3 y $6 \mathrm{~N}$, previo enriquecimiento en fracción arcillosa. La bentonita tratada con $\mathrm{HCl}$ demostró ser un buen adsorbente de $\mathrm{CO}_{2} \mathrm{y} \mathrm{SO}_{2}$, mientras que para $\mathrm{CO}$ los valores de adsorción no fueron significativos. El aumento de la fracción esmectita incrementó la retención de gases, lo que los autores relacionan con los cambios estructurales y propiedades texturales del adsorbente modificado. Las diferencias en los valores de retención en los gases que fueron estudiados hacen de éste proceso un potencial sistema de separación de gases.

Martinez Stagnaro y col. (2012), estudiaron un sistema multicomponente conformado por una solución de cationes $\mathrm{Cd}, \mathrm{Pb}$ y $\mathrm{Zn}$ contactado con una bentonita tratada térmicamente en un rango de temperatura de $150^{\circ} \mathrm{C}$ a $750^{\circ} \mathrm{C}$. Se alcanzaron valores de adsorción de $\mathrm{Zn}, \mathrm{Cd}$ y $\mathrm{Pb}$ de $0.11 \mathrm{mmol} \cdot \mathrm{g}^{-1}, 0.065 \mathrm{mmol} \cdot \mathrm{g}^{-1} \mathrm{y} 0.05 \mathrm{mmol} \cdot \mathrm{g}^{-1}$, respectivamente; manteniéndose, relativamente similares, hasta una temperatura de tratamiento del mineral adsorbente de $450^{\circ} \mathrm{C}$; encontrando que el orden de adsorción de los potenciales contaminantes $(\mathrm{Zn}>\mathrm{Cd}>\mathrm{Pb})$ se encuentra relacionada con el radio iónico de las especies. Así también concluyeron que a temperaturas superiores a $450^{\circ} \mathrm{C}$, la adsorción de los cationes disminuye drásticamente, debido al colapso de la estructura arcillosa, por la pérdida de los hidroxilos en ésta.

En relación al empleo de las arcillas como adsorbentes de colorantes de origen orgánico, si bien, en la actualidad ésta temática se encuentra en crecimiento, es probablemente uno de los sistemas que aún puede ser ampliamente desarrollado. En el 
caso de los colorantes orgánicos, las arcillas naturales son usualmente empleadas para la remoción de colorantes catiónicos, como por ejemplo el azul de metileno, debido a las cargas negativas naturales del mineral, sin embargo las modificaciones a nivel superficial, empleando surfactantes, pueden cambiar la carga superficial de las arcillas, de negativa a positiva, para así desarrollar una mayor afinidad por los tintes aniónicos (Dawood y col. 2014).

Algunos de los trabajos consultados proponen una modificación de los adsorbentes para incrementar los valores de retención de tintes orgánicos, debido a la naturaleza organofóbica de los minerales arcillosos. Tuesta y col. (2005), emplearon una esmectita modificada mediante un tratamiento termo-ácido, para la retención de Rojo 80 y Azul 71, demostrando en su estudio que la activación termo-ácida incrementa la adsorción de los colorantes empleados, en referencia a la esmectita sin tratamiento, logrando remover $70 \mathrm{mg} \cdot \mathrm{g}^{-1}$ con una concentración inicial de los colorantes en solución monosoluto de $5 \mathrm{mg} \cdot \mathrm{L}^{-1}$.

Hu y col. (2013), realizaron su investigación para remover Red Basic 2, de concentraciones iniciales variables, sobre una bentonita natural a diferente $\mathrm{pH}$, empleando también, un tratamiento con una sal de sodio para conocer la influencia de la misma en la retención del tinte. De éste trabajo observaron que la retención del tinte se lleva a cabo rápidamente durante los primeros 2 a 3 minutos, siendo un proceso más lento pasado éste tiempo, la sal de sodio agregada no tuvo un efecto significativo en la retención del colorante; sin embargo, los ensayos efectuados a diferente $\mathrm{pH}$, demostraron que la remoción del colorante Red Basic 2 se ve incrementada cuando se encuentra en un ambiente alcalino, comportamiento que se condice con la presencia de cargas negativas sobre la superficie del adsorbente.

\subsection{Arcillas en Argentina}

Entre las numerosas sustancias minerales que se extraen en la República Argentina, alrededor de $25 \%$ a $30 \%$ de la producción minera total está representada por rocas de aplicación, y un 9-10\% por minerales no metalíferos o industriales, dentro de las cuales se encuentran los minerales arcillosos. De acuerdo con los datos estadísticos publicados por el INDEC en el año 2010, la extracción de minerales arcillosos alcanzó las 1.221.874 toneladas, de las cuales 270.013 toneladas fueron exclusivamente 
bentonita, alcanzando un valor de producción a precio de productor por mineral en yacimiento de $\$ 9.392 .369$.

En la actualidad, Argentina es la segunda productora mundial de bentonita, habiendo desplazado a Brasil de éste privilegiado lugar, debido a la pureza que presentan éstos materiales en el territorio argentino.

De acuerdo a la Evaluación Estadística del último Censo Minero (2003-2004), publicado por el SEGEMAR y la Fundación EMPREMIN en el año 2005; la provincia de Buenos Aires es la de mayor producción y oferta de arcillas, tanto en volumen como en sus diferentes variedades y calidades. En general, Córdoba y Mendoza registran continuamente altos volúmenes de producción, en tanto que San Juan y Tucumán fluctúan fuertemente sus producciones, aún dentro de la alta variabilidad que registran los volúmenes producidos de arcilla en la Argentina. La tipificación de arcillas, fundamental para el reconocimiento de su característica utilitaria (plástica, refractaria, decolorante) se ha venido realizando como parte de distintos programas de organismos del Estado nacionales o provinciales o, en algunos casos, por las empresas propietarias debido, fundamentalmente, a las exigencias de las industrias consumidoras.

Arcillas comunes se encuentran en la producción de los yacimientos de las provincias de Buenos Aires, Córdoba, Chubut, Entre Ríos, Jujuy, La Rioja, Mendoza, Misiones, Neuquén, Salta, San Juan, San Luis, Santiago del Estero y Tucumán. Las arcillas comunes, que derivan a la industria de la construcción y el cemento, constituyen una amplia oferta en el país. Las arcillas para cerámica roja, si bien se explotan a gran escala en las provincias de Buenos Aires, Córdoba, Entre Ríos y Mendoza, pueden encontrarse en prácticamente todo el país.

Otras arcillas de características definidamente plásticas y alta calidad de material se han determinado en yacimientos de las provincias de Buenos Aires, Chubut, Neuquén y Santa Cruz.

La oferta de arcillas refractarias en la Argentina proviene de yacimientos ubicados básicamente en cuatro provincias: Buenos Aires, La Rioja, Neuquén y Chubut. Las cantidades son volumétricamente inferiores a la de las restantes variedades y su principal demanda la constituye la fabricación de ladrillos refractarios.

Las arcillas de mayor calidad provienen de depósitos ubicados en la Patagonia, en las provincias de Chubut (Las Chapas), Santa Cruz (San Julián) y Neuquén (Zapala). 
Constituyen en algunos casos productos con marca o identificación propia, que se comercializan tanto en terrones como triturados o molidos. Su calidad permite usos variados, entre ellos: la fabricación de sanitarios, pisos y revestimientos, aisladores, refractarios, cerámica artística, esmaltes, y gomas y plásticos. La demanda principal proviene de los materiales que derivan hacia la industria de la construcción, como es el caso de cerámica para revestimientos, pisos cerámicos esmaltados y porcelanato. Se destacan las plantas elaboradoras de cerámicos y porcelanatos que consumen minerales de origen nacional, entre ellas las ubicadas en la provincia de Neuquén.

Dentro de la amplia gama de depósitos de arcillas plásticas existentes, los de origen sedimentario son los que constituyen el mayor volumen y sustentan el flujo de materia prima hacia las principales plantas instaladas en la Argentina. La tendencia hacia el mejoramiento de calidad en los procesos productivos industriales condujo a la explotación racional de varios de los depósitos nacionales, orientada hacia la producción de material que cumpla especificaciones rigurosas para alimentar a las plantas de tratamiento, que formulan las mezclas de materiales de acuerdo con las características de cada una de las arcillas que intervienen en el composito final.

\subsubsection{Minerales arcillosos en San Juan}

A continuación se presenta una breve síntesis de dos provincias proveedoras de minerales y rocas industriales como son San Juan y Neuquén.

El $80 \%$ del territorio sanjuanino está cubierto por un terreno montañoso rico en minerales. El sector suma aproximadamente $76.000 \mathrm{~km}^{2}$. La provincia produce una gran variedad y cantidad de minerales industriales y rocas. Es el mayor y único productor de calcita y de sulfato de magnesio del país; el mayor productor de dolomita y de mármol travertino; el segundo mayor productor de caliza (el primero de alta calidad), mármol y talco; y el tercer mayor productor nacional de bentonitas, arcillas, feldespatos y micas, (Guerra y col. 2014). La Figura 3.5, exhibe la producción mineral de la provincia de San Juan, datos correspondientes al año 2013. 


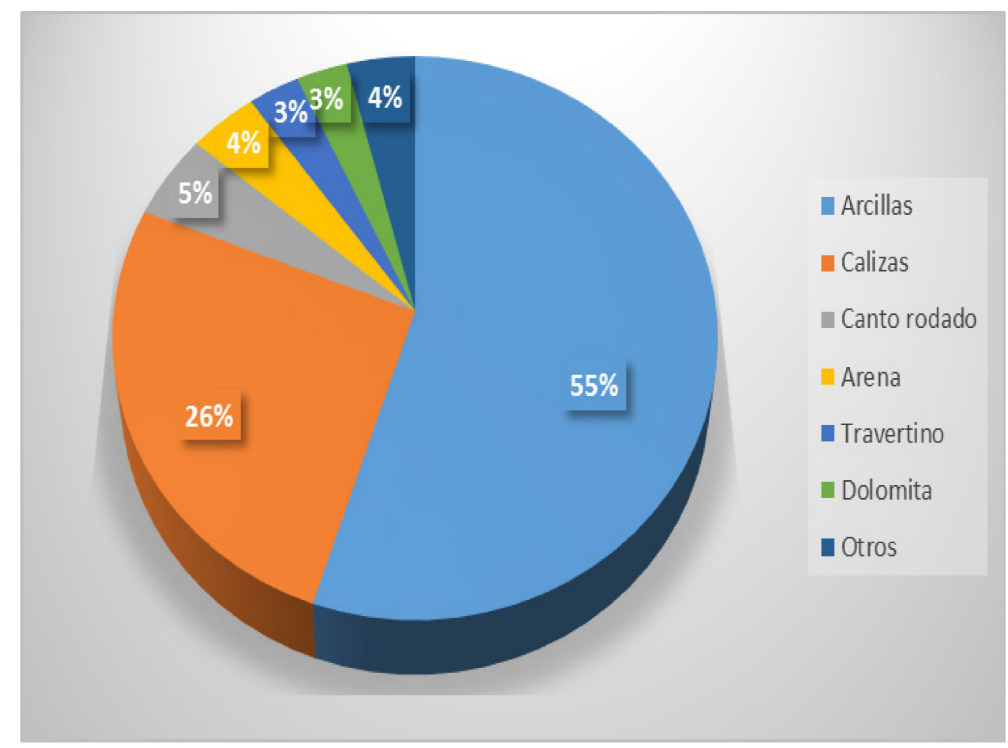

Figura 3.5. Producción mineral de la provincia de San Juan del año 2013.

\subsubsection{Minerales arcillosos en Neuquén}

La producción total de la provincia durante el año 2015, alcanzó valores de \$ 147.117.222 aprox., tomando como base los precios promedio del mercado local. De dicho valor, el 66,25\% (\$97.465.677) correspondió a no metalíferos y el 33,74\% (\$49.651.545) a rocas de aplicación. En la Figura 3.6, se exponen los datos de la producción del año 2015 de los minerales no metalíferos en la provincia de Neuquén.

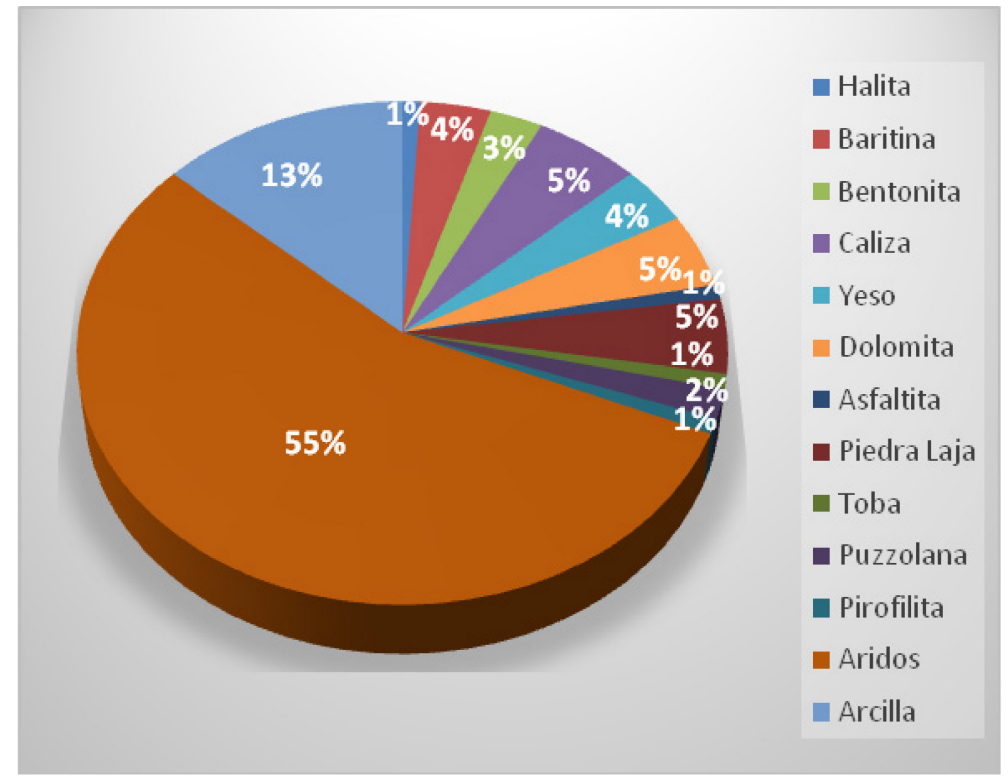

Figura 3.6. Producción mineral de la provincia de Neuquén del año 2015. 
Considerando el volumen físico producido, el total global fue de 1.967.258 tn, de las cuales 1.226.231 tn correspondió a rocas de aplicación (áridos, material volcánico, ornamentales). Para los minerales no metalíferos (arcilla, asfaltita, baritina, bentonita, caliza, dolomita, halita y yeso) la producción alcanzó un total de 741.027 tn, (Estadística Dirección Provincial de Minería y Policía Minera de Neuquén, 2015). 


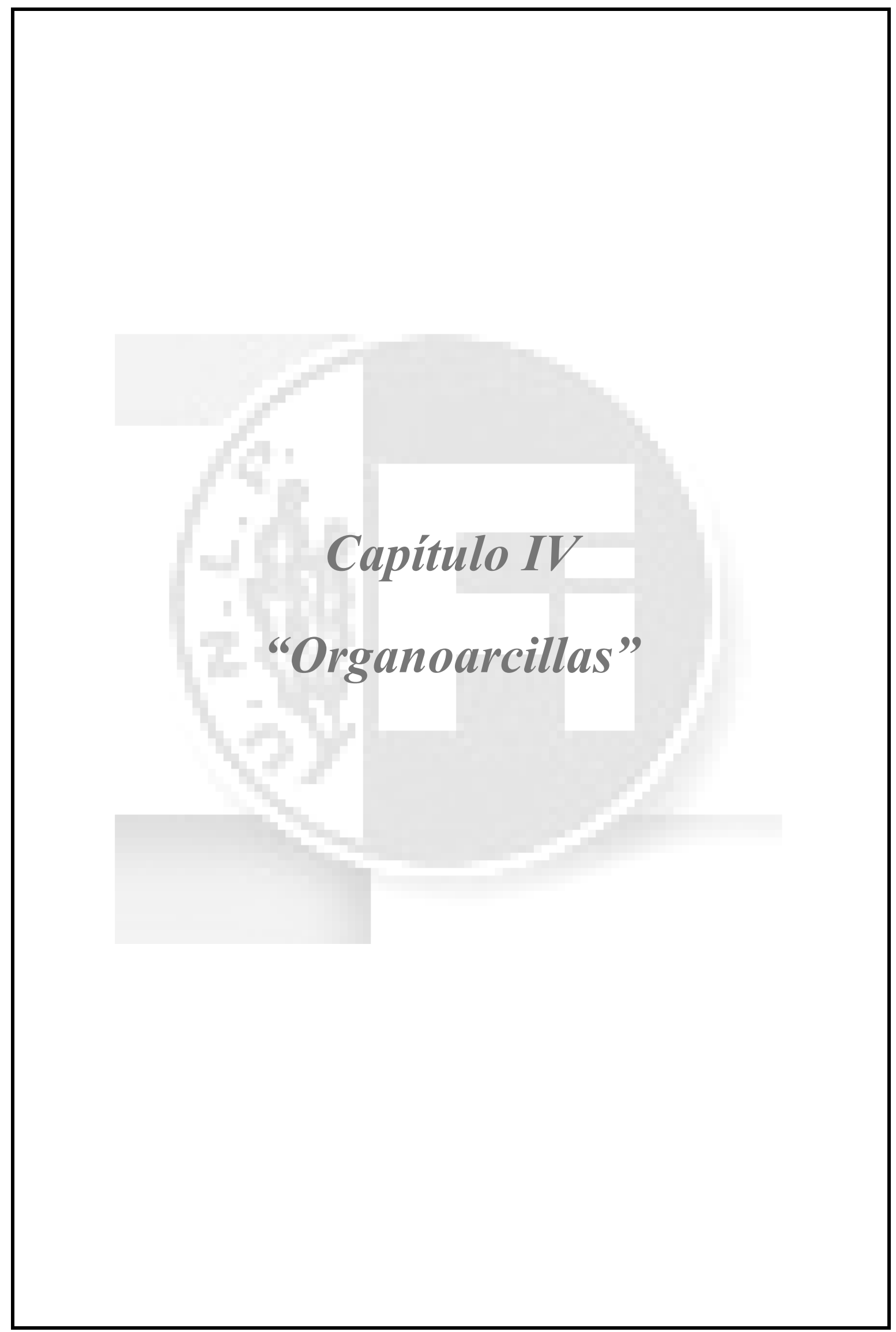





\section{ORGANOARCILLA}

El término organoarcilla hace referencia a aquellos materiales arcillosos que han sido tratados con sustancias de origen orgánico, comúnmente sales de amonio cuaternario, para modificar su estructura, y con ella sus propiedades fisicoquímicas.

Para conocer las características estructurales que contribuyen a la reactividad de los minerales arcillosos frente al tratamiento orgánico, que da origen a estos materiales, y así poder comprender los diversos y complejos mecanismos que implica este fenómeno, a continuación se introduce el concepto de "sitios activos". Además, se referencian publicaciones científicas que estudiaron las distintas interacciones que se llevan a cabo en el sistema arcilla/orgánico, y los métodos de obtención de éstos materiales.

\subsection{Sitios activos en minerales arcillosos}

El concepto de "sitios activos" describe la estructura y función de la superficie mineral. Los grupos funcionales superficiales, en los minerales arcillosos, aportan diferentes propiedades reactivas de acuerdo a su geometría, localización y grupos intervinientes en los arreglos atómicos sobre la superficie arcillosa. Estos sitios activos fueron clasificados en seis, predominantes en las arcillas (Johnston, 1996):

- Superficie siloxano ó silano neutra.

- Sitios de sustitución isomórfica.

- Cationes metálicos ocupando sitios de cationes de intercambio.

- Moléculas de agua alrededor de los cationes de intercambio.

- Sitios hidrofóbicos.

- Sitios de bordes rotos y superficie expuesta de grupos silicio y aluminio.

\subsubsection{Superficie siloxano neutra}

La estructura superficial del siloxano consiste en láminas de átomos de oxígeno formando un arreglo hexagonal, cada una de éstas superficies de átomos de oxígeno son coordinadas por dos átomos de silicio, la cual posee una distancia 
promedio en las arcillas de $0,16 \mathrm{~nm}$, siendo la distancia entre los átomos de oxigeno sobre la superficie del siloxano alrededor de 0,21 nm (Johnston, 1996). Esta superficie es esencialmente plana, y cada átomo de oxigeno está unido covalentemente a dos átomos de silicio, aunque se pueden formar algunos pliegues en la superficie del oxígeno. La superficie siloxano que se encuentra en las arcillas es muy inerte y no reactiva, debido a las fuertes uniones formadas entre los átomos de silicio y oxígeno.

\subsubsection{Sitios de sustituciones isomórficas}

Estos sitios resultan de la aparición de sustituciones isomórficas en las arcillas. Se caracterizan por tener una permanente carga negativa, proveniente de la naturaleza de los cationes de intercambio, y son comúnmente conocidos como sitios de carga constante. Dependiendo de la extensión de la sustitución isomórfica, estos sitios son separados de 1 a $2 \mathrm{~nm}$ sobre la superficie basal (Johnston, 1996). Las sustituciones isomórficas pueden ocurrir tanto en las láminas tetraédricas como octaédricas y muchas arcillas se caracterizan por su variado grado de sustitución en los bordes de láminas.

Los silicatos laminares tipo 2:1 tienen una gran influencia sobre la adsorción de solutos polares y cargados orgánicamente de acuerdo a la teoría ácido/base, sustituciones isomórficas en la lámina octaédrica crean bases débiles Lewis que cambian a bases fuertes, lo que genera cargas negativas que atraen las moléculas cargadas positivamente. Cuando las sustituciones ocurren en las láminas tetraédricas, la selectividad por cationes orgánicos o inorgánicos, grado de hinchamiento y accesibilidad de la región interlaminar, está fuertemente influenciada por el grado y tipo de sustitución isomórfica ocurrida entre las láminas de los silicatos. Aunque la superficie siloxano se considere no reactiva, debido a las fuertes uniones entre el silicio y el oxígeno, la sustitución de silicio por aluminio incrementa la reactividad y con ella la superficie ácida, por lo tanto la repulsión entre el par de electrones no enlazados sobre la superficie de los átomos de oxígeno incrementa, debido a la sustitución del aluminio (Yariv, 1976).

\subsubsection{Cationes metálicos ocupando sitios de cationes de intercambio}

En este caso, los cationes metálicos ubicados en los sitios de intercambio de la estructura de la arcilla se coordinan con un catión orgánico, es decir, no son reemplazados. Los altos contenidos de agua limitan la capacidad del catión orgánico de 
competir por los sitios de coordinación del catión metálico hidratado, mientras que con contenidos bajos de agua los solutos orgánicos transfieren fácilmente electrones con los cationes metálicos de intercambio.

\subsubsection{Moléculas de agua alrededor de los cationes de intercambio}

El conocido carácter hidrofílico de las arcillas proviene de los cationes de intercambio alcalino o alcalino térreos capaces de rodearse de una esfera de hidratación completa o parcialmente, además compensan cargas negativas provenientes de las sustituciones isomórficas, y por sus características tales como energía de hidratación y radio iónico, determinan el mencionado carácter hidrofílico y otras propiedades de las arcillas. El agua que rodea a éstos cationes tiene propiedades fisicoquímicas distintas al agua total del mineral, por encontrarse en cercanía a los cationes metálicos, lo que restringe su movilidad por el efecto de polarización y naturaleza de éste catión.

El trabajo publicado por Jhonston y col. (1996) sugiere que la interacción esmectita-agua puede explicarse por dos diferentes ambientes de adsorción, (i) las moléculas de agua que coordinan directamente con los cationes de intercambio, (ii) moléculas de agua adsorbidas físicamente en poros intersticiales, espacios interlaminares o sitios polares en la superficie.

\subsubsection{Sitios Hidrofóbicos}

La presencia del catión orgánico en la estructura arcillosa, incrementa el grado de hidrofobicidad de la superficie de ésta, adquiriendo propiedades de hidrofobicidad que hace de las organoarcillas, buenos adsorbentes de compuestos orgánicos no polares.

\subsubsection{Sitios de bordes rotos y superficie expuesta de grupos silicio y aluminio}

En los sitios de bordes rotos y superficie de grupos silicio y aluminio expuesta se considera que la superficie de grupos de oxidrilos situados en el borde roto de los minerales de arcilla, iones metálicos $\mathrm{Si}^{+4}, \mathrm{Al}^{+3}, \mathrm{Fe}^{+3}$, presentes en bordes rotos, escalones, pliegues o agujeros en la superficie de los minerales de arcilla, pueden reaccionar con las moléculas de agua formando grupos $\mathrm{OH}^{-}$. Este tipo de sitios y la presencia de ácidos húmicos, son los responsables de generar $\mathrm{pH}$ dependiente de la carga en suelos y sedimentos. A bajos valores de $\mathrm{pH}$, este sitio desarrolla una carga positiva debido a la adsorción de protones, en este caso ácidos orgánicos u oxianiones 
interactúan fuertemente con estos sitios. Cuando el pH aumenta, se desarrolla una carga neutra y por último, con un aumento mayor en el valor de $\mathrm{pH}$, una carga negativa de la superficie del mineral. La contribución total de este tipo de sitios a la capacidad de intercambio catiónico depende del tamaño y forma de las partículas de la arcilla. Para partículas tamaño arena o limo, la capacidad de intercambio es mínima, pero cuando el tamaño decrece la contribución de los sitios de borde al total de la reactividad de las partículas de arcilla es apreciable. Para algunas arcillas sin notables reemplazos isomórficos (ej. caolinita) el $\mathrm{pH}$ depende de los sitios activos y son la principal fuente de reactividad (Johnston, 1996).

\subsection{Adsorción de moléculas orgánicas sobre arcillas}

La interacción de un catión orgánico con arcilla se encuentra relacionada con los sitios activos, y dependerá del tipo de soluto orgánico con el que interactúe la superficie arcillosa.

Algunos cationes orgánicos estudiados en diversas investigaciones son: surfactantes catiónicos, colorantes orgánicos, herbicidas, pesticidas y productos de degradación de hidrocarburos insaturados. Los cationes orgánicos frecuentemente participan en reacciones de intercambio catiónico y generalmente poseen alta selectividad.

\subsubsection{Mecanismo de Adsorción}

Cowan y White $(1958,1960,1961)$ observaron que la energía libre de Gibbs de los cationes de intercambio de una montmorillonita sódica, incrementa al aumentar el largo de la cadena alquilo del orgánico con el que se modificó. Este comportamiento está relacionado con la contribución de fuerzas Van der Waals entre las cadenas alquilo y la superficie de la arcilla, es decir que los cationes alquilo-amonio son estabilizados por interacción electrostática de las aminas protonadas con sustituciones isomórficas y sitios de bordes rotos por intercambio iónico y a través de interacciones de Van der Waals de la porción hidrófoba del catión orgánico con la parte neutra de la superficie de siloxano, de hecho, la adsorción de cationes orgánicos es frecuentemente irreversible, debido a la alta selectividad de la superficie de la arcilla por cationes orgánicos por sobre los cationes metálicos (Smith y col. 1991). Las fuerzas de atracción de Van der Waals aumentan, en general, con el aumento de tamaño de los cationes orgánicos, 
pudiendo dominar el proceso de adsorción el largo de las cadenas orgánicas (Theng y col., 1967). Si las moléculas son demasiado grandes, sin embargo, el impedimento estérico puede limitar la cantidad adsorbida cuando los cationes orgánicos se vuelven demasiado grandes para caber en la región interlaminar. Además de los efectos estéricos, la densidad de carga de la arcilla influirá en la accesibilidad de los sitios de adsorción interlaminares.

El tamaño de las partículas arcillosas, tipo de catión de intercambio, carga total en la lámina y tipo de sustituciones isomórficas, a través de diversas investigaciones (Lagaly, 1975; Margulies y col., 1988; Lee y col., 2002; entre otros) tienen una significativa influencia en la interacción de los cationes orgánicos con los silicatos laminares tipo 2:1. El arreglo de los cationes orgánicos en la región interlaminar, depende fuertemente del tamaño y forma del catión, como también depende de la densidad de carga de la arcilla. Respecto a la orientación del catión orgánico de intercambio, Serratosa y col. (1984) y más tarde Petit y col. (1999) estudiaron mediante Espectroscopía Infrarroja, la orientación de los cationes orgánicos empleados para la modificación, entre las láminas arcillosas, concluyendo que la orientación perpendicular entre las láminas se da preferencialmente cuando la densidad de cargas aumenta, además, la orientación de los cationes alquilo-amonio en la región interlaminar tiene una gran influencia sobre las propiedades hidrofóbicas de la organoarcilla.

\subsection{Síntesis de organoarcillas}

Existen diversos métodos de preparación de organoarcillas. Petit y col. (1999) sintetizaron organoarcillas a partir de suspensiones de saponita y montmorillonita con solución $1 \mathrm{M}$ de acetato de amonio, en agitación durante 2 horas, repitiendo éste proceso una vez más, luego de la centrifugación, lavando posteriormente el material obtenido, hasta reacción negativa de sales de amonio con reactivo Nessler (reactivo para detectar pequeñas cantidades de amoníaco). En el trabajo publicado por Lee \& Kim (2002), la preparación de la organoarcilla se efectúo sobre una esmectita saturada con sodio en tubos de centrifuga contactada con una solución de hexadecil-trimetil-amonio, en un rango de 2 a 3 veces la capacidad de intercambio de la esmectita, agitando los tubos a temperatura ambiente, centrifugando la suspensión luego de transcurridos dos días, luego se lavó con agua destilada y fue secada en frio durante 36 horas. 
$\mathrm{Si}$ bien, es posible encontrar diversas maneras de preparación de organoarcillas, todas ellas consisten básicamente en contactar el mineral arcilloso con una solución de diferentes tipos de sustancias orgánicas, para posteriormente ser lavados los sólidos hasta eliminación del excedente orgánico, recuperando los sólidos así obtenidos, y secados hasta la eliminación total de agua.

\subsection{Uso de organoarcillas}

Las organoarcillas obtenidas por reemplazo de los cationes intercambiables de entre las láminas de los minerales de arcilla, con cationes orgánicos, de acuerdo con una amplia gama de investigaciones científicas, muestran variadas aplicaciones en la prevención de la contaminación y remediación ambiental, incluyendo tratamiento de aguas de desechos, como barreras de lodos y residuos peligrosos en vertederos y tanques de petróleo (Theng y col. 1967; Lee y col. 1989; Smith y Jaffe, 1994; Sheng y col. 1996).

Mortland y col. (1986); observaron que una esmectita tipo Wyoming modificada con hexadecil-trimetil-amonio, trimetil-fenil-amonio, tetrametil-amonio y hexadecil-piridina, en la remoción de fenol y clorofenol; de su trabajo se observó que la naturaleza del catión orgánico con el que se modifica el mineral arcilloso, y la naturaleza del solvente en el que se encuentra el contaminante, son variables sumamente importantes en la adsorción del fenol y clorofenol. Por ejemplo, en la modificación efectuada con trimetil-amonio, algunas superficies oxigenadas de la estructura de los silicatos fue expuesta, y esta pequeña molécula no pudo cubrir la superficie de la esmectita, consecuentemente, la superficie puede tener propiedades hidrofóbicas, debido a la presencia de moléculas orgánicas. Respecto a la naturaleza del solvente, cuando se emplea agua, el fenol, al unirse fuertemente al agua por medio de uniones puente hidrógeno, no es atraído por la superficie de la organoarcilla; sin embargo, cuando el solvente es el hexano, el fenol, al tener menos interacciones energéticas con el solvente, la interacción adsorbato/adsorbente es mayor, lo que conlleva a una mejor retención.

Zhu y Yuhong, (2002), emplearon organoarcillas para la remoción de vapor de benceno, concluyendo que las organoarcillas, sintetizadas a partir de una bentonita sódica modificada con bromuro de cetil-trimetil.-amonio, son materiales con un gran 
potencial para ser empleados en la retención de vapor de benceno; sobre la base de estos resultados, la adsorción de vapor de benceno del ambiente aéreo, sobre la organoarcilla, se atribuye principalmente a un proceso de partición con la fracción de materia orgánica del adsorbente.

Andini y col. (2006), en su trabajo de adsorción simultánea de 2-clorofenol e iones de cadmio y plomo, usando como adsorbente una bentonita tratada con una sal de cloruro de bencil-dimetil-octadecil-amonio, observaron que la retención de 2-clorofenol podía atribuirse a un mecanismo cooperativo multilaminar, y debido a la naturaleza organofílica del material, obtuvieron retenciones de hasta $0,7 \mathrm{~g} / \mathrm{g}$.

Por lo expuesto, y debido a que los mecanismos que controlan la adsorción de componentes sobre las organoarcillas dependen del tipo y forma del catión orgánico con el que se modificó la estructura arcillosa (Boyd y col. 1991), componentes orgánicos que básicamente confieren carácter organofílico al material adsorbente, éstos sustratos son excelentes adsorbentes de sustancias orgánicas contaminantes que pueden encontrarse tanto en suelos, aire, como en aguas subterráneas o superficiales. 


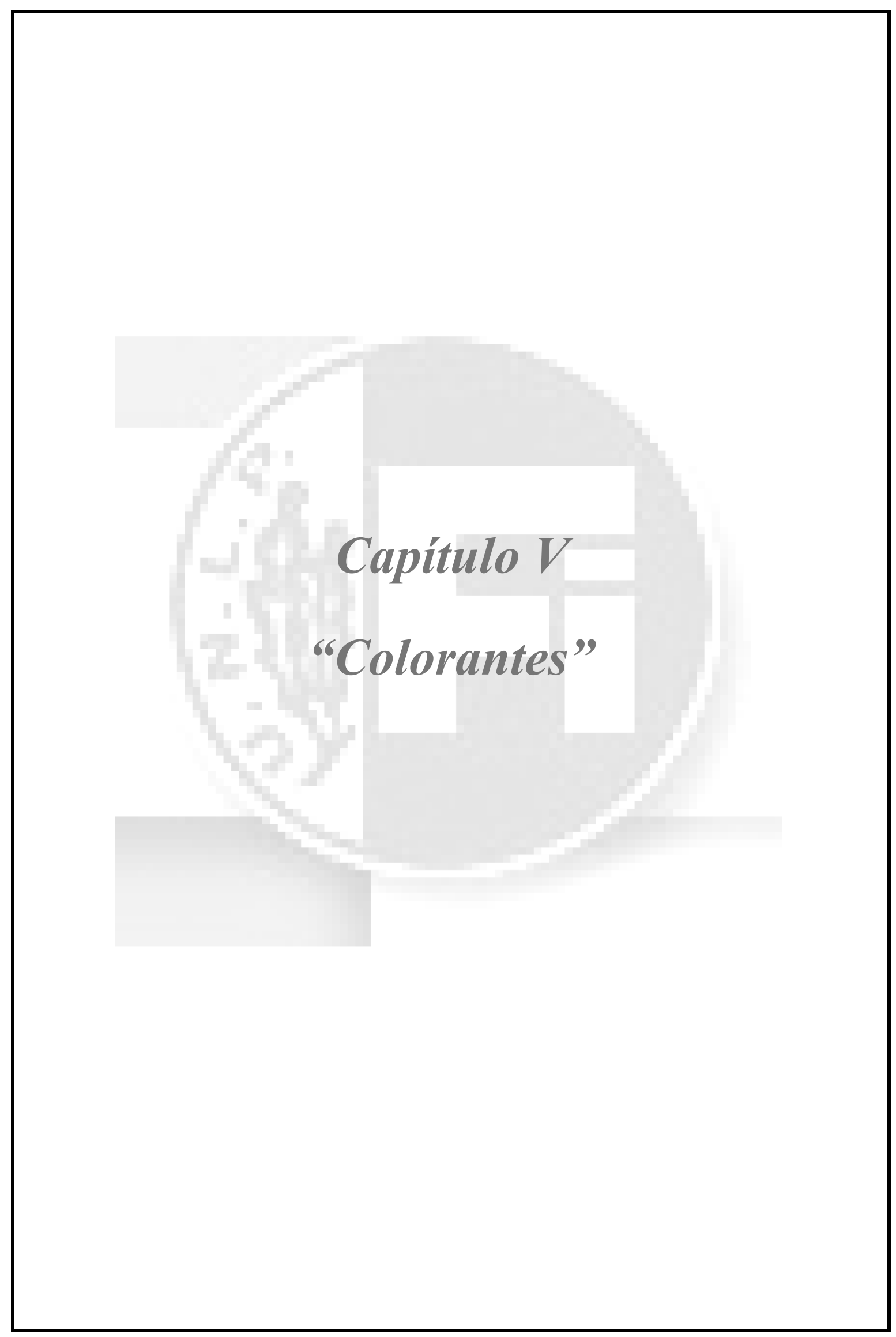





\section{COLORANTES}

Los colorantes son compuestos generalmente orgánicos que tienen la capacidad de impartir color a fibras de diversos orígenes, ya sea textil, como también cuero, papel, plástico e incluso alimentos (Dye Manufacturing, 1998).

Las sustancias coloreadas son las que absorben luz en la región visible del espectro (380 a $750 \mathrm{~nm}$ ), Figura 5.1. Una sustancia presenta el color complementario del que absorbe ya que este se resta de la luz reflejada o transmitida.

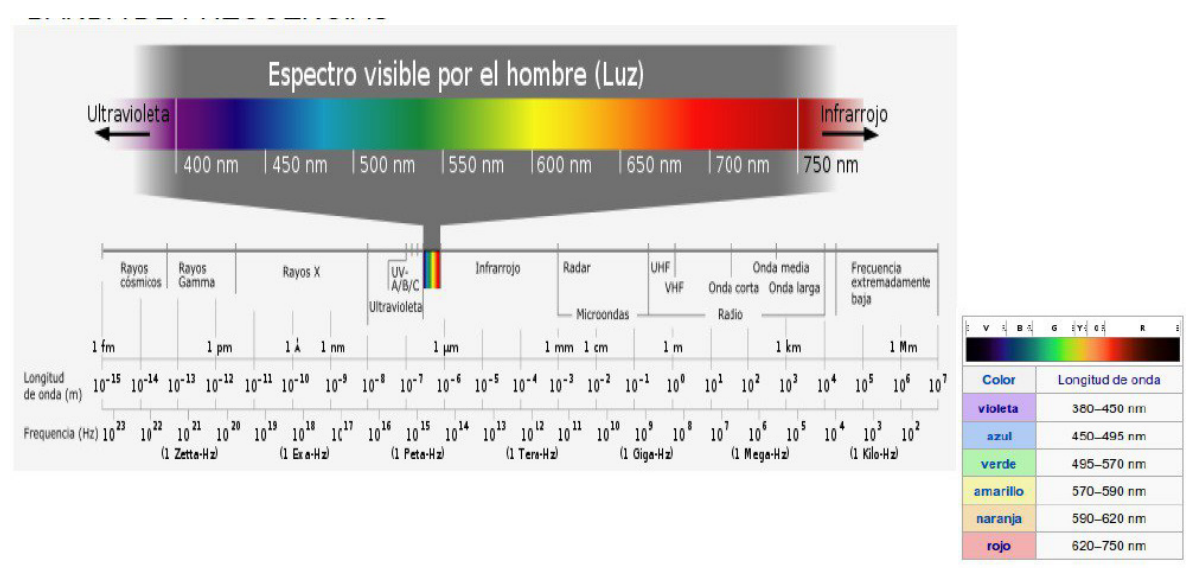

Figura 5.1. Región visible del espectro electromagnético.

En la Tabla 5.1 se presenta la relación entre la luz absorbida y el color que puede apreciarse por el ojo humano.

Tabla 5.1. Relación entre la luz absorbida y el color observado

\begin{tabular}{c|c|c}
$\begin{array}{c}\text { Longitud de Onda }(\lambda) \text { de la } \\
\text { luz absorbida }(\mathbf{n m})\end{array}$ & Zona del Espectro Visible & Color Observado \\
\hline $\mathbf{4 0 0 - 4 3 0}$ & Violeta-Añil & Amarillo \\
$\mathbf{4 3 0 - 4 7 0}$ & Azul & Naranja \\
$\mathbf{4 7 0 - 5 0 0}$ & Azul-Verde & Rojo \\
$\mathbf{5 0 0 - 5 2 0}$ & Verde & Púrpura \\
$\mathbf{5 2 0 - 5 4 0}$ & Verde-Amarillo & Violeta \\
$\mathbf{5 4 0 - 5 9 0}$ & Amarillo & Añil \\
$\mathbf{5 9 0 - 6 1 0}$ & Naranja & Azul \\
$\mathbf{6 1 0 - 7 0 0}$ & Rojo & Verde
\end{tabular}


La aplicación de los tintes se realiza en un medio acuoso y con una buena agitación ya que en el proceso compiten tres reacciones: reacción entre colorante y fibra, reacción entre agua y colorante (hidrólisis), y auto asociación o reacción entre moléculas de colorante (GBPA, 2009).

\subsection{Color y colorantes}

El color es producido cuando los electrones de las moléculas pasan a un estado electrónico superior, esto debido a la interacción de un quanto de radiación, se produce una absorción de radiación. Los dobles enlaces conjugados que presentan algunas moléculas provocan que las diferencias entre los niveles de energía se acorten y aumente la longitud de onda de la luz absorbida, a medida que aumentan éstos enlaces, siendo suficiente la energía de la luz visible para promover transiciones electrónicas entre orbitales. Ejemplo de algunas de las transiciones que pueden generarse se observan en la Tabla 5.2.

Tabla 5.2. Transiciones Electrónicas entre orbitales.

\begin{tabular}{c|ccc}
\hline Molécula & Transición & Energía $\left(\boldsymbol{k J . m o l} \boldsymbol{I}^{\mathbf{I}}\right)$ & Longitud de Onda (nm) \\
\hline etileno & $\pi \rightarrow \pi^{*}$ & 727 & 165 \\
benceno & $\pi \rightarrow \pi^{*}$ & 469 & 256 \\
formaldehído & $\mathrm{n} \rightarrow \pi^{*}$ & 395 & 305 \\
& $\sigma \rightarrow \sigma^{*}$ & & 200 \\
\hline
\end{tabular}

Las transiciones a las que se hace referencia dan lugar a los distintos colores, en la Tabla 5.3, se aprecia el color de las sustancias a medida que aumentan los dobles enlaces conjugados.

Tabla 5.3. Longitud de Onda absorbida en el espectro UV-Visible por polienos conjugados.

\begin{tabular}{c|ccc}
\hline Polieno Conjugado & $\lambda_{\max }(\mathbf{n m})$ & Zona del Espectro & Color Observado \\
\hline Butadieno & 215 & $\mathrm{UV}$ & Incoloro \\
$1,3,5-$ Hexatrieno & 260 & $\mathrm{UV}$ & Incoloro \\
$1,3,5,7-\mathrm{Octatetraeno}$ & 290 & $\mathrm{UV}$ & Incoloro \\
$\mathrm{Ph}-(\mathrm{CH}=\mathrm{CH})_{4}-\mathrm{Ph}$ & 410 & Visible & Amarillo Verdoso \\
$\mathrm{Ph}-(\mathrm{CH}=\mathrm{CH})_{5}-\mathrm{Ph}$ & 424 & Visible & Anaranjado \\
$\mathrm{Ph}-(\mathrm{CH}=\mathrm{CH})_{6}-\mathrm{Ph}$ & 445 & Visible & Café-Anaranjado \\
$\mathrm{Ph}-(\mathrm{CH}=\mathrm{CH})_{7}-\mathrm{Ph}$ & 465 & Visible & Bronce Cobrizo \\
$\mathrm{Ph}-(\mathrm{CH}=\mathrm{CH})_{10}-\mathrm{Ph}$ & 500 & Visible & Rojo \\
$\mathbf{P h}-(\mathbf{C H}=\mathbf{C H})_{\mathbf{1 5}} \mathbf{- P h}$ & 580 & Visible & Azul \\
\hline
\end{tabular}


La acción de agrupaciones atómicas distintas: el cromóforo y el auxocromo, dan origen al color. El cromóforo o grupo portador de color, es un grupo funcional tal como $-\mathrm{C}=\mathrm{C}-,-\mathrm{N}=\mathrm{N}-$ (grupo azo) y anillos aromáticos con varios electrones en orbitales $\mathrm{n}$ y/o $\pi$, lo que da origen al color que observamos. Los sistemas cromóforos más importantes son:

- Cromóforos etilénicos: $\operatorname{Ar}-(\mathrm{CH}=\mathrm{CH}) n-\mathrm{Ar} ;(\mathrm{n} \geq 4)$

- $\quad$ Cromóforos azo: $-\mathrm{R}-\mathrm{N}=\mathrm{N}-\mathrm{R}$

- Cromóforos aromáticos:

○ Derivados del trifenilmetano: $\left[\mathrm{Ar}_{3} \mathrm{CH}\right]$

- Derivados de la antraquinona

- Ftalocianinas

- Derivados hetero-aromáticos

Las moléculas que tienen un grupo cromóforo pueden actuar como colorantes. Dentro de los tipos de colorantes, de acuerdo al grupo cromóforo que lo conforma, son los azoicos y los antraquinónicos, aunque hay otros como los colorantes indólicos, ftalocianina y los derivados de triarilmetano.

La presencia en la molécula de grupos con pares de electrones no compartidos $\left(-\mathrm{NH}_{2} ;-\mathrm{OH} ;-\mathrm{NO}_{2} ;-\mathrm{COOR}\right.$, entre otros) modifican el color y la intensidad de la absorción característica de un grupo cromóforo. Estos grupos, que por sí mismos no confieren color, reciben el nombre de auxocrómicos. Los grupos auxocrómicos cuando son donadores de electrones $\left(-\mathrm{OH},-\mathrm{OMe},-\mathrm{NH}_{2}, \mathrm{NHR} ; \mathrm{NR}_{2}\right)$ intensifican la absorción de luz y desplazan el máximo del espectro a mayores longitudes de onda (fotones de menor energía), es decir, cambian el color a tonos azulados y verdes, recibiendo el nombre de batocrómicos. Los grupos que atraen electrones $\left(-\mathrm{NO}_{2} ;-\mathrm{COOR}\right)$ desplazan la absorción a longitudes de onda más cortas y el color a tonos amarillos y anaranjados y se llaman hipsocrómicos. El color siempre aparece como consecuencia de la acción conjunta de dos agrupaciones atómicas diferentes el cromóforo y el auxocromo, aunque el cromóforo es quien imparte el color, (Industrial Dyes, 2003).

La industria química ha desarrollado una amplia gama de colorantes sintéticos que permiten acceder a una gran diversidad de tonalidades. Para nombrar esta variedad 
de productos no se utiliza la nomenclatura sistemática sino un nombre comercial y un código numérico, que se encuentran registrados en Colour Index (CI). Los colorantes pueden clasificarse por su aplicación tintórea, su estructura química y su nombre comercial.

Un colorante industrial ha de cumplir una serie de propiedades imprescindibles:

- fijarse sobre la fibra textil a teñir

- tener resistencia al lavado y a la luz y

- cumplir determinadas condiciones de carácter sanitario.

Por ello en las moléculas de colorante se introducen, además de los grupos cromóforo y auxocrómicos, grupos ácidos, básicos, alquilo u otros que les confieren buenas propiedades para el teñido de las fibras y resistencia al lavado y a la luz.

\subsubsection{Colorantes azoicos}

En los colorantes azoicos, la parte de la molécula de colorante que proporciona la característica de color (grupo cromóforo) es el grupo azo, que consta de dos átomos de nitrógeno unidos a través de un doble enlace $(-\mathrm{N}=\mathrm{N}-)$, y estos a su vez están unidos a grupos alifáticos o aromáticos, más frecuentemente a aromáticos, (Industrial Dyes, 2003). Este enlace se puede romper por acción enzimática, térmica o fotocatalílica, dando lugar a las aminas correspondientes, que frecuentemente son cancerígenas.

Los colorantes azoicos se encuentran en una cantidad aproximada de $35 \%$ del total de los colorantes, y son los más consumidos por las industrias que emplean en alguna de sus etapas el proceso de tinción de diferentes productos.

\subsubsection{Cromóforos de los colorantes azoicos}

El grupo cromóforo, la extensión del sistema conjugado y los grupos auxocrómicos determinan el color. Los cromóforos azo de mayor importancia comercial se muestran en la Tabla 5.4, donde se observa un aumento en el número de grupos azo desplaza el color a tonos oscuros, verdes, azules y negros. 
Tabla 5.4. Cromóforos Azo.

\begin{tabular}{ll}
\multicolumn{1}{c}{ Grupos azo } & Color \\
\hline $\begin{array}{l}\text { monoazo: } \\
\text { Alquilo- } \mathrm{N}=\mathrm{N} \text {-alquilo } \\
\text { Alquilo- } \mathrm{N}=\mathrm{N} \text {-arilo } \\
\text { Arilo- } \mathrm{N}=\mathrm{N} \text {-arilo } \\
\text { Bisazo: }\end{array}$ & $\begin{array}{l}\text { Amarillo } \\
\text { Rojo anaranjado }\end{array}$
\end{tabular}

Trisazo:

$\operatorname{Ar}-\mathrm{N}=\mathrm{N}$-arilo- $\mathrm{N}=\mathrm{N}$-arilo- $\mathrm{N}=\mathrm{N}-\mathrm{Ar}$ café-azul verdoso

\subsubsection{Obtención de los colorantes azoicos}

Para la preparación de colorantes azoicos se utiliza siempre una amina aromática que por reacción con ácido nitroso (preparado in situ desde $\mathrm{NaNO}_{2}$ y $\mathrm{HCl}$ ) da lugar a un compuesto dinitrogenado llamado sal de diazonio, Reacción 5.1.

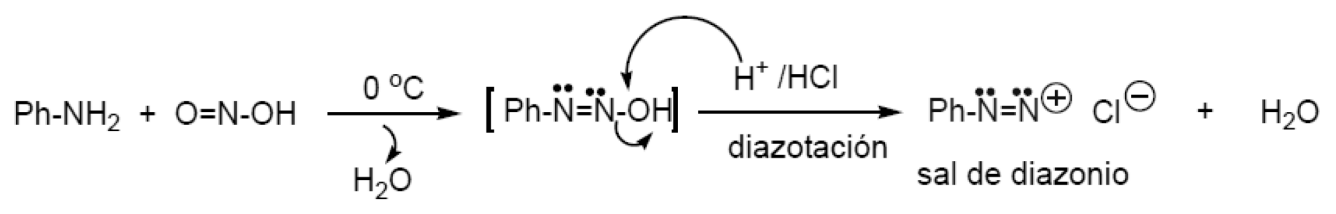

Reacción 5.1. Diazotación.

Las sales de diazonio aromáticas son compuestos estables que actúan como electrófilos débiles, y dan reacciones de sustitución electrófila aromática frente a fenoles y arilaminas. El proceso, que transcurre en frío y con rapidez, recibe el nombre de copulación. La copulación de fenoles se hace a pH ligeramente básico y la de aminas a $\mathrm{pH}$ ligeramente ácido. La sustitución se produce preferentemente en la posición para, salvo que esta se encuentre ocupada, Reacción 5.2.

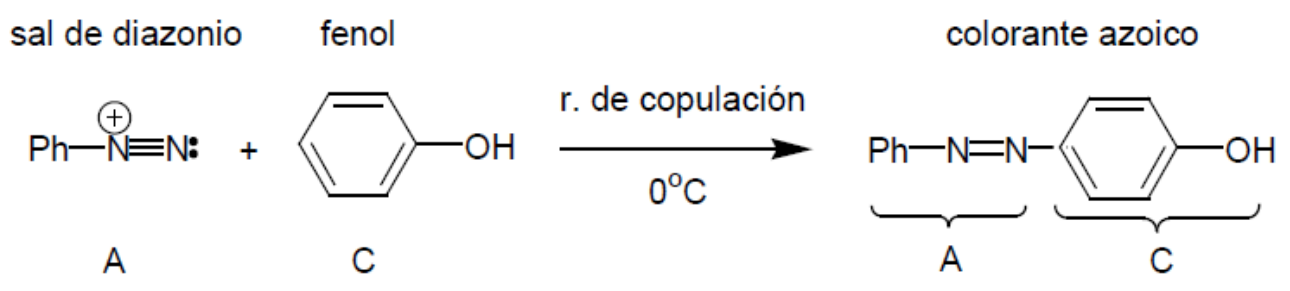

Reacción 5.2. Sustitución electrófila. 
La preparación de estos colorantes requiere, por tanto una amina aromática y otro compuesto aromático que se copule con el primero. Para este fin la industria utiliza una gran variedad de productos intermedios que, a su vez, se obtienen del petróleo, (Industrial Dyes, 2003).

\subsection{Los colorantes y el medioambiente}

Los colorantes residuales procedentes de las diferentes industrias son considerados sustancias contaminantes, por ser vertidos a recursos naturales de agua o sistemas de tratamiento de aguas residuales.

Una de las principales fuentes de problemas de contaminación grave es el ámbito de la industria textil, con aguas residuales con altas cargas y diversidad de tintes orgánicos, estimados en 10.000 especies distintas con una producción anual estimada en 7.150 toneladas métricas, y el 30\% de estos colorantes son empleados en más de 1.000 toneladas al año, siendo el 90\% de los productos utilizados en la industria textil (Baban y col. 2010; Robinson y col. 2001; Soloman y col. 2009).

Durante el proceso de tinción de fibras se pierde $10 \%$ a $25 \%$ de colorantes de los que un $2 \%$ a $20 \%$ son descargados al ambiente durante el teñido, como efluentes acuosos.

El vertido de efluentes que contienen un colorante en el medio ambiente acuoso es indeseable, no solo por su color, sino también porque muchos de los tintes liberan subproductos tóxicos, cancerígenos o mutagénicos dañinos para todas las formas de vida; productos tales como: bencidina, naftaleno y otros compuestos aromáticos (Zaharia y col. 2009). Sin un tratamiento adecuado estos colorantes pueden permanecer en el medioambiente durante un largo periodo de tiempo, un ejemplo de ello es el tinte Reactive Blue 19 , que posee una vida media aproximada de 46 años a pH 7 y $25^{\circ} \mathrm{C}$ (Hao y col. 2000).

Además de los problemas ambientales mencionados anteriormente, la industria textil consume grandes volúmenes de agua potable y agua industrial. El reciclaje de aguas residuales tratadas ha sido recomendado debido a los altos niveles de contaminación en proceso de teñido y acabado, es decir colorantes y sus productos de descomposición, pigmentos, colorantes, productos intermedios, químicos auxiliares y metales pesados. 
Las aguas residuales de las plantas textiles presentan una concentración de colorantes típica de 10 a $200 \mathrm{mg} . \mathrm{L}^{-1}$, por lo tanto son aguas teñidas ya que tan solo con $1 \mathrm{mg} . \mathrm{L}^{-1}$ se manifiesta el color en el agua. Estos colorantes pueden ser bioacumulables e infiltrarse a la cadena alimenticia, por lo tanto implican un daño ecotóxico (Van der Zee, 2002). Es por esto que deben buscarse métodos eficientes de degradación para que ni estos, ni las aminas producto del rompimiento de su molécula, puedan representar un peligro al liberarse a las corrientes acuosas.

\subsection{Colorantes empleados en este trabajo de Tesis}

Los colorantes comúnmente denominados Yellow (Y), Orange (O) y Red Allura AC (R) se seleccionaron en este estudio por ser tintes que presentan en su estructura una o dos grupos azo. El cromóforo azo es uno de los grupos funcionales que aportan color, más comúnmente observados, en los colorantes orgánicos utilizados en diferentes industrias.

\subsubsection{Red Allura AC}

El Red Allura AC es un colorante sintético de color rojo. Se trata de una sal disódica de un compuesto azoderivado, se presenta en forma de polvo de color rojo oscuro. $\mathrm{Su}$ denominación IUPAC es disodio 6-hidroxi-5-((2-metoxi-5-metil-4sulfofenil)azo)-2-naftalensulfonato.

\subsubsection{Toxicidad}

La producción y el uso de tinte Red Allura AC, como un aditivo colorante en alimentos, medicamentos, telas, cosméticos, entre otros, puede dar lugar a su liberación al medio ambiente a través de diversos flujos de residuos. Si se libera al aire el colorante Red Allura AC se dispersará en forma de partículas en la atmósfera, pudiendo eliminarse de ésta por deposición húmeda. Si es liberado en la tierra, este compuesto forma aniones en el medio ambiente, los que generalmente no se adsorben fácilmente en los suelos; además al ser compuestos aniónicos, éstos no se volatilizan fácilmente. Si se elimina en el agua, los sólidos que pueden estar en suspensión y los sedimentos presentes adsorben pobremente éste colorante por su naturaleza iónica. La bioconcentración en organismos acuáticos es baja debido al carácter iónico del compuesto, sin embargo, al ser altamente solubles en agua, la coloración de los efluentes es significativa, lo que impide el proceso de fotosíntesis en la plantas acuáticas 
al impedir que lleguen a ellas los rayos solares; lo que provoca una disminución en la vida vegetal acuática, y en consecuencia la disminución de alimento para muchas especies animales (Dye Manufacturing, 1998). En los seres humanos éste colorante al contacto dérmico puede provocar reacciones alérgicas; además varios metabolitos, posiblemente resultantes de azo-reducción en el tracto gastrointestinal, dos aminas aromáticas y ácido p-cresidina (el más importante), es considerado un colorante carcinogénico. Investigaciones como las realizadas por Vorhees y col. (1983) reportaron la acumulación de componentes carcinogénicos en la vejiga de ratas, al administrar dosis altas del colorante (10\% de la dieta alimenticia), por lo que se concluye que puede ocasionar cáncer de vejiga, aunque aún no se han registrado casos en seres humanos, en algunos países de Europa se ha prohibido su uso en sustancias comestibles.

\subsubsection{Estructura Química}

El colorante Red Allura AC está formado por un grupo cromóforo azo, dos grupos funcionales auxocromo sulfonato de sodio, uno de ellos unido al grupo p-metil, p-metoxi-benceno y el otro a un grupo naftol, Figura 5.2.

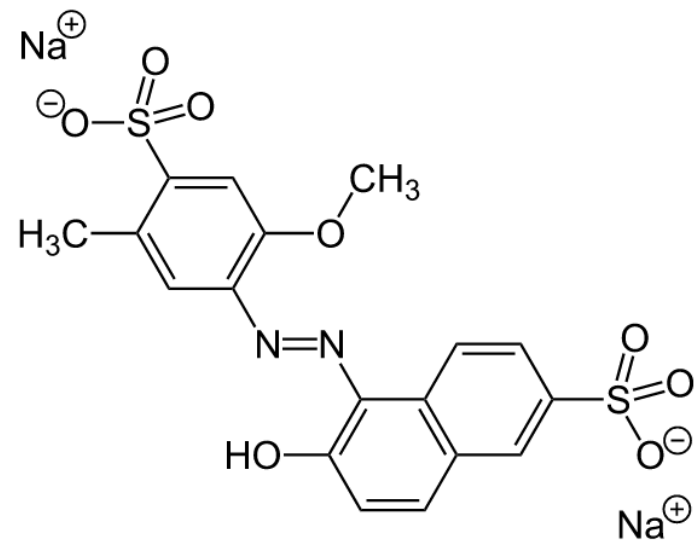

Figura 5.2. Molécula Red Allura AC.

\subsubsection{Propiedades y Usos}

Se trata de un polvo de color rojo oscuro, sin olor, altamente soluble en agua y también puede disolver en glicerina y propilenglicol, siendo ligeramente soluble en etanol e insoluble en grasa. Es resistencia a la luz, al calor, a la sal, y a los ácidos, 
siendo estable frente a ácidos orgánicos como el ácido cítrico y el ácido tartárico; presenta una buena resistencia a los álcalis y los oxidantes.

En la Tabla 5.5., se aprecian las propiedades del colorante Red Allura AC más importantes.

Tabla 5.5. Propiedades Red Allura AC.

\begin{tabular}{c|c}
\hline Peso Molecular & $496,42{\mathrm{~g} \cdot \mathrm{mol}^{-1}}^{-1}$ \\
Fórmula Molecular & $\mathrm{C}_{18} \mathrm{H}_{14} \mathrm{~N}_{2} \mathrm{Na}_{2} \mathrm{O}_{8} \mathrm{~S}_{2}$ \\
Superficie polar topológica & $182 \AA^{2}$ \\
Átomos de Metales & 32 \\
Longitud de Onda máxima & $499 \pm 2 \mathrm{~nm}$ \\
Solubilidad en Agua & $22 \mathrm{mg} \cdot 100 \mathrm{~mL}^{-1}$ \\
Número CAS & $25956-17-6$ \\
Concentración estimada aceptable en humanos & $0-7 \mathrm{mg} \cdot \mathrm{g}^{-1}$ \\
\hline
\end{tabular}

Si bien en 2006 O'Neil, M. J. (2006) propuso, y luego la EPA (2011) aceptó el uso de éste colorante como aditivo en alimentos, medicamentos y cosméticos; el mismo ha siendo, además, utilizado en gelatinas de color, budines, flanes, bebidas alcohólicas y no alcohólicas, salsas, coberturas, dulces, azúcares, glaseados, frutas, zumos, productos lácteos, productos de panadería, mermeladas, jaleas, condimentos, carne y aves de corral; en algunos países de Europa, tales como Dinamarca, Bélgica, Francia, Alemania, Suiza, Suecia y Austria, se prohíbe su uso desde el año 2007 (UK Food Guide, 2007).

\subsubsection{Orange $G$}

El colorante Orange $\mathrm{G}$ es un colorante sintético orgánico aniónico monoazoico, de colora naranja brillante. Es una sal disódica que se presenta en forma de polvo naranja intenso. Su denominación IUPAC es disodio- 7-oxo-8-(fenilhidracinilideno) naftaleno-1,3-disulfonato.

\subsubsection{Toxicidad}

Este compuesto se puede degradar en condiciones anaerobias; una amplia variedad de bacterias anaerobias tiene la capacidad de escindir el enlace azo para producir aminas aromáticas.

Al igual que el colorante Red Allura AC, el Orange G puede liberarse al ambiente en forma de partículas que contaminan el aire, la eliminación de éste se 
efectúa por medio del método de deposición húmeda, y en ocasiones seca. Al liberarse en el suelo, por su naturaleza iónica puede dar lugar a procesos de intercambio catiónico con los componentes de éste, retardando el proceso de lixiviación. Es un colorante resistente a la biodegradación aeróbica, por lo que para sistemas biológicos de descontaminación solo es posible degradar anaeróbicamente, por medio de una amplia variedad de bacterias anaeróbicas que actúan en el cromóforo azo, produciendo aminas aromáticas, muy peligrosas, con lo cual éste no es un proceso recomendable, debido a que, aunque decolora los suelos contaminados, genera compuestos aún más peligrosos. Por ser altamente soluble en agua, posee la capacidad de transportarse por éste medio y producir un amplio daño, interfiriendo en los procesos biológicos de la biota acuática, y mutando a sustancias nocivas para las personas, por contener en su estructura aminas y compuestos aromáticos. El contacto directo con la piel puede provocar reacciones alérgicas, y su ingestión es sumamente peligrosa, debido a la presencia de los componentes nombrados con anterioridad, que al ser ionizados pueden mutar transformándose en sustancias altamente carcinogénicas.

\subsubsection{Estructura Química}

Orange $\mathrm{G}$ es un colorante monoazoico aniónico que se hace mediante el acoplamiento de la anilina diazotado en ácido G (ácido 2-naftol-6,8-disulfónico) y convertir el producto de acoplamiento de la sal disódica,(Green, 1990).

El colorante Orange G está formado por un grupo cromóforo azo, dos grupos funcionales auxocromos sulfonato de sodio, unidos a un grupo naftol y un grupo benceno, Figura 5.3.<smiles>O=S(=O)(O)c1cc(S(=O)(=O)O)c2c(/N=N/c3ccccc3)c(O)ccc2c1</smiles>

Figura 5.3. Molécula Orange G. 


\subsubsection{Propiedades y Usos}

Se trata de un polvo de color naranja oscuro, sin olor, altamente soluble en agua y también puede disolver en glicerina y propilenglicol, siendo ligeramente soluble en etanol e insoluble en grasa. Al descomponerse térmicamente emite humos tóxicos de nitrógeno y óxidos de azufre.

En la Tabla 5.6., se aprecian las propiedades del colorante Orange G más importantes.

Tabla 5.6. Propiedades Orange G.

\begin{tabular}{c|c}
\hline Peso Molecular & $452,37 \mathrm{~g} \cdot \mathrm{mol}^{-1}$ \\
Fórmula Molecular & $\mathrm{C}_{16} \mathrm{H}_{10} \mathrm{~N}_{2} \mathrm{Na}_{2} \mathrm{O}_{7} \mathrm{~S}_{2}$ \\
Superficie polar topológica & $173 \AA^{2}$ \\
Átomos de Metales & 29 \\
Longitud de Onda máxima & $504 \pm 2 \mathrm{~nm}$ \\
Solubilidad en Agua & $80 \mathrm{mg} .100 \mathrm{~mL}^{-1}$ \\
Número CAS & $136-15-8$ \\
Concentración estimada aceptable en humanos & Desconocido \\
\hline
\end{tabular}

El Orange G tiñe la lana y la seda directamente desde un baño de ácido fórmico o ácido sulfúrico. Dentro de los usos industriales no textiles se incluyen la tinción de papel, cuero y madera y producción de tintas para colorear y lápices de copia, (Green, 1990). Además dentro de los usos más importantes se destaca su empleo como marcador biológico utilizado ampliamente como un fondo o contraste para una serie de manchas nucleares importantes. Es un excelente colorante para la tinción de plasma y un componente importante de una de las soluciones de tinción utilizados en el método para la detección de Papanicolaou vaginal, cervical, y cáncer de útero, (Green, 1990). En los Estados Unidos, este color se usó en drogas y cosméticos hasta octubre de 1966, cuando su uso para estas aplicaciones fue prohibido (IARC, 1972).

\subsubsection{Yellow GR}

El colorante Yellow GR es un colorante sintético orgánico aniónico diazoico, de color amarillo brillante. La formación de éste pigmento implica la reacción de diaminas aromáticas diazotizadas (derivados de bencidina) con derivados de aceto-acetanilida; los diferentes compuestos de ésta reacción da origen a diversos pigmentos desde coloración 
amarilla a verdosa, dependiendo del grado de sustitución de los anillos bencénicos, entre ellos se encuentra el Yellow GR. Su nomenclatura IUPAC es 2-[[2-cloro-4-[3-cloro-4[1-(2,4-dimetilanilino)-1,3-dioxobutan-2-acenil]fenil]fenil]diacenil]-N-(2,4-dimetilfenil)-3-oxobutanamida).

\subsubsection{Toxicidad}

El pigmento Yellow GR se considera no tóxico, sin embargo, y al igual que los colorantes Red Allura AC y Orange G, hay evidencia de que estos pigmentos pueden mutar a especies altamente carcinogénicas, debido a las moléculas que conforman su estructural total; en el caso particular del Yellow GR, puede liberar 3,3-diclorobencidina, que es un carcinógeno y está listado en el Inventario de Emisiones Tóxicas de la EPA de EE.UU. Además en contacto directo con la piel puede provocar reacciones alérgicas., y si se encuentra en solución, al llegar a cursos de aguas, también produce efectos dañinos en la vida acuática.

\subsubsection{Estructura Química}

El colorante Yellow GR está formado por dos grupos cromóforos azo, dos grupos cloro-benceno, dos grupos hidroxo-butanamina y dos grupos benceno, Figura 5.4 .

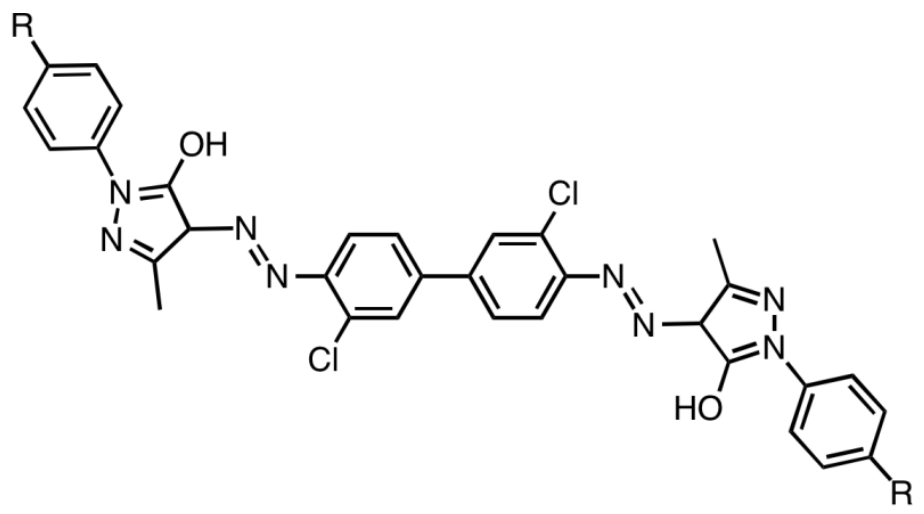

Figura 5.4. Molécula Yellow GR.

\subsubsection{Propiedades y Usos}

Se trata de un polvo de color amarillo intenso y brillante, soluble en agua.

En la Tabla 5.7., se aprecian las propiedades del colorante Yellow GR más importantes. 
Se emplea en la industria artística como material de tinción de diversas artesanías. También es empleado en tintas, tóner y los productos colorantes de pinturas y recubrimientos. Al igual que se mencionó anteriormente, se utiliza para la tinción de papel, plástico, caucho y productos textiles.

Tabla 5.7. Propiedades Yellow GR.

\begin{tabular}{c|c}
\hline Peso Molecular & $685,60 \mathrm{~g} \cdot \mathrm{mol}^{-1}$ \\
Fórmula Molecular & $\mathrm{C}_{36} \mathrm{H}_{34} \mathrm{Cl}_{2} \mathrm{~N}_{6} \mathrm{O}_{4}$ \\
Superficie polar topológica & $142 \AA^{2}$ \\
Átomos de Metales & 48 \\
Longitud de Onda máxima & $500 \pm 2 \mathrm{~nm}$ \\
Solubilidad en Agua & $5 \mathrm{mg} .100 \mathrm{~mL}^{-1}$ \\
Número CAS & $5102-83-0$ \\
Concentración estimada aceptable en humanos & Desconocido \\
\hline
\end{tabular}

\subsection{Métodos de Remoción de Colorantes}

Para la remoción de colorantes los científicos han estudiado diferentes tratamientos, destacándose entre la bibliografía consultada trabajos como el de Yonni y col. (2008), quien empleó hongos para la remoción de Rojo Ácido y Negro Directo por biodegradación. La cepa empleada Bjerkandera. Posee capacidad de degradación de los colorantes textiles estudiados, los cuales son normalmente resistentes al ataque bacteriano; obtuvieron una mayor remoción de Rojo Ácido respecto a Negro Directo. Sin embargo se trata de un sistema sumamente complejo, debido a las condiciones en las que la cepa se encuentra óptima para el proceso de biodegradación, y los valores de remoción de los tintes no justifican la complejidad del tratamiento.

Alonso-Calderón y col. (2008); emplearon la oxidación como técnica de eliminación de fenol, 2-clorofenol y colorantes en aguas artificialmente contaminadas y aguas residuales textiles, empleando como medio oxidante biológico una enzima conocida como peroxidasa, proveniente de una fuente vegetal alternativa y disponible en la zona de estudio, el chayote. Los valores de remoción de los contaminantes fueron de $88,5 \%$ para fenol, 95,9\% para 2-clorofenol, 93,2\% para el colorante Negro Directo y $84,3 \%$ para el Negro 22. 
La investigación de Sánchez y col. (2010), en relación a la adsorción del colorante Azo RR239 (colorante reactivo azo), utilizando nanopartículas de hierro cero valente inmovilizadas sobre aserrín, demuestra una alta sensibilidad al $\mathrm{pH}$ atribuible a las propiedades superficiales del adsorbente, particularmente del potencial de carga cero.

Solis-Oba y col. (2009); realizaron una comparación de técnicas para el tratamiento de una solución de colorante índigo. Las técnicas estudiadas fueron: electroincineración y coagulación química y enzimática, concluyendo que estas tecnologías podrían ser empleadas a gran escala para el tratamiento de las aguas residuales de las industrias que empleen el colorante índigo para tinción, debiéndose aplicar los tratamientos en conjunto para mejores resultados, lo que conlleva un gasto sumamente importante por las condiciones específicas que deben mantenerse para la actividad enzimática y los excesivos costos de los electrodos usados en la electro-incineración.

Muchos de éstos tratamientos se basan en la decoloración de las soluciones contaminadas con colorantes, sin embargo, en algunos casos, la eliminación de los componentes realmente nocivos para la vida humana y el medioambiente, como los son los compuestos aromáticos y las aminas, no es posible; además la aplicación de éstas tecnologías en la industria es sumamente compleja, requiriendo además de un gran gasto económico, un riguroso control de las variables que deben controlarse. Por ello, algunos investigadores han optado por metodologías menos complejas y relativamente económicas, con la finalidad de hacer más viable la implementación de las técnicas de descontaminación. Los estudios que continúan esta línea son, en líneas generales, aquellos que emplean como principal proceso la adsorción.

Los estudios efectuados por Lin y col. (2004); utilizaron la adsorción en sustratos arcillosos ácidos de colorantes ácidos. El tratamiento de la arcilla con ácido a temperatura ambiente reemplaza los iones $\mathrm{Ca}$ y $\mathrm{Na}$ de intercambio con protones, lo que aumenta el volumen de los microporos y en consecuencia el área superficial, derivando esto en una mayor capacidad de adsorción. El valor de adsorción obtenido para el colorante Acid Yellow 194 sobre la arcilla natural fue de 24,9 mg. $\mathrm{g}^{-1}$, aumentando éste a $71,1 \mathrm{mg} \cdot \mathrm{g}^{-1}$ cuando se contactó el colorante con la arcilla ácida; además, para el colorante Acid Red 423, las adsorciones sobre la arcilla sin tratamiento y la arcilla tratada con ácido, fueron de $29,1 \mathrm{mg} \cdot \mathrm{g}^{-1}$ y $85,2 \mathrm{mg} \cdot \mathrm{g}^{-1}$, respectivamente. 
Trabajos publicados como el de Hedley y col. (2007); demostraron que la modificación de la estructura de los minerales arcillosos utilizando surfactantes con contenido de iones de fósforo cuaternario, aumenta significativamente la remoción de colorantes orgánicos, relacionando éste fenómeno con la atracción de los contaminantes orgánicos con la materia orgánica proveniente del tratamiento de la arcilla con el surfactante.

Lo anteriormente expuesto indica que para los diferentes tipos de colorantes (aniónicos, catiónicos, polares, etc.) existen condiciones fisicoquímicas de las arcillas que deben tenerse en cuenta para su aplicación como adsorbentes. 



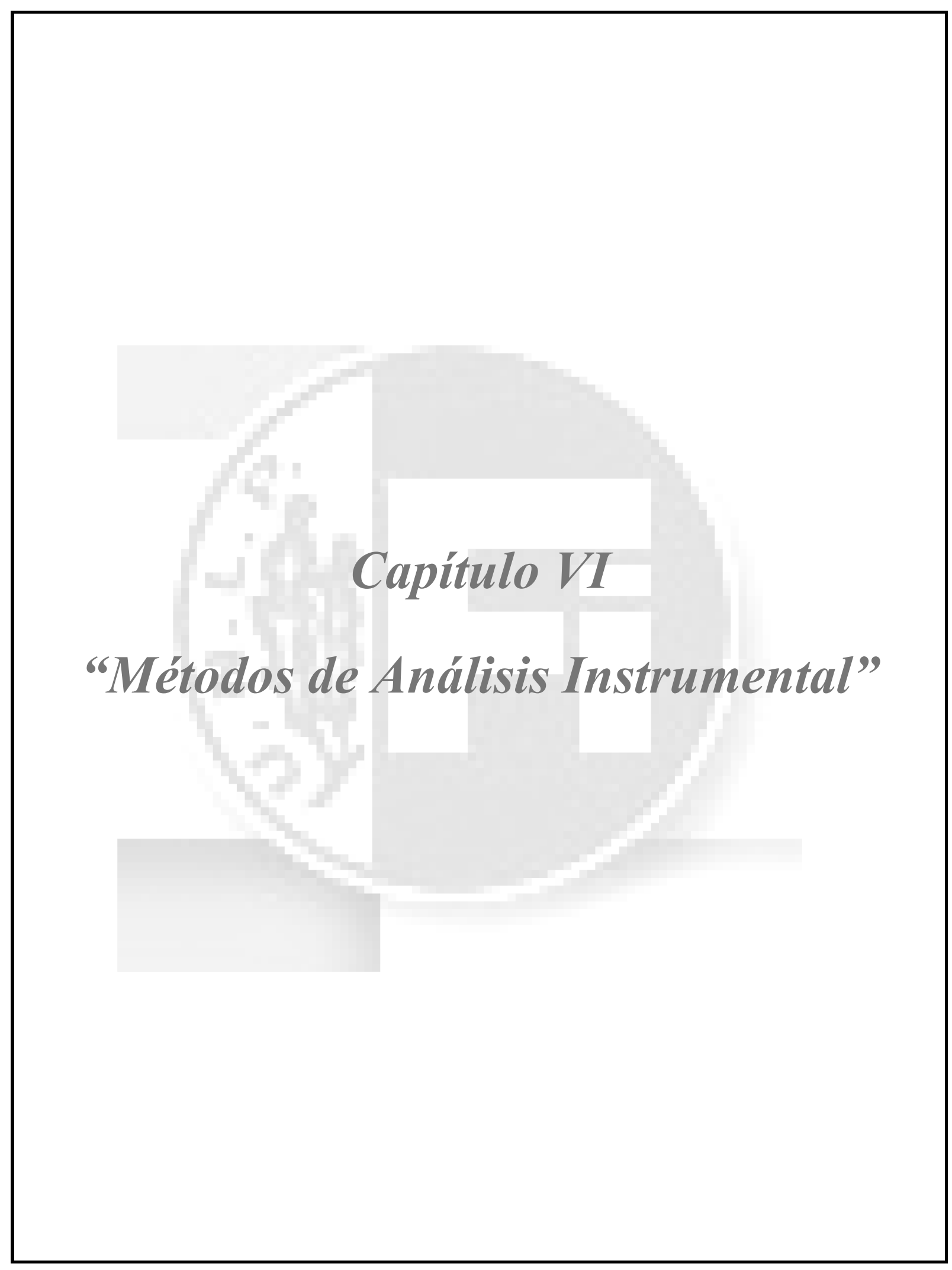




\section{MÉTODOS DE ANÁLISIS INSTRUMENTAL}

Los métodos instrumentales que se presentan a continuación fueron una herramienta indispensable para el estudio de los materiales, en el caso de la presente tesis, tanto de los adsorbentes como de las soluciones empleadas en las experiencias de retención de los colorantes textiles seleccionados. Éstas técnicas no sólo permiten caracterizar los materiales sino también estudiar su comportamiento frente a las modificaciones que pueden sufrir de índole físico o químico.

Dentro de las técnicas instrumentales fundamentales se presentan a continuación aquellas que han sido utilizadas en éste estudio.

\subsection{Espectrometría}

El término Espectrometría sugiere la medición de la cantidad de energía radiante que absorbe un sistema químico en función de la longitud de onda de la radiación.

La interacción de la energía radiante con las partículas, da origen a una energía característica de cada especie relacionada con la frecuencia de la luz mediante la Ecuación 6.1.1.

$$
\text { Ecuación 6.1.1. } \quad \mathrm{E}=\mathrm{hv}
$$

Donde $h$ es la constante de Planck y $v$ la frecuencia.

La luz de una cierta longitud de onda está relacionada con los fotones, los que poseen una cantidad definida de energía; ésta cantidad de energía es la que determina si una cierta especie absorberá o emitirá la luz de la longitud de onda correspondiente.

La energía interna que posee una molécula puede ser de tres tipos. Primera, la molécula puede rotar en varios ejes y poseer una cierta cantidad de energía rotacional. Segunda, los átomos o grupos de átomos que están en la molécula pueden vibrar, este es, moverse periódicamente uno con respecto al otro en sus posiciones de equilibrio, lo que da a la molécula una energía de vibración. Por último, una molécula posee energía electrónica, 
la cual es el potencial asociado con la distribución de las cargas de los electrones en los núcleos de los átomos con carga positiva, Ecuación 6.1.2.

$$
\text { Ecuación 6.1.2. } \quad \mathrm{E}_{\mathrm{Int}}=\mathrm{E}_{\text {elec }}+\mathrm{E}_{\text {vib }}+\mathrm{E}_{\text {rot }}
$$

Si una molécula absorbe energía para pasar a un nivel energético superior, debe absorber una cantidad definida para la transición. Esta cantidad de energía molecular junto al concepto de que los fotones poseen cantidades de energía definidas, establece el grado de selectividad que tiene las moléculas para absorber energía radiante. Cuando se irradian las moléculas con muchas longitudes de onda, del haz incidente solo se sustraerán aquellas longitudes de onda que correspondan a los fotones de energía apropiados para permitir las transiciones de energía molecular y las demás longitudes de onda serán emitidas.

Los niveles de energía rotacional de una molécula requieren relativamente poca energía y se inducen por medio de radiaciones de muy baja frecuencia (longitud de onda larga), en las regiones del infrarrojo lejano y de microondas $(100 \mu \mathrm{m} \mathrm{a} 10 \mathrm{~cm})$. Los estudios en ésta región aportan información fundamental con respecto a la estructura molecular. En la región del infrarrojo del espectro se observa la absorción, debido a transiciones de vibración, aproximadamente de 2 a $100 \mu \mathrm{m}$, sin embargo, no es posible observar cambios en la energía de vibración puros, ya que se sobreponen las transiciones rotacionales, por ello el espectro está formado de bandas complejas. Los espectros de absorción en la región visible o en la ultravioleta generalmente son una serie de picos que poseen una curvatura tenue, aumentando la energía de una molécula, permitiendo que los electrones venzan las fuerzas que los mantienen unidos al núcleo, trasladándose hacia orbitales de mayor energía, (Day y Underwood, 1989).

La relación que existe entre la absorción de radiación y la longitud de la trayectoria a través del medio absorbente fue formulada en primera instancia por el científico francés Pierre Bougher (1729) y posteriormente por el alemán Johann H. Lambert (1768) a quien se le atribuye. La ley propuesta por ambos científicos se expresa según la Ecuación 6.1.3. 


$$
\text { Ecuación 6.1.3. } \log \frac{\mathrm{P}_{\mathrm{o}}}{\mathrm{P}}=\mathrm{k} \cdot \mathrm{b}
$$

Donde $\mathrm{P}_{\mathrm{o}}$ es la energía radiante incidente y $\mathrm{P}$ es la que sale de una capa de espesor b.

La mencionada ley puede anunciarse como: "la energía de la radiación transmitida disminuye en forma exponencial al aumentar en forma aritmética el espesor del medio absorbente".

August Beer (1859), físico y matemático alemán, formuló la relación entre la concentración de la especie absorbente y el grado de adsorción, siendo ésta una formulación análoga a lo propuesto por Bougher, la Ecuación 6.1.4 describe éste postulado.

$$
\text { Ecuación 6.1.4. } \log \frac{\mathrm{P}_{\mathrm{o}}}{\mathrm{P}}=\mathrm{k.c}
$$

De la combinación de ambas expresiones matemáticas es posible arribar a la denominada Ley de Lambert-Beer, la que se expresa en la Ecuación 6.1.5.

$$
\text { Ecuación 6.1.5. } \log \frac{\mathrm{P}_{\mathrm{o}}}{\mathrm{P}}=\mathrm{K} \text {.b.c }
$$

La instrumentación analítica que emplea el mencionado principio para la determinación cualitativa y/o cuantitativa de los analitos, lo hace a través de la cantidad de luz absorbida o transmitida a través de su medio, es así que existen dos expresiones de medida que hacen referencia a esto, la absorbancia y transmitancia.

La transmitancia normalmente se da en términos de una fracción de 1 (uno), o como porcentaje, Ecuación 6.1.6. 


$$
\text { Ecuación 6.1.6. } \mathrm{T}=\frac{\mathrm{P}}{\mathrm{P}_{\mathrm{o}}} \quad \text { ó } \% \mathrm{~T}=\frac{\mathrm{P}}{\mathrm{P}_{0}} \times 100
$$

Mientras que la absorbancia es la expresión logarítmica inversa de la transmitancia, indicada en la Ecuación 6.1.7.

$$
\text { Ecuación 6.1.7. } A=\log \frac{1}{T} \quad \text { ó } \% A=\log \frac{1}{T} \times 100
$$

\subsubsection{Instrumentación}

Los espectrómetros son los encargados de medir Tansmitancia ( $\mathrm{T}$ ) ó Absorbancia (A) de una muestra en función de una longitud de onda determinada.

Estos instrumentos pueden clasificarse en manuales o de registro, de simple o doble haz. En la práctica, generalmente los instrumentos de un solo haz se operan de forma manual; mientras que los de doble haz poseen un registro automático de los espectros de absorción. Además es posible clasificar éstos instrumentos de acuerdo a la región espectral en la que operan. A continuación se mencionarán los espectrofotómetros de infrarrojo y ultravioleta utilizados en el presente estudio.

\subsubsection{Espectrometría Infrarroja}

La Espectrometría IR es una herramienta de rutina para detectar grupos funcionales, identificar compuestos y analizar mezclas, a partir del estudio de los movimientos de vibración, y en ocasiones de rotación, dentro de las moléculas.

En la Figura 6.1, se observan los movimientos vibracionales de tensión y flexión básicos de los enlaces entre los átomos.

Cada átomo que constituye una molécula está desplazándose permanentemente, uno con respecto al otro, sobre una distancia promedio llamada longitud de enlace, es decir, las distancias interatómicas oscilan continuamente alrededor de un valor que le es propio, 
manteniéndose por ejemplo, en el estado basal de energía y a temperatura ambiente, a una distancia promedio llamada longitud de enlace. Cada enlace dentro de una molécula está vibrando a una frecuencia determinada que le es característica, y puede efectuar un movimiento de estiramiento a lo largo del eje del enlace, o un movimiento de deformación en donde uno de los átomos del enlace se aparta del eje del enlace. Una molécula biatómica, solo poseerá un modo de vibración que será el de estiramiento a lo largo del enlace. Si la molécula tiene más de dos átomos, los posibles modos de vibración aumentan de manera considerable. Por lo tanto, las vibraciones moleculares son en realidad, el resultado de la contribución de todos los átomos que la componen, por ello, al describir la estructura de una molécula en términos de longitudes y ángulos de enlaces fijos, se describe una situación probabilística.

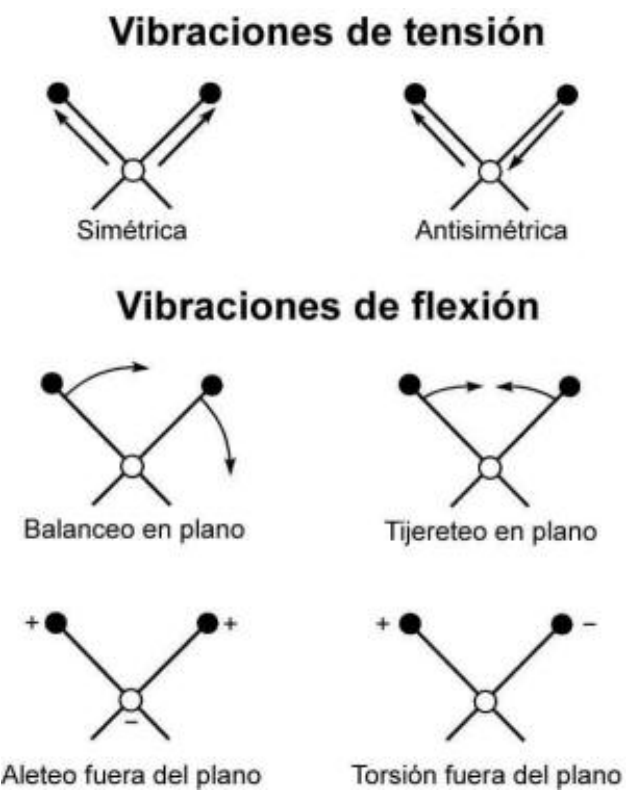

Figura 6.1. Movimientos vibracionales de los átomos.

Madejová y col. (2003), emplearon técnicas de FTIR (espectrometría infrarroja por transformada de Fourier) para estudiar la estructura, uniones y propiedades químicas de minerales arcillosos, siendo objeto de su investigación una caolinita y una montmorillonita, en una región de $4000 \mathrm{~cm}^{-1}$ a $400 \mathrm{~cm}^{-1}$. Concluyendo que las bandas de absorción $\mathrm{OH}$ y SiO frecuentemente juegan un papel importante en la diferenciación de éstos minerales, 
debido a que la caolinita con mayoría de $\mathrm{Al}$ en la capa octaédrica posee cuatro bandas de absorción en la región stretching $\mathrm{OH}$, los grupos internos $\mathrm{OH}$ entre los tetraedros y los octaedros, poseen bandas de absorción cercanas a $3620 \mathrm{~cm}^{-1}$, los otros tres grupos $\mathrm{OH}$ residen en la capa octaédrica de las láminas y forman uniones leves puente hidrógeno, con los $\mathrm{O}$ de los grupos $\mathrm{Si}-\mathrm{O}-\mathrm{Si}$, en la superficie inferior de la capa siguiente, además la presencia de una fuerte banda a $3695 \mathrm{~cm}^{-1}$ se encuentra relacionada a la fase de vibración stretching. En el espectro obtenido de la montmorillonita, los autores identificaron bandas cercanas a $3620 \mathrm{~cm}^{-1}$ de vibración stretching de la estructura $\mathrm{OH}$, y una banda ancha cerca de $3440 \mathrm{~cm}^{-1}$, relacionada a la vibración stretching $\mathrm{OH}$ del agua presente en la esmectita.

Bishop y col. (1997), determinaron por medio de técnicas de espectrometría en el infrarrojo la fuerte influencia de los cationes interlaminares y la humedad ambiental, en las vibraciones moleculares del $\mathrm{H}_{2} \mathrm{O}$ presente en una montmorillonita.

Además del empleo de la técnica para la caracterización de minerales arcillosos naturales, diversas publicaciones científicas estudiaron las modificaciones estructurales de las arcillas al ser modificadas por medio de diversos procesos. Dentro de los trabajos científicos abocados a ésta temática se encuentra el trabajo realizado por Petit y col. (1999), quienes evaluaron las variaciones espectrales de la región infrarroja de una saponita y una esmectita, ambas modificadas con una solución de acetato de amonio 1M. Demostrando que el uso de sales de amonio intercambiadas en la estructura del mineral, y su posterior caracterización por técnicas de IR, permiten caracterizar la carga de la arcilla a partir de las intensidades de las bandas.

Las moléculas orgánicas, tanto la de los tintes textiles, como la del surfactante empleado en la modificación de la estructura de las arcillas adsorbentes utilizadas en éste trabajo, fueron sometidas a éste método analítico, con lo cual, se obtuvieron espectros IR con bandas que son resultado de la superposición de los distintos materiales. Este método permitió reconocer los grupos funcionales intervinientes en el proceso de adsorción, por medio del instrumento IR Spectrum One Perkin Elmer, Figura 6.2. 


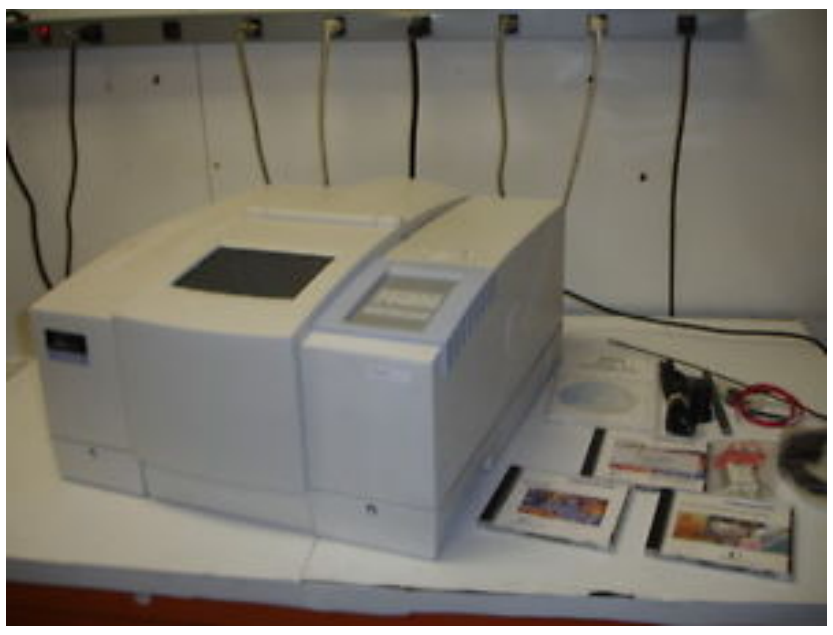

Figura 6.2. Espectometro IR Spectrum One Perkin Elmer.

\subsubsection{Espectrometría $U V$-visible}

La espectrometría UV-visible identifica y cuantifica sustancias cuya longitud de onda se encuentre en el rango de longitud de onda desde $190 \mathrm{~nm}$ a $800 \mathrm{~nm}$. La mayor parte de los autores que son citados en la presente tesis, han empleado la técnica de espectrometría UV-visible para la cuantificación de las soluciones con cargas de colorantes empleadas en las investigaciones referentes a los distintos tipos de técnicas de remediación (Šmelceroviç y col. 2010; Ignat y col. 2012; Khodaeer, 2014; Machado y col. 2014; Daraei, 2013).

El método de Espectrofotometría UV-visible es limitado en la identificación cualitativa de muestras, ya que el espectro de la mayoría de los compuestos en solución posee uno, o algunos pocos picos en ésta región. Sin embargo, éste método es uno de los más empleados para el análisis cuantitativo, ampliamente utilizado para la cuantificación de especies orgánicas, inorgánicas y bioquímicas, encontrándose límites de detección de $10^{-4} \mathrm{a}$ $10^{-7} \mathrm{M}$. Tienen exactitud y precisión razonable y su selectividad es moderada a elevada. La gran ventaja de éste método de análisis instrumental es la simplicidad de la técnica ya que son fácilmente automatizados y la lectura de los analitos conllevan unos pocos segundos una vez introducidos en el instrumento. 
El control de las concentraciones de los colorantes antes y después de los ensayos de adsorción, se efectúo por medio de ensayos analíticos instrumentales utilizando un espectrómetro UV-visible PG-Instruments Modelo T60, Figura 6.3.

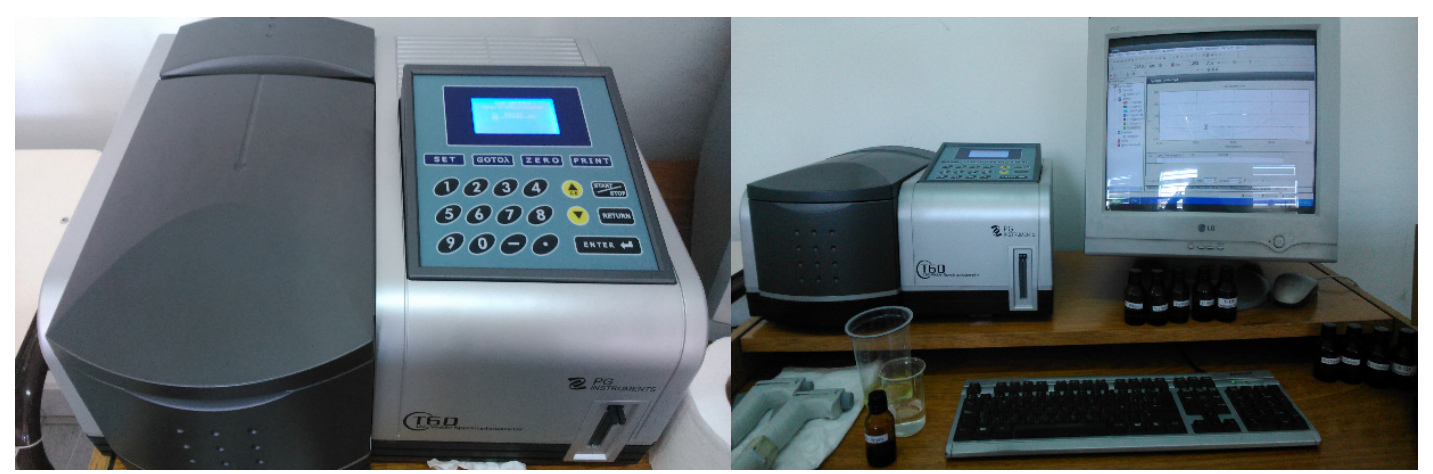

Figura 6.3. Espectometro UV-Visible PG Instruments T60.

\subsection{Fluorescencia de Rayos $X$}

El bombardeo de una muestra mediante el empleo de una fuente de haz de Rayos $\mathrm{X}$, genera dos fenómenos en el analito: excitación y emisión. La excitación se produce con el choque del fotón incidente con un electrón de las capas internas de un átomo, produciendo la expulsión de dicho electrón a niveles superiores; mientras que la emisión se debe al electrón en estado excitado que vuelve a su estado fundamental, lo que produce un salto de electrones de niveles externos para cubrir huecos, desprendiendo energía en forma de emisiones características electromagnéticas (Jenkins, 1999). La técnica de Fluorescencia de Rayos X emplea las emisiones de fluorescencia de éstos electrones excitados, las que poseen determinada longitud de onda característica del elemento al que pertenecen, dando además la posibilidad de cuantificar el elemento a partir de la intensidad de la emisión.

Empleando la Fluorescencia de Rayos X se caracterizaron químicamente los materiales adsorbentes utilizados para éste estudio. A partir de ésta caracterización química, junto a otros procedimientos, como la purificación en fracción arcillosa de los sólidos, es posible efectuar el cálculo de la fórmula estructural de la arcilla, conociendo de ésta manera las cargas presentes en las laminas que las constituyen.

Para un conocimiento detallado de los adsorbentes S, Z, So y Zo, se realizaron ensayos de caracterización química, utilizando un equipo de Fluorescencia de Rayos X, 
Shimadzu EDX-800HS, Figura 6.4; y un espectrómetro IR Spectrum One Perkin Elmer, Figura 6.4.

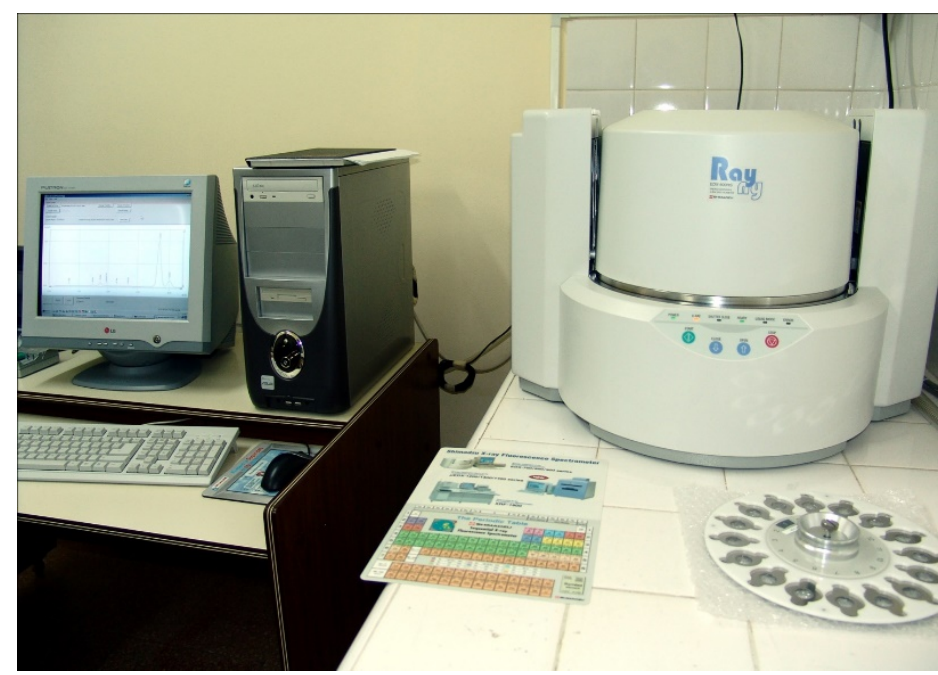

Figura 6.4. Equipo de Fluorescencia de Rayos X, Shimadzu EDX-800HS.

\subsection{Análisis Diferencial Térmico-Gravimétrico}

Un análisis térmico comprende el estudio de la evolución de las propiedades de una muestra o compuesto cuando es sometida a un calentamiento a altas temperaturas. La medida del cambio de masa en una muestra con la temperatura, se realiza en una termobalanza.

La técnica de mide la diferencia de temperatura entre una muestra y un material de referencia, ambos sometidos al mismo proceso de calentamiento. En el caso de que ocurra un proceso endotérmico ( $\Delta \mathrm{H}$ positivo), la temperatura de la muestra sufrirá un retraso respecto a la de la referencia, mientras continua el programa de calentamiento. Si ocurre un proceso exotérmico en la muestra ( $\Delta \mathrm{H}$ negativo), la respuesta será en sentido contrario.

El material de referencia debe de cumplir las características:

- No exhibir fenómeno térmico en el rango de temperatura seleccionado.

- No reaccionar con el portamuestras o termopar.

- Presentar una conductividad térmica y capacidad calorífica similar a los de la muestra. 
Las referencias se suelen usar en forma de polvo. Las mayormente empleadas son de tipo inorgánico el $\mathrm{Al}_{2} \mathrm{O}_{3}$ y $\mathrm{SiC}$; mientras que los materiales de referencia de tipo orgánico frecuentemente son ftalato de octilo y aceite de silicona. También proveen la posibilidad de trabajar bajo una atmósfera controlada al permitir la purga del horno con un gas inerte.

Mackenzie (1970) en su trabajo Diferential Thermal Analysis, emplea la técnica de análisis térmico diferencial como herramienta de caracterización de silicatos y fundamentalmente minerales arcillosos, por medio de las variaciones y características de las curvas ATD

Hedley y col. (2007) proponen el análisis térmico en montmorillonitas modificadas con amonio y fósforo cuaternario, como técnica no solo de caracterización del mineral natural sino también como instrumento para la cuantificación del contenido de carbono aportado por el tratamiento de la montmorillonita con las sales orgánicas, por medio de la degradación del carbono aportado por los surfactantes con la temperatura.

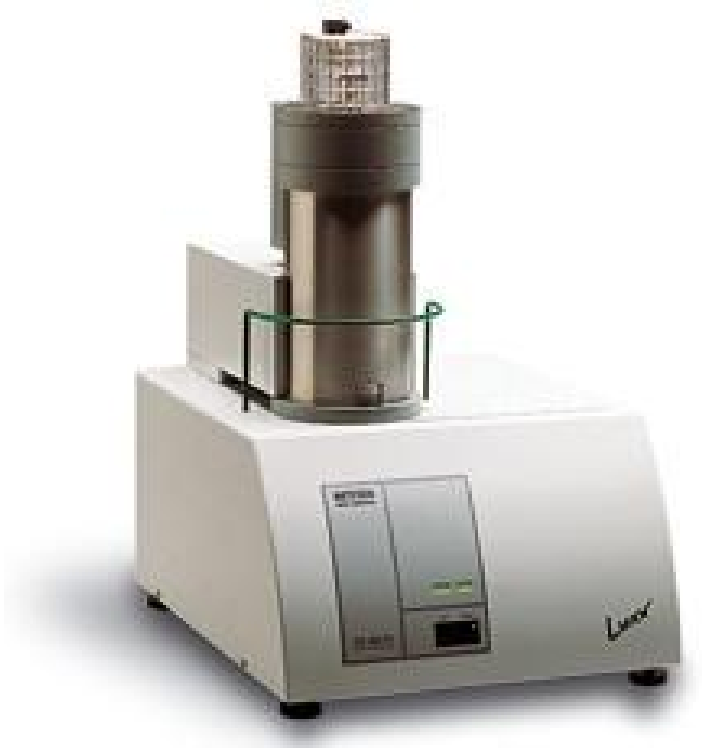

Figura 6.5. Equipo de análisis térmico Netzsch 409.

Mediante el empleo de un horno gravimétrico Netzsch 409, Figura 6.5., a una velocidad de calentamiento de $10^{\circ} \mathrm{C} \cdot \mathrm{min}^{-1}$, se estudió la modificación estructural del 
material respecto a la temperatura, cuantificando, además, por medio de las pérdidas de masa registradas y los picos DTA, los grupos moleculares o iones volatilizados durante el ensayo térmico.

\subsubsection{Termo-gravimetría (TG)}

La información que puede proporcionar el uso de la técnica TG es:

- Rango de estabilidad térmica de los materiales.

- Conocer, mediante el uso de una atmósfera de aire u oxígeno, las condiciones en que se oxidan los metales o se degradan los polímeros.

- Las curvas TG de materiales complejos, minerales y polímeros, no son fáciles de interpretar, pero sin embargo se utilizan como patrones de identificación que constituyen una base de datos.

- Se puede determinar la cinética de una reacción a partir de la curva TG de un compuesto cuando esta describe un proceso bien definido, como por ejemplo la estequiometría de deshidratación de un hidrato. De este modo se calcula la energía de activación, y a partir de ella extrapolar las condiciones de reacción de un compuesto a baja o alta temperatura.

\subsubsection{Análisis Térmico Diferencial (ATD)}

La información que puede proporcionar el uso de la técnica ATD es:

- Obtener información relacionada con las temperaturas y cambios de entalpía a los que ocurren los fenómenos térmicos.

- Estimar la pureza de la muestra a partir de la forma del pico endotérmico que pueda presentar la muestra.

- Detectar las transiciones sólido-sólido y la medida de $\Delta \mathrm{H}$ de las mismas.

- Aplicación al estudio de polímeros.

- Análisis de la composición de plástico reutilizado. 
- Observación de la evolución del comportamiento de los cristales líquidos.

\subsection{Difracción de Rayos $X$}

La Difracción de Rayos X (DRX) es una técnica que permite conocer la composición mineralógica de las muestras a partir de la incidencia de rayos $\mathrm{X}$ sobre los planos cristalinos que la componen.

Los cristales poseen una estructura ordenada tridimensional con periodicidades características, situados a lo largo de los ejes cristalográficos, la interacción de la estructura con los rayos $\mathrm{X}$ provoca un fenómeno de dispersión, los átomos dispersan la radiación incidente en todas las direcciones, en algunas de éstas direcciones los rayos dispersados estarán completamente en fase, y por ello se refuerzan entre ellos para forman rayos difractados, interfiriendo constructivamente, Figura 6.6.

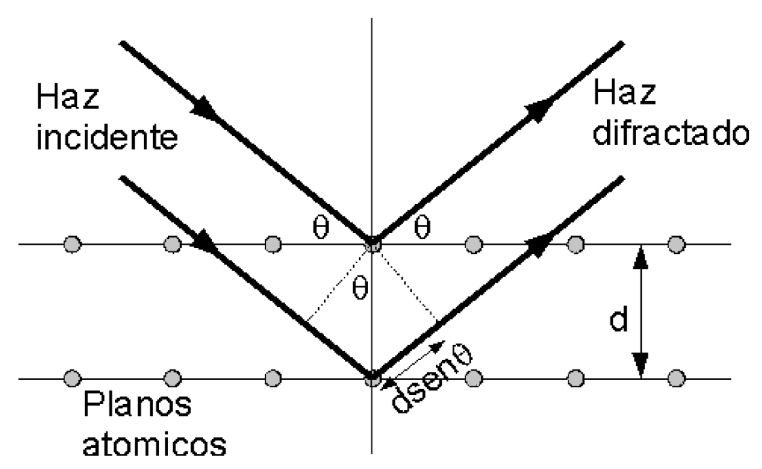

Figura 6.6. Dispersión de Rayos $X$ en un cristal.

Los rayos dispersados estarán completamente en fase si esa diferencia de fase es igual a un número entero $\mathrm{n}$ de longitudes de onda. Éste enunciado se conoce como Ley de Bragg, Ecuación 6.4.1.

Ecuación 6.4.1. $\mathrm{n} \cdot \lambda=2 \cdot \mathrm{d} \cdot \operatorname{sen} \theta$ 
Donde:

n: es un número entero $(1,2,3, \ldots \mathrm{n})$

$\lambda$ : longitud de onda

d: distancia entre los planos paralelos sucesivos

$\theta$ : ángulo de incidencia $\mathrm{y}$ reflexión de los rayos $\mathrm{X}$ sobre el plano considerado

Entre las aplicaciones de los DRX se encuentran el estudio de reacciones químicas, transiciones de fase, estudio de disoluciones sólidas, expansión térmica, crecimiento de grano, entre otras aplicaciones.

Lee y col. (2002) estudiaron la expansión de una esmectita tratada con hexadeciltrimetil-amonio por DRX, observando que la variación del espaciado interlaminar se debe a la concentración de hexadecil-trimetil-amonio y a la posición que adopta el catión orgánico entre las láminas.

Paiva y col. (2008) emplearon en su estudio de arcillas organofílicas la técnica de difracción para reconocer la estructura de las montmorillonitas organofílicas en función de la variación de la concentración del surfactante empleado para la modificación de carácter, observando por medio de la interpretación de los difractogramas obtenidos de las muestras en estudio la variación en el espaciado basal, observando en algunos de los casos la parcialidad del estado organofílico en algunos materiales en función de la concentración del surfactante utilizado.

Los análisis DRX se realizaron con un instrumento Bruker modelo D8 Advance, con radiación $\mathrm{CuKa}$ y filtro de $\mathrm{Ni}$, Figura 6.7. Por medio de éste ensayo analítico instrumental, se identificaron las fases mineralógicas de S y Z, y se determinó el espaciado entre las láminas de la fase arcilla a través de la ecuación de Bragg. 


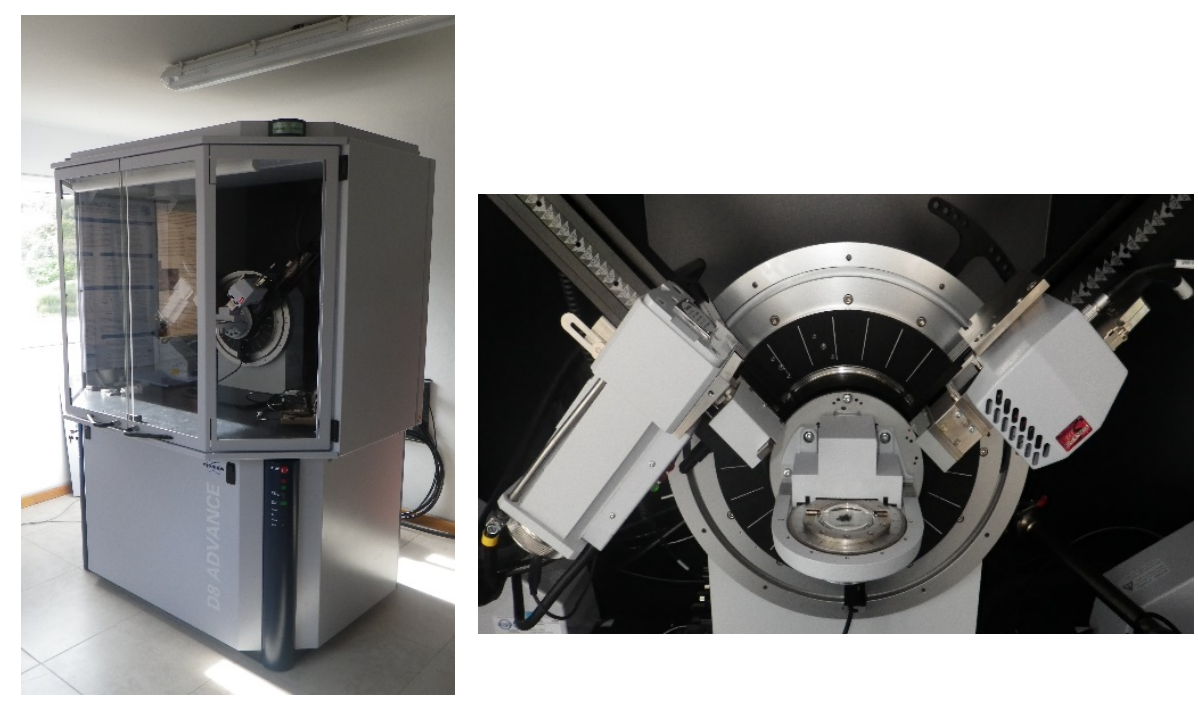

Figura 6.7. Equipo de Difracción de Rayos X Bruker D8 Advance.

\subsection{Potencial Zeta}

Cuando dos fases se contactan es común que éstas experimenten una fuerza de repulsión entre ellas, es por ello que se entiende que la región entre las fases se separa por medio de cargas eléctricas.

Los fundamentos teóricos de la técnica para la determinación del potencial zeta, puede explicarse mediante el modelo de doble capa, Figura 6.8.

El modelo de doble capa estudia las diferentes etapas que ocurren alrededor de un coloide cargado negativamente si las partículas iónicas que neutralizan su carga son separadas repentinamente. La capa más cercana al coloide negativo provoca que iones cargados positivamente formen una capa de contraiones rígida conocida como capa de Stern, los cationes restantes intentan acercarse al coloide, siendo rechazados, generando un equilibrio dinámico con la concentración de contraiones; dando origen a lo que se conoce como capa difusa. Además, en ésta capa difusa existen iones negativos o coiones, que a medida que se alejan del coloide su presencia se incrementa. De ésta manera, la densidad de cargas es mucho más alta en cercanías del coloide, disminuyendo a medida que las concentraciones de cargas positivas y negativas se igualan, en lejanías de éste. Los contraiones de la capa difusa y los aniones del coloide son los que conforman la denominada capa difusa. 


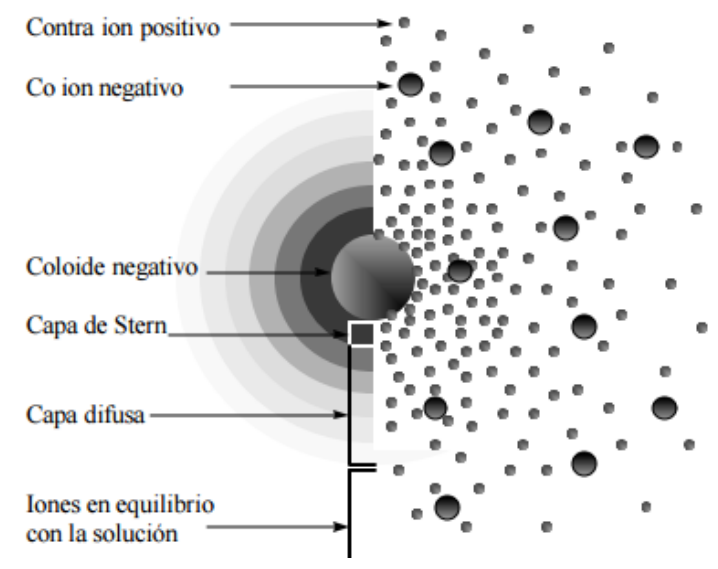

Figura 6.8. Capa Difusa.

El punto en el que une la capa difusa y la capa de Stern, es lo que se conoce como potencial zeta y es la medida de la potencia electrostática que existe entre la separación de capas que rodean un coloide, en resumidas cuentas, es la medida de la estabilidad de una partícula e indica el potencial que se requiere para penetrar la capa de iones alrededor de ésta, para desestabilizarla. En el caso práctico de la medida del potencial zeta, al conocerse la fuerza externa aplicada, el potencial permite caracterizar el equilibrio entre los iones de la solución electrolítica y los adsorbidos en la superficie sólida.

Las medidas de potencial zeta se emplean para calcular puntos isoeléctricos de distintos sólidos, caracterizar la estructura química superficial de los sólidos, determinar la energía libre de adsorción de tensoactivos sobre los sólidos, calcular la densidad de carga superficial y el espesor de la capa polimérica adsorbida.

Markiewicz y col. (2013) efectuaron medidas de potencial zeta sobre cuarzo, caolinita y arcillas modificadas con una molécula orgánica conocida como imidazol. Los resultados que obtuvieron hacen referencia a que la sustitución produce un impacto en la estabilidad eléctrica y en consecuencia, un cambio en las características del mineral, como por ejemplo la disminución del contacto entre la superficie del sólido y las moléculas de agua. 



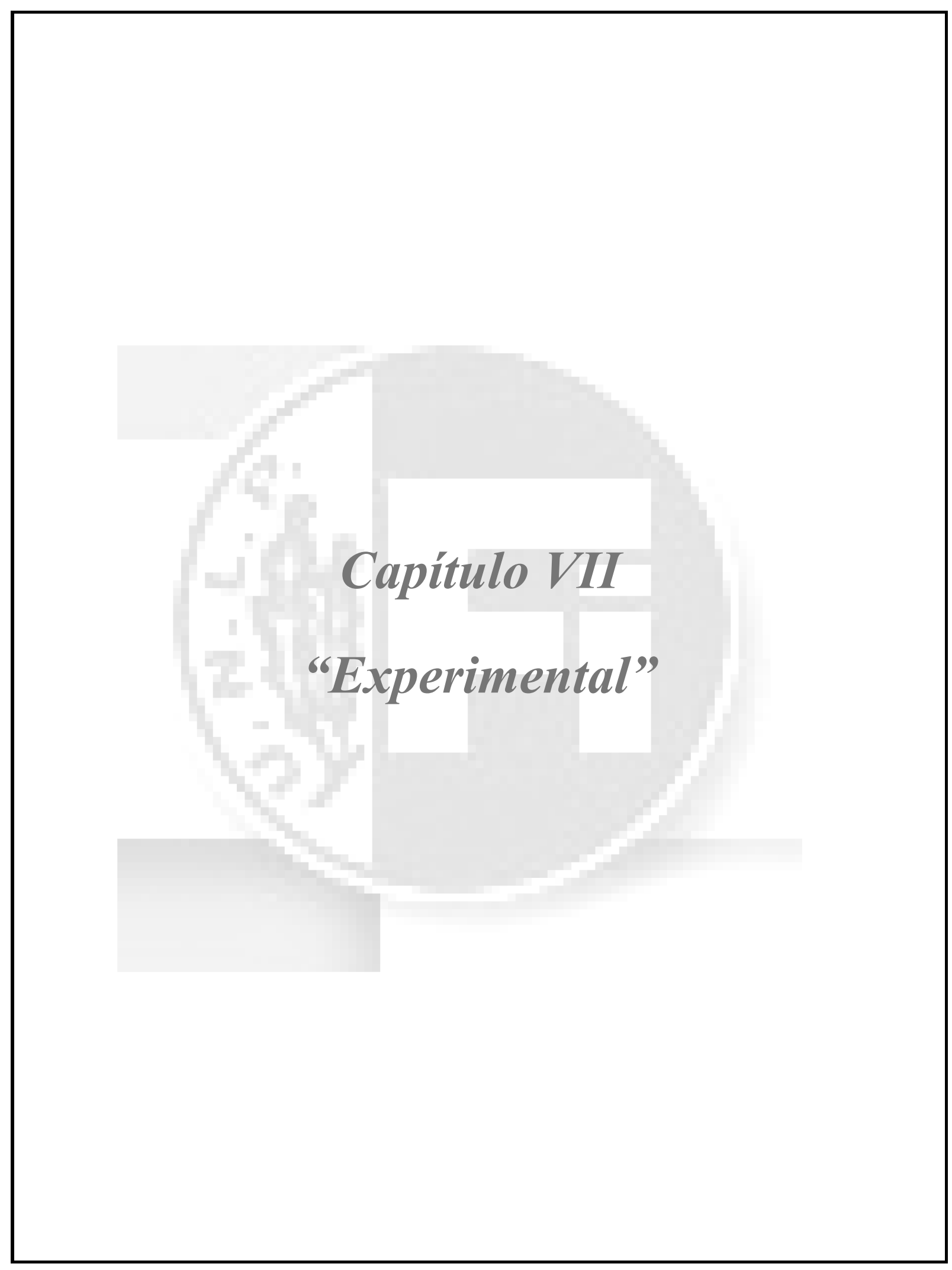




\section{EXPERIMENTAL}

En el presente capítulo se detallará la metodología experimental empleada durante el desarrollo de la tesis, indicando en cada uno de los casos, los ensayos e instrumentos analíticos utilizados, en cada experiencia, para la recolección de datos experimentales, que posteriormente serán analizados en el capítulo de resultados.

\subsection{Adsorbentes arcillosos}

\subsubsection{Arcillas naturales}

Las arcillas empleadas para la presente tesis corresponden a dos bentonitas de diferentes regiones de Argentina. La bentonita identificada como S, proveniente de la provincia de San Juan, Argentina, mientras que el adsorbente bentonítico denominado Z, es originario de la provincia de Neuquén.

El mineral arcilloso proveniente de la provincia de Neuquén $(Z)$, fue extraído del yacimiento 7 de Mayo, propiedad de la empresa minera MINARMCO S.A. Se encuentra ubicado en el departamento Zapala, en la zona denominada Barda Negra. El sector posee una superficie de 27 ha. La geología de la región es preponderantemente de formaciones sedimentarias, en especial de antigüedad cretácica y terciario-cuaternaria en el ambiente geológico de la Cuenca Neuquina. Se trata de sucesiones de bancos de arcillitas y areniscas del Grupo Homónimo y secuencias de la formación conocida regionalmente como CollónCura, también integrada por sucesiones de sedimentos detríticos y pelíticos. Dentro de las variables minerales presentes en ésta formación se encuentran las bentonitas, constituidas preponderantemente por montmorillonitas, asociadas a minerales no arcillosos como feldespatos, cuarzo y yeso (Informe de Impacto Ambiental, 1997).

El yacimiento denominado Santa Gema, ubicado en la Región de Cuyo, al noreste de la provincia de San Juan, aproximadamente a $100 \mathrm{~km}$ de la ciudad capital, desde donde proviene la bentonita identificada en la presente tesis como " $\mathrm{S}$ ", perteneciente al periodo Terciario (Mioceno). En ésta región, las bentonitas se encuentran intercaladas con rocas sedimentarias rojizas, en algunos casos con una pronunciada inclinación de los mantos, en ocasiones plegados o fracturados. 


\subsubsection{Arcillas modificadas}

Las arcillas mencionadas con anterioridad, $\mathrm{S}$ y Z, fueron modificadas por medio tratamiento con la sal de amonio denominada bromuro de hexadecil-trimetil-amonio (BrHDTMA). La aminas cuaternarias como el HDTMA, son surfactantes catiónicos de cadena larga, contienen dieciséis átomos de carbono en su molécula, presenta cuatro grupos orgánicos que se encuentran covalentemente ligados al átomo de nitrógeno, y una carga positiva de éste átomo es neutralizada por el anión bromo (Lagaly, 1982; Paiva y col., 2008; Fungaro y Borrely, 2012), Figura 7.1. Los iones de alquilamonio cuaternarios son ampliamente utilizados para modificar esmectitas; los derivados orgánicos así obtenidos son adsorbentes adecuados para el control de la contaminación ambiental (Harvey y Lagaly, 2006).

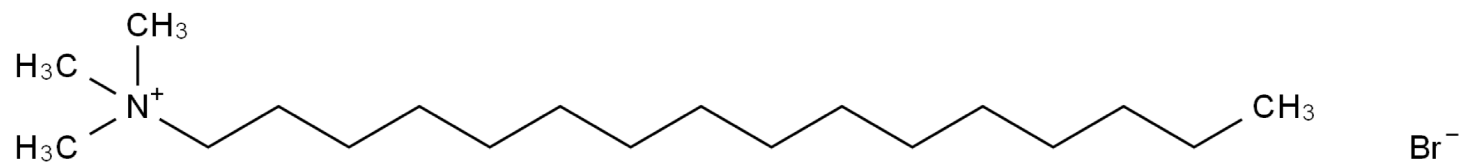

Figura 7.1. Molécula de Br-HDTMA.

La modificación orgánica de las arcillas se realizó contactando cada una de ellas con una solución del surfactante (HDTMA-Br), en agua desionizada y agitación. La cantidad agregada de sal orgánica por arcilla fue igual a la capacidad de intercambio catiónico (CIC) de las mismas (Ver Capítulo 8). El contacto en agitación se mantuvo durante 24 horas. Posteriormente los sólidos fueron lavados y secados a $25^{\circ} \mathrm{C}$, obteniéndose así los adsorbentes orgánicos (arcillas orgánicas) So y Zo, Figura 7.2. 

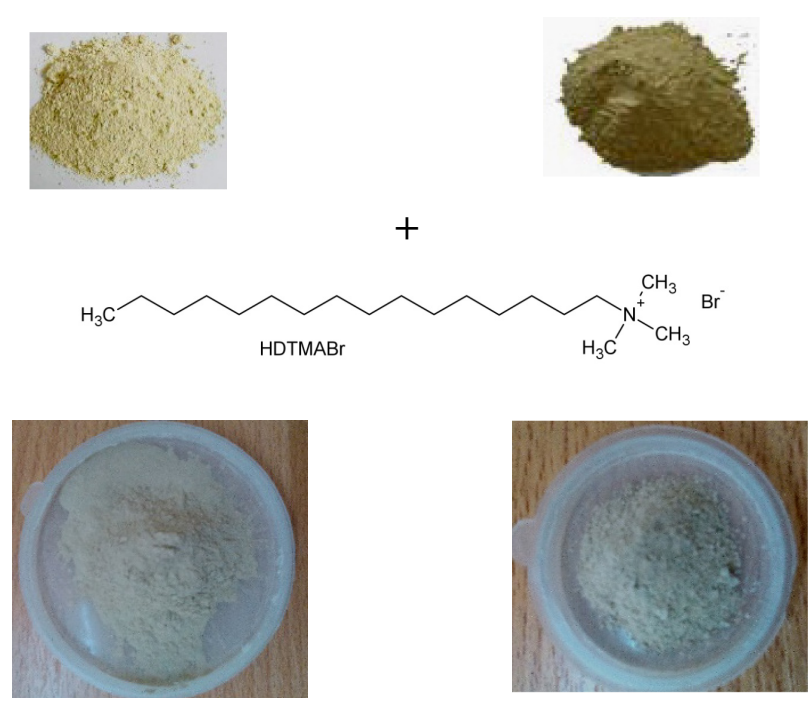

Figura 7.2. Preparación de los sólidos adsorbentes So y Zo.

\subsection{Colorantes}

Los colorantes azoicos utilizados en éste trabajo de tesis fueron: Yellow GR, Orange G y Red Allura AC, los cuales se identificaron como Y, O y R, respectivamente. Se prepararon soluciones con agua desionizada, de concentración de $125 \mathrm{mg} . \mathrm{L}^{-1}$. Las soluciones obtenidas se identificaron como Y, O y R respectivamente, Figura 7.3.

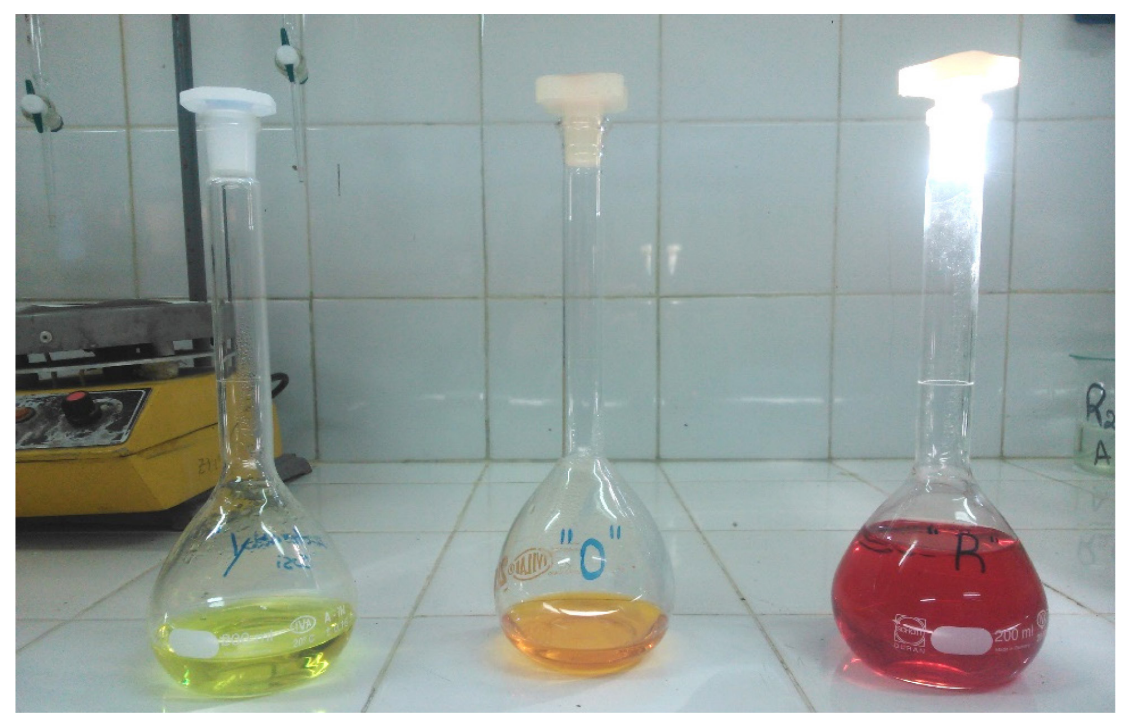

Figura 7.3. Soluciones $\mathrm{Y}, \mathrm{O}$ y R. 
La identificación de los grupos característicos de los colorantes se realizó por análisis IR, utilizando el mismo equipamiento con el que se caracterizaron los adsorbentes, y UV-visible con un espectrómetro PG Instruments T60.

Para la cuantificación de los distintos colorantes se realizaron curvas de calibración por medio de un espectrómetro UV-visible (Ver Ítem 7.4. y Anexo A“Cálculos y Calibración”).

\subsection{Ensayos de Adsorción}

Los ensayos de adsorción se realizaron en sistema batch, contactando cantidades de adsorbentes (arcillas naturales S y Z y orgánicas preparadas So y Zo) en el rango de 0,45 g por L de solución preparada con los tintes Y, O y R, Figura 7.3. Las suspensiones (Figura 7.4) fueron agitadas durante 24 horas. Posteriormente, fueron centrifugadas a 2500rpm, y las soluciones sobrenadantes fueron utilizadas para evaluar las cantidades retenidas por los sólidos, Figuras 7.5 y 7.6.

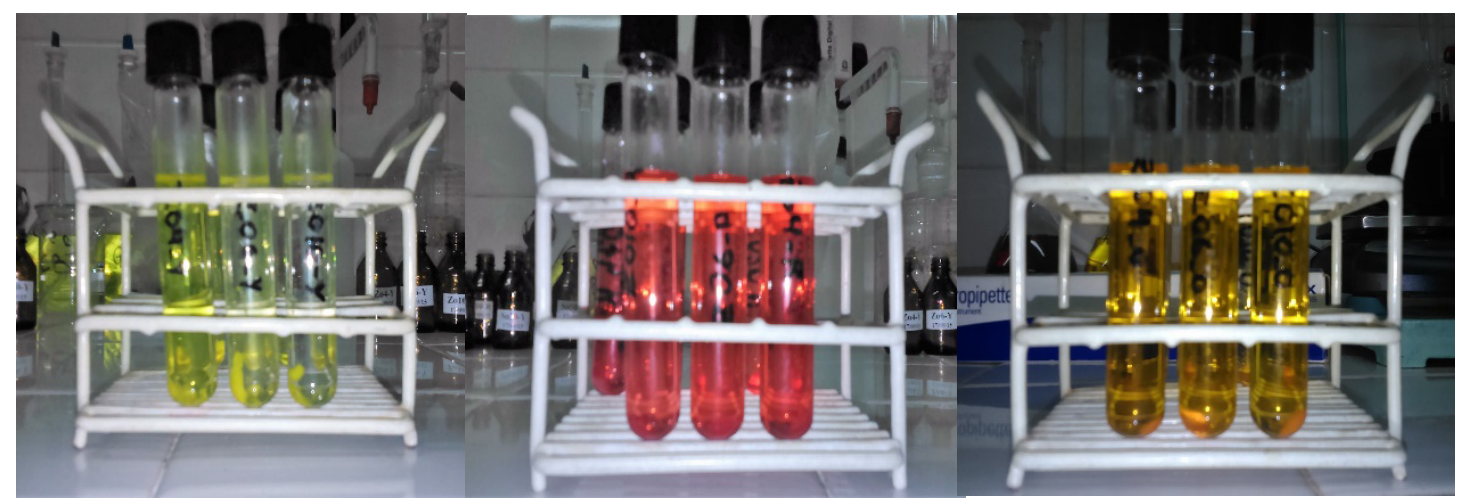

Figura 7.4. Inicio ensayos de adsorción.

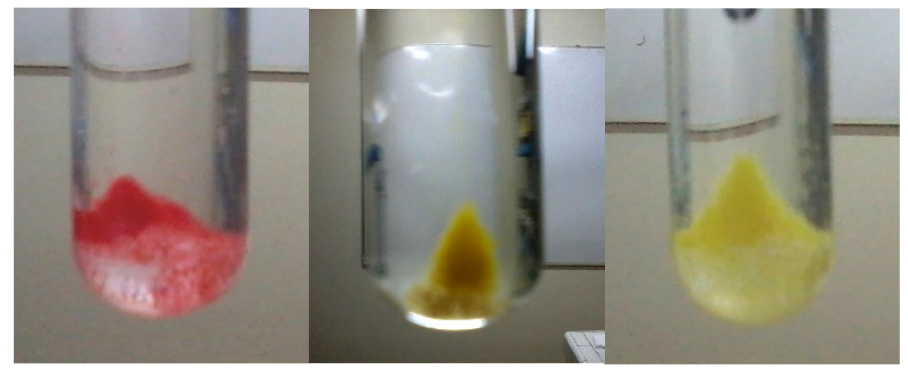

Figura 7.5. Finalización de los ensayos de adsorción. 
Los sólidos adsorbentes con los colorantes retenidos fueron lavados $\mathrm{y}$ centrifugados hasta la eliminación de la coloración del líquido, Figura 7.6., para ser recuperados para su posterior caracterización, Figura 7.7.

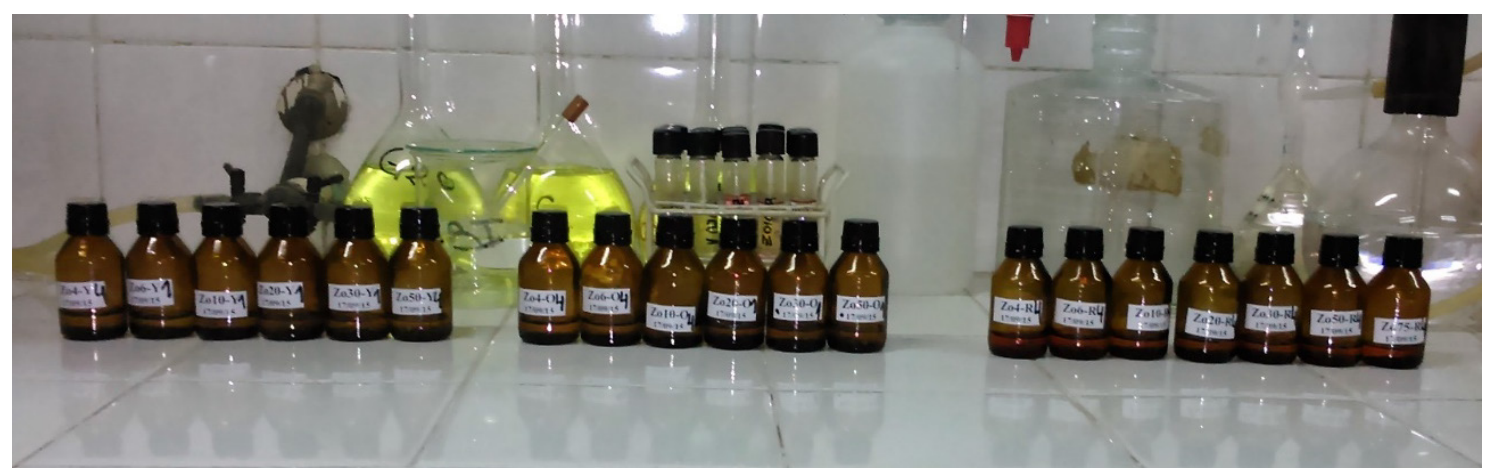

Figura 7.6. Muestras de soluciones sobrenadantes.

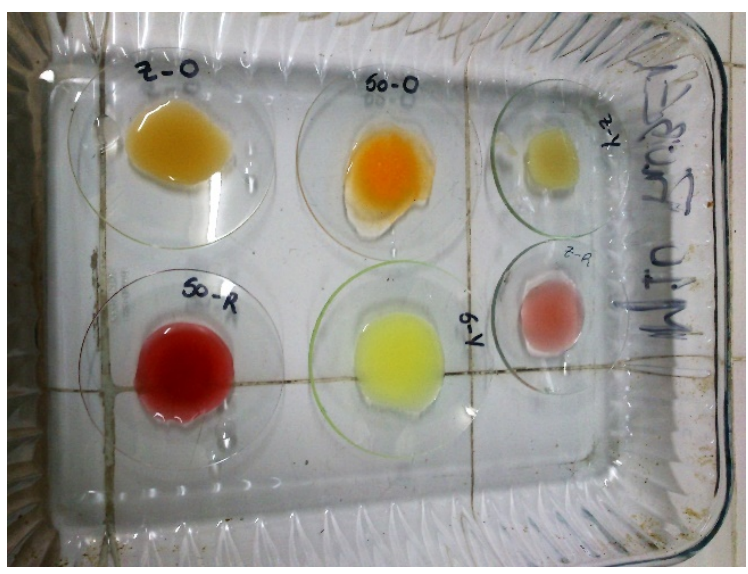

Figura 7.7. Sólidos adsorbentes recuperados.

Tanto los sólidos recuperados, como las soluciones sobrenadantes, fueron identificados como Ma-B, donde $\mathrm{M}$ corresponde al adsorbente $\mathrm{S}$, Z, So y Zo; a indica la relación sólido/líquido empleada en las diferentes experiencias $\left(0,4\right.$ a $\left.7,5 \mathrm{~g} \cdot \mathrm{L}^{-1}\right)$; y finalmente $\mathrm{B}$ hace referencia al colorante contactado con el adsorbente. De ésta manera, y a modo de ejemplo se tiene el ensayo identificado como S2-Y, que indica que la relación sólido/líquido fue de $2 \mathrm{~g} \cdot \mathrm{L}^{-1}$ del adsorbente $\mathrm{S}$ (arcilla de San Juan) con la solución coloreada Y (Yellow GR).

En la Figura 7.8., se esquematiza la metodología experimental de los ensayos de adsorción efectuados. 


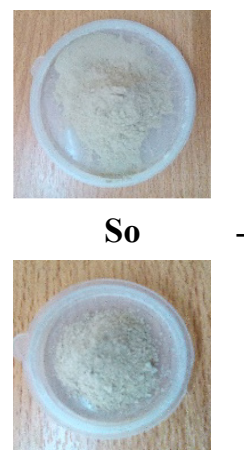

Zo

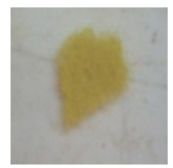

So/Zo-Y

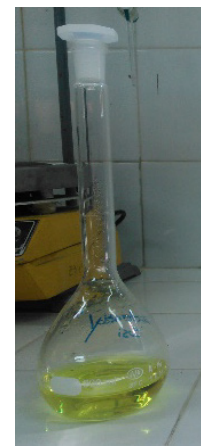

$\mathbf{Y}$

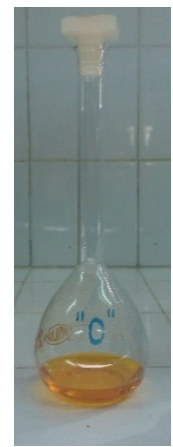

$\mathbf{O}$

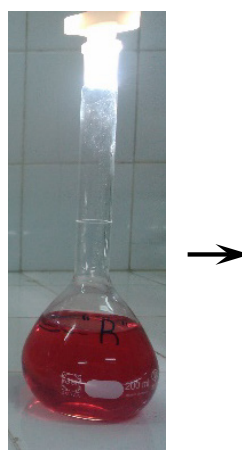

$\mathbf{R}$

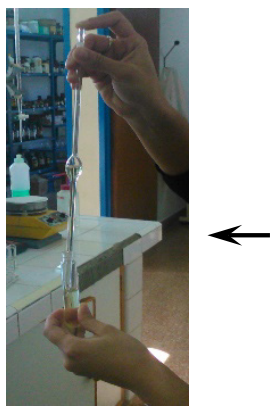

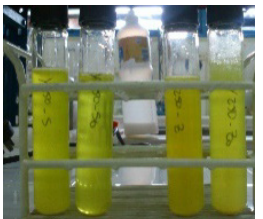
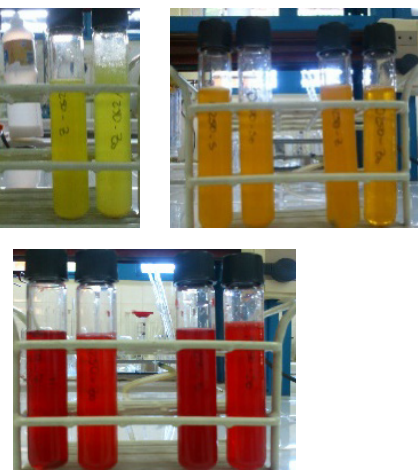

$\downarrow$

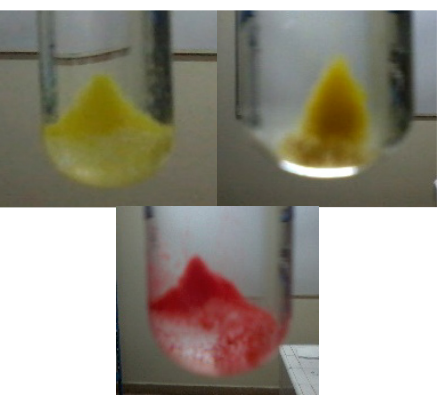

Figura 7.8. Esquema de Adsorción de colorantes.

\subsection{Ensayos de Desorción}

A partir de los productos de adsorción obtenidos a mayor relación sólido/líquido (7,5 g.L $\left.\mathrm{L}^{-1}\right)$, se realizaron ensayos de desorción pesando 0,020 g de éstos y contactándolos con $10 \mathrm{~mL}$ de agua destilada. En la Figura 7.9. se observan las desorciones realizadas para los colorantes $\mathrm{Y}, \mathrm{O}$ y $\mathrm{R}$ retenidos sobre las organobentonitas So y Zo.
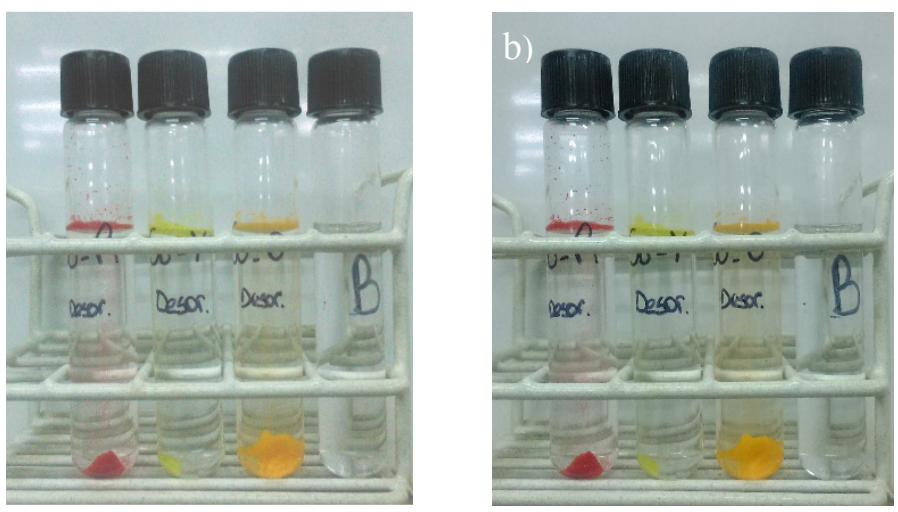

Figura 7.9. a) Ensayos de desorción So; b) Ensayos de desorción Zo. 



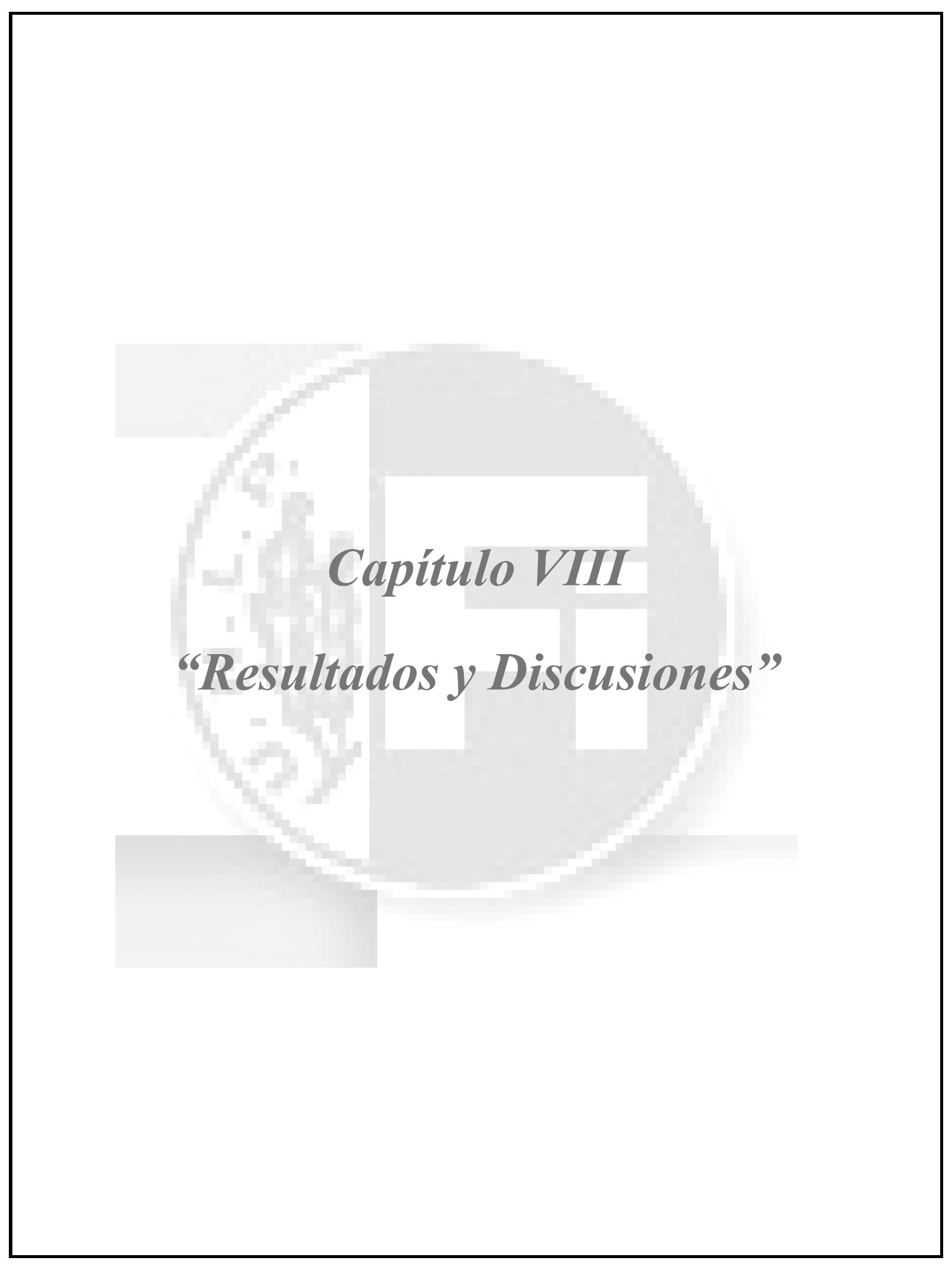




\section{RESULTADOS Y DISCUSIONES}

En el presente capítulo se expondrán los resultados obtenidos y el análisis de las diferentes experiencias, efectuadas a lo largo del trabajo de tesis.

\subsection{Composición estructural de los colorantes estudiados - Análisis comparativo}

Para una mejor comprensión del estudio estructural de los colorantes, se exhibe en

la Tabla 8.1.1, un cuadro comparativo entre las principales características de los colorantes $\mathrm{R}, \mathrm{O}$ e Y; que atañen al presente estudio.

Tabla 8.1.1. Comparación estructural colorantes R, O e Y.

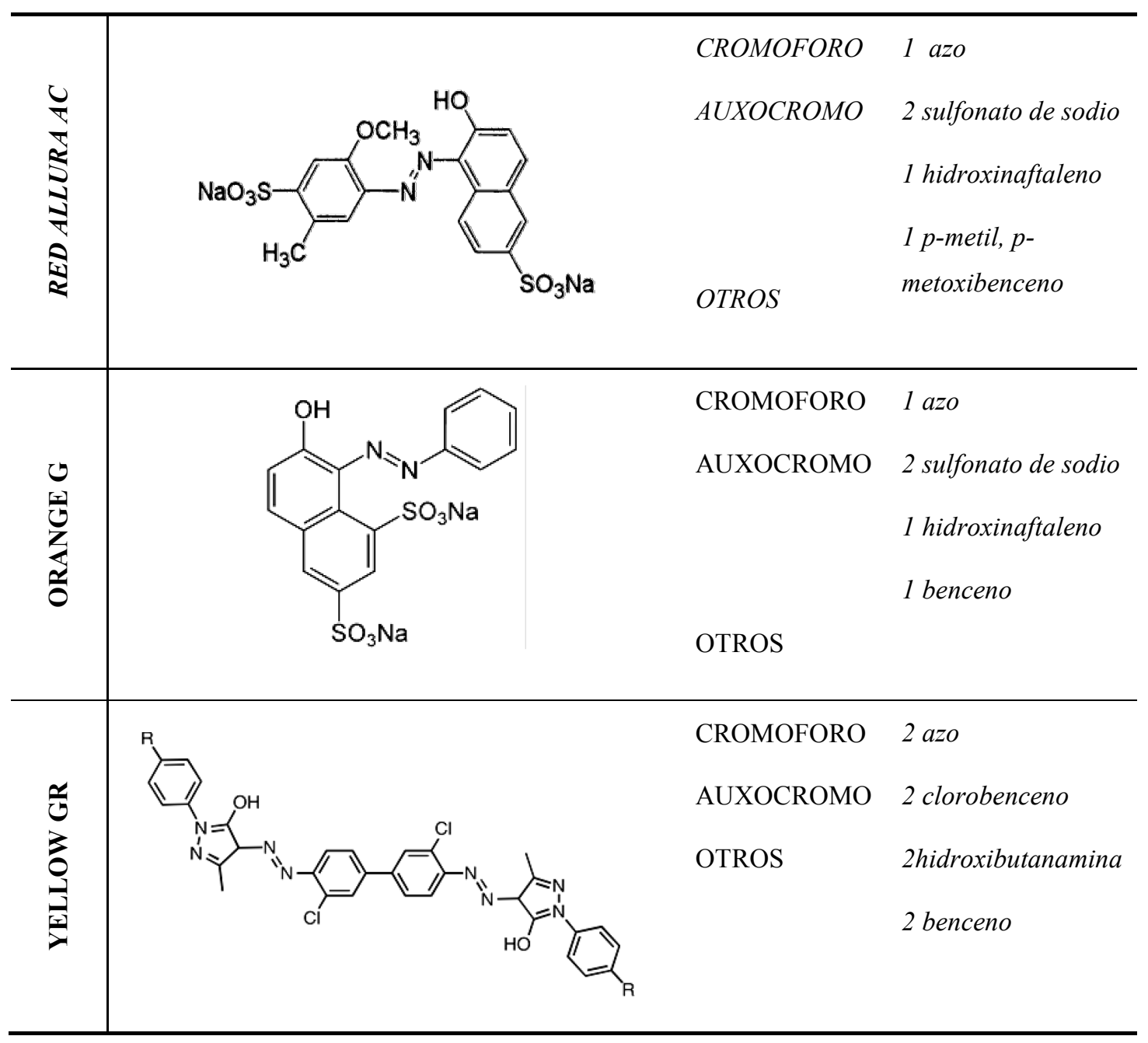


El grupo cromóforo, encargado de impartir el color, en la totalidad de los colorantes, es el azo, identificándose en los colorantes $\mathrm{R}$ y $\mathrm{O}$ una sola estructura azoica (colorantes monoazoicos), y para $\mathrm{Y}$ dos grupos azo (colorante diazoico).

Los auxocromos, encargados de dar solidez al color y aportar carácter iónico a los colorantes, que constituyen la estructura de los tintes $\mathrm{R}$ y $\mathrm{O}$ son: 1 (uno) grupo hidroxinaftaleno y 2 (dos) sulfonato de sodio. La diferencia entre los tintes radica en la posición de éstos últimos, en el $\mathrm{O}$ ambos auxocromos se encuentran unidos al hidroxinaftaleno, a diferencia del $\mathrm{R}$, que se une, uno de los grupos sulfonato al hidroxinaftaleno, y el otro al grupo p-metil, p-metoxibenceno en su posición "o". En el tinte $Y$ se aprecia una estructura diferente, conformada por los auxocromos hidroxibutanamina y clorobenceno.

\subsection{Caracterización de los colorantes}

Los tres colorantes utilizados fueron caracterizados mediante técnicas UVvisible, empleando un equipo PG-Instruments Modelo T60 y por Espectroscopia Infrarroja, utilizando un equipo Spectrum One Perkin-Elmer.

\subsubsection{Red Allura AC}

\subsubsection{UV-visible}

Una solución del colorante Red Allura AC de concentración conocida, $100 \mathrm{mg} . \mathrm{L}^{-1}$, fue caracterizada por medio de UV-visible, Figura 8.2.1. En la misma se aprecian tres bandas pertenecientes a los grupos: benceno, naftaleno y azo, ubicadas a $215 \mathrm{~nm}, 316 \mathrm{~nm}$ y $496 \mathrm{~nm}$ respectivamente.

La banda perteneciente al benceno se encuentra influenciada por la presencia del grupo funcional sulfonato (ver Tabla 8.1.1) al igual que el grupo naftaleno, el que se ve afectado por el mismo grupo funcional unido a su estructura, con lo cual se aprecia un leve corrimiento hacia longitudes de onda mayores, en ambos casos. Consecuentemente, la presencia de grupos funcionales unidos a la estructura azo, conlleva el efecto de desplazamiento hacia mayores longitudes de onda. 


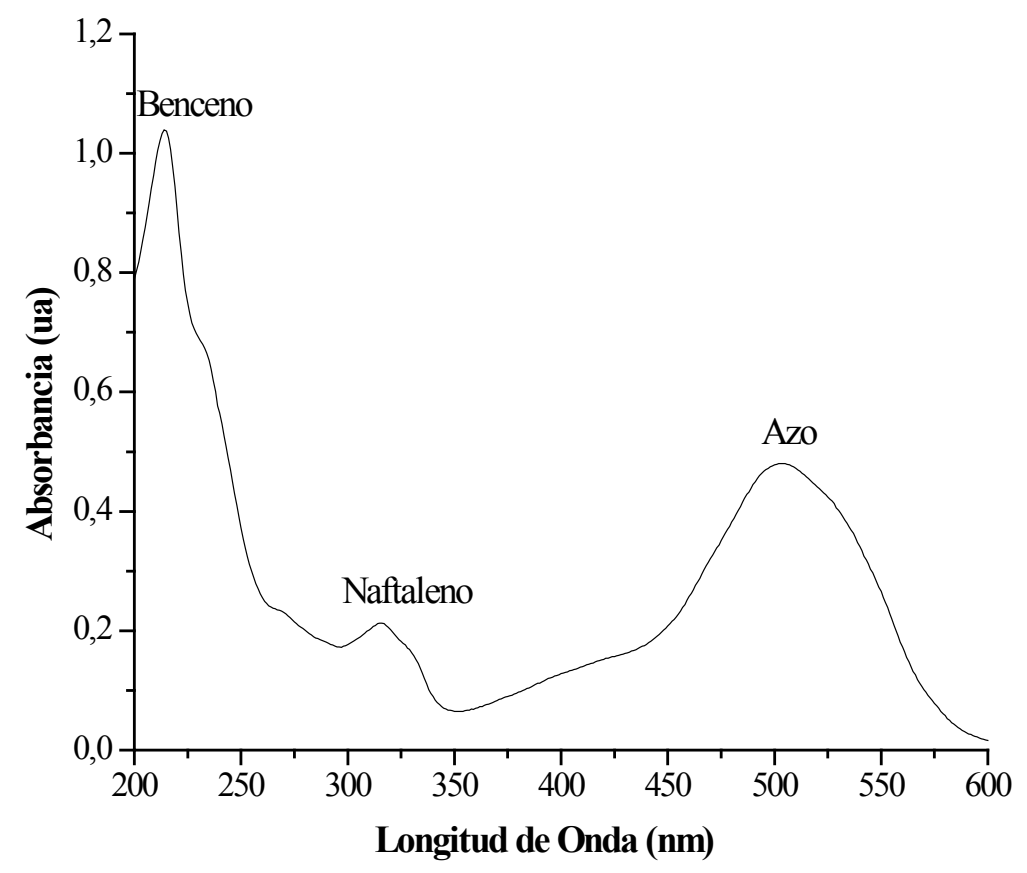

Figura 8.2.1. UV-Visible Red Allura AC.

\subsubsection{Infrarrojo}

Los ensayos de IR resultantes del análisis de la muestra Red Allura AC se observan en la Figura 8.2.2 y Figura 8.2.3.

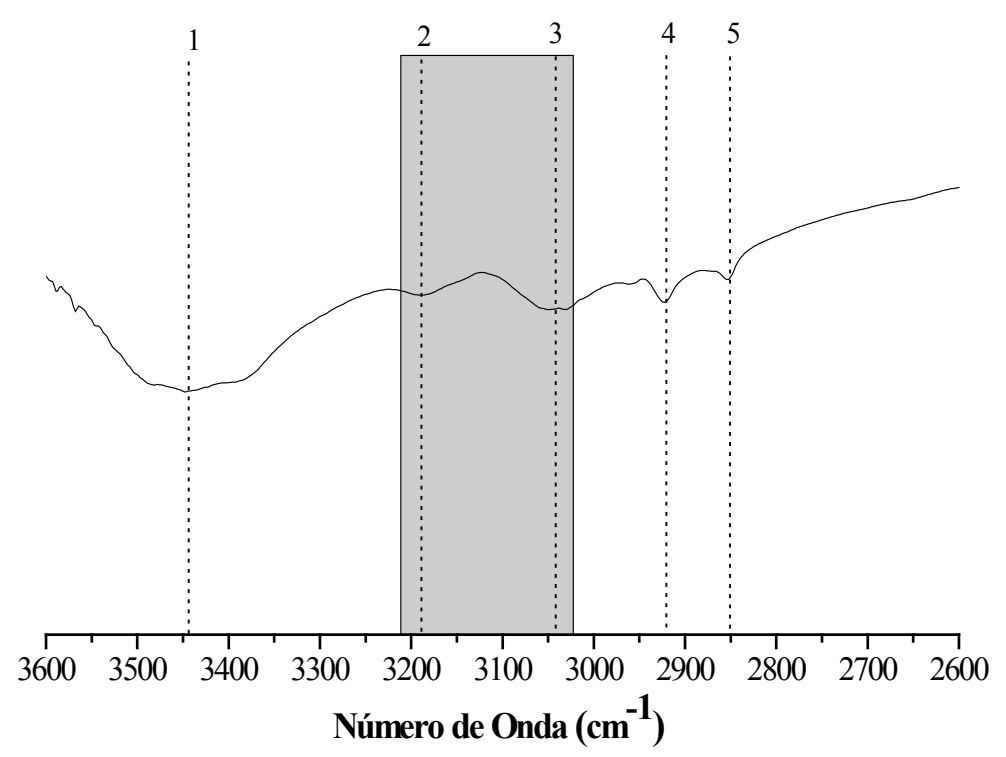

Figura 8.2.2. IR (2600-3600 $\left.\mathrm{cm}^{-1}\right)$ del colorante Red Allura AC. 


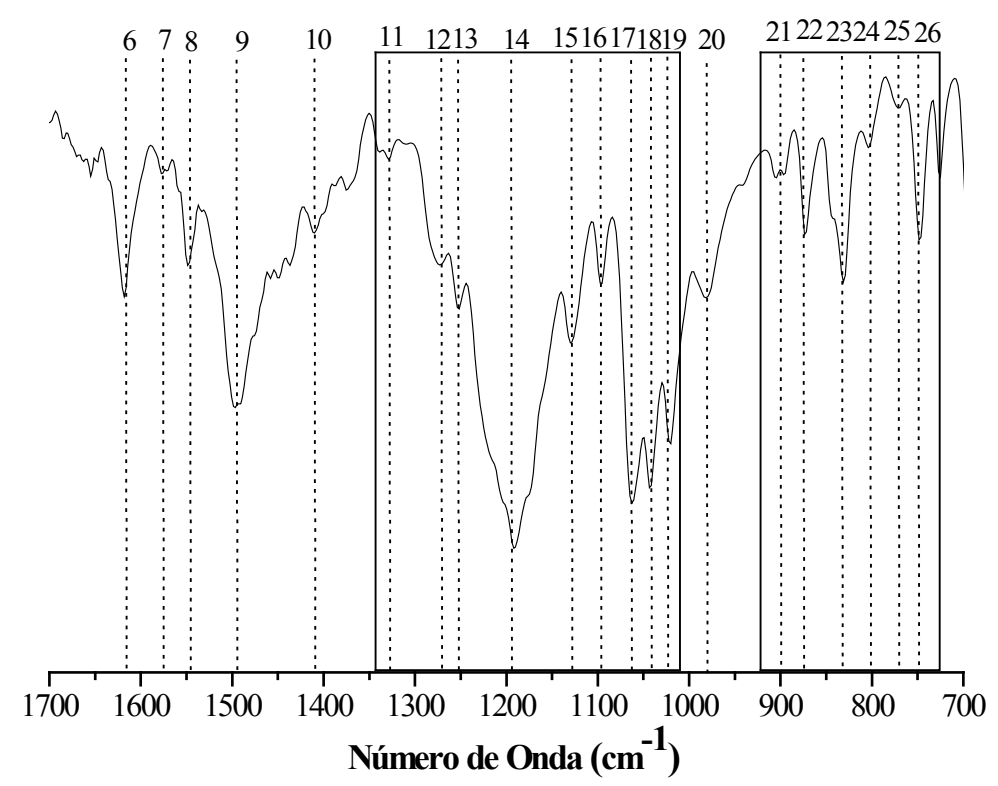

Figura 8.2.3. IR $\left(1700-700 \mathrm{~cm}^{-1}\right)$ del colorante Red Allura AC.

De acuerdo a lo observado, existen grupos principales que conforman la estructura del colorante $\mathrm{R}$, correspondientes principalmente a vibraciones de grupos $\mathrm{N}=\mathrm{N}, \mathrm{SO}_{3}{ }^{2}, \mathrm{Ar}$, C-N y N-H. Las bandas identificadas a menor número de onda, en su mayoría, son señales complementarias de grupos aromáticos.

Con la finalidad de facilitar la interpretación de las figuras anteriores, la Tabla 8.2.1, muestra las bandas de absorción identificadas y los grupos asociados a éstas.

Los valores resaltados con diferentes patrones, tanto en la Tabla 8.2.1, como en la Figura 8.2.2 y Figura 8.2.3, indican regiones en el espectro IR de tensión C-H y combinaciones en aromáticos $\left(3184 \mathrm{~cm}^{-1}-3141 \mathrm{~cm}^{-1}\right)$, señales complemetarias de los grupos aromáticos $\left(1275 \mathrm{~cm}^{-1}-1022 \mathrm{~cm}^{-1}\right)$; o señales pertenecientes a un mismo grupo $\left(897 \mathrm{~cm}^{-1}-746 \mathrm{~cm}^{-1}\right)$. 
Tesis Doctoral: Susana Y. Martinez Stagnaro "Evaluación sobre el uso de arcillas para la adsorción de colorantes utilizados en la industria textil"

Tabla 8.2.1. Bandas de absorción y grupos asociados Red Allura AC.

\begin{tabular}{|c|c|c|}
\hline Bandas & Número de Onda $\left(\mathrm{cm}^{-1}\right)$ & Grupos Asociados \\
\hline 1 & 3446 & Stretching del agua $\mathrm{H}-\mathrm{O}-\mathrm{H}$ \\
\hline 2 & 3184 & \multirow{2}{*}{ Tensión C-H y combinaciones en aromáticos } \\
\hline 3 & 3041 & \\
\hline 4 & 2921 & \multirow{7}{*}{$\begin{array}{c}\text { Flexión - } \mathrm{CH}_{2-} \\
\text { Flexión }-\mathrm{CH}_{3}, \mathrm{O}_{-} \mathrm{CH}_{3} \\
\text { Bending } \mathrm{N}-\mathrm{H} \\
\text { Flexión núcleo } \mathrm{C}_{6} \mathrm{H}_{6} \\
\text { Tensión } \mathrm{C}=\mathrm{C}, \mathrm{Ar} \\
\text { Vibración } \mathrm{N}=\mathrm{N} \\
\text { Tensión } \mathrm{C}-\mathrm{N}\end{array}$} \\
\hline 5 & 2852 & \\
\hline 6 & 1618 & \\
\hline 7 & 1575 & \\
\hline 8 & 1547 & \\
\hline 9 & 1498 & \\
\hline 10 & 1410 & \\
\hline 11 & 1328 & \multirow{9}{*}{$\begin{array}{l}\text { Estas señales son complementarias ya que los estiramientos } \\
\qquad \text { C-C, C-N y C-O caen en la misma región. } \\
\text { Aparecen varias señales en función del número de hidrógenos. } \\
\text { Señales débiles, pero agudas, que pueden aumentar } \\
\text { significativamente en presencia de grupos polares. }\end{array}$} \\
\hline 12 & 1275 & \\
\hline 13 & 1252 & \\
\hline 14 & 1194 & \\
\hline 15 & 1130 & \\
\hline 16 & 1095 & \\
\hline 17 & 1063 & \\
\hline 18 & 1043 & \\
\hline 19 & 1022 & \\
\hline 20 & 981 & Vibración $\mathrm{SO}_{3}{ }^{=}$ \\
\hline 21 & 897 & \multirow{6}{*}{$\begin{array}{l}\text { Estas señales son características de sustitución triple en } \\
\text { aromáticos. }\end{array}$} \\
\hline 22 & 871 & \\
\hline 23 & 829 & \\
\hline 24 & 804 & \\
\hline 25 & 771 & \\
\hline 26 & 746 & \\
\hline
\end{tabular}

\subsubsection{Orange $G$}

Se caracterizó el colorante Orange G utilizando las técnicas analíticas descriptas con anterioridad, en los ítems desarrollados para el colorante Red Allura AC. 


\subsubsection{UV-visible}

La solución coloreada con el tinte Orange G, de concentración $100 \mathrm{mg} . \mathrm{L}^{-1}$, caracterizada por Espectroscopia UV-visible, se aprecia en la Figura 8.2.4.

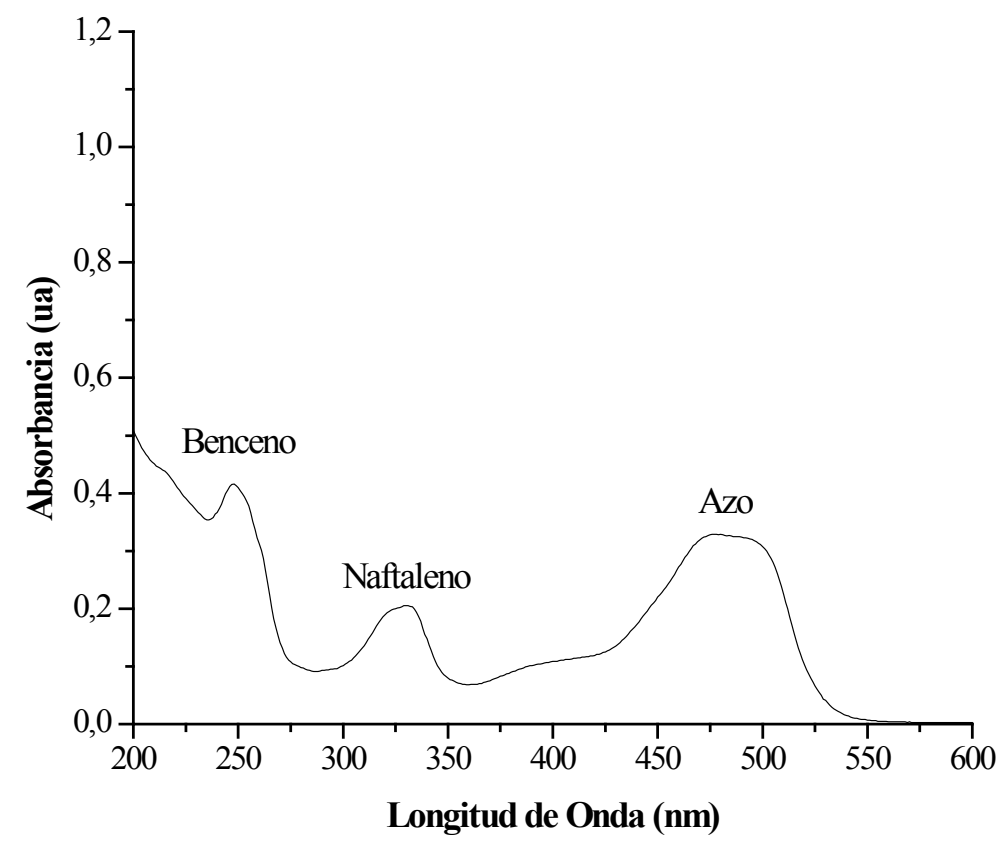

Figura 8.2.4. UV-Visible Orange G.

El espectro UV-visible evidencia la presencia de tres bandas bien definidas, pertenecientes a los grupos: benceno, naftaleno y azo, ubicadas a $248 \mathrm{~nm}, 330 \mathrm{~nm}$ y $485 \mathrm{~nm}$ respectivamente. Las bandas correspondientes al benceno, naftaleno y azo, también sufren la influencia de los grupos funcionales unidos a éstas, por lo tanto se evidencia, al igual que en el colorante R, un corrimiento en la longitud de onda hacia valores superiores.

\subsubsection{Infrarrojo}

Los ensayos por espectroscopia infrarroja, del colorante Orange, exhibidos en la Figura 8.2.5 y Figura 8.2.6, al igual que en el colorante R, se identificaron las principales bandas detectadas en $\mathrm{O}$ características de los grupos $\mathrm{N}=\mathrm{N}, \mathrm{SO}_{3}{ }^{\circ}, \mathrm{Ar}, \mathrm{C}-\mathrm{N}$ y N-H.

Las bandas menores a $1300 \mathrm{~cm}^{-1}$, a excepción de la vibración del grupo $\mathrm{SO}_{3}{ }^{2}$

$\left(981 \mathrm{~cm}^{-1}\right)$, al igual que lo observado en el colorante $\mathrm{R}$, conforman líneas complementarias a los grupos principales. 
Los espectros analizados para los tintes $\mathrm{R}$ y $\mathrm{O}$ son análogos, debido a la similitud de las moléculas, sin embargo poseen intensidades diferentes, y al encontrarse grupos funcionales iguales, pero ubicados en diferente posición, se presentan levemente desplazadas, como lo observado en los espectros UV (ver Tabla 8.1.1).

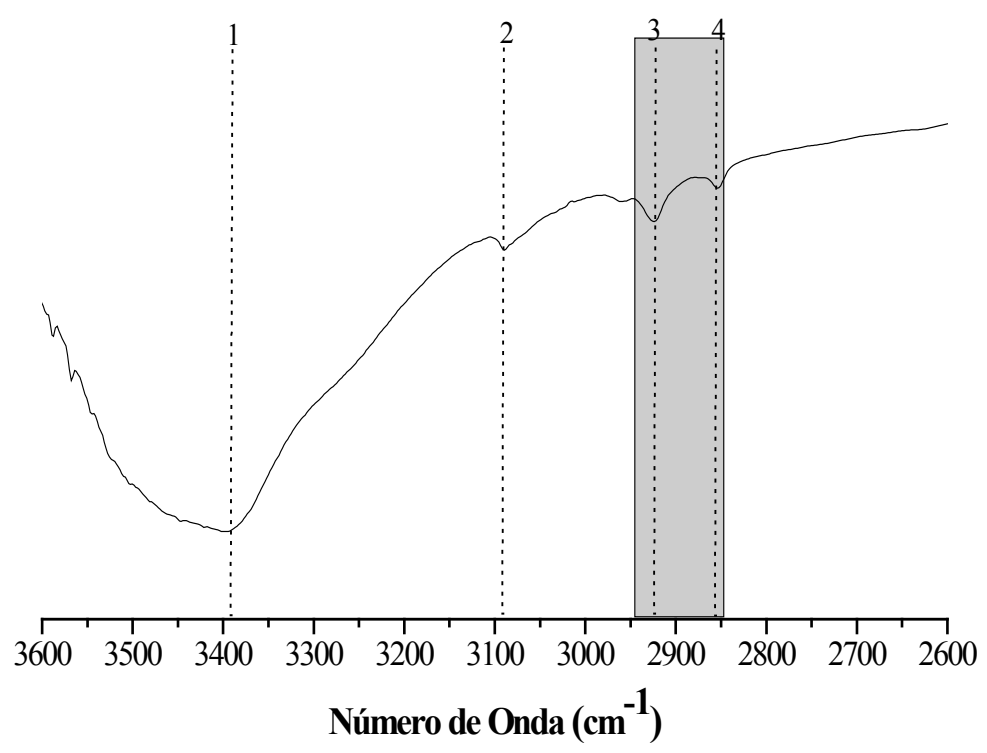

Figura 8.2.5. IR (3600-2600 $\left.\mathrm{cm}^{-1}\right)$ del colorante Orange G.

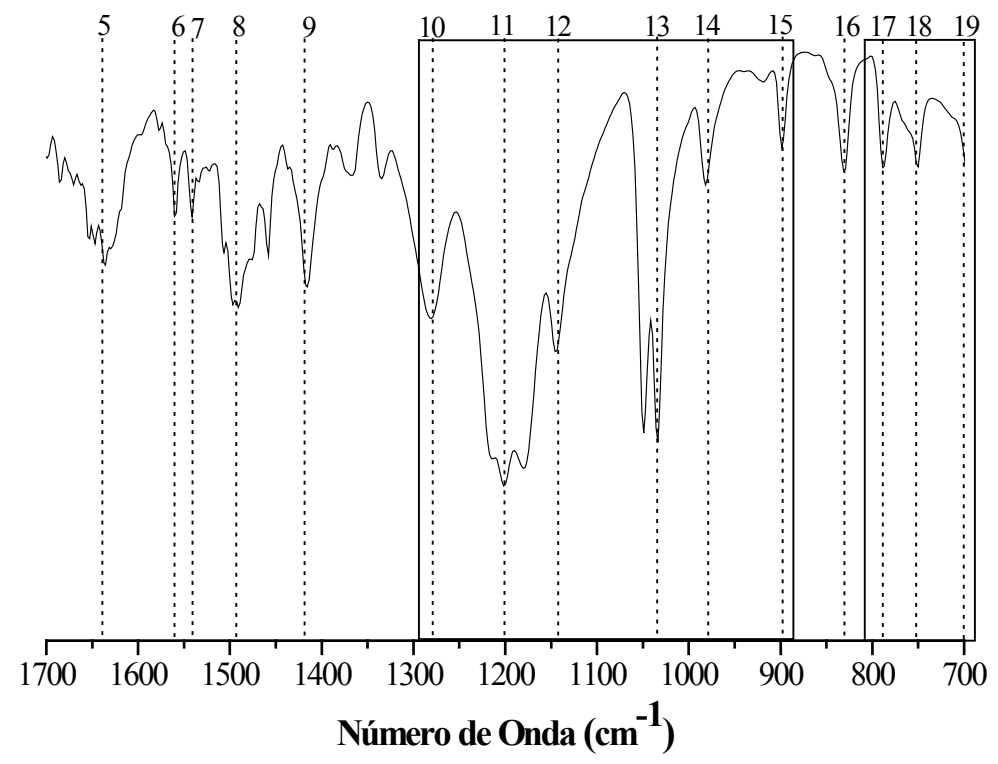

Figura 8.2.6. IR $\left(1700-700 \mathrm{~cm}^{-1}\right)$ del colorante Orange G. 
En la Tabla 8.2.2, se exhiben las bandas de absorción en el infrarrojo identificadas para el colorante Orange G y sus grupos asociados. La Figura 8.2.5, Figura 8.2.6 y Tabla 8.2.2, presentan regiones con diferentes patrones en gris, stretching $-\mathrm{CH}_{2^{-}}\left(2962 \mathrm{~cm}^{-1}\right.$ $\left.2923 \mathrm{~cm}^{-1}\right)$, señales complementarias $\left(1280 \mathrm{~cm}^{-1}-1033 \mathrm{~cm}^{-1}\right)$ e intensidades asociadas a un mismo grupo $\left(898 \mathrm{~cm}^{-1}-788 \mathrm{~cm}^{-1}\right)$.

Tabla 8.2.2. Bandas de absorción y grupos asociados Orange G.

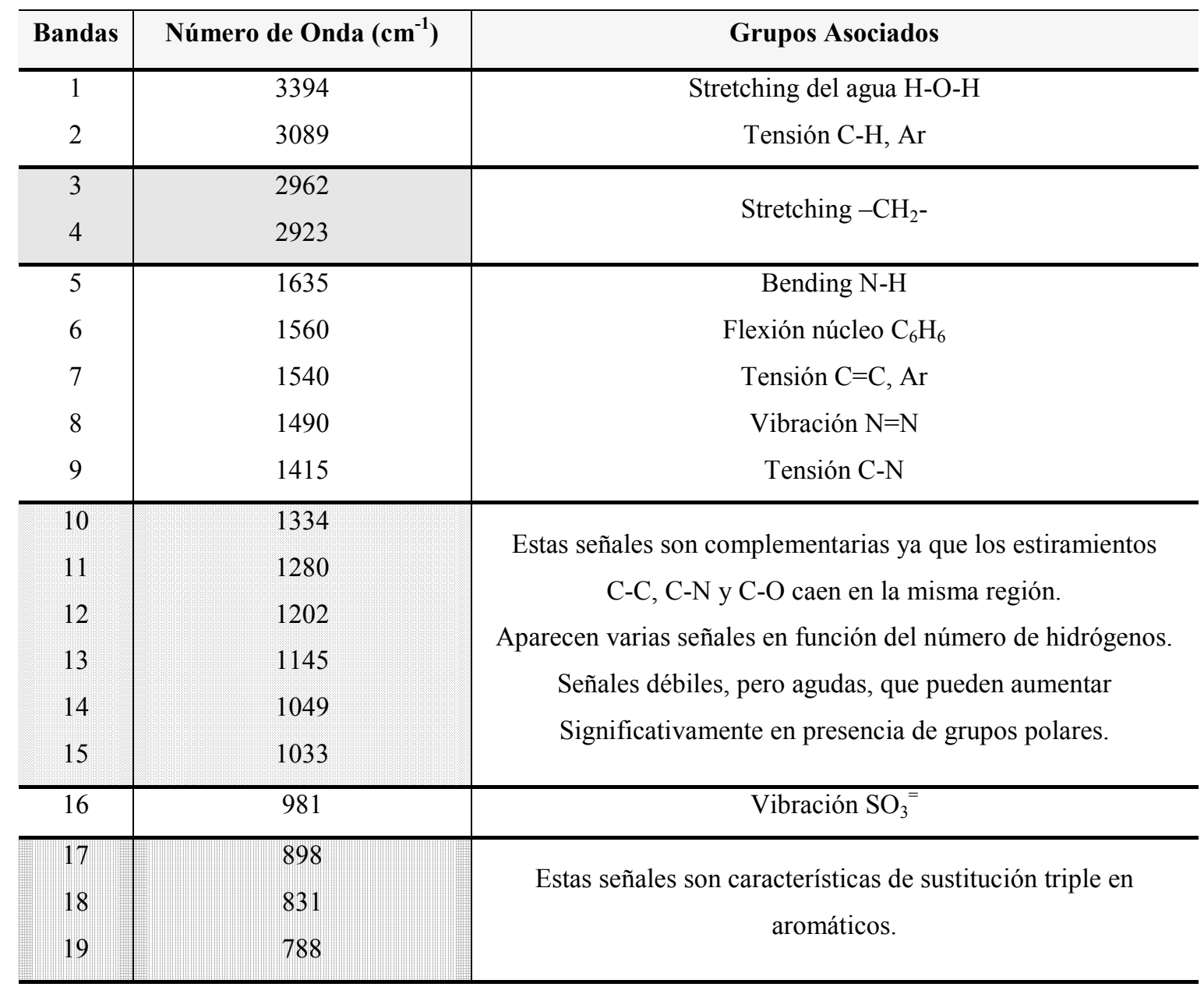

\subsubsection{Yellow GR}

Al igual que para los colorantes Red Allura AC y Orange G, la caracterización del Yellow GR se llevó a cabo empleando técnicas UV- visible, con un equipo PG-Instruments Modelo T60, e Infrarrojo utilizando un equipo Spectrum One Perkin-Elmer. 


\subsubsection{UV-visible}

Una solución del colorante Yellow GR, de concentración $100 \mathrm{mg} . \mathrm{L}^{-1}$, fue caracterizada por espectroscopía UV-visible, como se aprecia en la Figura 8.2.7.

En el espectro UV, se identifica una única banda de absorción, ubicada a una longitud de onda de $400 \mathrm{~nm}$, perteneciente al grupo cromóforo azoico.

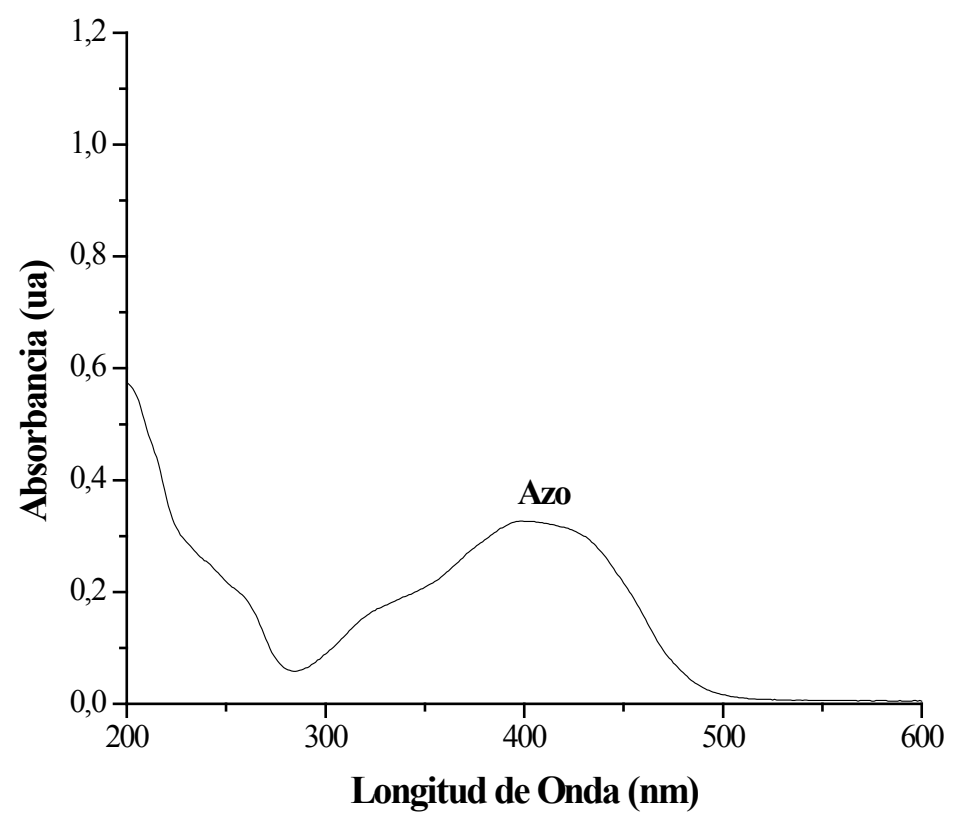

Figura 8.2.7. UV-Visible Yellow GR.

\subsubsection{Infrarrojo}

Los ensayos en el infrarrojo del tinte Yellow GR se observan en las Figura 8.2.8 y

Figura 8.2.9.

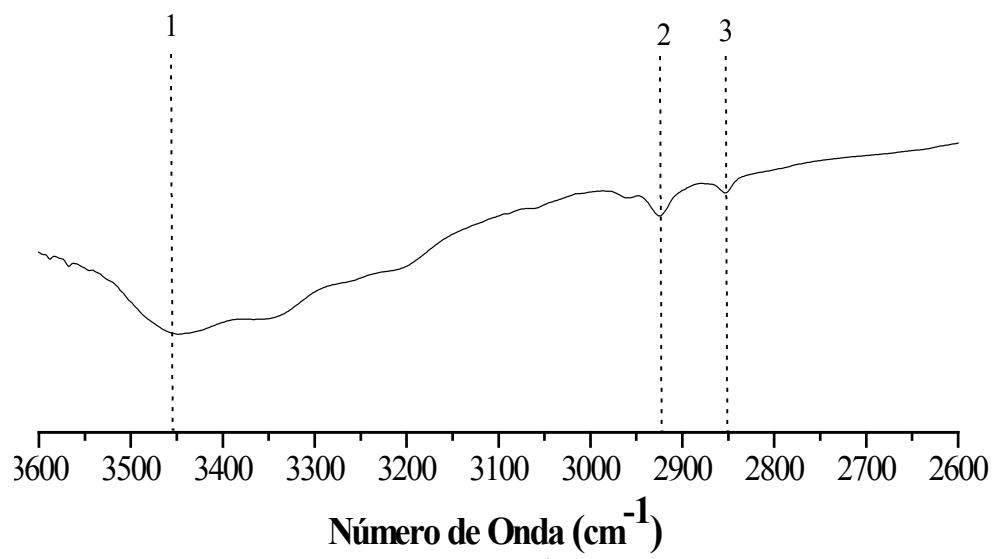

Figura 8.2.8. IR $\left(3600-2600 \mathrm{~cm}^{-1}\right)$ del colorante Yellow GR. 


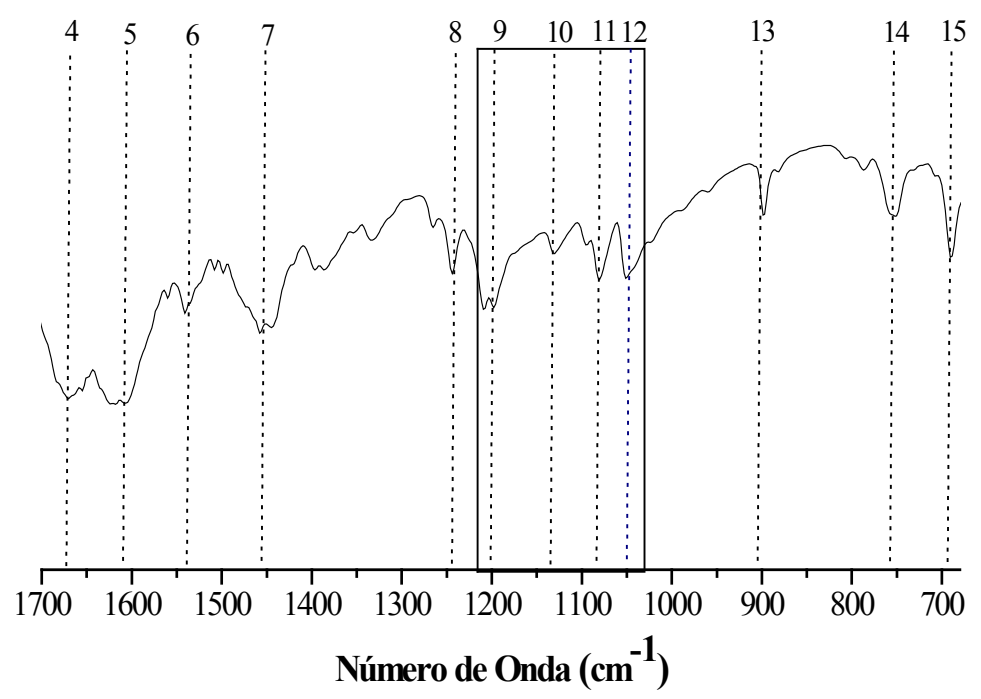

Figura 8.2.9. IR $\left(1700-680 \mathrm{~cm}^{-1}\right)$ del colorante Yellow GR.

La Tabla 8.2.3, presenta las bandas y los grupos característicos que se identificaron por medio de los ensayos de espectroscopia infrarroja. De igual manera que en los colorantes $\mathrm{R}$ y $\mathrm{O}$, la región sombreada corresponde a señales complementarias o asociadas a los mismos grupos.

Tabla 8.2.3. Bandas de absorción y grupos asociados Yellow GR.

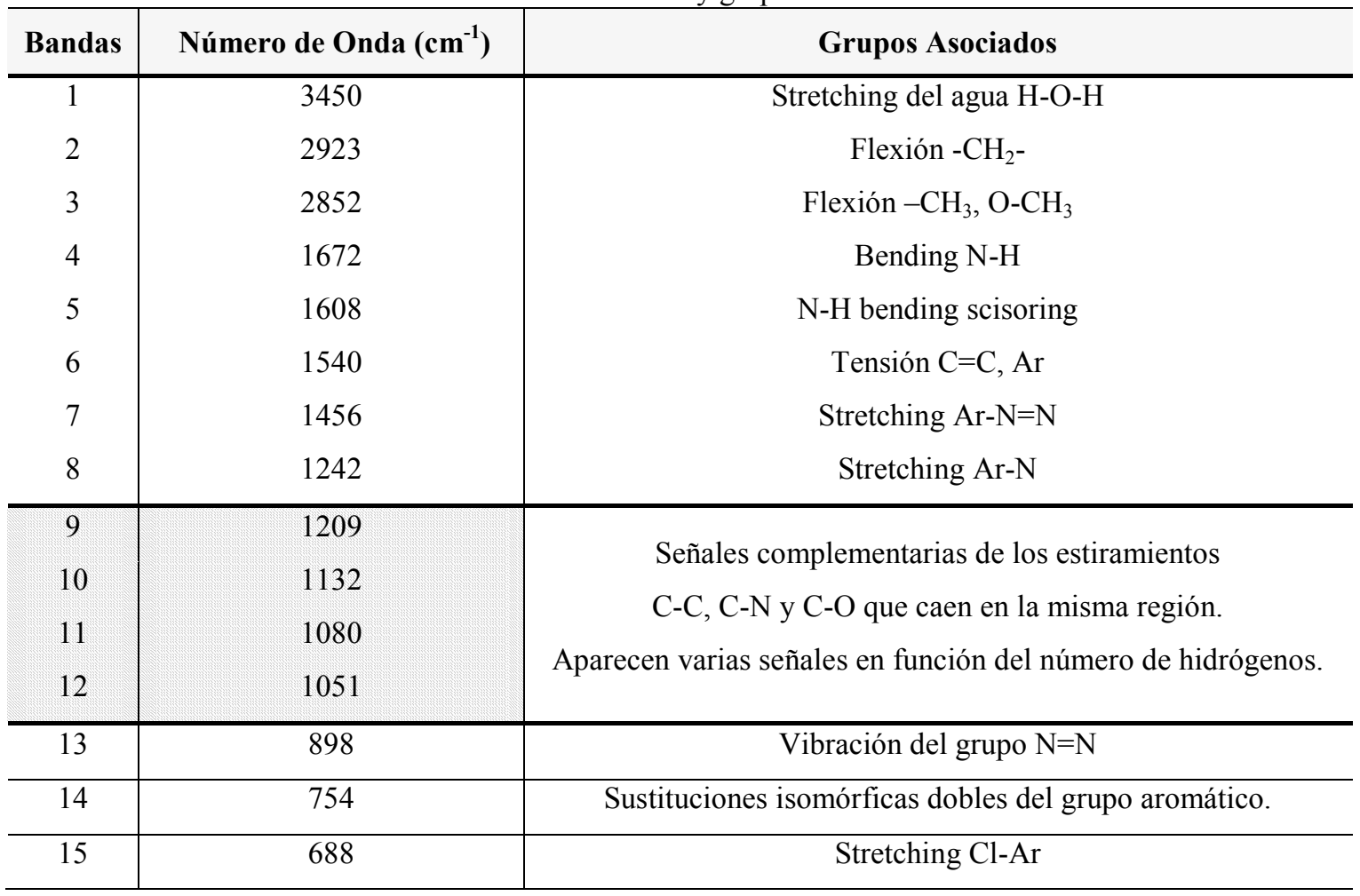




\subsubsection{Análisis comparativo de los colorantes $R, O$ e $Y$}

Si comparamos los espectros UV-visible de los colorantes, Figura 8.2.10, se observa que existe un desplazamiento, hacia mayores longitudes de onda, bien marcado, en el grupo azo, corrimiento que se produce al intensificarse el color, siendo el grupo azo del colorante $\mathrm{Y}$, el que se ubica a menores longitudes de onda, seguido por $\mathrm{O}$ y finalmente $\mathrm{R}$. Además la absorbancia emitida por éste grupo se diferencia en su intensidad siendo ésta $\mathrm{R}_{(\mathrm{azo})}=\mathrm{O}_{(\mathrm{azo})}>\mathrm{Y}_{(\mathrm{azo})}$.

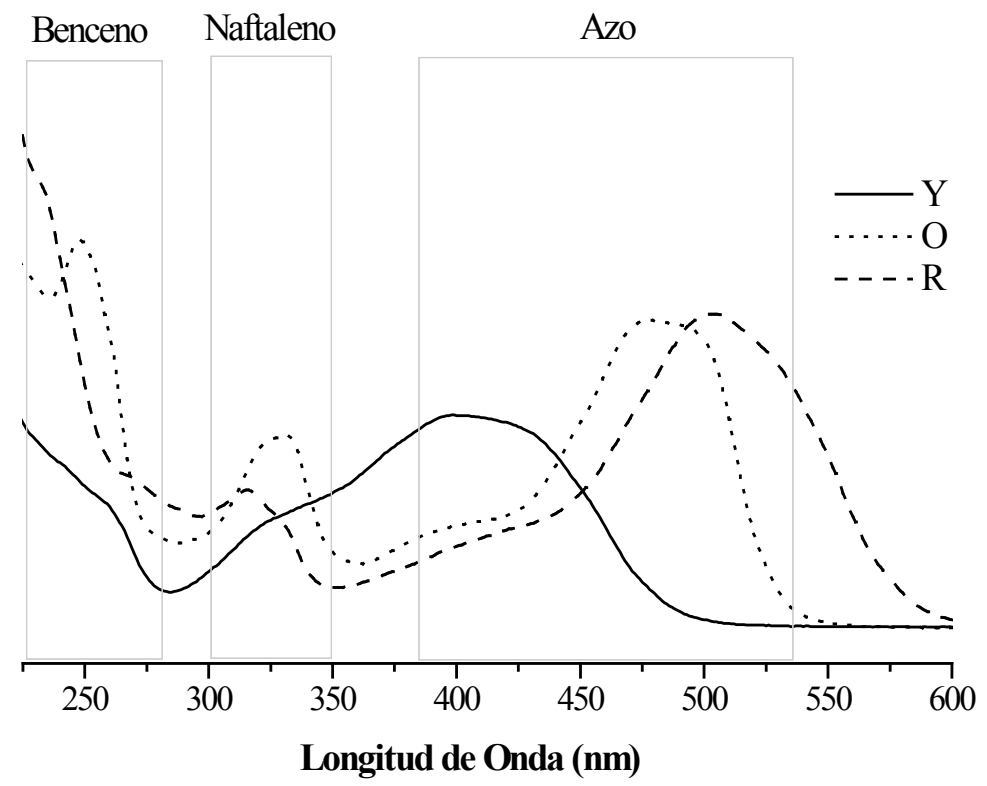

Figura 8.2.10. UV-visible de los colorantes $\mathrm{Y}, \mathrm{O}$ y R.

En referencia a los colorantes $\mathrm{R}$ y $\mathrm{O}$, existen diferencias tanto en la absorbancia como en las longitudes de onda características de los grupos naftaleno y benceno. Estas diferencias pueden atribuirse a la influencia de los grupos funcionales que se encuentran unidos a los distintos colorantes. El grupo naftaleno, de los colorantes $\mathrm{R}$ y $\mathrm{O}$, al igual que en el caso del grupo cromóforo azo, se observa desplazado; éste desplazamiento se ve influenciado por los grupos asociados a la molécula. En el caso del tinte $\mathrm{R}$, el grupo naftaleno presenta un solo grupo sulfonato, mientras que en $O$, éste se encuentra influenciado por dos grupos naftaleno (ver Tabla 8.1.1), es por ello que se aprecia un corrimiento hacia mayores longitudes de onda del tinte $\mathrm{O}$, respecto a $\mathrm{R}$, en la banda característica del naftaleno. Para el grupo benceno, la banda característica se observa a aproximadamente $250 \mathrm{~nm}$, por lo cual solo fue cuantificado en el colorante $\mathrm{O}$, debido a que 
en $\mathrm{R}$, la posición de esta banda se presenta muy cercana al límite del espectro UV-visible, además de una intensidad elevada, lo que dificulta un análisis apropiado.

La Figura 8.2.11, exhiben las bandas IR comunes a los tres colorantes, detallándose en la Tabla 8.2.4, los grupos relacionados a ellas.

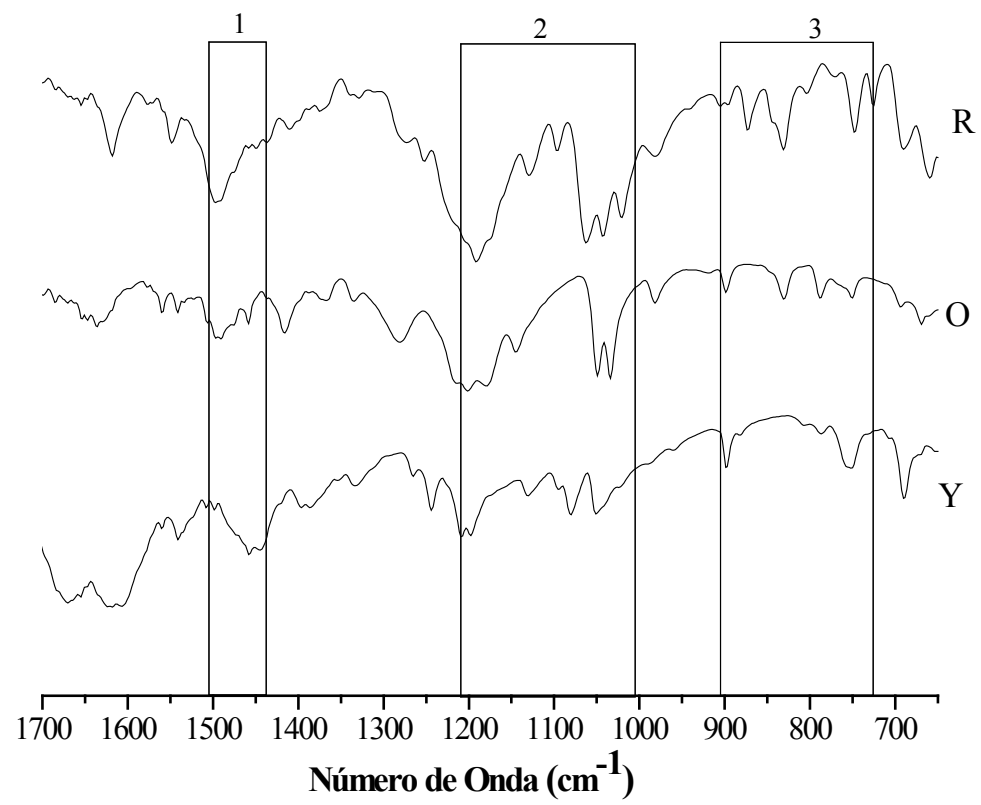

Figura 8.2.11. IR $\left(1700-600 \mathrm{~cm}^{-1}\right)$ colorantes $\mathrm{Y}, \mathrm{O}$ y R.

Tabla 8.2.4. Bandas de absorción y grupos asociados $\mathrm{Y}, \mathrm{O}$ y $\mathrm{R}$.

\begin{tabular}{c|c|c|c}
\hline Bandas & \multicolumn{2}{|c|}{ Número de Onda $\left(\mathbf{c m}^{-\mathbf{1}}\right)$} & Grupos Asociados \\
\hline \multirow{3}{*}{1} & Red & 1498 & $\mathrm{~N}=\mathrm{N}$ \\
& Orange & 1490 & \\
& Yellow & 1456 & Señales complementarias a estiramientos de los \\
& Red & $1275-1022$ & grupos C-C, C-N y C-O, la cantidad de señales \\
2 & Orange & $1280-1033$ & dependen del número de hidrógenos sustituyentes \\
\hline \multirow{3}{*}{3} & Yellow & $1209-1051$ & Sustituciones del grupo aromático \\
\hline \multirow{2}{*}{3} & Red & $897-746$ & \\
\hline
\end{tabular}

Al comparar los resultados del ensayo IR de la totalidad de los colorantes es posible distinguir que el colorante $\mathrm{R}$ posee bandas características, ubicadas a $874 \mathrm{~cm}^{-1}$ (sustituciones aromáticas triples), $981 \mathrm{~cm}^{-1}\left(\mathrm{SO}_{3}{ }^{=}\right)$y $1498 \mathrm{~cm}^{-1}(\mathrm{~N}=\mathrm{N})$. Para O, las bandas 
características son: $788 \mathrm{~cm}^{-1}$ (sustituciones aromáticas triples), $981 \mathrm{~cm}^{-1}\left(\mathrm{SO}_{3}{ }^{=}\right)$y $1490 \mathrm{~cm}^{-1}$ $(\mathrm{N}=\mathrm{N})$. Mientras que para $\mathrm{Y}$ se identifican las bandas característica a $1456 \mathrm{~cm}^{-1}$ (stretching $\mathrm{Ar}-\mathrm{N}=\mathrm{N}$ ) y $688 \mathrm{~cm}^{-1}$ banda correspondiente al estiramiento del cloro-benceno. 


\subsection{Adsorbentes}

Las arcillas naturales $\mathrm{S}$ y Z empleadas como adsorbentes de los tintes Yellow, Red y Orange; como también los productos de éstas arcillas luego de la modificación con la sal de amonio, muestras So y Zo, se sometieron a ensayos de caracterización química, mineralógica y térmica, con el objetivo de reconocer las características de cada adsorbente, y por medio de ellas reconocer los factores que intervienen en el fenómeno de retención de los tintes orgánicos. Las arcillas naturales seleccionadas fueron las llamadas bentonitas, abundantes en la Argentina.

\subsubsection{Análisis por DRX}

Los ensayos efectuados mediante la técnica de DRX permitieron reconocer la composición mineralógica de las bentonitas en estudio, y los cambios luego del tratamiento con la sal orgánica bromuro de hexadecil-trimetil-amonio (HDTMA-Br).

\subsubsection{Caracterización mineralógica}

\subsection{Bentonitas naturales}

La Figura 8.3.1, muestra el difractograma de la bentonita Z. En la misma se identificó esmectita como especie mineral arcillosa, siendo los minerales accesorios reconocidos por difracción: yeso, cuarzo y feldespato.

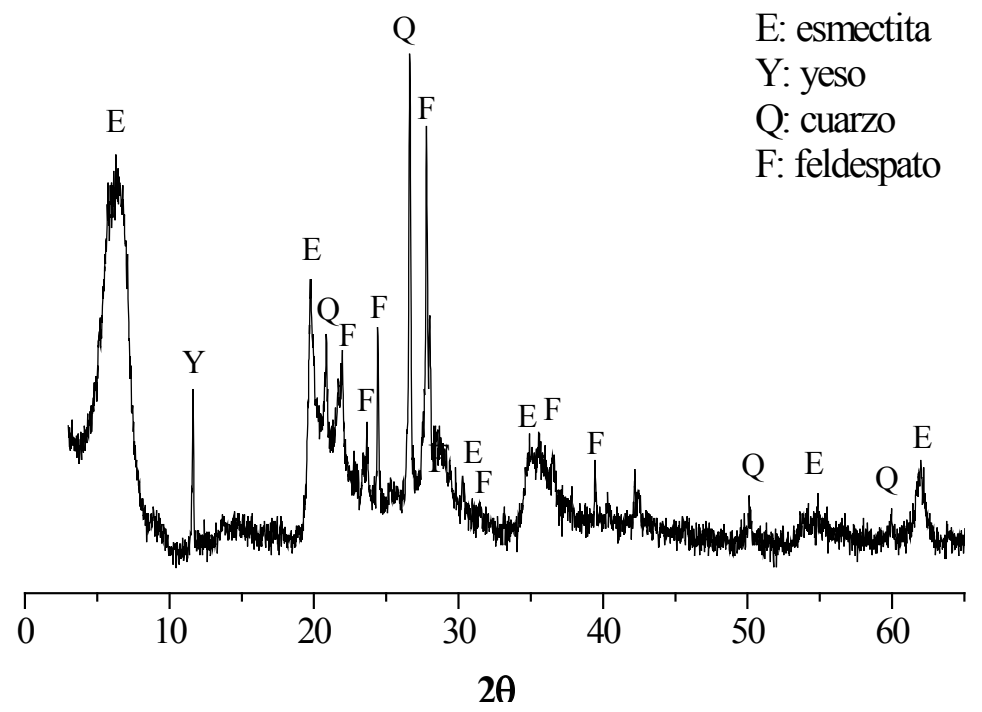

Figura 8.3.1. DRX adsorbente $Z$. 
La Figura 8.3.2, exhibe las especies minerales que componen el adsorbente S. Esta bentonita también está constituida por esmectita como componente principal y el único mineral accesorio reconocido por difracción, el cuarzo.

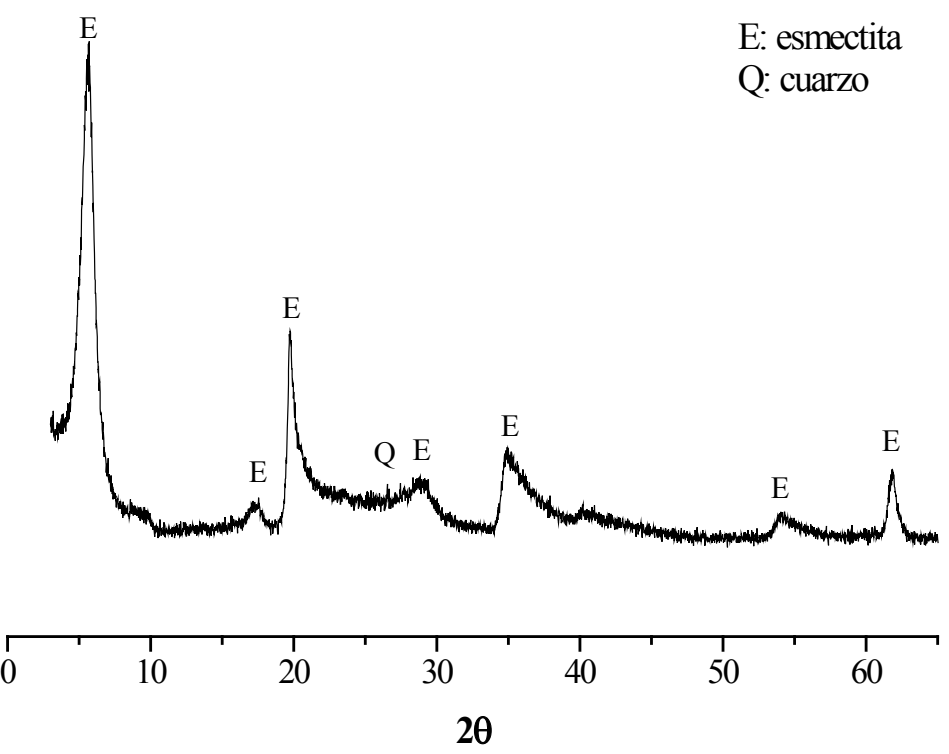

Figura 8.3.2. DRX adsorbente $\mathrm{S}$.

La esmectita presente en la bentonita $\mathrm{S}$ muestra una mayor cristalinidad respecto a la Z, al observar un pico más agudo, correspondiente a la reflexión d001, ubicado aproximadamente a $5^{\circ} 2 \theta$ en la muestra S, Figuras 8.3.1 y Figura 8.3.2 (Brindley y col. 1980).

Las Figuras 8.3.3 y 8.3.4, exhiben los resultados obtenidos por DRX, en las muestras $\mathrm{Z}$ y S al ser tratadas por medio de ensayos de orientación de minerales arcillosos, los cuales permiten determinar el tipo de mineral arcilloso que conforma cada muestra, en éste caso para corroborar la presencia de esmectita. Es así que se identifican como Z-n y S$\mathrm{n}$, a los adsorbentes en su condición normal, Z-g y S-g, al tratarse las muestras con etilenglicol, y Z-c y S-c, luego de ser calcinadas a $600^{\circ} \mathrm{C}$ (Brindley y col. 1980). 


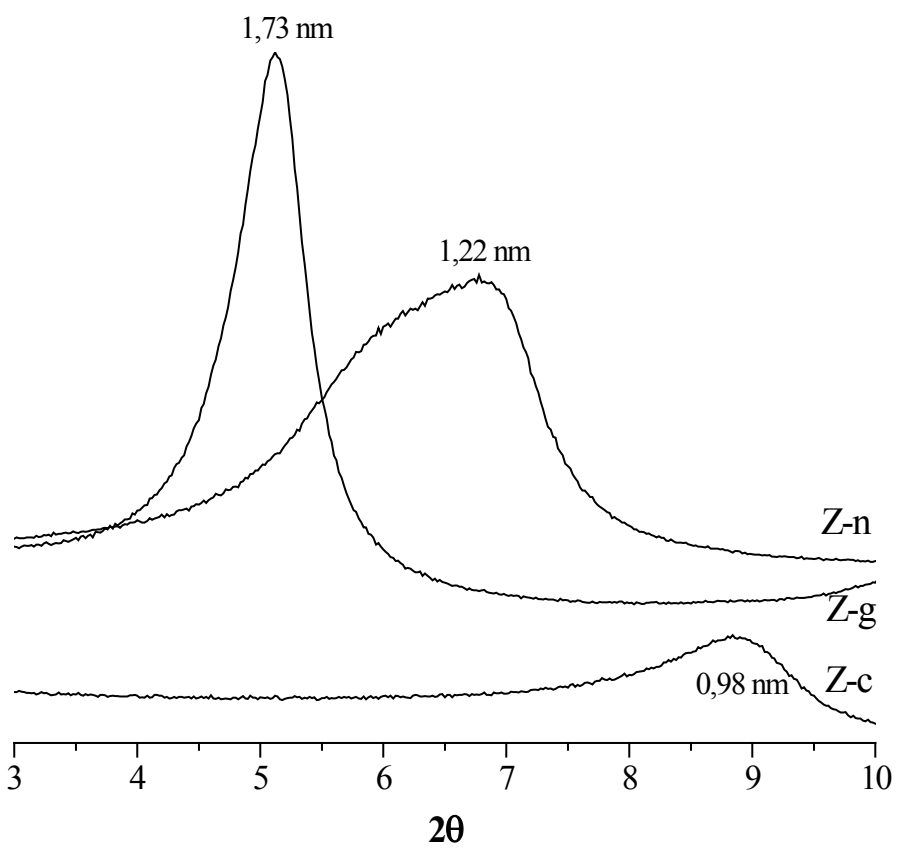

Figura 8.3.3. DRX de la bentonita $Z$ en su condición natural Z-n, glicolada Z-g y calcinada Z-c.

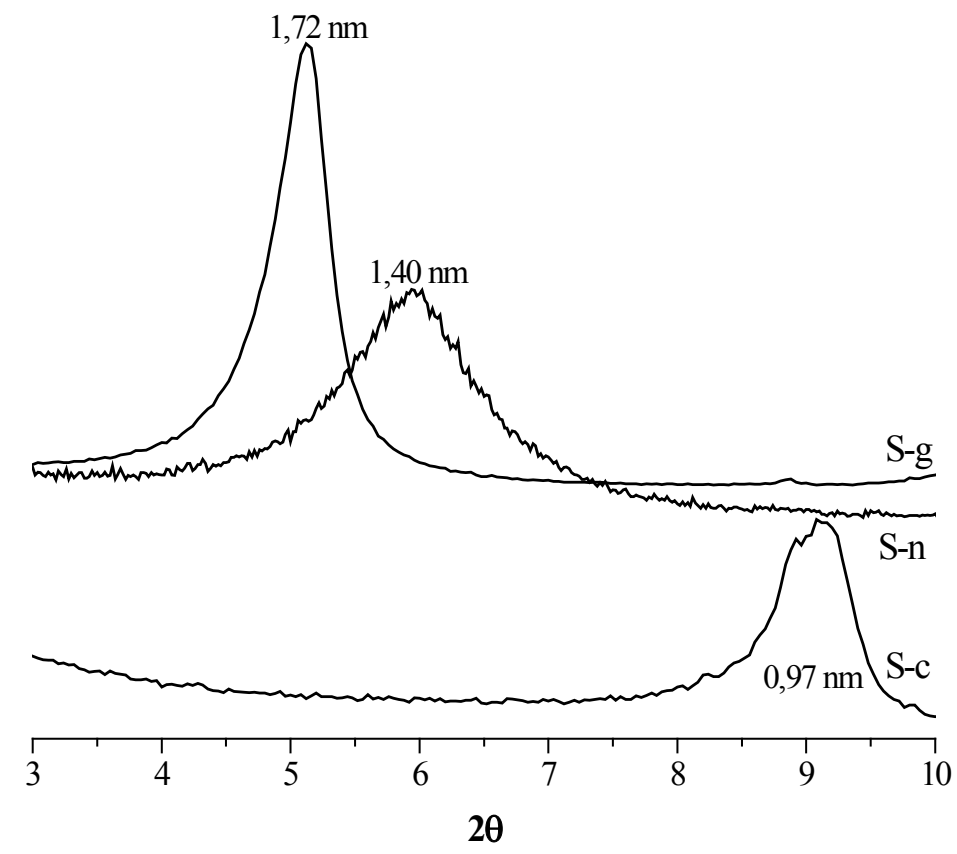

Figura 8.3.4. DRX de la bentonita $S$ en su condición natural S-n, glicolada S-g y calcinada S-c.

La expansión del espaciado interlaminar a valores de 1,73 nm y 1,72 nm de las muestras al ser glicoladas (Z-g y S-g), y la contracción a valores $0,98 \mathrm{~nm}$ en la Z y 0,97 
luego de los ensayos por calcinación (Z-c y S-c) concuerdan con la presencia de esmectita como mineral arcilloso constituyente de ambos sustratos (Brindley y Brown, 1980).

El ensayo de Greene-Kelly (1953) permite identificar montmorillonita de otras esmectitas dioctaédricas (beidelita/nontronita) y trioctaédricas. El mismo consiste en tratar a la arcilla con cloruro o bromuro de litio, posterior tratamiento térmico a $250^{\circ} \mathrm{C}, \mathrm{y}$ glicolación. Los resultados del tratamiento aplicado a las bentonitas $\mathrm{S}$ y Z se muestran en la Figura 8.3.5. La contracción del espaciado interlaminar posterior al ensayo de Greene-Kelly en la muestra $\mathrm{S}$, al valor de $0,93 \mathrm{~nm}$, es indicativo de presencia de montmorillonita como especie esmectítica; en tanto que, para la arcilla Z, la presencia de otro pico con valor de espaciado de 1,74 $\mathrm{nm}$ indica, además de presencia de beidelita o nontronita como especie esmectítica.

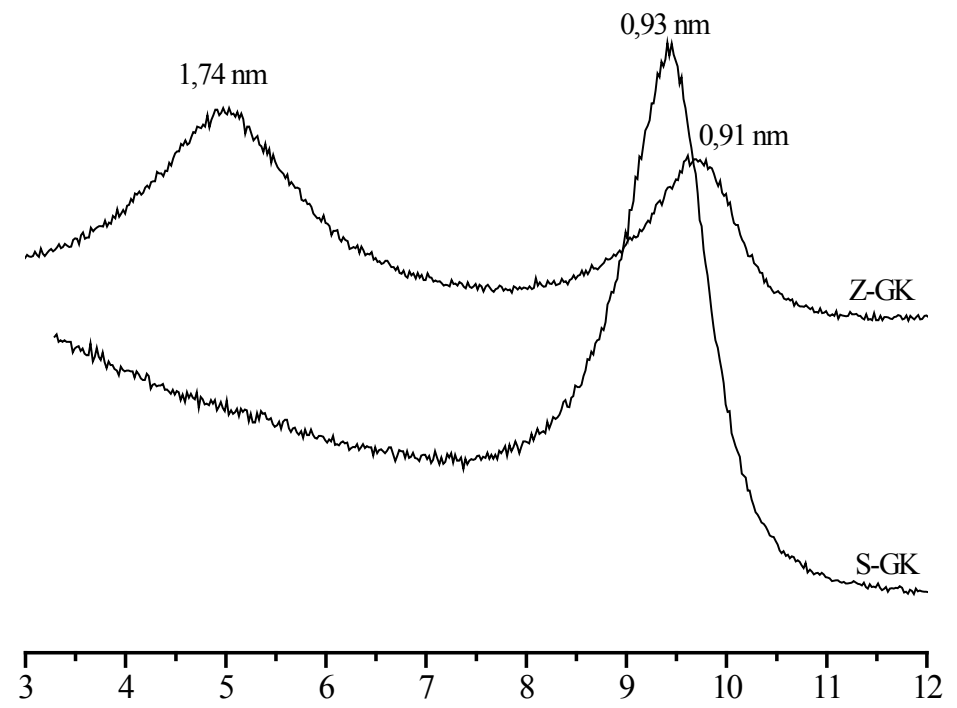

$2 \theta$

Figura 8.3.5. DRX comparativo Z-GK y S-G

\subsection{Organobentonitas}

El difractograma total de la organobentonita Zo, Figura 8.3.6, no presenta diferencias en las reflexiones $h k$ de la esmectita respecto a la natural. Sin embargo las reflexiones $00 l$ muestran un corrimiento hacia ángulos menores. En la Figura 8.3.7, la reflexión 001, correspondiente al espaciado interlaminar de la esmectita de Z y la misma 
reflexión posterior, donde se desplazó de 1,19 (Z) a 1,91 nm (Zo) luego de la intercalación con el catión orgánico.

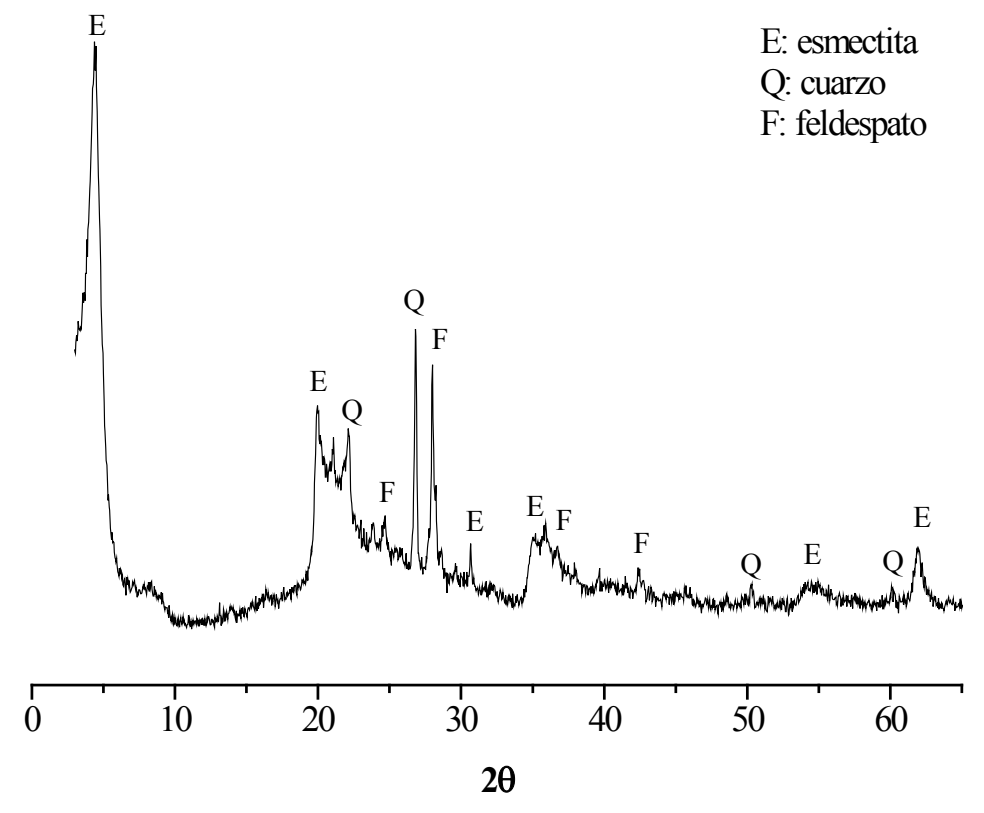

Figura 8.3.6. DRX adsorbente Zo.

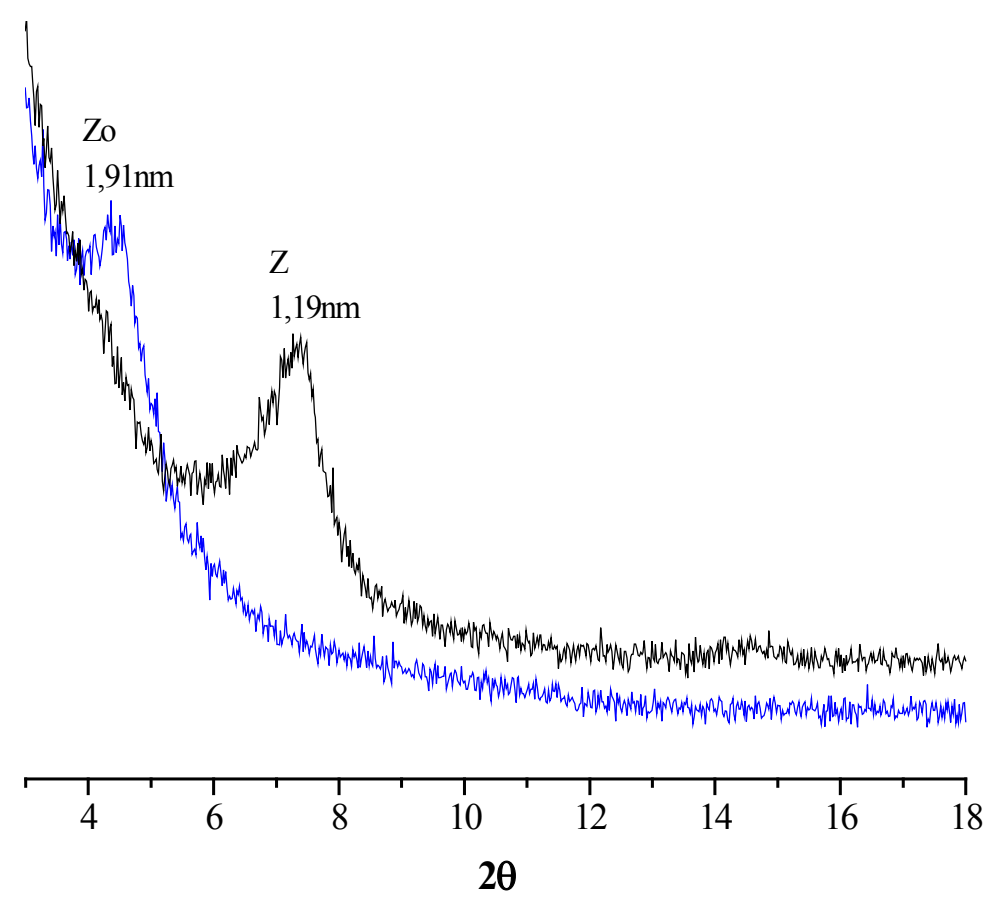

Figura 8.3.7. Espaciado interlaminar $Z$ y Zo.

La organobentonita So presentó un comportamiento similar a la Zo, respecto a su correspondiente natural (Figura 8.3.8). En la Figura 8.3.9 se observa el corrimiento del 
espaciado de la esmectita originado por la presencia del catión orgánico para el caso de la esmectita S. En este caso el valor de 1,24 nm (S) de la muestra natural cambio a 2,22 nm (So).

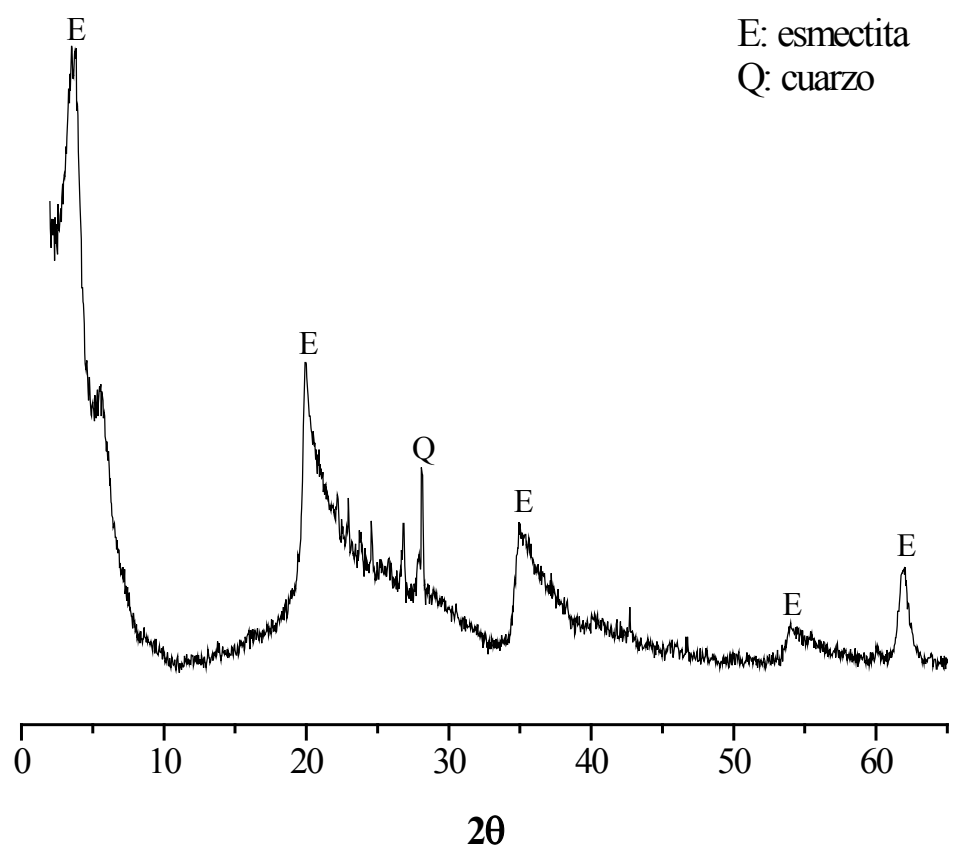

Figura 8.3.8. DRX adsorbente So.

So

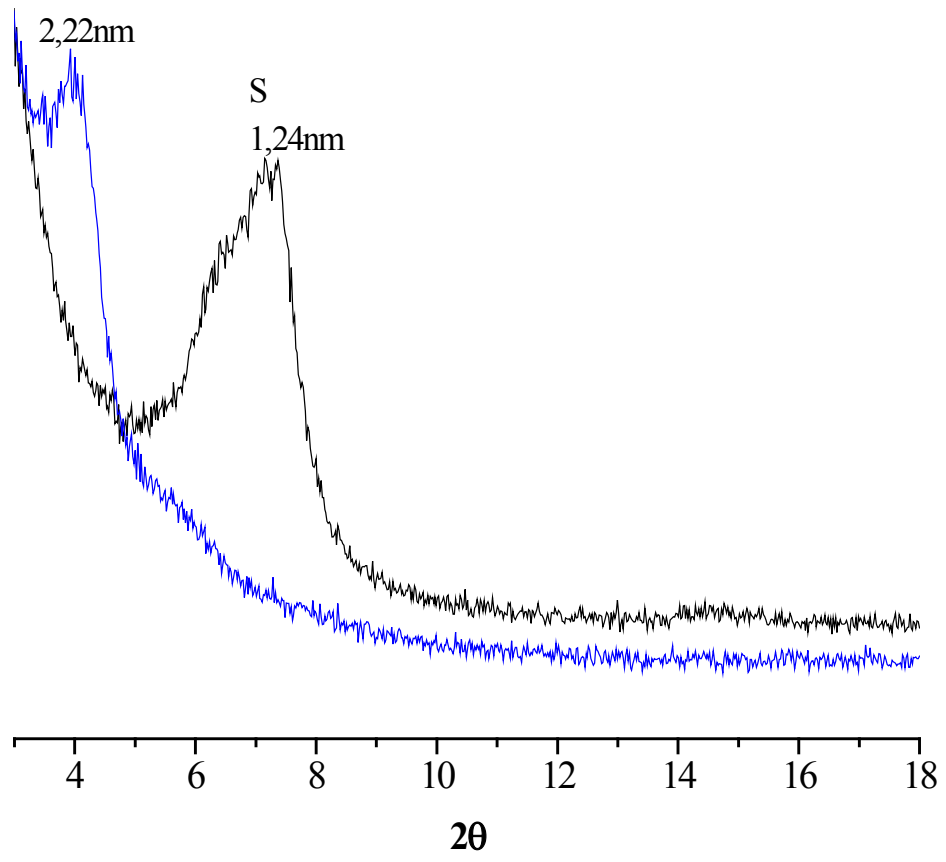

Figura 8.3.9. Espaciado interlaminar $\mathrm{S}$ y So. 
El efecto del agregado del catión $\mathrm{HDTMA}^{+}$en la modificación del espaciado interlaminar de la esmectita de ambas bentonitas, queda en evidencia a partir de la variación en los valores del espaciado entre las láminas, posterior al tratamiento.

Los iones alquilo-amonio de la sal orgánica pueden tener diferente orientación dentro del espaciado basal de las arcillas, dependiendo de la densidad del empaquetamiento, tamaño del catión orgánico y de la carga del mineral, disponiéndose básicamente en cuatro grupos; es así que los iones orgánicos pueden formar una monolámina, bilamina, pseudotrilámina e inclinados formando una estructura conocida como parafina, Figura 8.3.10, correspondiéndole valores de espaciados (distancia d en la figura) de hasta 1,37; 1,77; 2,17 y 2,17 nm, (Brindley, 1965; Lagaly, 1979; Lagaly, 1982; Jaynes y Boyd, 1991; Xu y Boyd, 1995; Sheng y Boyd, 2000; Paiva y col. 2008).

d

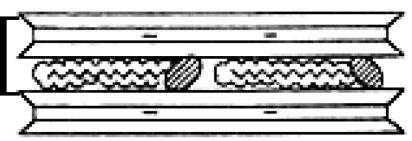

Monolamina

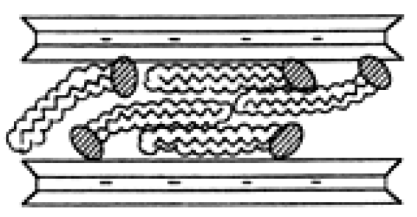

Pseudotrilamina

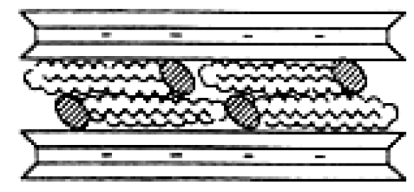

Bilamina

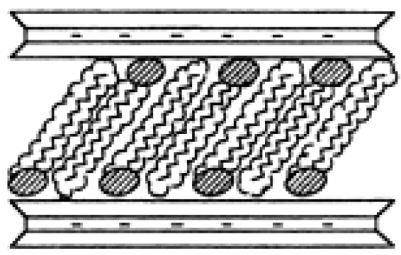

Parafina

Figura 8.3.10. Orientación de los cationes orgánicos entre las láminas del mineral arcilloso.

De acuerdo a la bibliografía científica consultada, y los valores obtenidos posteriores al tratamiento con el catión orgánico, la variación interlaminar del adsorbente So $(2,22 \mathrm{~nm})$ se corresponde con una disposición de la molécula orgánica tipo parafina; en tanto que, el espaciado entre las láminas en el adsorbente Zo $(1,91 \mathrm{~nm})$, concuerda con una disposición tipo pseudo trilaminar. 


\subsubsection{Análisis químico por FRX}

Las bentonitas $\mathrm{S}$ y $\mathrm{Z}$, fueron sometidas a análisis por FRX para conocer su composición química, los resultados obtenidos se observan en la Tabla 8.3.1.

Tabla 8.3.1. Análisis químico por FRX de los adsorbentes

\begin{tabular}{|c|c|c|c|c|c|c|c|c|c|c|c|c|}
\hline Muestras & $\begin{array}{l}\mathrm{SiO}_{2} \\
(\%)\end{array}$ & $\begin{array}{c}\mathrm{Al}_{2} \mathrm{O}_{3} \\
(\%)\end{array}$ & $\begin{array}{c}\mathrm{Fe}_{2} \mathrm{O}_{3} \\
(\%)\end{array}$ & $\begin{array}{c}\mathrm{MgO} \\
(\%)\end{array}$ & $\begin{array}{l}\mathrm{CaO} \\
(\%)\end{array}$ & $\begin{array}{c}\mathrm{Na}_{2} \mathrm{O} \\
(\%)\end{array}$ & $\begin{array}{r}\mathrm{K}_{2} \mathrm{O} \\
(\%)\end{array}$ & $\begin{array}{l}\mathrm{SO}_{3} \\
(\%)\end{array}$ & $\begin{array}{c}\mathrm{TiO}_{2} \\
(\%)\end{array}$ & $\begin{array}{c}\mathrm{MnO} \\
(\%)\end{array}$ & $\begin{array}{c}P P C^{*} \\
(\%)\end{array}$ & $\begin{array}{c}C I C^{* *} \\
\left(m e q .100 g^{-1}\right)\end{array}$ \\
\hline $\mathbf{Z}$ & 57,44 & 18,08 & 4,98 & 1,53 & 2,14 & 1,66 & 0,71 & 0,44 & 0,64 & 0,02 & 12,36 & 81 \\
\hline $\mathbf{S}$ & 58,82 & 13,50 & 1,42 & 5,15 & 1,25 & 2,00 & 0,50 & - & 0,23 & 0,01 & 17,24 & 105 \\
\hline
\end{tabular}

El contenido de $\mathrm{SiO}_{2}$ de 58,82\% del adsorbente $\mathrm{S}$, es algo mayor que en $\mathrm{Z}$, que se registró un 57,44\%, sin embargo, la cantidad de $\mathrm{Al}_{2} \mathrm{O}_{3}$ del adsorbente $\mathrm{Z}$ (18,08\%), es mayor que en el adsorbente $\mathrm{S}(13,50 \%)$. $\mathrm{El} \mathrm{SO}_{3}(0,44 \%)$ cuantificado en la muestra $\mathrm{Z}$, es atribuible a la presencia de yeso. El contenido de potasio $\left(\mathrm{K}_{2} \mathrm{O}\right)$ en la bentonita, en general, es atribuido a su presencia en el espaciado interlaminar como catión de intercambio de la esmectita presente. En este caso el contenido levemente superior en la bentonita Z, respecto a la S, se lo atribuye al contenido de feldespato presente en la Z. Se detectó mayor contenido de $\mathrm{MgO}(5,15 \%)$, en la $\mathrm{S}$ respecto a la $\mathrm{Z}(1,53 \%)$, elemento que generalmente reemplaza al aluminio presente en la capa octaédrica (Newman, 1987) y como posible catión de intercambio. Sin embargo, el contenido de hierro en la $\mathrm{Z}\left(\mathrm{Fe}_{2} \mathrm{O}_{3}: 4,98 \%\right)$ es mayor que en la $\mathrm{S}\left(\mathrm{Fe}_{2} \mathrm{O}_{3}: 1,42 \%\right)$ y esto último podría sugerir posible presencia de nontronita como mineral arcilloso ó mineral arcillosos rico en hierro, en concordancia con lo encontrado por medio del ensayo de Greene y Kelly.

La fracción de mineral arcilloso para cada una de las arcillas, determinada por medio de la purificación en fracción inferior a $2 \mu \mathrm{m}$, siguiendo la Ley de Stoke, Ecuación 8.3.1, se aprecia en la Tabla 8.3.2, donde la mayor fracción de mineral arcilloso le corresponde a la muestra $\mathrm{S}$ con un $94 \%$ respecto a la bentontia $\mathrm{Z}$ con un $78 \%$.

Ecuación 8.3.1. $\mathrm{V}=\frac{\left(2 \mathrm{gr}^{2}\right)(\rho 1-\rho 2)}{9 \mu}$ 
Donde:

$$
\begin{aligned}
& \mathrm{V}=\text { velocidad de caída }\left(\mathrm{cm} \cdot \mathrm{seg}^{-1}\right) \\
& \mathrm{g}=\text { aceleración de la gravedad }\left(\mathrm{cm} \cdot \mathrm{seg}^{-2}\right) \\
& \mathrm{r}=\text { radio de la partícula }(\mathrm{cm}) \\
& \rho 1=\text { densidad de la partícula }\left(\mathrm{g} \cdot \mathrm{cm}^{-3}\right) \\
& \rho 2=\text { densidad del medio }\left(\mathrm{g} \cdot \mathrm{cm}^{-3}\right) \\
& \mu=\text { viscosidad del medio }\left(\mathrm{g} \cdot \mathrm{cm}^{-1} \cdot \mathrm{seg}^{-1}\right)
\end{aligned}
$$

Tabla 8.3.2. Fase mineralógica de las muestras $\mathrm{S}$ y $\mathrm{Z}$.

\begin{tabular}{c|cc}
\hline Fase mineralógica & $\boldsymbol{S}$ & $\boldsymbol{Z}$ \\
\hline Esmectita & $94 \%$ & $78 \%$ \\
Mineral no arcilloso & $6 \%$ & $22 \%$ \\
\hline
\end{tabular}

A partir de los análisis químicos, y la fracción de mineral arcilloso presente en cada una de las muestras, se calculó la fórmula estructural para ambas bentonitas, siendo éstas:

$$
\begin{aligned}
& \mathrm{S}:\left(\mathrm{Si}_{3,96} \mathrm{Al}_{0,04}\right)\left(\mathrm{Al}_{1,36} \mathrm{Ti}_{0,01} \mathrm{Fe}_{0,08} \mathrm{Mg}_{0,51}\right)\left(\mathrm{Ca}_{0,13} \mathrm{Na}_{0,21} \mathrm{~K}_{0,04}\right) \\
& \mathrm{Z}:\left(\mathrm{Si}_{3,83} \mathrm{Al}_{0,17}\right)\left(\mathrm{Al}_{1,41} \mathrm{Ti}_{0,04} \mathrm{Fe}_{0,33} \mathrm{Mg}_{0,14}\right)\left(\mathrm{Ca}_{0,02} \mathrm{Na}_{0,25} \mathrm{~K}_{0,01}\right)
\end{aligned}
$$

El primer paréntesis desde izquierda a derecha indica la composición de las capas tetraédricas, el segundo corresponde a la capa octaédrica y, finalmente el último pertenece a la composición de los cationes en posición interlaminar, que componen la celda unidad de la esmectita. Un análisis de las mismas indica que la $\mathrm{Z}$ posee un mayor contenido en aluminio tetraédrico y mayor contenido de hierro en la capa octaédrica, en tanto que en la $S$ el magnesio se encuentra sustituyendo en mayor proporción al aluminio octaédrico. 


\subsubsection{Análisis ATD-TG}

En la Figura 8.3.11 y Figura 8.3.12, se observan los resultados del análisis de la pérdida de masa de los adsorbentes naturales y orgánicos, logrados hasta los $1000^{\circ} \mathrm{C}$.

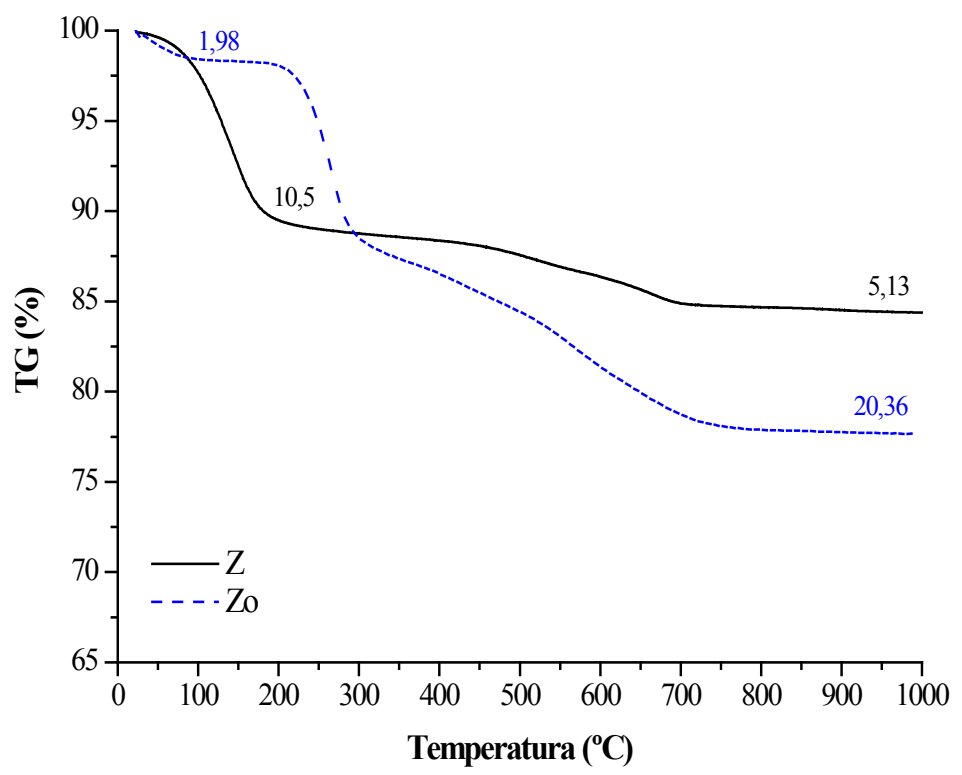

Figura 8.3.11. TG adsorbentes $\mathrm{Z}$ y Zo.

Para los sustratos naturales $\mathrm{Z}$ y S se distinguieron pérdidas de masa de 10,5\% y $17 \%$ hasta $200^{\circ} \mathrm{C}$, respectivamente, etapa en la cual se elimina el agua fisiadsorbida y agua asociada con los cationes entre las láminas. Posteriormente se apreció una segunda pérdida de masa hasta los $800^{\circ} \mathrm{C}$ de $5,13 \%$ para la $\mathrm{Z}$ y 4,68\% para S. Dicha pérdida es característica del agua estructural o deshidroxilación del mineral arcilloso (hasta $\sim 750^{\circ} \mathrm{C}$ ) no observándose cambios hasta los $1000^{\circ} \mathrm{C}$.

Los resultados obtenidos de los $\mathrm{TG}$ de las organobentonitas varían significativamente, respecto a las naturales. En ellas se observa una reducida pérdida de masa hasta $\operatorname{los} 200^{\circ} \mathrm{C}, 1,98 \%$ para Zo y $5,43 \%$ para So. Esta reducción en el contenido de agua a bajas temperaturas es indicativa del cambio de carácter hidrofílico a hidrofóbico de las bentonitas por la presencia del catión orgánico en la esmectita. En tanto que, la mayor pérdida de masa de las órgano bentonitas a mayores temperaturas y hasta aproximadamente los $800{ }^{\circ} \mathrm{C}$, se atribuye a la descomposición del orgánico proveniente del catión HDTMA ${ }^{+}$, en simultáneo en una zona, con la deshidroxilación del mineral arcilloso. 


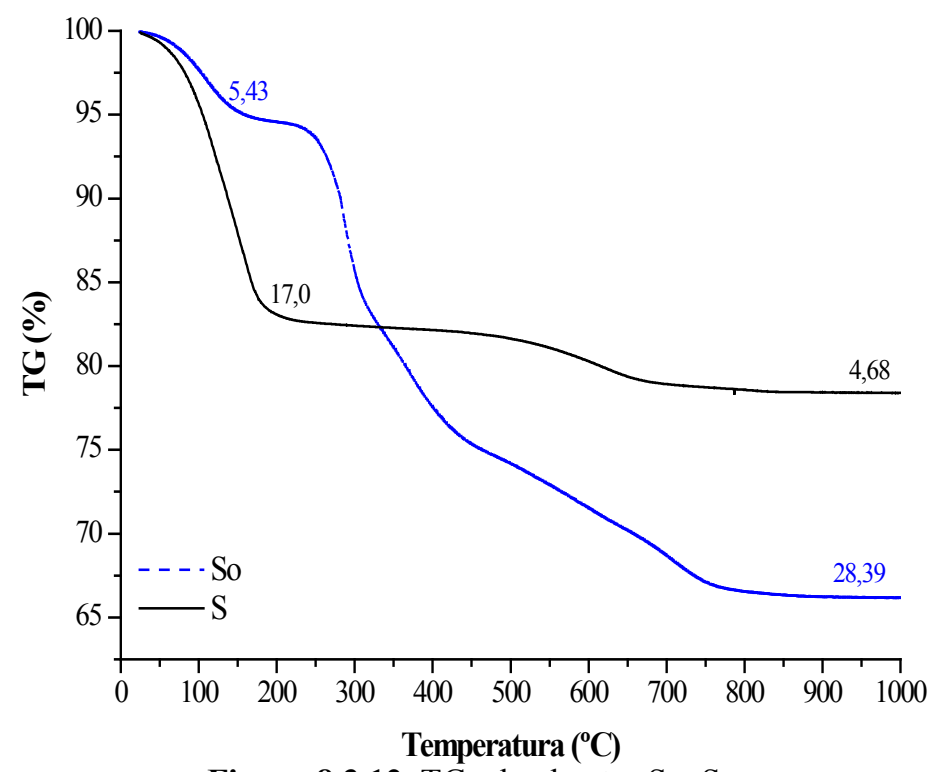

Figura 8.3.12. $\mathrm{TG}$ adsorbentes $\mathrm{S}$ y So.

Efectuando una comparación entre los adsorbentes naturales y los orgánicos, y para una mejor interpretación, se presentan en la Tabla 8.3.3, los valores obtenidos de los ensayos térmicos. Puede apreciarse que los cambios relevantes en las pérdidas de masa ocurren en ambos rangos de temperaturas, es decir a bajas y altas. A bajas temperaturas (menor a $200^{\circ} \mathrm{C}$ ) las bentonitas orgánicas pierden menor cantidad de masa en forma de agua por el carácter hidrofóbico conferido por el tratamiento, es decir de 10,5-17\% para las naturales a 1,98-5,43 para las orgánicas; en tanto que a mayores temperaturas y hasta los $1000^{\circ} \mathrm{C}$, los valores de pérdida de masa de las bentonitas originales $(5,07-4,68 \%)$ aumentaron drásticamente $\left(20,36-28,39^{\circ} \mathrm{C}\right)$ por la pérdida del orgánico presente en el espaciado interlaminar.

Tabla 8.3.3. Pérdidas de masa de los adsorbentes S, So, Z y Zo.

\begin{tabular}{|c|c|c|c|c|}
\hline \multirow{3}{*}{$\begin{array}{c}\text { Temperatura } \\
\left({ }^{\circ} \mathrm{C}\right)\end{array}$} & \multicolumn{4}{|c|}{ Pérdida de masa (\%) } \\
\hline & \multicolumn{2}{|c|}{ Arcilla } & \multicolumn{2}{|c|}{ Organoarcilla } \\
\hline & $\mathbf{Z}$ & $\mathbf{S}$ & Zo & So \\
\hline $25-200$ & 10,50 & 17,00 & 1,98 & 5,43 \\
\hline $200-1000$ & 5,07 & 4,68 & 20,36 & 28,39 \\
\hline Total & 15,63 & 21,68 & 22,34 & 33,82 \\
\hline
\end{tabular}


Para evaluar el contenido de carbono orgánico total (COT) proveniente del tratamiento de la bentonita con el catión $\mathrm{HDTMA}^{+}$se efectuaron los cálculos correspondientes empleando los valores obtenidos en los ensayos térmicos. Los resultados se aprecian en la Tabla 8.3.4. De esta manera se deduce que la organobentonita So ha retenido mayor contenido del catión orgánico y esto es debido a que la capacidad de intercambio catiónico de la bentonita original, $\mathrm{S}$ es mayor que la $\mathrm{Z}$.

Tabla 8.3.4. Carbono orgánico total.

\begin{tabular}{c|cc}
\hline Muestras & $\begin{array}{c}\text { Cagregado } \\
\text { (mgC.g } \text { arcilla })^{-1}\end{array}$ & $\begin{array}{c}\text { COT } \\
\text { (mgC.g }{ }^{-1} \text { arcilla) }\end{array}$ \\
\hline Zo & 228 & 157 \\
\hline So & 228 & 185 \\
\hline
\end{tabular}

Los resultados obtenidos del análisis térmico diferencial (ATD) de la bentonita $\mathrm{Z}$ y Zo se observan en la Figura 8.3.13 y Figura 8.3.14, respectivamente; mientras que los ATD de $\mathrm{S}$ y So se aprecian en las Figuras 8.3.15 y 8.3.16.

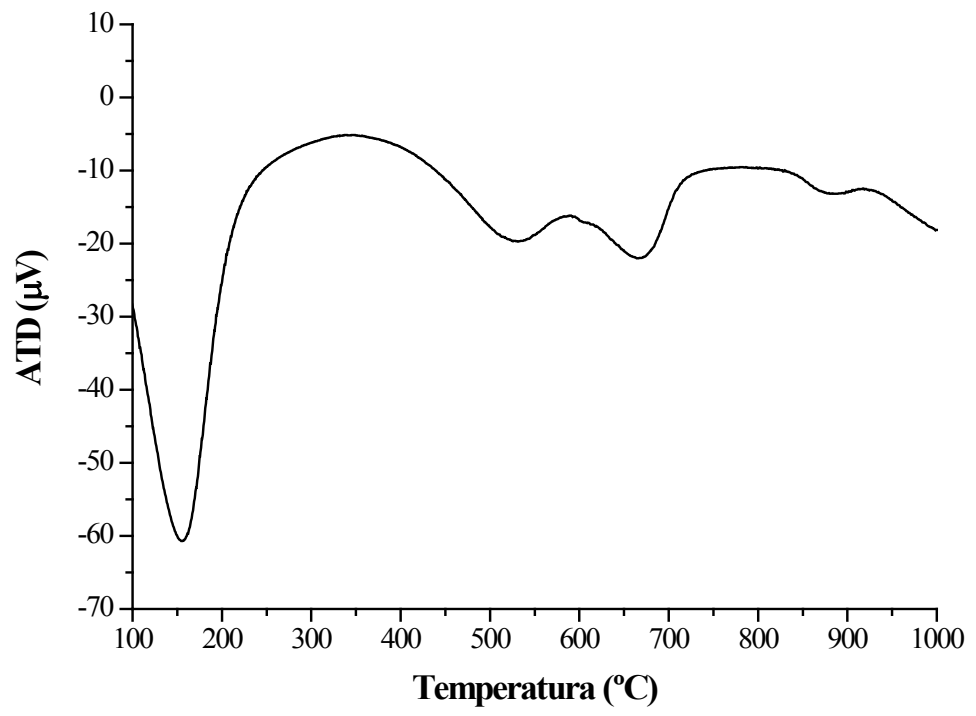

Figura 8.3.13. ATD de la bentonita $Z$. 


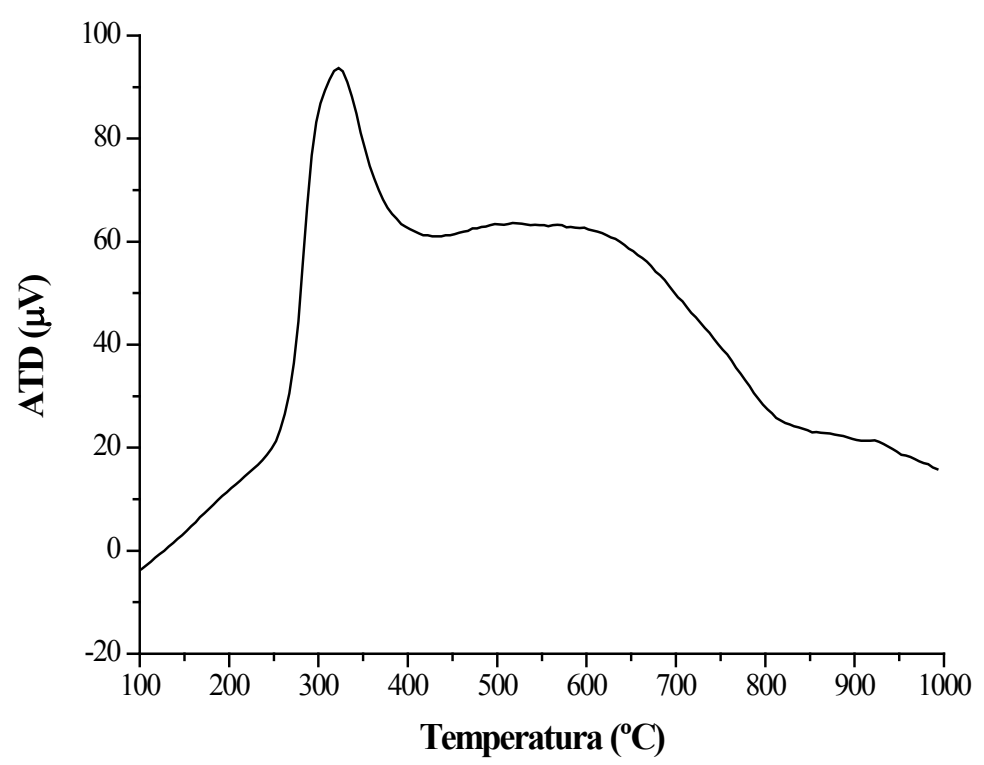

Figura 8.3.14. ATD de la organobentonita Zo.

Las bentonitas naturales $\mathrm{S}$ y Z, presentan picos característicos de esmectitas, es decir un pronunciado pico endotérmico en aproximadamente $150^{\circ} \mathrm{C}$ correspondiente a la pérdida de agua interlaminar; un segundo pico endotérmico en el rango de $500-700^{\circ} \mathrm{C}$ que corresponde a la pérdida de oxhidrilos de la estructura mineral y, posteriormente es posible observar, en general, un doblete endo-exo, a mayores temperaturas de $800^{\circ} \mathrm{C}$ en donde ocurre la ruptura de la estructura y reorganización a nuevas fases. La Tabla 8.3.5, presenta los valores de temperaturas de los picos para ambas muestras. Así, los valores del primer pico endotérmico para la $\mathrm{Z}$ y $\mathrm{S}$ fueron $155^{\circ} \mathrm{C}$ y $161^{\circ} \mathrm{C}$, respectivamente. Dos picos endotérmicos a $520^{\circ} \mathrm{C}$ y $670^{\circ} \mathrm{C}$ se detectaron en la $\mathrm{Z}$, coincidentes con la deshidroxilación de la estructura mineral arcilloso de la bentonita; mientras que para S solo es observable un pico endotérmico a aproximadamente $620^{\circ} \mathrm{C}$, también atribuible a la eliminación de oxhidrilos. La presencia de dos pequeños picos endotérmicos en el rango de $550^{\circ} \mathrm{C}-700^{\circ} \mathrm{C}$, en el adsorbente $Z$, se relaciona con la existencia de dos tipos de esmectitas, el primero de ellos coincidentes con la estructura de deshidroxilación de beidellita-nontronita, y el segundo de ellos perteneciente a la montmorillonita. La existencia de solo un pico endotérmico, cercano a los $620^{\circ} \mathrm{C}$ en el adsorbente $\mathrm{S}$, concuerda con una montmorillonita. Ambas observaciones se encuentran en concordancia con lo observado en los análisis por 
DRX anteriormente expuestos. Estas diferencias se relacionan de alguna manera con la energía con la que los grupos oxhidrilos se encuentran en la estructura arcillosa, pudiendo además estar relacionada a composiciones diferentes en los cationes interlaminares (Mackenzie, 1970).

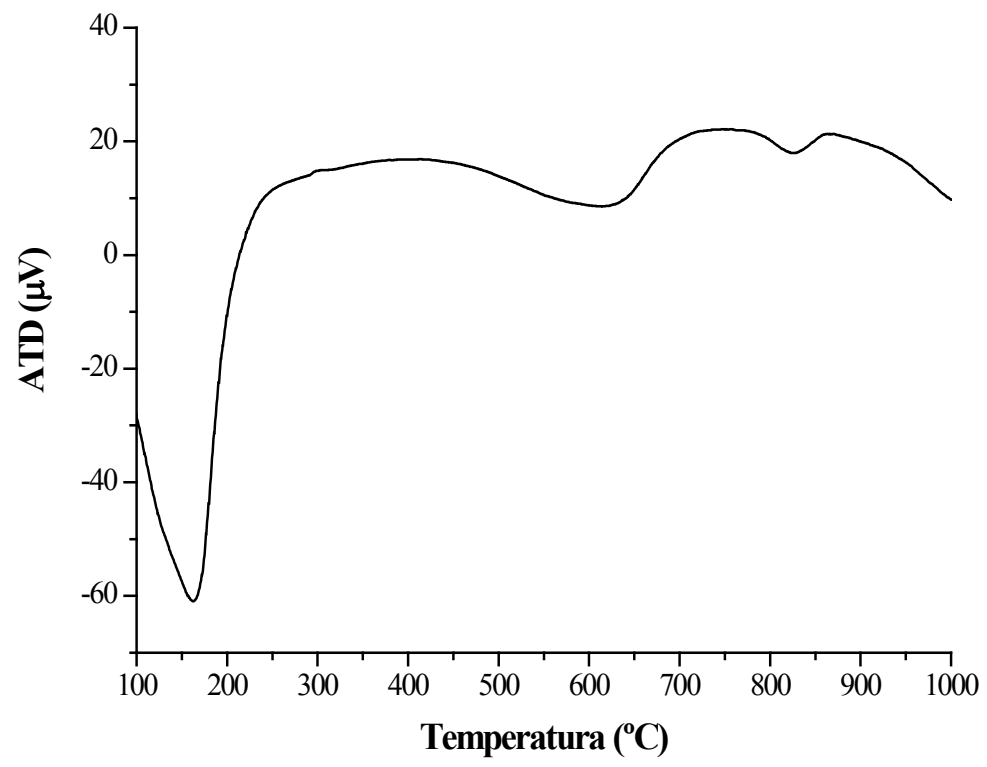

Figura 8.3.15. ATD bentonita S.

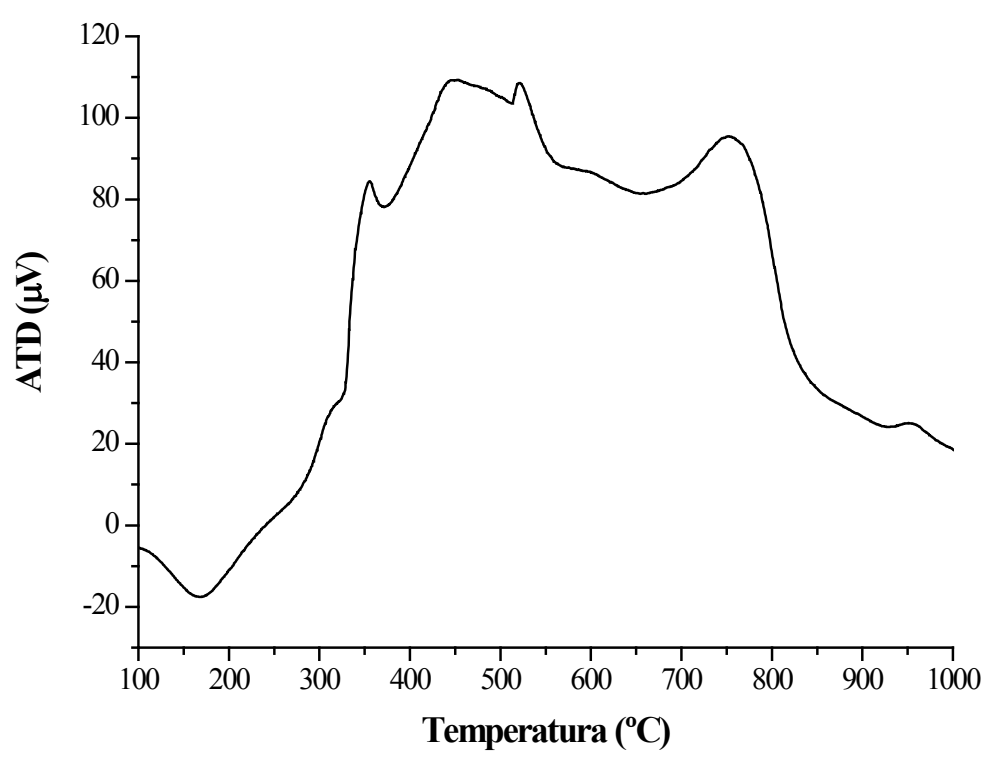

Figura 8.3.16. DTA adsorbente So. 
Tabla 8.3.5. Temperatura de picos endo/exo-térmicos establecidos de los espectros ATD de las bentonitas naturales $\mathrm{S}$ y $\mathrm{Z}$.

\begin{tabular}{|c|c|c|c|}
\hline Muestras & $\begin{array}{c}\mathbf{1}^{\mathbf{o}} \text { Endo } \\
\left({ }^{\circ} \mathbf{C}\right)\end{array}$ & $\begin{array}{c}\mathbf{2}^{\mathbf{o}} \text { Endo } \\
\left({ }^{\circ} \mathbf{C}\right)\end{array}$ & $\begin{array}{c}3^{\circ} \text { Endo } \\
\left({ }^{\circ} \mathbf{C}\right)\end{array}$ \\
\hline $\mathbf{Z}$ & 155 & $520-670$ & 890 \\
\hline $\mathbf{S}$ & 161 & 620 & 825 \\
\hline
\end{tabular}

Finalmente, a temperaturas de $890^{\circ} \mathrm{C}$ y $825^{\circ} \mathrm{C}$ para las muestras $\mathrm{Z}$ y S pierden la estructura arcillosa para posteriormente formar muevas fases, como podrían ser espinela, cristobalita y mullita (Grim, 1968; Mackenzie, 1970; Xie y col. 2001; Hedley y col. 2007).

En los ensayos de ATD de las organobentonitas, Figuras 8.3.14 y 8.3.16, existen grandes diferencias respecto a los adsorbentes naturales. Las muestras Zo y So evidencian la presencia de picos exotérmicos relacionados con la descomposición del surfactante, a $340{ }^{\circ} \mathrm{C}$ para Zo y entre $340-480{ }^{\circ} \mathrm{C}$ para la So. En ambas muestras los picos de deshidroxilación de la esmectita no son fáciles de distinguir.

\subsubsection{Análisis IR}

La Figura 8.3.17 presenta el espectro IR correspondiente a la bentonita Z.

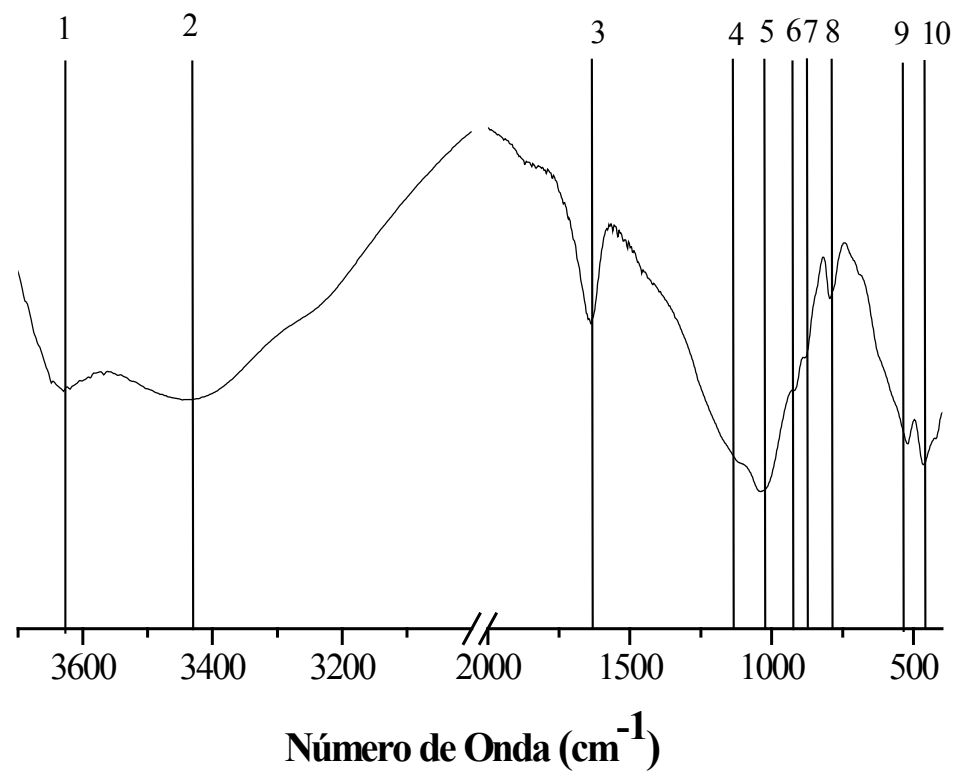

Figura 8.3.17. IR del adsorbente Z. 
Las bandas identificadas en los ensayos IR del sustrato Z, pueden observarse en la Tabla 8.3.6.

Tabla 8.3.6. Bandas de absorción y grupos asociados del adsorbente Z.

\begin{tabular}{|c|c|c|}
\hline Bandas & Número de Onda $\left.\mathbf{( c m}^{-\mathbf{1}}\right)$ & Grupos Asociados \\
1 & 3631 & OH stretching del grupo $\mathrm{Al}_{2} \mathrm{OH}$ o Al-Mg-OH \\
2 & 3431 & Stretching del agua H-O-H \\
3 & 1629 & Bending del grupo H-O-H \\
4 & 1122 & Stretching (modo longitudinal) Si-O-Si \\
5 & 1033 & Stretching Si-O-Si \\
6 & 925 & Bending Al-OH \\
7 & 883 & Stretching Al-Fe'-OH \\
8 & 792 & Stretching del cuarzo Si-O \\
9 & 540 & Bending Si-O-Al \\
10 & 470 & Si-O-Si vibración bending \\
\hline
\end{tabular}

Al igual que la muestra $\mathrm{Z}$, la bentonita $\mathrm{S}$ fue analizada por espectroscopia infrarroja, obteniéndose como resultado del mencionado ensayo el espectro que se presenta en la Figura 8.3.18.

Las especies y tipos de vibraciones reconocidas en el espectro infrarrojo se detallan en la Tabla 8.3.7.

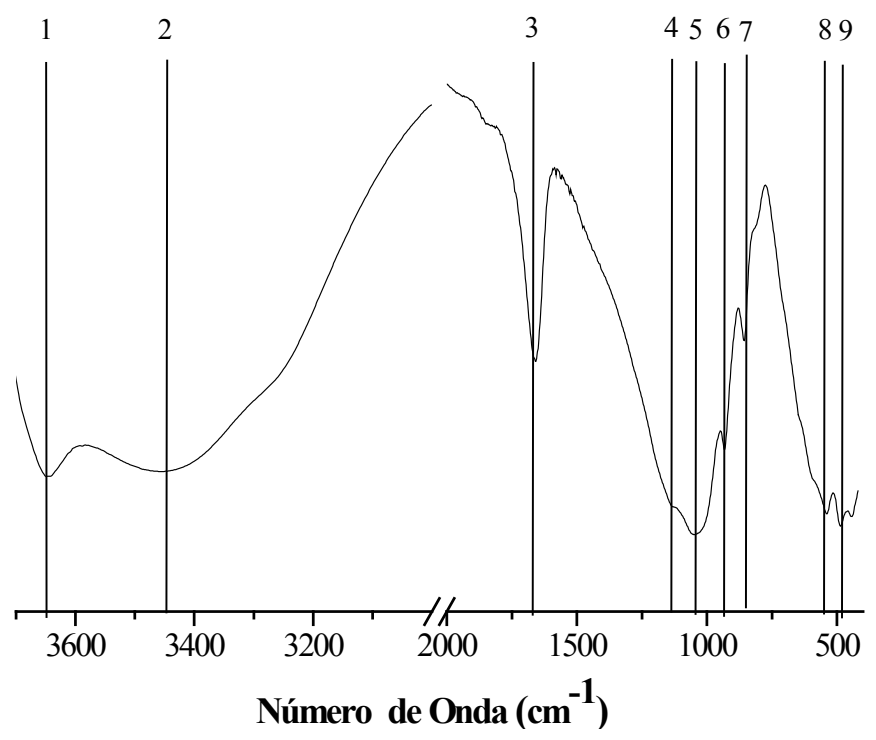

Figura 8.3.18. IR adsorbente $S$. 
Tabla 8.3.7. Bandas de absorción y grupos asociados del adsorbente $\mathrm{S}$.

\begin{tabular}{|c|c|c|}
\hline Bandas & Número de Onda $\left.\mathbf{( c m}^{\mathbf{- 1}}\right)$ & Grupos Asociados \\
1 & 3649 & OH stretching del grupo $\mathrm{Al}_{2} \mathrm{OH}$ o Al-Mg-OH \\
2 & 3458 & Stretching del agua H-O-H \\
3 & 1660 & Bending del grupo H-O-H \\
4 & 1136 & Stretching (modo longitudinal) Si-O-Si \\
5 & 1036 & Stretching Si-O-Si \\
6 & 931 & Bending Al-OH \\
7 & 856 & Bending Al-Mg-OH \\
8 & 542 & Bending Si-O-Al \\
9 & 490 & Si-O-Si vibración bending \\
\hline
\end{tabular}

Las bandas de absorción características de la estructura de la esmectita de ambas bentonitas en $\sim 3631 \mathrm{~cm}^{-1}$ (Z) y $\sim 3649 \mathrm{~cm}^{-1}$ (S), corresponden a la tensión de los grupos hidroxilo. El agua se encuentra presente a frecuencias de $3431 \mathrm{~cm}^{-1}$ y $1629 \mathrm{~cm}^{-1}$ (Z) y $3458 \mathrm{~cm}^{-1}$ y $1660 \mathrm{~cm}^{-1}(\mathrm{~S})$. Las vibraciones cercanas a $1033 \mathrm{~cm}^{-1}$ y $470 \mathrm{~cm}^{-1}$ en $\mathrm{Z}$ se deben a las vibraciones stretching y bending $\mathrm{Si}-\mathrm{O}$ frecuentemente acoplados con otros cationes. Las bandas correspondientes a vibraciones bending $\mathrm{Al}-\mathrm{OH}$, se aprecian en $931 \mathrm{~cm}^{-1}-925 \mathrm{~cm}^{-1}$ para S y Z, respectivamente. Además de las especies características de los minerales arcillosos que han sido identificadas por IR, se observa la presencia de una banda $792 \mathrm{~cm}^{-1}$, característica del cuarzo en el mineral arcilloso Z (Madejová y col. 1994; Petit y col. 1998; Xie y col. 2002; Madejová, 2003; Paiva y col. 2008).

El análisis por espectroscopia IR permitió comprobar que las bandas de las arcillas naturales $\mathrm{S}$ y $\mathrm{Z}$, en las posiciones de las vibraciones stretching de Si-O-Si y bending de las uniones $\mathrm{Al}_{2} \mathrm{OH}$, Al-Mg-OH, Si-O-Al, Si-O-Si, pertenecen a esmectitas tipo montmorillonita; en tanto que la banda del grupo $\mathrm{Al}-\mathrm{Fe}^{+3}-\mathrm{OH}\left(883 \mathrm{~cm}^{-1}\right)$ presente en $\mathrm{Z}$, correspondería con una esmectita rica en hierro.

En el espectro infrarrojo de la organoarcilla Zo, Figura 8.3.19, además de las bandas características de la esmectita, se aprecia una banda ubicada $3022 \mathrm{~cm}^{-1}$ correspondiente al stretching asimétrico del grupo metilo, $2923 \mathrm{~cm}^{-1}$ de la vibración stretching de la cabeza del trimetil-amonio (Petit y col. 1998; Witkowski y col. 2000), 
señales de los grupos orgánicos a $2850 \mathrm{~cm}^{-1}, 1469 \mathrm{~cm}^{-1}$ y $725 \mathrm{~cm}^{-1}$, propias de diferentes vibraciones del grupo metileno $\left(=\mathrm{CH}_{2}\right), 912 \mathrm{~cm}^{-1}(\mathrm{~N}-\mathrm{C})$; y la formación de una nueva señal asociada a la interacción de la superficie siloxano de la arcilla con la sal orgánica, evidenciada a 1043 $\mathrm{cm}^{-1}$ (Bodoardo y col. 1998; Petit y col. 1999; Madejová, 2003).

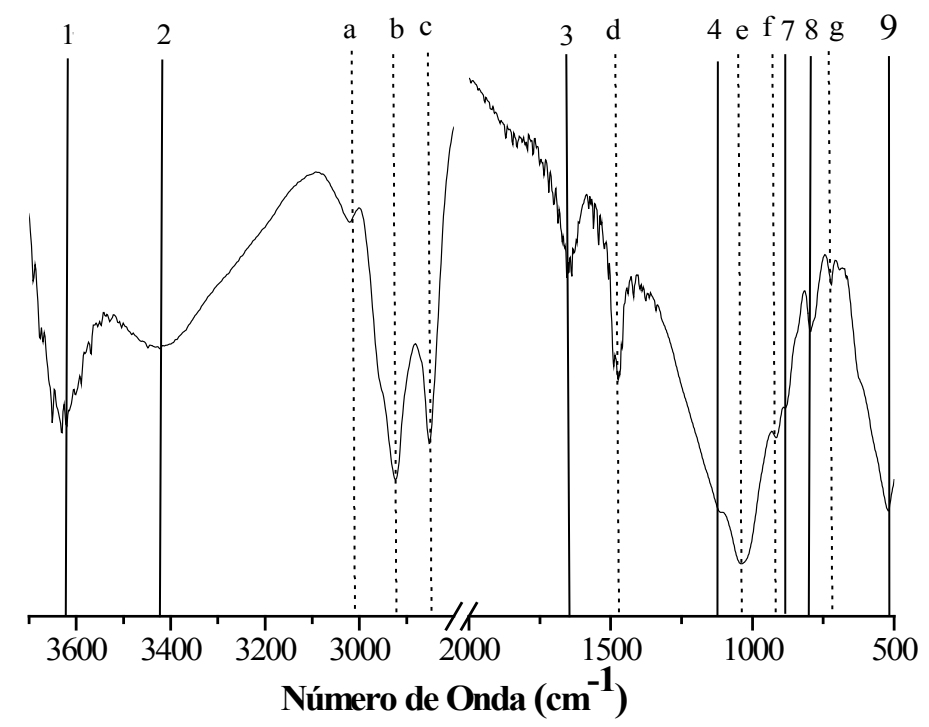

Figura 8.3.19. IR adsorbente Zo.

Tabla 8.3.8. Bandas de absorción y grupos asociados del adsorbente Zo.

\begin{tabular}{|c|c|c|}
\hline Bandas & Número de Onda $\left(\mathbf{c m}^{-1}\right)$ & Grupos Asociados \\
1 & 3629 & OH stretching del grupo $\mathrm{Al}_{2} \mathrm{OH}$ o Al-Mg-OH \\
2 & 3417 & H-O-H Stretching del agua \\
a & 3022 & Stretching asimétrico del grupo metil $\left(-\mathrm{CH}_{3}\right)$ \\
b & 2923 & $\mathrm{CH}_{3}-\mathrm{N}$ Stretching simétrico de \\
c & 2850 & la cabeza trimetilamonio \\
3 & 1654 & C-H Stretching simétrico del grupo metileno $\left(=\mathrm{CH}_{2}\right)$ \\
d & 1469 & Bending del grupo H-O-H \\
4 & 1118 & C-H Scisoring del grupo metileno $\left(=\mathrm{CH}_{2}\right)$ \\
e & 1043 & Stretching longitudinal Si-O-Si \\
f & 912 & Interacción orgánico-superficie siloxano \\
7 & 879 & N-C Stretching asimétrico \\
8 & 798 & Stretching Al-Fe ${ }^{+3}-\mathrm{OH}$ \\
g & 725 & Stretching del cuarzo Si-O \\
9 & 522 & C-H Rocking del grupo metileno $\left(=\mathrm{CH}_{2}\right)$ \\
\hline
\end{tabular}


La Tabla 8.3.8, muestra las bandas infrarrojas características de la esmectita, identificadas con anterioridad, como las señales de absorción provenientes de la sal de amonio cuaternaria con la que se realizó la modificación orgánica de la bentonita natural.

La Figura 8.3.20, exhibe los resultados obtenidos de los ensayos por espectroscopia infrarroja del adsorbente orgánico So.

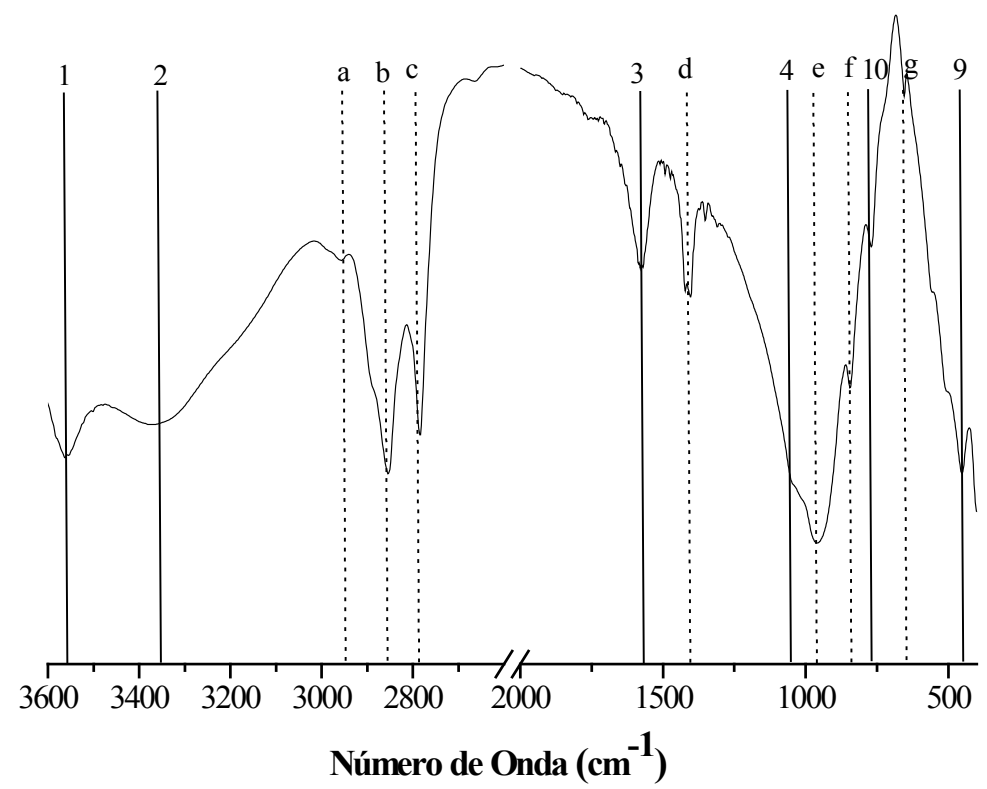

Figura 8.3.20. IR adsorbente So.

Las bandas infrarrojas características de las esmectitas, detectadas en la arcilla sin tratamiento $\mathrm{S}$, se mantienen, al igual que en $\mathrm{Zo}$; sumado a esto, la presencia de los grupos aportados por el tratamiento con la sal de amonio cuaternario se aprecia en la banda ubicada a $2960 \mathrm{~cm}^{-1}\left(\mathrm{CH}_{3}-\mathrm{N}\right.$ stretching simétrico de la cabeza del trimetil-amonio), como también las provenientes de los grupos alquilo a $3025 \mathrm{~cm}^{-1}$ stretching asimétrico del grupo metil, $2854 \mathrm{~cm}^{-1}$ (stretching asimétrico $\mathrm{C}-\mathrm{H}$ en el grupo $-\mathrm{CH}_{3}$ ), $1411 \mathrm{~cm}^{-1}$ (scisoring del $\left.=\mathrm{CH}_{2}\right)$ y $651 \mathrm{~cm}^{-1}$ (C-H rocking); y la vibración a $844 \mathrm{~cm}^{-1}$ (N-C stretching asimétrico). Además, al igual que en el caso de la organobentonita Zo, se forma una nueva banda infrarroja de la interacción superficie siloxano-orgánico a $958 \mathrm{~cm}^{-1}$ (Petit y col. 1998; Bodoardo y col. 1998; Witkowski y col. 2000; Madejová, 2003).

Las bandas detalladas en la Tabla 8.3.9, correspondientes a la organoarcilla So, presentan grupos arcillosos característicos, registrando además bandas de especies orgánicas pertenecientes al HDTMA . 
Tabla 8.3.9. Bandas de absorción y grupos asociados del adsorbente So

\begin{tabular}{|c|c|c|}
\hline Bandas & Número de Onda $\left(\mathbf{c m}^{-1}\right)$ & Grupos Asociados \\
1 & 3566 & OH \\
2 & 3369 & stretching del grupo $\mathrm{Al}_{2} \mathrm{OH}$ o Al-Mg-OH \\
a & 3025 & H-O-H Stretching del agua \\
b & 2960 & Stretching asimétrico del grupo metil $\left(-\mathrm{CH}_{3}\right)$ \\
c & 2854 & $\mathrm{CH}_{3}-\mathrm{N}$ Stretching simétrico de \\
3 & 1575 & la cabeza trimetilamonio \\
$\mathrm{d}$ & 1411 & C-H Stretching simétrico del grupo metileno $\left(=\mathrm{CH}_{2}\right)$ \\
4 & 1049 & Bending del grupo H-O-H \\
e & 958 & C-H Scisoring del grupo $=\mathrm{CH}$ \\
f & 844 & Interacción orgánico-superficie siloxano \\
10 & 769 & Bending Al-OH \\
g & 651 & N-C vibración stretching asimétrico \\
9 & 470 & Bending Al-Mg-OH \\
\hline
\end{tabular}

Es evidente la disminución de las señales propias del agua fisiadsorbida, aproximadamente $3431 \mathrm{~cm}^{-1}$ y $1629 \mathrm{~cm}^{-1}$ en $\mathrm{Z}$ y $3458 \mathrm{~cm}^{-1}$ y $1660 \mathrm{~cm}^{-1}$ en $\mathrm{S}$, debido a la modificación con HDTMA ${ }^{+}$, (Boboardo y col. 1998). En concordancia con lo observado en los ensayos térmicos, la ausencia de las señales del agua en las estructuras arcillosas orgánicas (Zo y So), es atribuible a un cambio en la superficie hidrofílica de los minerales arcillosos a hidrofóbica, por el reemplazo de los cationes inorgánicos originales entre las láminas, por la presencia de cationes alquilo y/o arilo organocationes (Madejová, 2003).

\subsubsection{Análisis Potencial Zeta}

La Tabla 8.3.10 presenta los valores de potencial zeta obtenidos para las bentonitas naturales y organobentonitas preparadas. Los mismos corresponden a valores de $\mathrm{pH}$ 5-6 de las muestras en suspensión debido a que fue el rango de $\mathrm{pH}$ en que se encontraba cada una de las muestras al momento del contacto con cada uno de los colorantes (Y, R, O). Los valores iniciales de potencial zeta de las bentonitas naturales $\mathrm{Z}$ y $\mathrm{S}$ fueron -20 y -28 , relacionados de alguna manera a cargas superficiales. El tratamiento con el catión 
$\mathrm{HDTMA}^{+}$en una vez la capacidad de intercambio catiónico (CIC) de cada una de ellas, originó un cambio de cargas superficiales hacia valores positivos de $+26 \mathrm{y}+10$ para las Zo y So, respectivamente. Estas cargas positivas podrían ser mayores si el agregado de $\mathrm{HDTMA}^{+}$superara el número de veces de la CIC

Tabla 8.3.10. Potencial zeta de los adsorbentes naturales (S y Z) y orgánicos (So y Zo).

\begin{tabular}{c|c}
\hline Adsorbente & $\begin{array}{c}\text { Potencial Zeta } \\
(\boldsymbol{m} \boldsymbol{V})\end{array}$ \\
\hline $\mathrm{Z}$ & -20 \\
\hline S & -28 \\
\hline Zo & +26 \\
\hline So & +10 \\
\hline
\end{tabular}

\subsubsection{Comparación de los adsorbentes}

La caracterización mineralógica por DRX de las arcillas utilizadas, $\mathrm{S}$ y Z, permitió determinar que se trata de bentonitas compuestas mayoritariamente de montmorillonita, como mineral arcilloso esmectítico. Por medio del ensayo de GreeneKelly pudo determinarse que la bentonita Z, además de montmorillonita se encuentra presente nontronita (o rica en hierro), otro tipo de esmectita que contiene hierro en su composición estructural. Referente a impurezas presentes, la $\mathrm{S}$ contiene bajo contenido de cuarzo, en tanto que la $\mathrm{Z}$ además posee feldespato y yeso.

El tratamiento con el catión orgánico $\mathrm{HDTMA}^{+}$en las bentonitas (So y Zo) solo modificó el espaciado interlaminar de la esmectita, llegando a valores de espaciados de 2,22 $\mathrm{nm}$ y 1,91 nm para la muestra So y Zo, respectivamente. Estos valores dan idea de la orientación del organocatión en el espaciado basal, ubicándose éste en forma casi perpendicular tipo parafina en So y en forma de pseudotrilamina en Zo.

El análisis por FRX corrobora la presencia de los elementos que conforman las fases minerales detectadas por DRX. El adsorbente $\mathrm{Z}$ posee un mayor contenido de $\mathrm{Fe}$ y $\mathrm{Na}$ que el determinado para $\mathrm{S}$. La presencia de Fe se relaciona con la naturaleza del tipo de esmectita que constituye la bentonita $\mathrm{Z}$ que, de acuerdo con los resultados de los ensayos de GK, existiría presencia de montmorillonita y nontronita (esta última responsable por el 
hierro presente). El contenido de $\mathrm{Mg}$ y $\mathrm{Ca}$ es superior en la bentonita $\mathrm{S}$, siendo el $\mathrm{Mg}$ el elemento presente en las montmorillonita, única fase arcillosa detectada por los diferentes ensayos DRX realizados sobre la muestra, y el Ca proveniente de la capa de intercambio de ésta misma esmectita.

Los análisis térmicos realizados a ambas bentonitas también han marcado diferencias entre ellas. Al comparar los ATD entre los adsorbentes Z y S, se distinguen dos picos entre $550^{\circ} \mathrm{C}-1000^{\circ} \mathrm{C}$ en la bentonita $\mathrm{Z}$, que indicarían la presencia de dos tipos de esmectitas (montmorillonita y nontronita/ó rica en hierro), en tanto que la existencia de un solo pico aproximadamente a $600^{\circ} \mathrm{C}$ en $\mathrm{S}$, condice con una montmorillonita. Así mismo, los contenidos de $\mathrm{MgO}$ y $\mathrm{Fe}_{2} \mathrm{O}_{3}$ determinados por $\mathrm{FRX}$, corroboran las especies citadas anteriormente y condicen con lo observado por DRX. En cuanto los ATD de las organobentonitas se diferencian de las originales principalmente por la aparición de picos exotérmicos en el rango de $300-800^{\circ} \mathrm{C}$ relacionado con la pérdida de carbono y agua del orgánico. Referente a las pérdidas de masa (TG) de las bentonitas originales se condicen con valores típicos de este tipo de mineral de arcilla, en tanto que las pérdidas correspondientes a las organobentonitas (Zo y So) se observó una reducción importante del agua interlaminar (eliminación de agua fisiadsorbida), indicando un importante y casi total carácter hidrofóbico. Además la reducción muy importante de masa, a temperaturas de inicio a partir de $\operatorname{los} 300^{\circ} \mathrm{C}$ que es atribuida a la descomposición del orgánico incorporado.

Los análisis por IR mostraron bandas características de esmectitas tipo montmorillonita en ambas bentonitas. La muestra $\mathrm{Z}$ presentó además, una banda de absorción correspondiente al grupo $\mathrm{Al}-\mathrm{Fe}^{+3}-\mathrm{OH}$ atribuida en parte a la presencia de posible nontronita (o mineral arcilloso rico en hierro) que también la compone, con presencia de un banda de cuarzo proveniente de la impureza de la roca. El tratamiento de intercambio con el catión orgánico puso de manifiesto, en ambas organobentonitas, una reducción de las bandas asociadas a la presencia de agua. Se observaron, además, bandas relacionadas al catión $\mathrm{HDTMA}^{+}$, de los grupos $=\mathrm{CH}_{2}, \mathrm{~N}-\mathrm{C}$ y $\mathrm{CH}_{3}-\mathrm{N}$, y una nueva banda resultante de la interacción orgánico superficie siloxano.

El análisis del potencial zeta permitió corroborar, para ambas bentonitas, que el tratamiento con el catión orgánico $\mathrm{HDTMA}^{+}$, modifica la carga de las mismas de negativa 
(S y Z) a positiva (So y Zo), que haría posible y/o favorecería la adsorción de los colorantes aniónicos (Y, O y R). 


\subsection{Ensayos de adsorción}

En el presente ítem se exponen las experiencias de los resultados observados luego de la realización de los ensayos de adsorción con los tintes $\mathrm{R}, \mathrm{O}$ e $\mathrm{Y}$, sobre las bentonitas naturales ( $\mathrm{S} \mathrm{y} \mathrm{Z}$ ) y las bentonitas modificadas con la sal de amonio cuaternaria (So y Zo).

\subsubsection{Retención sobre arcillas naturales}

Para conocer la capacidad natural de las bentonitas en estudio, S y Z, se efectuaron ensayos de adsorción de los colorantes $\mathrm{Y}, \mathrm{O}$ y R en solución en concentración $125 \mathrm{mg} . \mathrm{L}^{-1}$ con cantidades de sólidos en el rango de $1-5 \mathrm{~g} . \mathrm{L}^{-1}$.

Las Figuras 8.4.1-8.4.6 presentan los resultados obtenidos por medio de espectrometría UV-visible, de las soluciones sobrenadantes resultantes de los ensayos con las bentonitas sin tratamiento, $\mathrm{S}$ y Z, contactadas con las diferentes soluciones coloreadas (R, O, e Y).

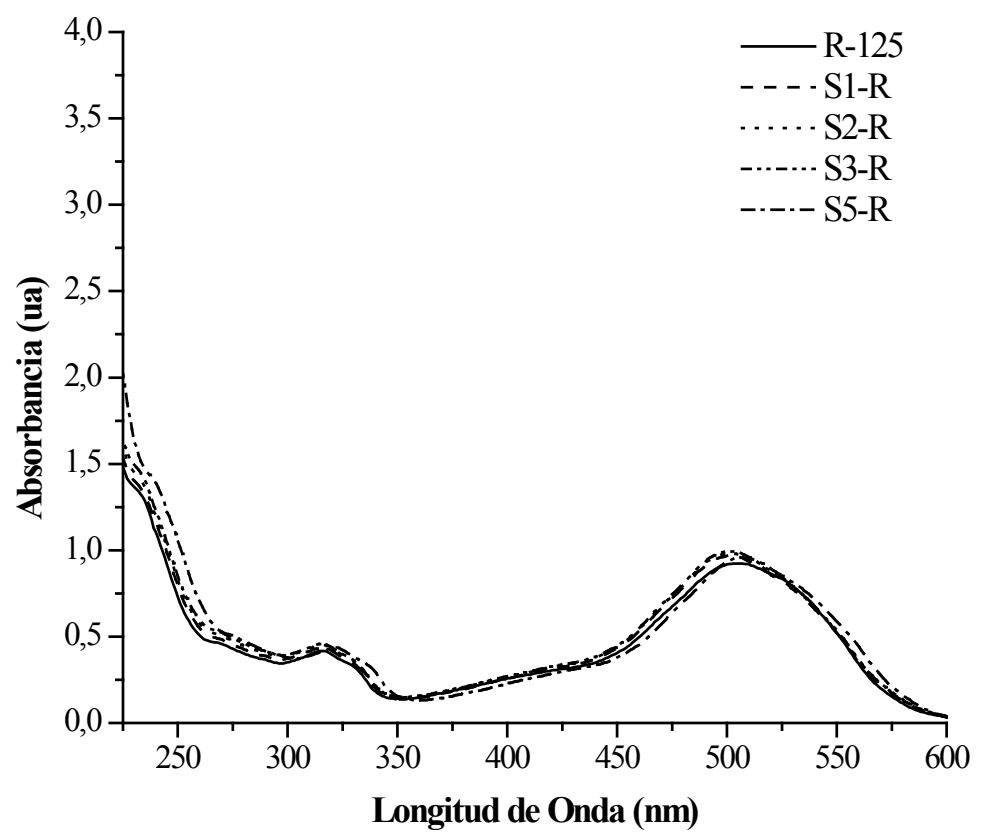

Figura 8.4.1. Ensayos UV-vis de las soluciones sobrenadantes resultantes de los ensayos sobre el adsorbente natural $\mathrm{S}$ y el tinte $\mathrm{R}$. 


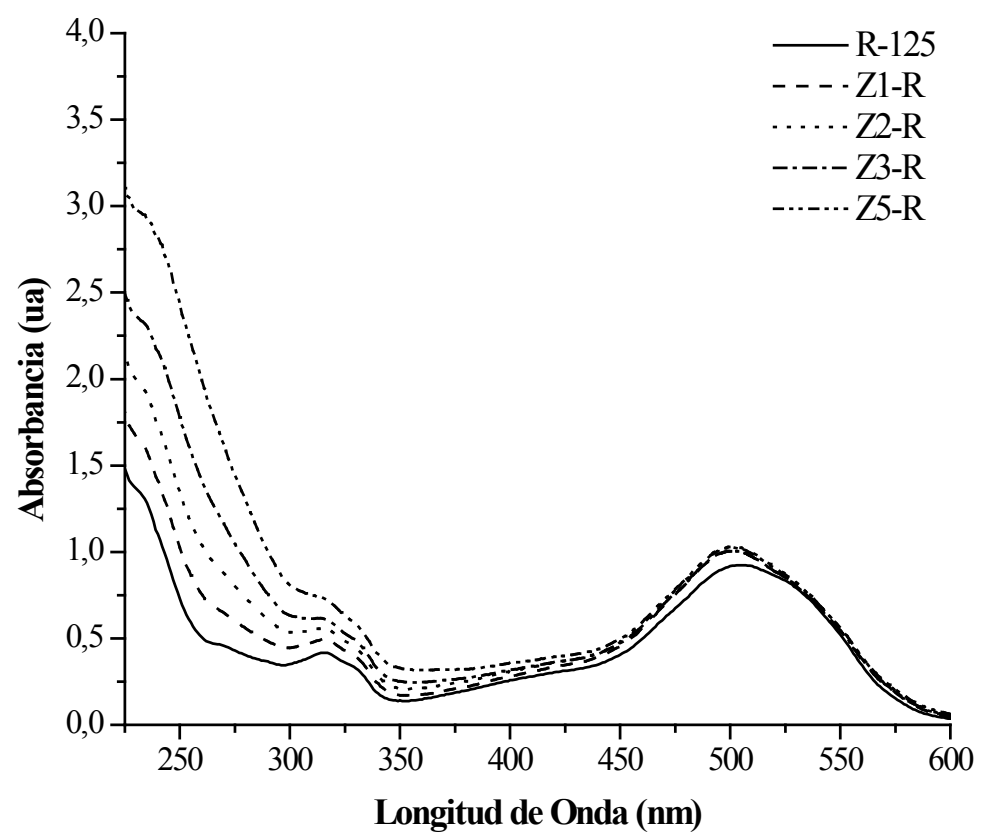

Figura 8.4.2. Ensayos UV-vis de las soluciones sobrenadantes resultantes de los ensayos sobre el adsorbente natural $\mathrm{Z}$ y el tinte $\mathrm{R}$.

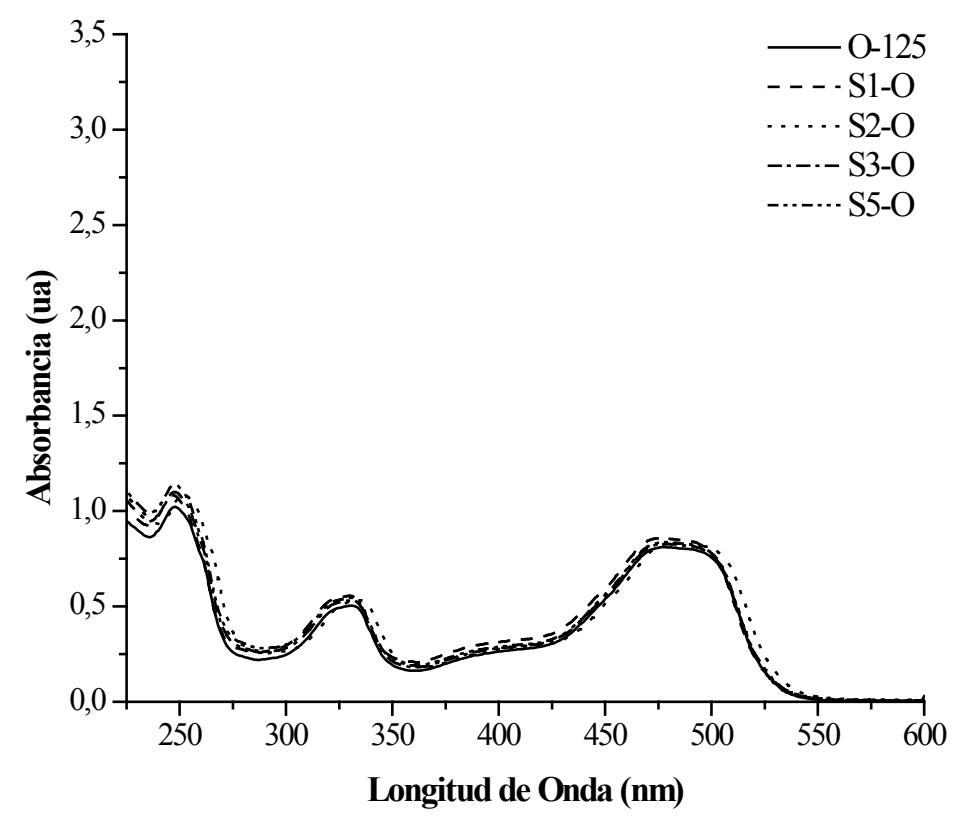

Figura 8.4.3. Ensayos UV-vis de las soluciones sobrenadantes resultantes de los ensayos sobre el adsorbente natural S y el tinte $\mathrm{O}$. 


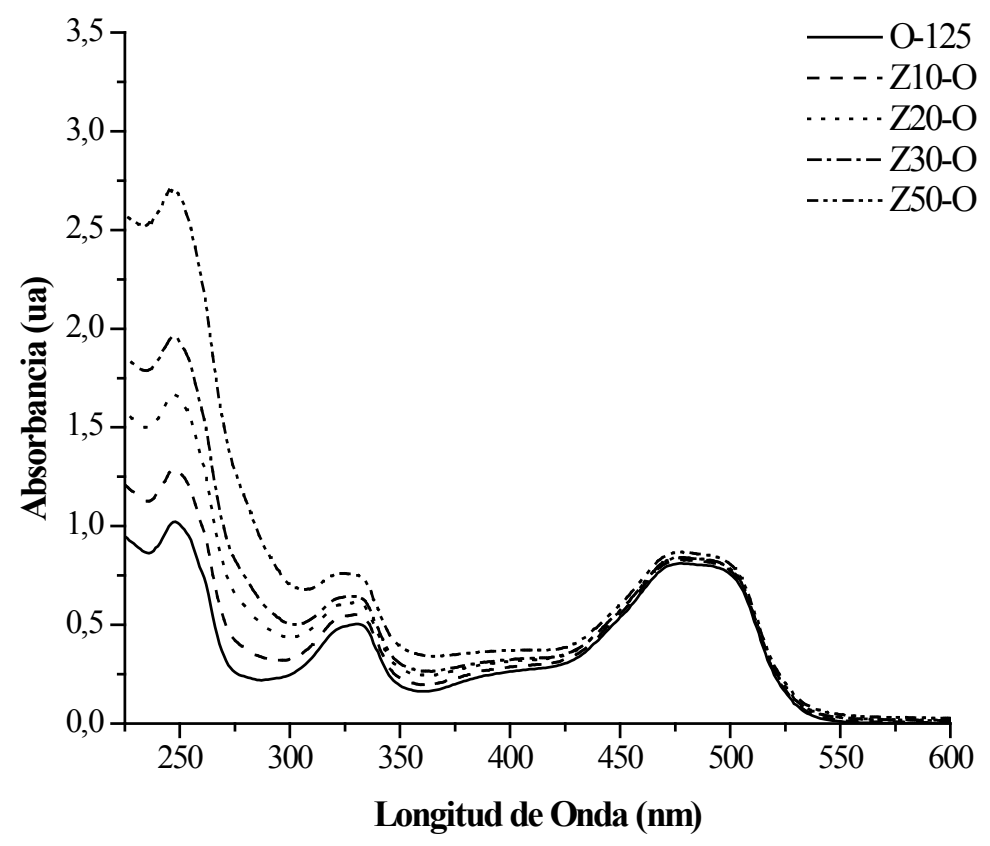

Figura 8.4.4. Ensayos UV-vis de las soluciones sobrenadantes resultantes de los ensayos sobre el adsorbente natural $\mathrm{Z}$ y el tinte $\mathrm{O}$.

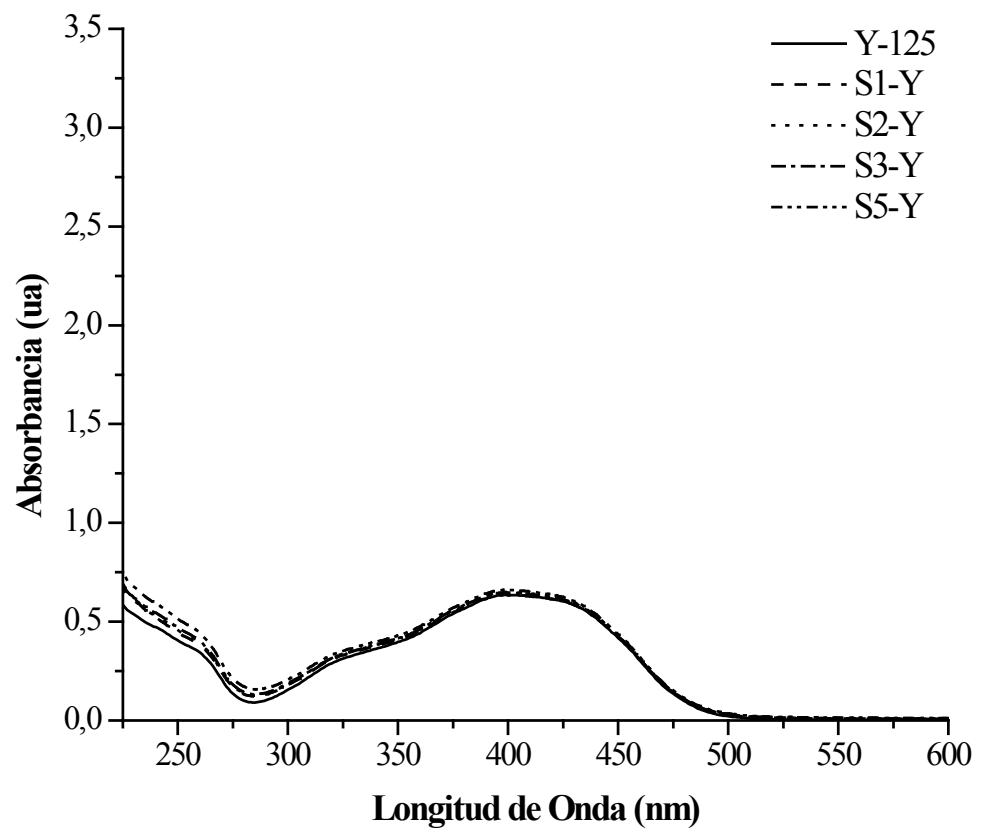

Figura 8.4.5. Ensayos UV-vis de las soluciones sobrenadantes resultantes de los ensayos sobre el adsorbente natural $\mathrm{S}$ y el tinte $\mathrm{Y}$. 


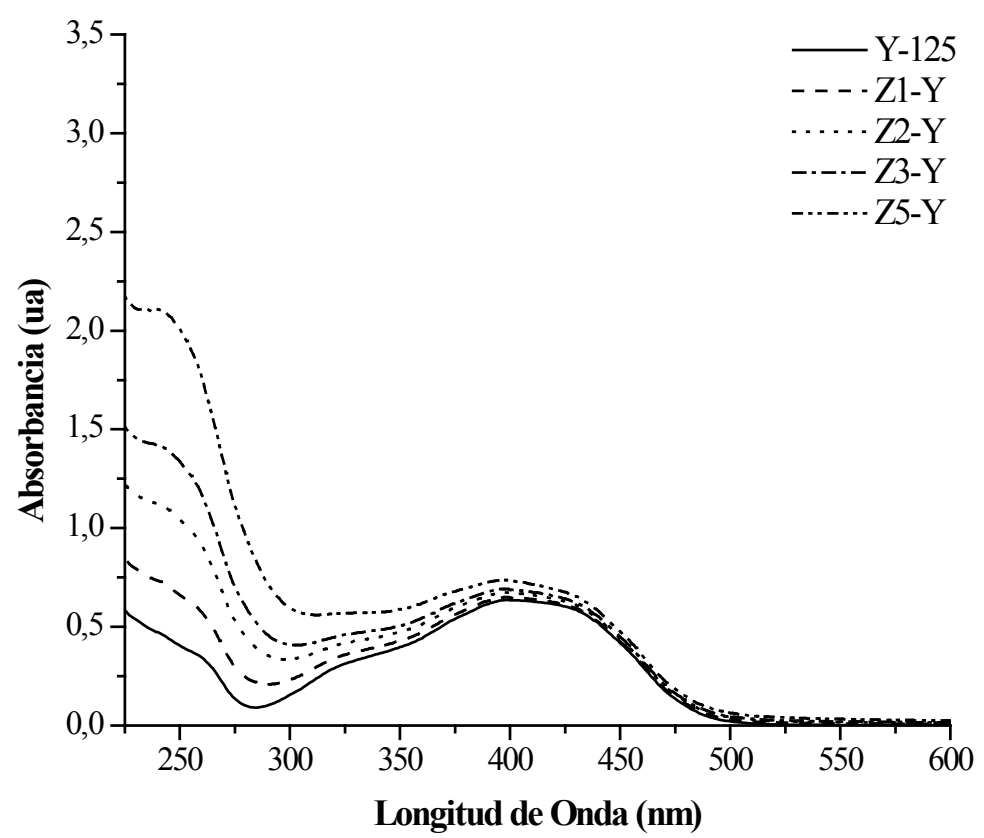

Figura 8.4.6. Ensayos UV-vis de las soluciones sobrenadantes resultantes de los ensayos sobre el adsorbente natural $\mathrm{Z}$ y el tinte $\mathrm{Y}$.

Es posible observar que para los sobrenadantes obtenidos en los ensayos de retención de la totalidad de los colorantes en contacto con la arcilla $\mathrm{S}$, las bandas no presentan una variación significativa respecto de la solución primitiva; sin embargo, en las figuras en las que se presentan las experiencias sobre la arcilla $\mathrm{Z}$ y los distintos tintes, se aprecia una dispersión de las bandas de los sobrenadantes, éste efecto aumenta a medida que aumenta la cantidad de adsorbente y con la reducción de longitud de onda (es decir hasta el UV). Por tal motivo se diseñaron ensayos de "blancos", es decir suspensiones centrifugadas de sistema bentonita y agua, sin el tinte, para evaluar posible influencia del solido disperso en el espectro de UV-visible, como se detalla en el siguiente punto. De todas maneras en ninguno de los casos se observó una retención de las soluciones $\mathrm{Y}, \mathrm{O}$ y R, lo que corrobora la dificultad que estas bentonitas en su estado natural puedan retener los colorantes aniónicos orgánicos, estudiados en la presente tesis. 


\subsubsection{Análisis por UV-visible de suspensiones centrifugadas de sistema agua-}

\section{bentonita}

Es sabido que la turbidez afecta el uso de la técnica de UV-visible, principalmente en la zona del UV. En el punto anterior se observó posible interferencia atribuida a la presencia de partículas tipo coloides en el sistema. Teniendo en cuenta que las esmectitas en ciertas circunstancias de dispersión tienen comportamiento coloidal, es que se pensó realizar este ensayo.

Las bentonitas naturales, $\mathrm{S}$ y Z, individualmente, fueron contactadas durante $24 \mathrm{~h}$ y en agitación con agua destilada en una relación $5 \mathrm{~g} . \mathrm{L}^{-1}$. Posteriormente, fueron centrifugadas y los sobrenadantes identificados como S24h y Z24h.

La Figura 8.4.7, muestra los tubos de ensayos centrifugados, con el sólido y la solución sobrenadante, en ésta se aprecia una mayor opalescencia en los ensayos efectuados con el adsorbente $\mathrm{Z}$.
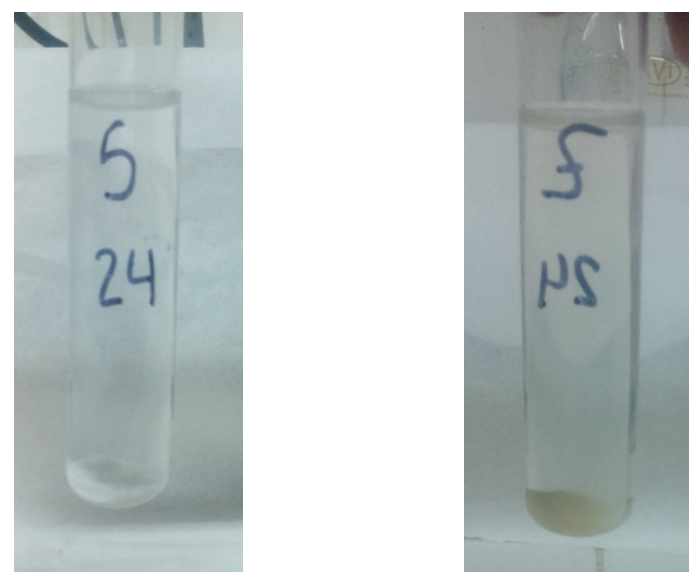

Figura 8.4.7. Finalización de ensayos S24h y Z24h.

Las Figuras 8.4.8 y 8.4.9 presentan los resultados obtenidos luego de realizar el análisis por medio del espectrómetro UV-visible.

Existe una diferencia significativa entre los espectros UV de las Figuras anteriores. En el caso de la bentonita S24h, la línea base es aproximadamente seis veces menor que para el caso de la Z24h, correspondiéndose esto, en parte, con lo observado en la Figura 8.4.7. En adición, en la muestra Z24h se aprecia un aumento en la absorbancia a una longitud de onda menor, aproximadamente a 209nm. Éste efecto óptico en los ensayos UV 
de la muestra $\mathrm{Z}$ se condice con el efecto de un coloide observado por Karickhoff y Bailey (1973). Los autores estudiaron éste fenómeno óptico en los espectros UV-visible de minerales arcillosos. En su trabajo reconocieron transiciones en el UV que revelan la presencia de sitios de sustitución y estados de valencia del hierro en la red. Es así que es posible decir que en el caso de la bentonita Z24h, el aumento de la dispersión que incrementa la absorbancia y la pérdida de la resolución espectral se condice con la transferencia de cargas oxo-Fe(III) octaédrico, de acuerdo a los autores mencionados anteriormente.

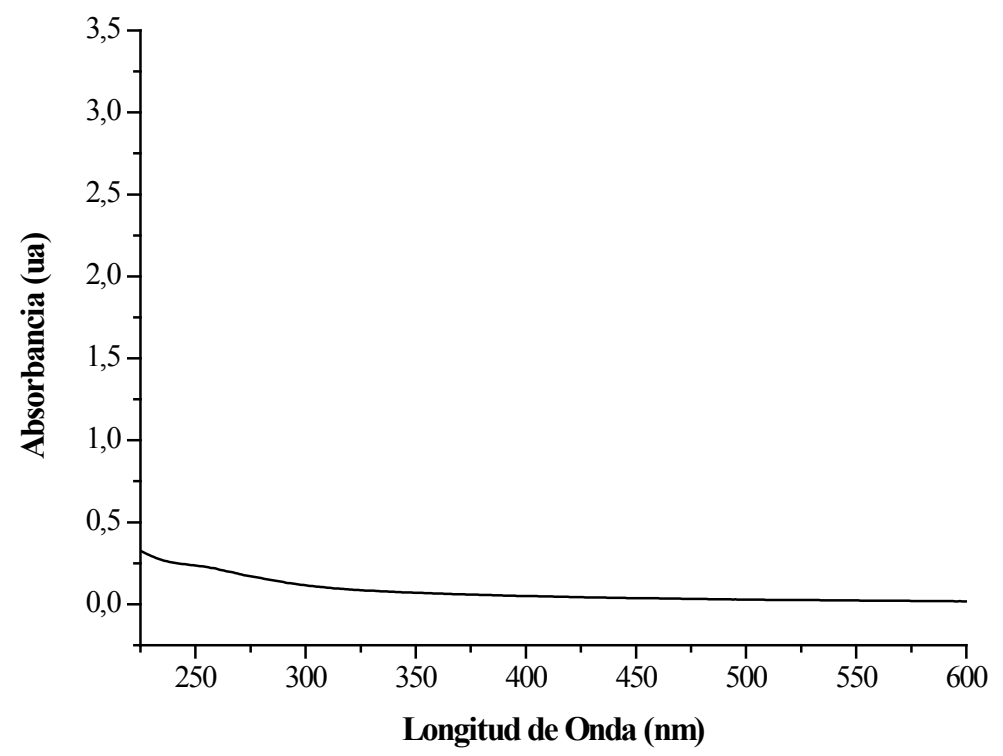

Figura 8.4.8. Análisis UV-vis de los sobrenadantes del sistema bentonita/agua S24h.

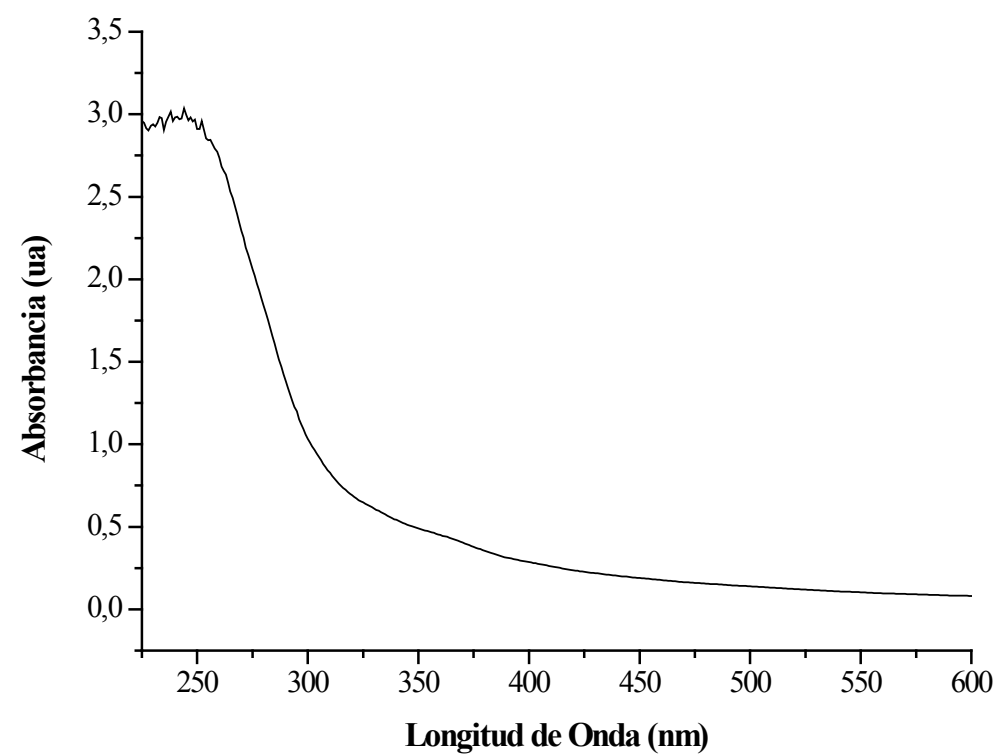

Figura 8.4.9. Análisis UV-vis del sobrenadante del sistema bentonita/agua Z24h. 
En los resultados UV del sistema la bentonita $\mathrm{S}$ /agua, no se aprecian valores de absorbancia elevados a bajas longitudes de onda, observándose un leve aumento de la absorbancia a longitudes de onda cercanas a $200 \mathrm{~nm}$, esto indicaría un bajo contenido de hierro en la red; lo que concuerda con los análisis químicos de ambas bentonitas. 


\subsubsection{Retención sobre organoarcillas}

La cuantificación de los colorantes se realizó utilizando las bandas de los grupos cromóforos constituyentes, a longitudes de onda de $247 \mathrm{~nm}$ para el cromóforo bencénico de O; 316nm y 330nm para el naftaleno de R y O respectivamente; y 400nm, 478nm y 500nm para el grupo azoico de Y, R y O, respectivamente. En el caso de los espectros de UVvisible de los colorantes luego del contacto con las organobentonitas se observó un comportamiento diferente a los correspondientes ensayos con las bentonitas naturales.

Previo a la presentación de las isotermas propiamente dichas, las Figuras 8.4.10 a 8.4.15 muestran los espectros de las soluciones sobrenadantes obtenidas luego del contacto con las organobentonitas (So y Zo) con cada colorante (R, O, Y), y cada uno de los colorantes en concentración de $125 \mathrm{mg} . \mathrm{L}^{-1}$. En estos casos sólo se grafican los correspondientes a los ensayos de agregado de adsorbente por volumen de solución coloreada de 0,4 g. $\mathrm{L}^{-1}$ y 2 g. $\mathrm{L}^{-1}$, para observar un comportamiento general.

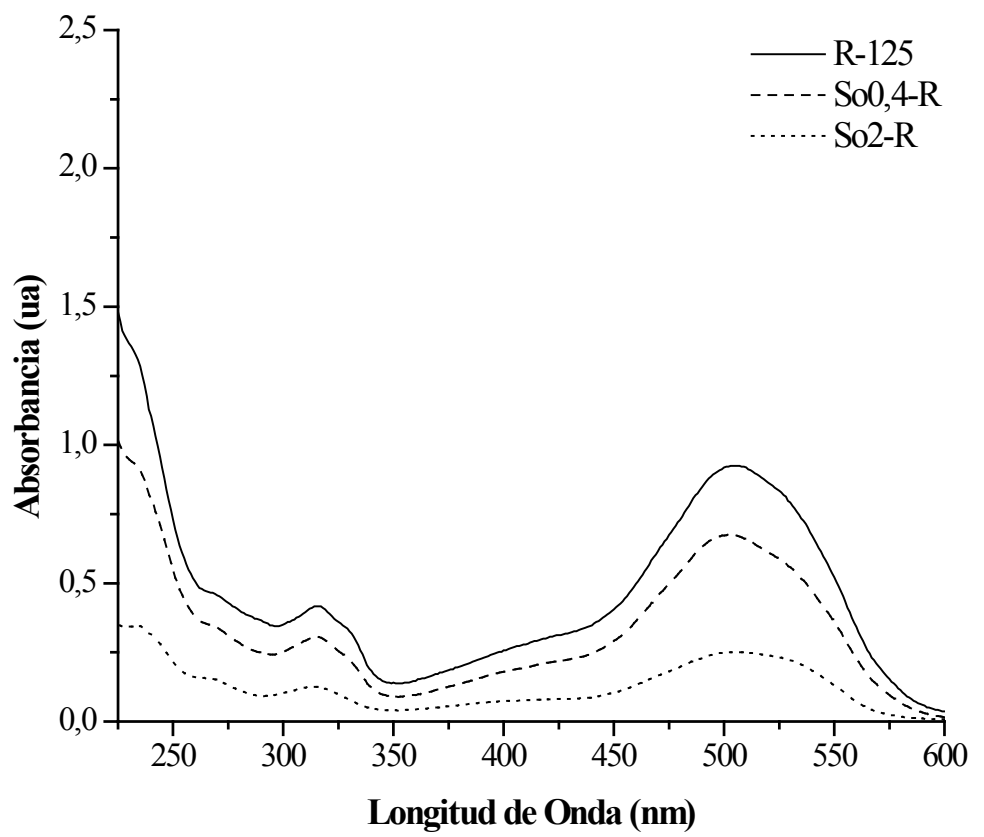

Figura 8.4.10. Ensayos UV-vis de las soluciones sobrenadantes resultantes de los ensayos sobre el adsorbente So y el tinte R.

En todos los casos se aprecia una reducción importante en los valores de absorbancia de las bandas que pertenecen a los diferentes colorantes, indicando que las organobentonitas son eficientes para la remoción de los mismos. Además puede observarse 
que el agregado de organobentonita no afecta, el valor de la absorbancia a bajas longitudes de onda, como ocurría con las bentonitas originales. A continuación de este análisis preliminar, se realizará detalladamente el estudio de la adsorción de los tres colorantes seleccionados para las organobentonitas.

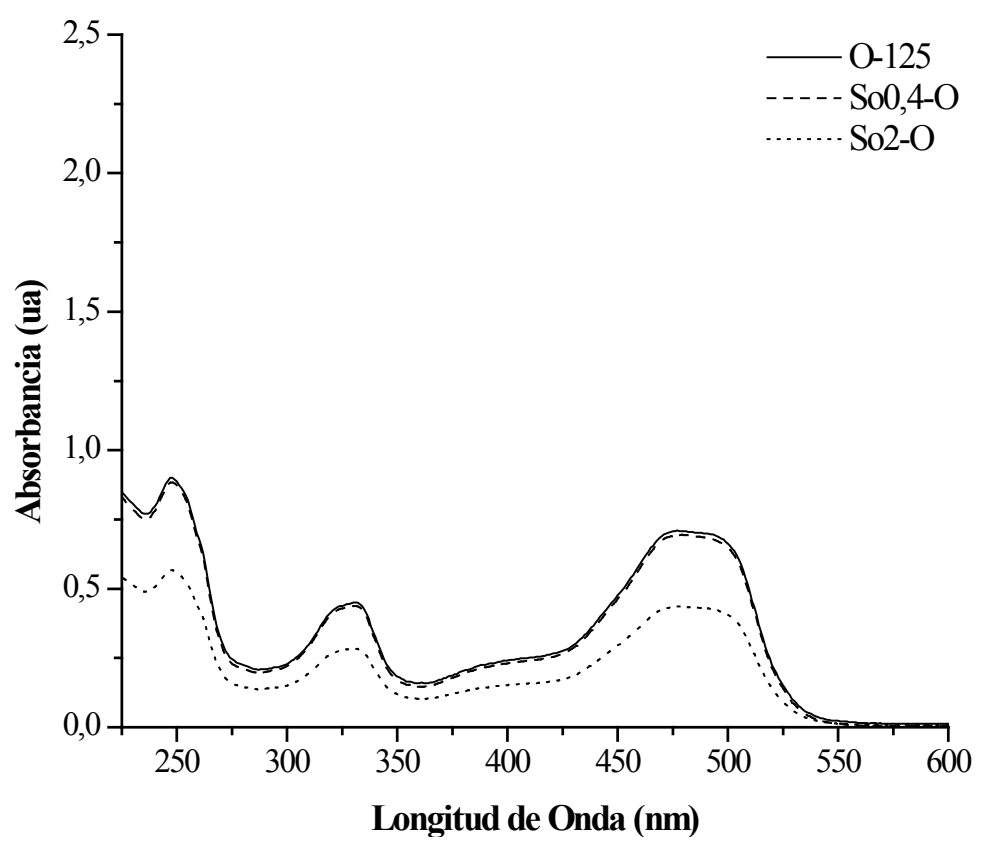

Figura 8.4.11. Ensayos UV-vis de las soluciones sobrenadantes resultantes de los ensayos sobre el adsorbente So y el tinte $\mathrm{O}$.

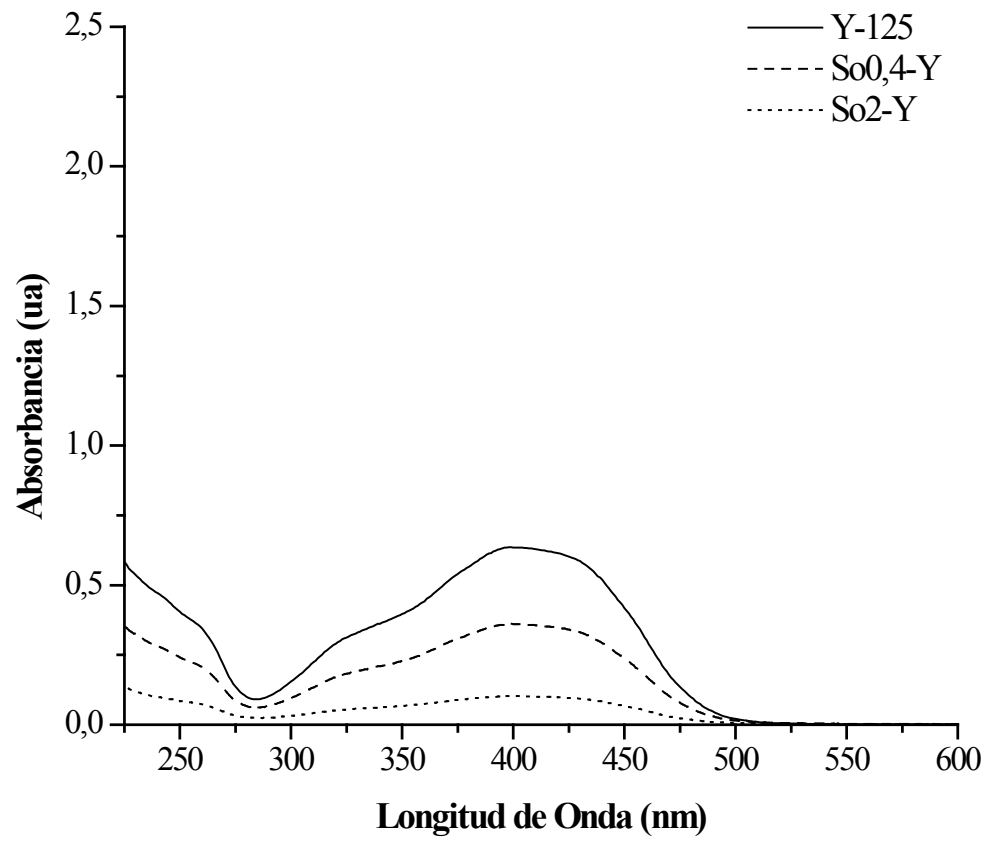

Figura 8.4.12. Ensayos UV-vis de las soluciones sobrenadantes resultantes de los ensayos sobre el adsorbente So y el tinte Y. 


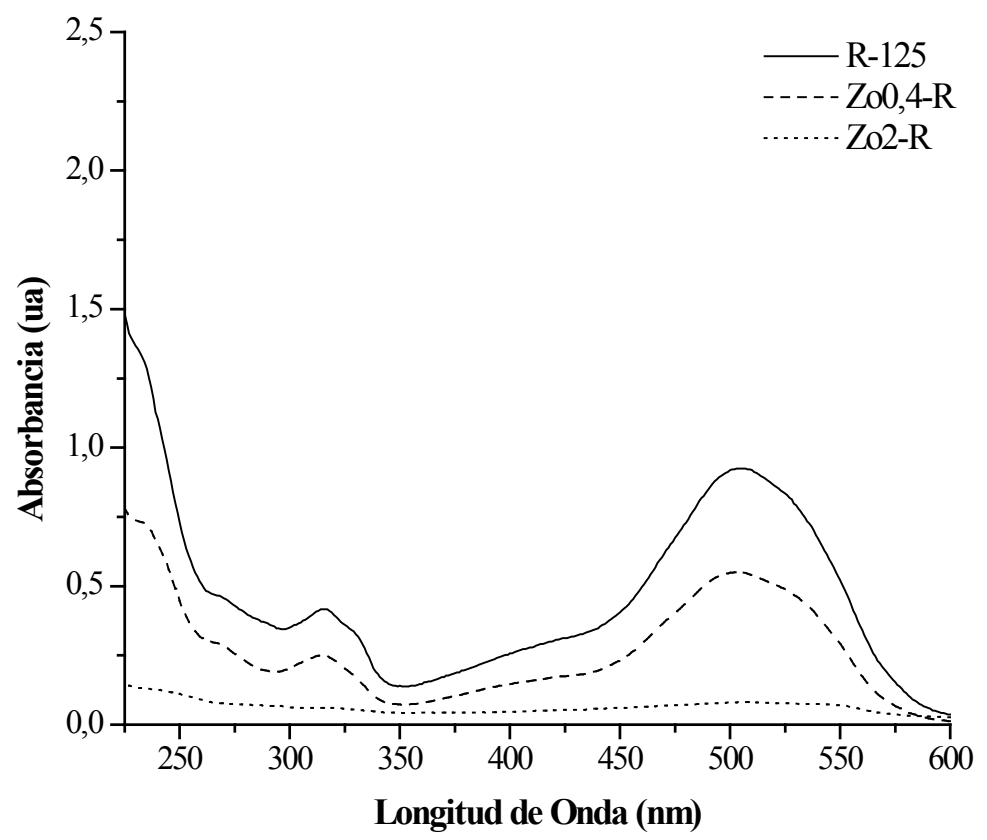

Figura 8.4.13. Ensayos UV-vis de las soluciones sobrenadantes resultantes de los ensayos sobre el adsorbente Zo y el tinte R.

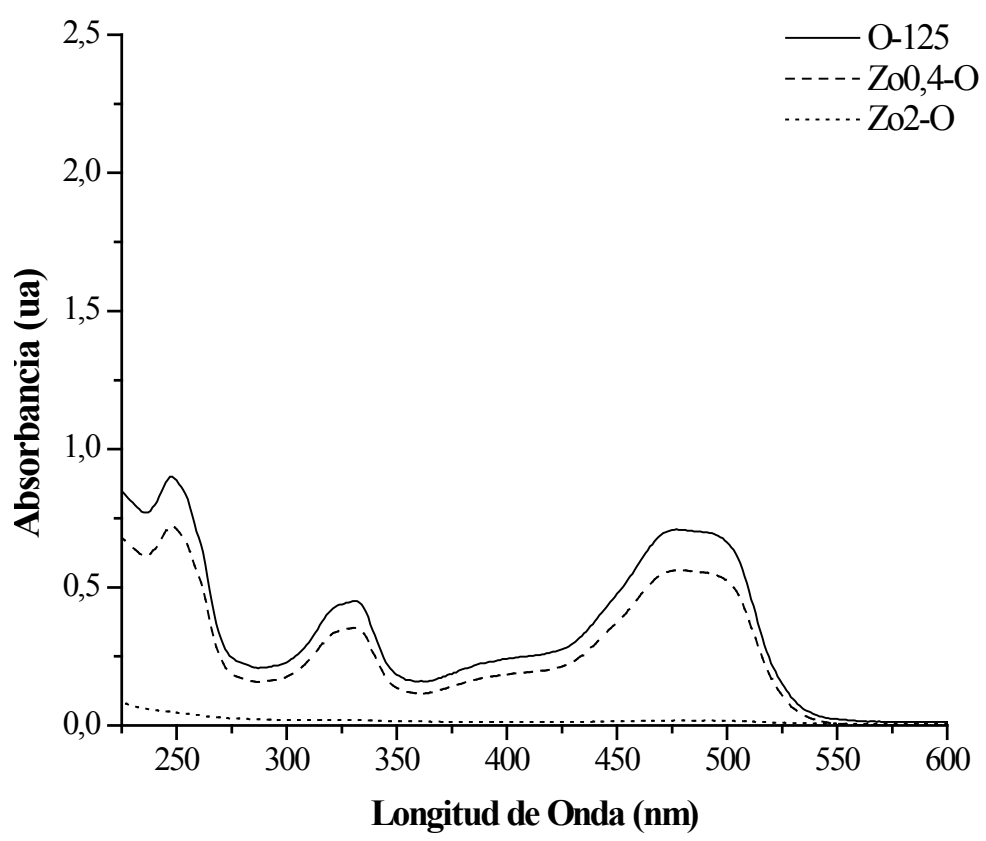

Figura 8.4.14. Ensayos UV-vis de las soluciones sobrenadantes resultantes de los ensayos sobre el adsorbente Zo y el tinte $\mathrm{O}$. 


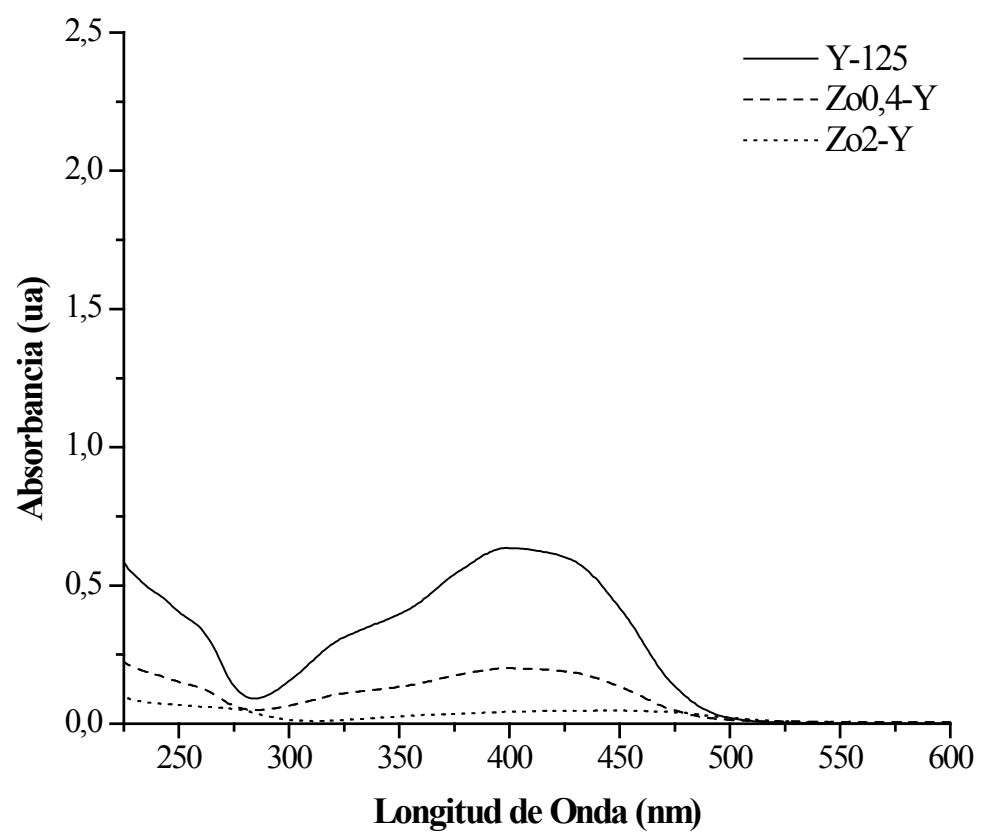

Figura 8.4.15. Ensayos UV-vis de las soluciones sobrenadantes resultantes de los ensayos sobre el adsorbente Zo y el tinte $Y$.

\subsubsection{Análisis de la cantidad agregada del adsorbente por volumen de colorante} vs retención de colorante

Para interpretar visual y sencillamente los resultados obtenidos, se realizaron gráficos de la relación sólido/líquido $\left(\mathrm{g} . \mathrm{L}^{-1}\right)$ versus el valor de retención de los diferentes tintes $(\%)$.

Con el objetivo de reconocer la existencia o no, de una afinidad diferente entre la superficie de los adsorbentes y la estructura química de los colorantes, los gráficos fueron confeccionados de acuerdo con los diferentes grupos cromóforos (azo, naftaleno y/o benceno) que constituyen la molécula de cada colorante.

En los adsorbentes naturales $\mathrm{S}$ y $\mathrm{Z}$, no fue posible retener los diferentes cromóforos constituyentes de las estructuras de los tintes R, O e Y (Ver 8.4.1 "Retención sobre arcillas naturales"); lo que era de esperar, debido a que las arcillas son naturalmente organofóbicas. Es por lo expuesto que a continuación solo se presentan los gráficos de retención de los colorantes orgánicos sobre las organoarcillas So y Zo. 


\subsection{Red Allura AC}

Para los ensayos de adsorción realizados con el adsorbente So y el colorante R, se confeccionó un gráfico para el grupo cromóforo azo $(500 \mathrm{~nm})$ y el grupo naftaleno $(316 \mathrm{~nm})$, el que se observa en la Figura 8.4.16.

Los valores de retenciones alcanzados para los grupos naftaleno (316nm) y azo (500nm) del colorante $\mathrm{R}$ fueron semejantes, con valores de 99\%. A una relación de sólido/solución tinte agregada de 2 g. $\mathrm{L}^{-1}$, la muestra So-R retuvo el 66,4\% de naftaleno y $70,2 \%$ de cromóforo azo, evidenciando una afinidad sutilmente mayor, del adsorbente So, por éste último grupo.

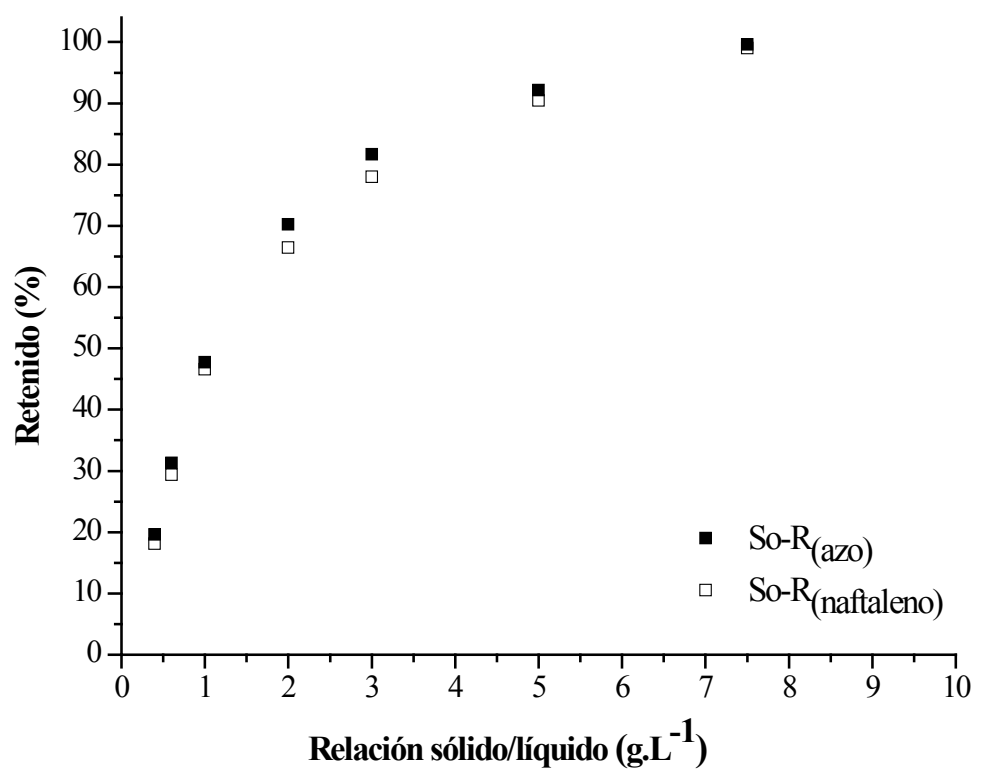

Figura 8.4.16. Ensayos de retención So- $\mathrm{R}_{(\mathrm{azo})} \mathrm{y}$ So- $\mathrm{R}_{(\text {naftaleno). }}$

Para el caso del adsorbente Zo, las retenciones de los grupos cromóforos azo y naftaleno del colorante R, también fueron semejantes, alcanzando valores del 98\%, Figura 8.4.17. Sin embargo para agregados de 2 g. $\mathrm{L}^{-1}$, los porcentajes de retención de ambos cromóforos fueron muy superiores (92\%) a los del adsorbente So (aprox. 70\%) (Figura 8.4.16), observado por la pendiente en la curva inicial, mostrando así una mayor afinidad del sustrato Zo. 


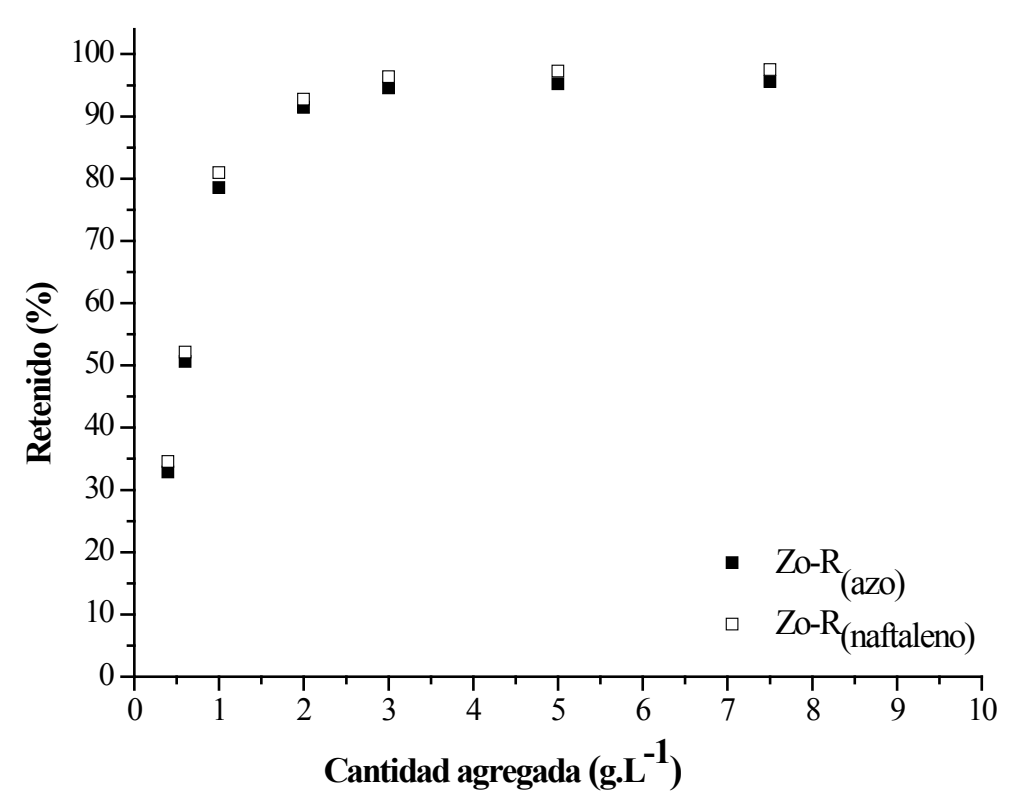

Figura 8.4.17. Ensayos de retención $Z o-R_{(a z o)}$ y Zo- $R_{(\text {naftaleno). }}$

\subsection{Orange $G$}

En los ensayos de adsorción realizados con el adsorbente So y Zo, reteniendo el colorante O, se confeccionaron los gráficos exhibidos en la Figura 8.4.18 y Figura 8.4.19

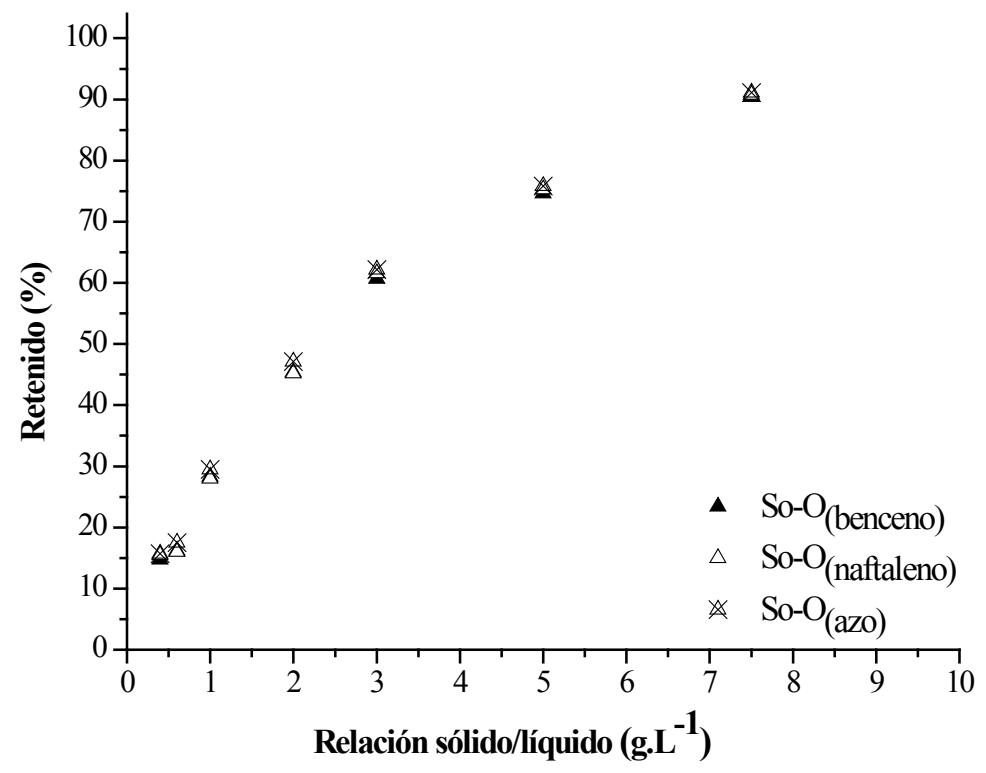

Figura 8.4.18. Ensayos de retención So- $\mathrm{O}_{(\text {azo })}$, So- $\mathrm{O}_{(\text {naftaleno) }}$ y So- $\mathrm{O}_{(\text {benceno) }}$. 
Para el adsorbente So, Figura 8.4.18, se observa la retención del grupo cromóforo azo $(478 \mathrm{~nm})$, el naftaleno $(330 \mathrm{~nm})$ y por último para el grupo bencénico $(247 \mathrm{~nm})$. Los valores porcentuales en las retenciones de los distintos grupos cromóforos sobre el adsorbente So (ver Figura 8.4.18), alcanzaron valores de 91,1\% para azo, 90,7\% para el naftaleno y 90,4\% para el benceno. Por lo tanto la tendencia a la adsorción para cada grupo encargado de impartir color fue azo $>$ naftaleno $\geq$ benceno.

Al igual que en los ensayos descriptos anteriormente, si fijamos la relación sólido/líquido a 2 g.L $\mathrm{L}^{-1}$, se llegó a retenciones de los cromóforos en valores del orden de

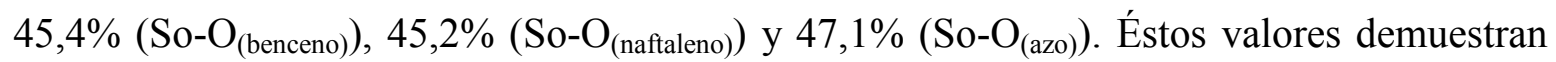
que la organobentonita So, posee una mayor afinidad por el grupo cromóforo azo, al igual que lo expuesto para el mismo adsorbente en la remoción del colorante R.

La tendencia de retención en la organobentonita Zo (ver Figura 8.4.19) por los diferentes grupos fue azo>naftaleno $\geq$ benceno, con valores de 99,9\%, 99,5\% y 99,2\% respectivamente. Similar orden de adsorción se observa a 2 g. $\mathrm{L}^{-1}$, que los porcentajes de

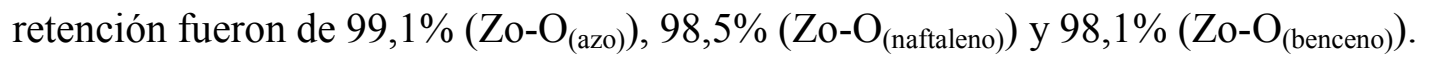

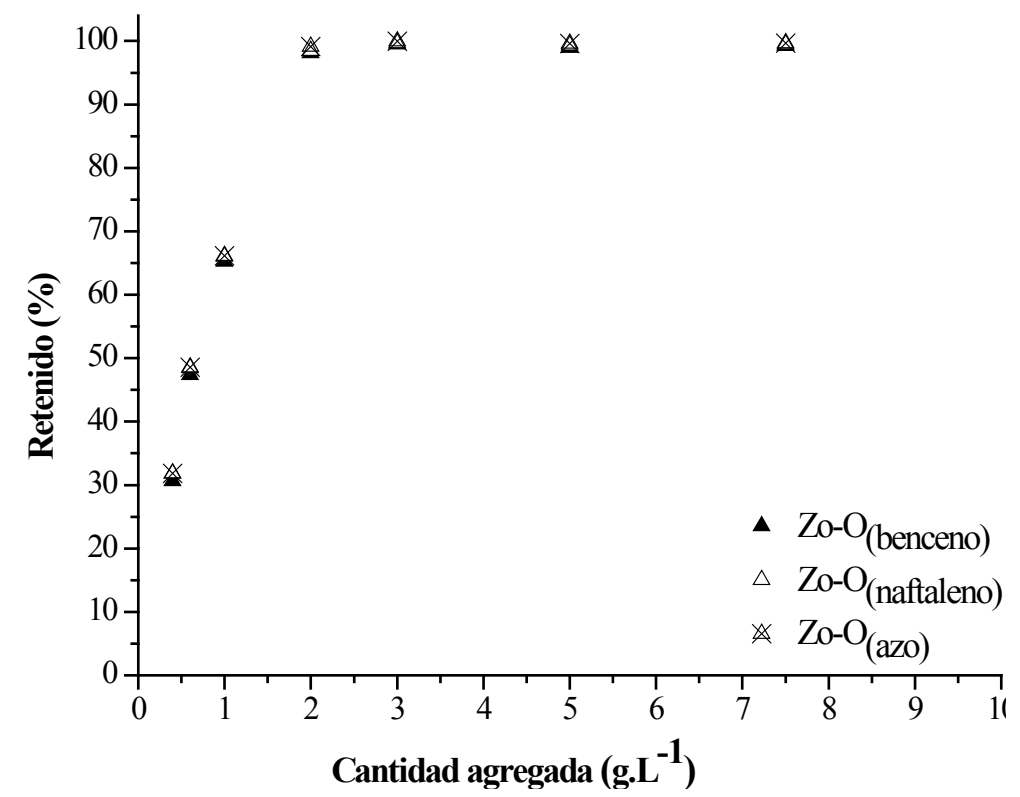

Figura 8.4.19. Ensayos de retención $\mathrm{Zo}-\mathrm{O}_{(\mathrm{azo})}, \mathrm{Zo}_{\mathrm{o}} \mathrm{O}_{(\text {naftaleno) }} \mathrm{y} \mathrm{Zo}-\mathrm{O}_{(\text {(benceno) }}$. 
Las pendientes iniciales en las curvas de las adsorciones de los tres grupos cromóforos para el sustrato So, son menores, lo que concuerda con los valores de 2 g.L $\mathrm{L}^{-1}$, las retenciones superaron el 98\% para los grupos azo, naftaleno y benceno en la organoarcilla Zo, y llegando a superar levemente el 45\% en So, para los tres cromóforos estudiados en el tinte $\mathrm{O}$.

\subsection{Yellow GR}

En la gráficas de retención del colorante $Y$, solo se cuantifico el grupo azo a $400 \mathrm{~nm}$ de longitud de onda, por ser ésta la única especie cromófora que posee la estructura molecular del tinte.

En la Figura 8.4.20, se observan los resultados de adsorción de los ensayos realizados con la organoarcilla So, los valores de retenciones alcanzaron 99,9\% a 400nm a 5 g. $\mathrm{L}^{-1}$.

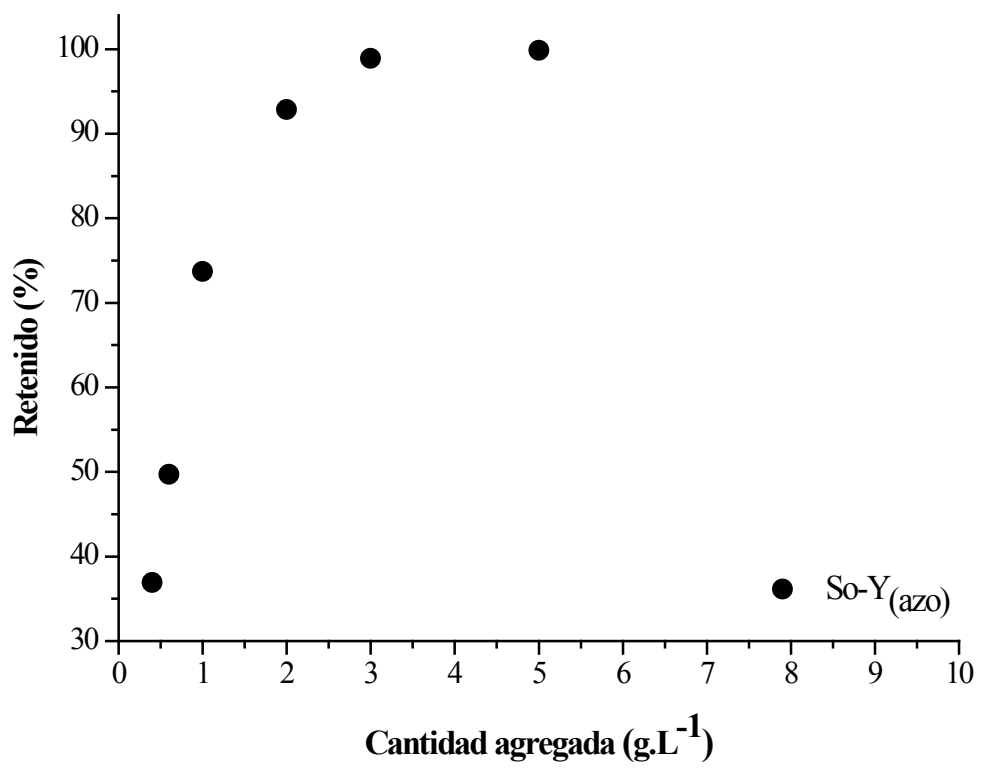

Figura 8.4.20. Ensayos de retención So- $Y_{(\text {azo })}$.

Para los adsorbentes Zo, Figura 8.4.21 de igual manera que en los tintes R y O, observamos el valor de retención a 2 g. $\mathrm{L}^{-1}$, los porcentajes en los valores de retención fueron $92,8 \%$ para el adsorbente So, y $96,8 \%$ para Zo. 
Comparando la Figura 8.4.20 y Figura 8.4.21, la pendiente inicial en los ensayos de adsorción de $\mathrm{Y}$ sobre So, es menor a la pendiente que se aprecia en los ensayos efectuados sobre la organobentonita Zo, lo que se condice con una mayor afinidad de éste último adsorbente (Zo) en referencia a So.

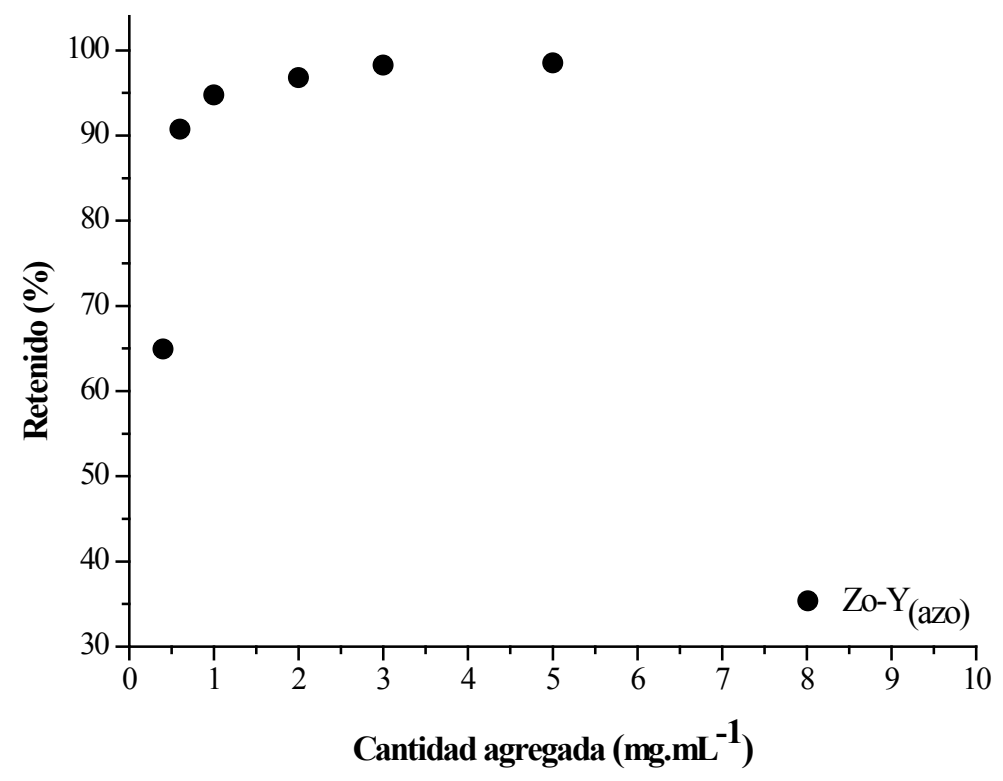

Figura 8.4.21. Ensayos de retención $\mathrm{Zo}-\mathrm{Y}_{(\text {azo })}$.

\subsection{Comparación de retenciones de los tres colorantes $R, O$ e Y por las} organobentonitas considerando cantidad agregada de sólido.

Concluida la interpretación en los gráficos de \% retenido para cada colorante, y si bien, al efectuar una comparación entre éstos, solo es posible relacionar la tendencia observada, se aprecia una mayor retención sobre la organoarcilla Zo en los tres colorantes, superando el $90 \%$ para agregados de 2 g. $\mathrm{L}^{-1}$.

La remoción del cromóforo azoico, grupo constituyente en los tres colorantes, sobre las organobentonitas So y Zo, observada en la Figura 8.4.22, muestra que para obtener adsorciones satisfactorias para cada uno de los colorantes Y, O y R, la cantidad que debe agregarse de Zo es menor que So, ratificando la mayor afinidad por el grupo azoico de los colorantes en estudio en la muestra Zo. También puede observarse que el grupo azo del Y es retenido "a mayor velocidad" por ambas organobentonitas que el mismo grupo azo 
presente en el tinte R y O. Esto podría atribuirse a que existen otros grupos, naftaleno (R y O) y benceno $(\mathrm{O})$, que compiten inicialmente a la retención.

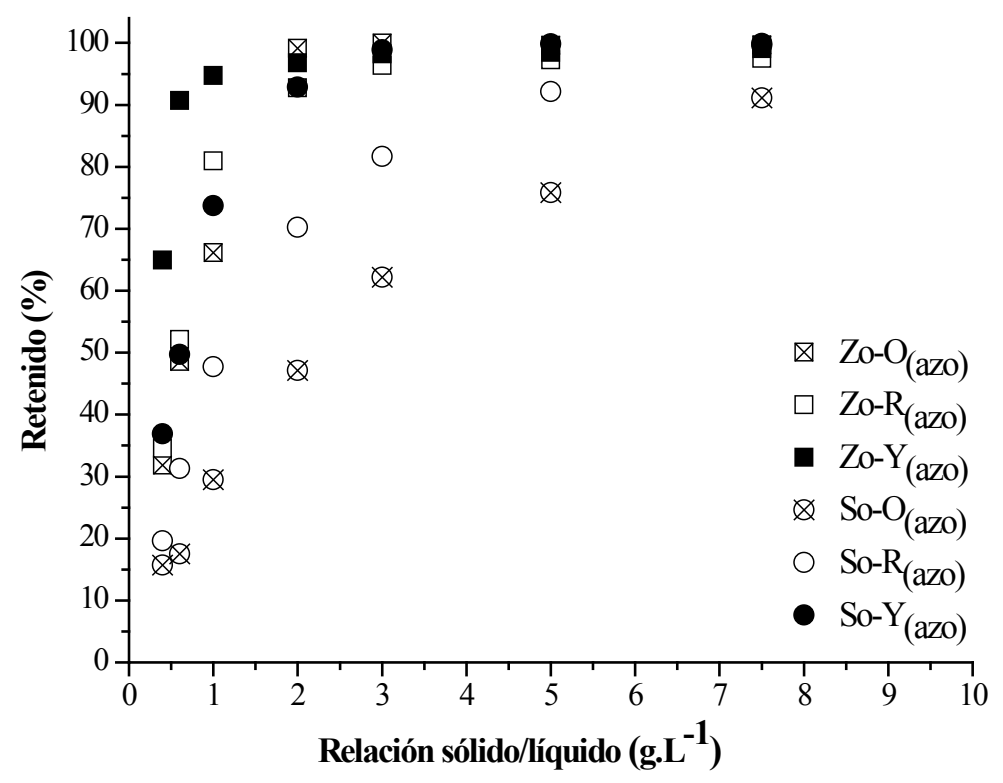

Figura 8.4.22. Comparación de retención del grupo azoico en R, O e Y sobre los adsorbentes So y Zo.

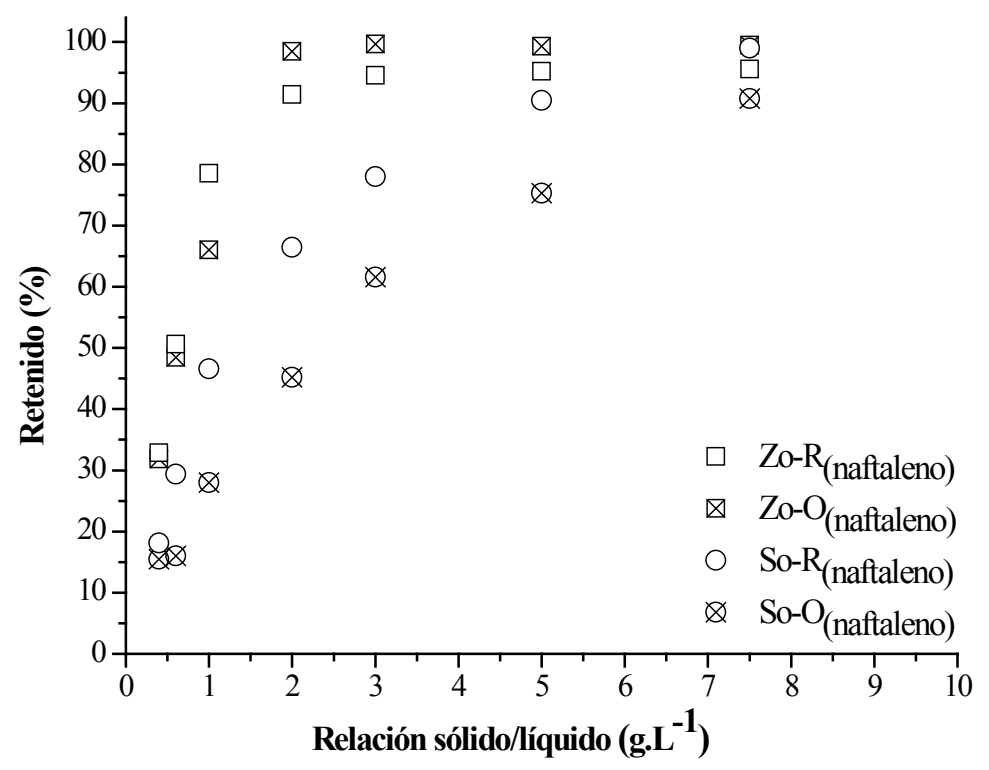

Figura 8.4.23. Comparación de retención del grupo naftaleno en R y O sobre los adsorbentes So y Zo. 
En el caso del grupo naftaleno, presente en la estructura química del colorante $\mathrm{O}$ y $\mathrm{R}$, las mayores retenciones también se presentaron en los ensayos de laboratorio realizados sobre la organobentonita Zo, respecto a la So, Figura 8.4.23, y con mayor preponderancia del grupo naftaleno presente en el R.

Finalmente, al comparar los resultados obtenidos para las adsorciones del grupo benceno, solo observada en el tinte $\mathrm{O}$, sobre ambas organoarcillas (Zo y So), al igual que lo visto en las anteriores comparaciones, el sustrato Zo, posee la mayor retención respecto a la So, Figura 8.4.24.

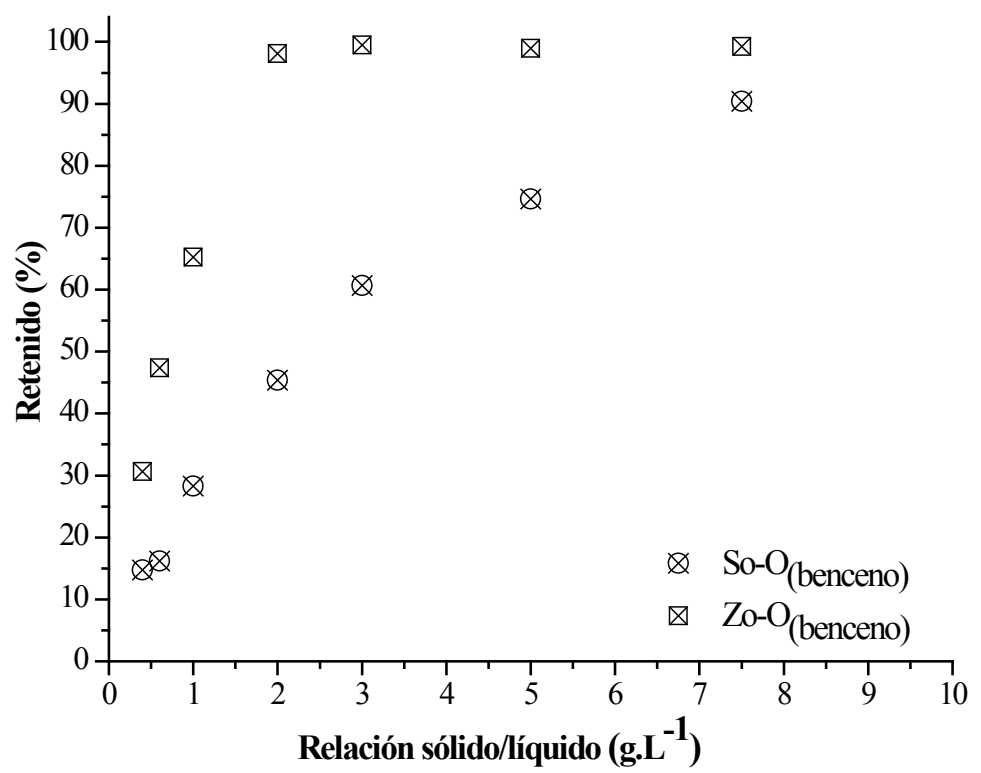

Figura 8.4.24. Comparación de retención del grupo bencénico en O sobre los adsorbentes So y Zo.

\subsubsection{Isotermas de adsorción}

Se realizaron las isotermas de adsorción de los distintos grupos cromóforos, que conforman la estructura de los colorantes (R, O, Y), por los adsorbentes So y Zo.

\subsection{Isotermas de adsorción grupo cromóforo azo de los colorantes $Y, O$ y $R$}

En los puntos anteriores se representaron las figuras en porciento retenido en tanto que en adelante se confeccionaron las isotermas de adsorción en cantidad retenida (mmol. $\left.\mathrm{g}^{-1}\right)$ vs. Concentración de equilibrio $\left(\mathrm{mmol} . \mathrm{L}^{-1}\right)$. Las isotermas se realizaron para cada grupo cromóforo presente en los colorantes. 
En la Figura 8.4.25, se presentan las isotermas de adsorción del cromóforo azo, constituyente de los tres colorantes, retenido sobre el adsorbente So. Puede apreciarse que en el caso del grupo azoico del tinte Y, la forma de la isoterma obtenida describe un comportamiento de mayor afinidad a concentraciones en equilibrio de hasta $0,025 \mathrm{mmol} . \mathrm{L}^{-1}$, por encima de ésta, y debido a la disminución en los sitios de adsorción, la capacidad de retención del adsorbente So disminuye, llegando a ser prácticamente constante, observándose un plateau en la curva, indicando esto que la monocapa se ha saturado, lo que se corresponde con isotermas tipo L2 (Giles y col. 1960).

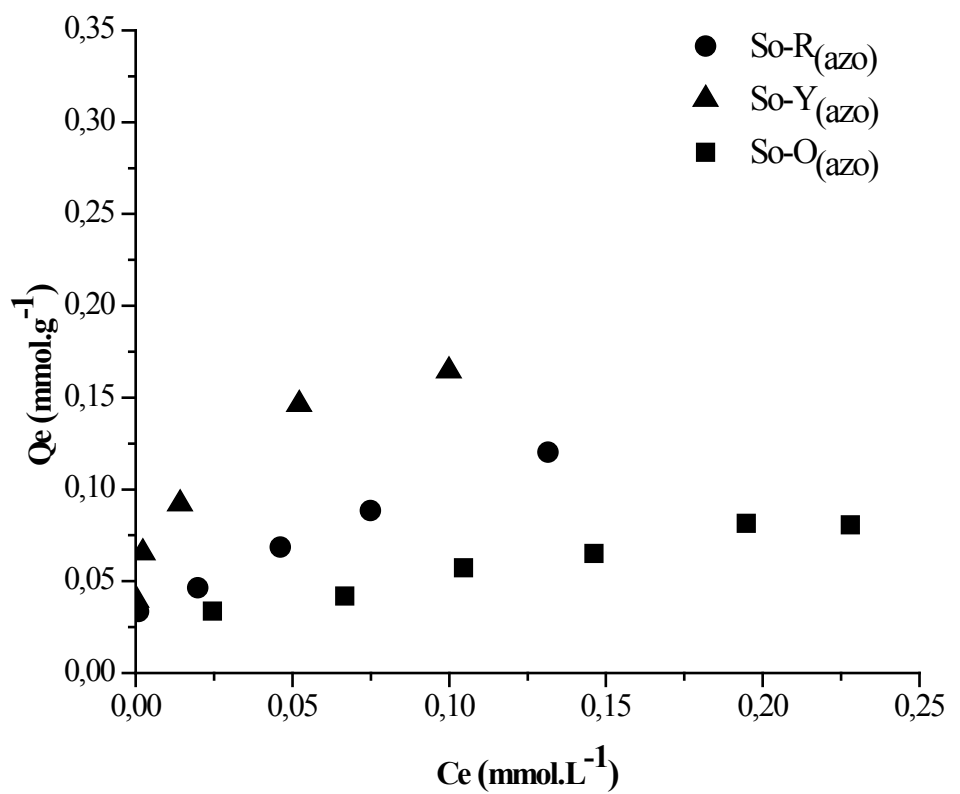

Figura 8.4.25. Isotermas de adsorción del grupo azo en $\mathrm{Y}, \mathrm{O}$ y R sobre So.

Las isotermas para el grupo azo, perteneciente a los diferentes colorantes, por el adsorbente Zo, Figura 8.4.26, muestran una importante capacidad de retención de ese grupo, a concentraciones en equilibrio iguales o menores a $0,02 \mathrm{mmol} . \mathrm{L}^{-1}$. Posteriormente, se aprecia un cambio de pendiente abrupto para el caso de los colorantes $\mathrm{R}$ y $\mathrm{O}$, es decir una reducción en la retención del adsorbente por el soluto en fase líquida. Este tipo de isoterma que se observa en los ensayos de adsorción por el adsorbente Zo, responde al tipo L2 de la clasificación de Giles y col. (1960) también conocida como isoterma de Langmuir. Para el caso de la retención del grupo azo del colorante Y por el adsorbente Zo, la forma de la isoterma se corresponde con el tipo L1. 


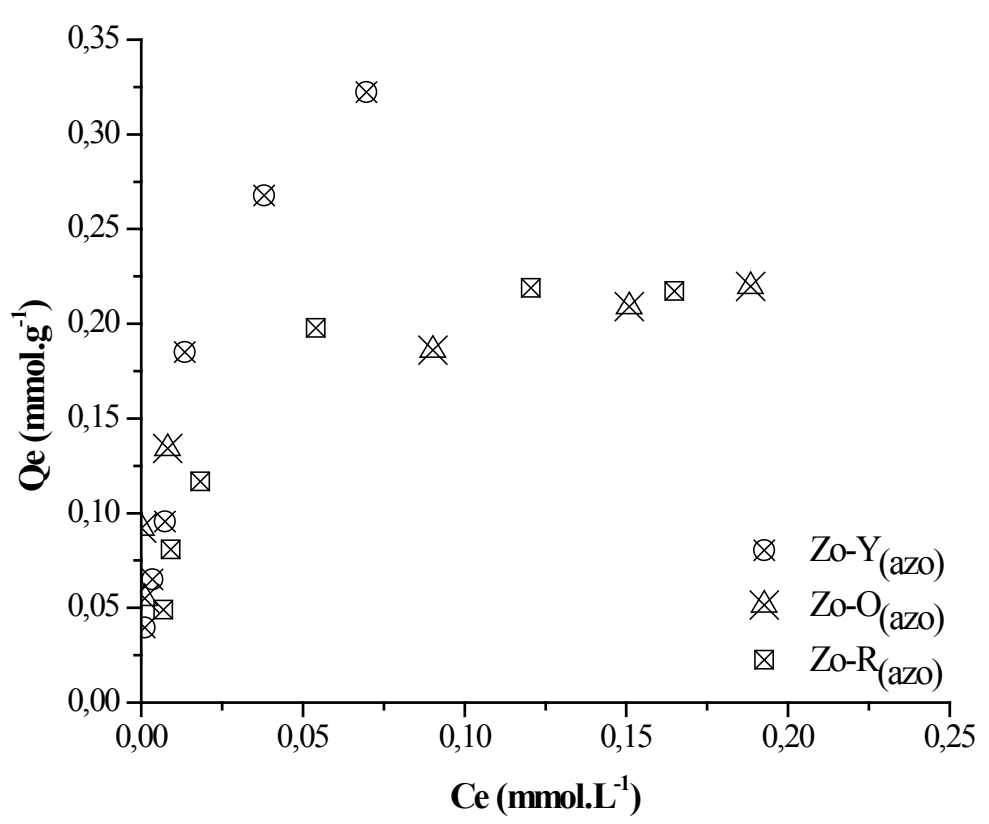

Figura 8.4.26. Isotermas de adsorción del grupo azo en $\mathrm{Y}, \mathrm{O}$ y R sobre Zo.

Comparando las isotermas correspondientes a las muestras So y Zo (Figuras 8.4.25 y 8.4.26) es fácil apreciar la diferente capacidad de adsorción que poseen ambas muestras.

En la Tabla 8.4.1, se presentan los parámetros, según lo obtenido de las isotermas de adsorción del grupo azoico, aplicando el modelo matemático de Langmuir, en la totalidad de los colorantes.

Tabla 8.4.1. Parámetros de Langmuir del cromóforo azo.

\begin{tabular}{|c|c|c|c|}
\hline Muestra & $\begin{array}{c}\text { Xm } \\
\left(\mathrm{mmol.g}^{-1}\right)\end{array}$ & $\begin{array}{c}\text { b } \\
\left(\text { L.mmol }{ }^{-1}\right)\end{array}$ & $\mathbf{R}^{2}$ \\
\hline So-R $($ azo) & 0,039 & 0,005 & 0,993 \\
\hline So-O ${ }_{(\mathrm{azo})}$ & 0,020 & 0,001 & 0,975 \\
\hline So- $Y_{(\text {azo })}$ & 0,140 & 0,046 & 0,983 \\
\hline$Z_{0}-R_{(a z o)}$ & 0,120 & 0,030 & 0,993 \\
\hline $\mathrm{Zo}_{0}-\mathrm{O}_{(\mathrm{azo})}$ & 0,113 & 0,028 & 0,991 \\
\hline $\mathrm{Z}_{0}-\mathrm{Y}_{(\mathrm{azo})}$ & 0,277 & 0,111 & 0,997 \\
\hline
\end{tabular}


La tabla de parámetros de Langmuir muestra las mayores energías de unión (b) y capacidades de adsorción (Xm), para los ensayos Zo-Y y So-Y, le siguen Zo-R, Zo-O, So-R y So-O.

La cantidad de cromóforo azo del colorante amarillo (Y) retenido en ambas muestras es superior al mismo grupo de los colorantes $\mathrm{R}$ y $\mathrm{O}$, pudiendo atribuirse a que el colorante Y posee dos grupos azo respecto al resto de los otros colorantes.

\subsection{Isotermas de adsorción grupo cromóforo naftaleno de los colorantes $O$ y $R$}

Las isotermas del grupo cromóforo naftaleno de $\mathrm{R}$ y $\mathrm{O}$ por las organobentonitas So y Zo, se exhiben en las Figuras 8.4.27 y 8.4.28.

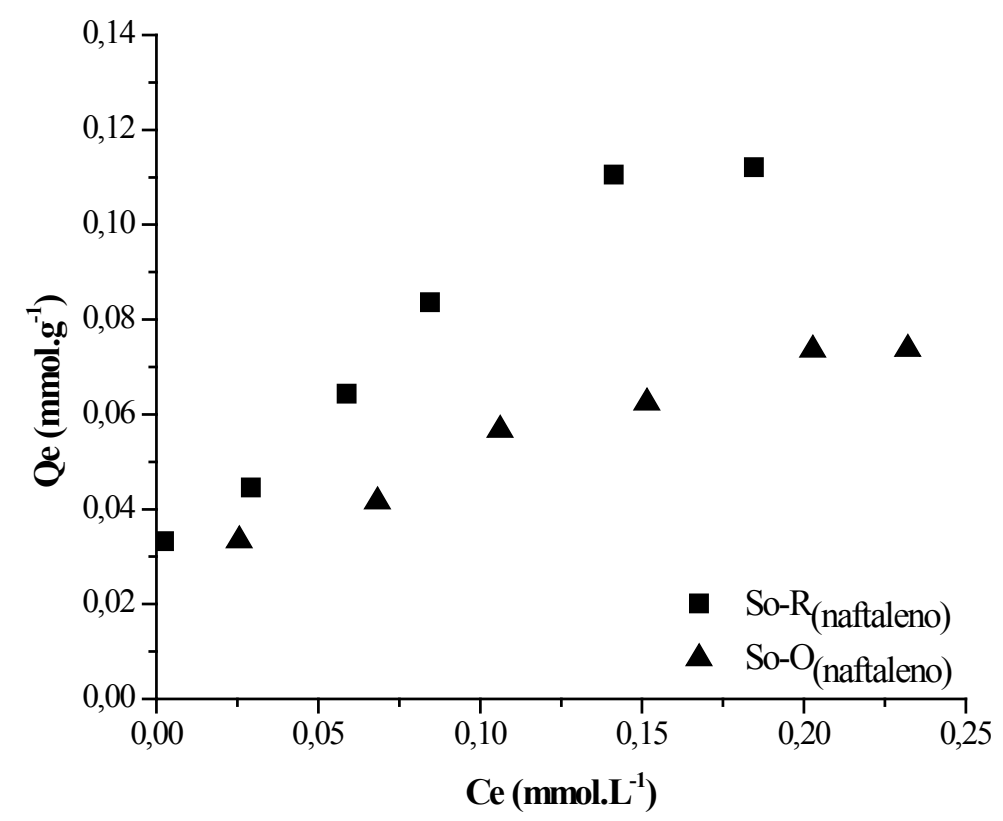

Figura 8.4.27. Isotermas de adsorción del grupo naftaleno en O y R sobre So.

Las isotermas exhiben inicialmente una gran afinidad del grupo naftaleno por el adsorbente Zo, para luego observarse un cambio de pendiente, semejante a lo ocurrido con el grupo azo, en tanto que para la muestra So la afinidad es menor. El tipo de isoterma para el adsorbente Zo y So del grupo naftaleno en los colorantes $\mathrm{O}$ y $\mathrm{R}$ responde al tipo L1 para la primera muestra y L2 para la segunda. 


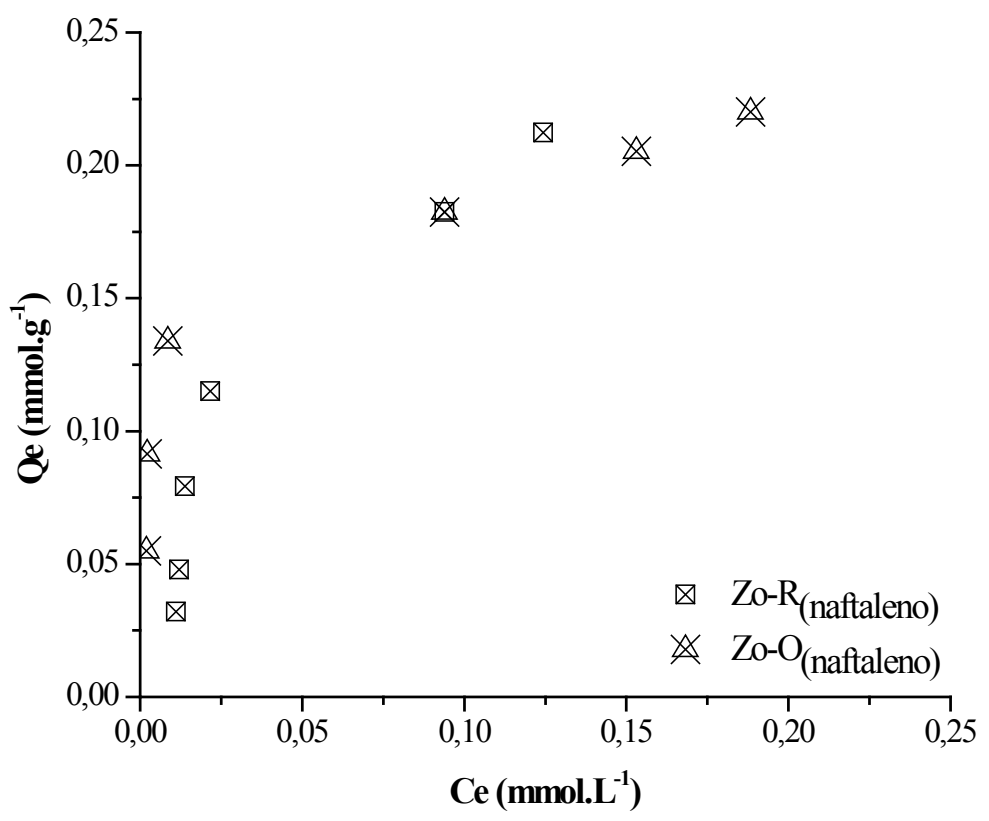

Figura 8.4.28. Isotermas de adsorción del grupo naftaleno en $\mathrm{O}$ y R sobre Zo.

La mayor capacidad de adsorción y energía de unión corresponde al adsorbente Zo (Tabla 8.4.2), para ambos colorantes, marcando una diferencia relevante respecto a la retención por parte de la muestra So. Así, es importante destacar que se requiere agregar menor cantidad de masa del adsorbente Zo respecto a So, para alcanzar éstos valores.

Tabla 8.4.2. Parámetros de Langmuir del cromóforo naftaleno.

\begin{tabular}{|c|c|c|c|}
\hline Muestra & $\begin{array}{c}\text { Xm } \\
\left(\mathrm{mmol.g}^{-1}\right)\end{array}$ & $\begin{array}{c}\text { b } \\
(\text { L.mmol } \\
\left.\text { L }^{-1}\right)\end{array}$ & $\mathbf{R}^{2}$ \\
\hline So- $R_{\text {(naftaleno) }}$ & 0,04 & 0,004 & 0,978 \\
\hline So-O (naftaleno) & 0,02 & 0,046 & 0,961 \\
\hline Zo-R (naftaleno) & 0,196 & 0,046 & 0,990 \\
\hline Zo-O (naftaleno) & 0,210 & 0,069 & 0,992 \\
\hline
\end{tabular}

\subsection{Isotermas de adsorción grupo cromóforo benceno del colorante $O$}

En la Figura 8.4.29 se observan las isotermas resultantes del grupo cromóforo benceno presente en el colorante O, para ambas organobentonitas (So y Zo); la isoterma $\mathrm{Zo-O}_{\text {(benceno) }}$ muestra una alta afinidad por el grupo benceno de $\mathrm{O}$, afinidad que luego

$0,02 \mathrm{mmol} . \mathrm{L}^{-1}$ se ve reducida por el cambio de pendiente de la misma, pudiendo clasificarse 
como tipo $\mathrm{H}$ para la primer parte, en tanto que para la muestra So la isoterma se condice con una isoterma tipo L, según lo observado en el trabajo de Giles y col. (1963).

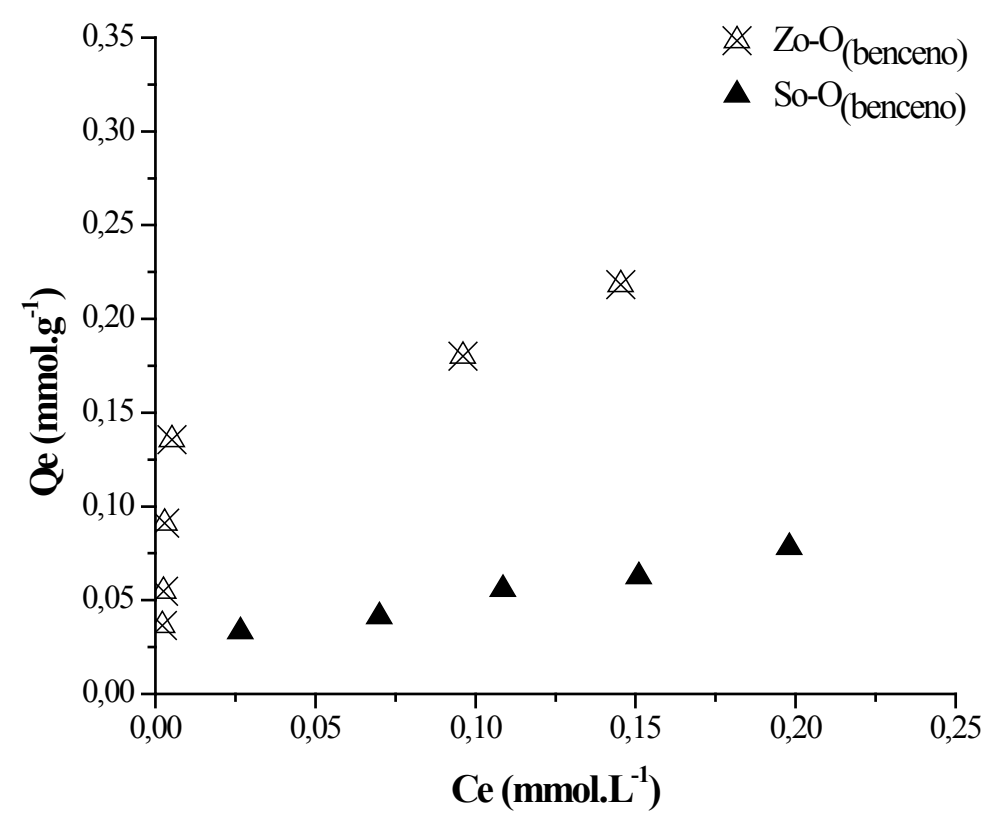

Figura 8.4.29. Isotermas de adsorción del grupo bencénico en O para So y Zo.

La Tabla 8.4.3, en la que se exponen los parámetros de Langmuir de los ensayos con el grupo benceno, muestra valores de $\mathrm{R}^{2}$ de 0,978 para So y 0,986 para Zo.

Tabla 8.4.3. Parámetros de Langmuir del cromóforo benceno

\begin{tabular}{c|c|c|c}
\hline Muestra & $\begin{array}{c}\mathbf{X m} \\
\left(\mathbf{m m o l . g}^{-1}\right)\end{array}$ & $\begin{array}{c}\mathbf{b} \\
\left(\mathbf{L}^{\prime} \mathbf{m o l}^{-1}\right)\end{array}$ & $\mathbf{R}^{\mathbf{2}}$ \\
\hline So-O(benceno) & 0,010 & 0,001 & 0,978 \\
\hline Zo-O(benceno) & 0,173 & 0,039 & 0,986 \\
\hline
\end{tabular}

Al igual que lo observado en la totalidad de los ensayos, el adsorbente Zo, es quien posee la mayor capacidad de retención y energía de unión del grupo benceno que compone la molécula del colorante orgánico O. De ésta manera el orden de adsorción para éste grupo es $\mathrm{Zo}^{-\mathrm{O}_{(\text {benceno }}}{ }^{>>\text {So- }} \mathrm{O}_{(\text {benceno) }}$.

Las diferencias entre las pendientes iniciales de las isotermas de adsorción de los adsorbatos So y Zo, se relacionaría con la posición que adopta el catión orgánico en las diferentes estructuras arcillosas. La disposición tipo pseudo-trilamina del $\mathrm{HDTMA}^{+}$en la 
muestra Zo, produce una mayor densidad de cargas positivas entre las láminas, proporcionando un cierto número de posiciones para la adsorción, y es ésta densidad de cargas lo que provoca un aumento en la capacidad de adsorción de Zo. Mientras que la forma tipo parafina, adquirida por el organocatión en So, dispone las moléculas de $\mathrm{HDTMA}^{+}$en forma paralela, con lo cual disminuye la cantidad de cargas positivas, que propician la retención de los tintes aniónicos en estudio, en concordancia con los valores de potencial zeta encontrado para ambos adsorbentes.

Ceyhan y Baybas (1999) han informado que diferentes colorantes textiles retenidos por HDTMA-bentonitas, alcanzan valores de retención entre 60 - $99 \%$, contactando soluciones de $10 \mathrm{mg} . \mathrm{L}^{-1}$ a $100 \mathrm{mg} . \mathrm{L}^{-1}$ con $0,1 \mathrm{~g}$ de adsorbente, semejantes a valores encontrados en este trabajo de tesis. Tuesta y col. (2005), retuvieron dos colorantes azoicos (azul y rojo), sobre arcillas termo-ácidas, demostrando que la activación termo-ácida incrementa la capacidad de retención, adsorbiendo un máximo de $75 \mathrm{mg}$ de colorante azul y $30 \mathrm{mg}$ del tinte rojo, a partir de soluciones de concentración inicial 50ppm, sobre $1 \mathrm{~g}$ de arcilla activada. Si estos colorantes tuvieran un peso molecular del orden de los $500 \mathrm{mg}$ los valores se retención podrían ser de $0,06 \mathrm{mmol} / \mathrm{g}$. Lian y col. (2009) reportaron retenciones superiores a 90\% de colorante Congo Red con una concentración inicial de 100mg.L ${ }^{-1}$, sobre una bentonita cálcica, concluyendo que la capacidad de retención de éste adsorbente es altamente dependiente de la concentración del tinte, y cambia levemente con la temperatura y el pH de la solución. Daraei (2013) empleando una organoarcilla para sorber colorantes reactivos textiles obtiene un valor de 1,2 g. $\mathrm{L}^{-1}$ (estimativamente $0,002 \mathrm{mmol} / \mathrm{g}$ ) de colorante de concentración inicial $2 \mathrm{~g} . \mathrm{L}^{-1}$, logrando las mejores condiciones de retención a los 30 minutos de tratamiento a $\mathrm{pH}=4,5$.

Algunos de las publicaciones consultadas, como la investigación desarrollada por Bhatt y col. (2012), quienes estudiaron la adsorción de un colorante aniónico en solución acuosa sobre organoadsorbentes preparadas a partir de atapulgita y bentonita, modificadas con HDTMA-Br, exponen que la naturaleza de las isotermas obtenidas en la remoción de remazole brilliant blue para ambos sustratos adsorbentes, fueron de alta afinidad $(\mathrm{H})$, respondiendo correctamente al modelo propuesto por Langmuir, seguida de una rama extensa lineal, que respondería a isotermas tipo $\mathrm{C}$, o de partición lineal, demostrando 
distribución de partición en moléculas de colorante entre la solución y los adsorbentes. Daraei, (2013), en su trabajo sobre el tratamiento de aguas residuales provenientes de la industria textil, utilizando una organoarcilla, concluyó, al igual que Bhatt y col. (2012), que las isotermas siguen la ecuación de Langmuir. En discrepancia con los trabajos mencionados, Andreo do Santos y col. (2013), investigó la adsorción del tinte Orange II, sobre una bentonita comercial modificada con sal de amonio cuaternario, empleando los modelos de Langmuir y Freundlich, para conocer el mecanismo de adsorción, reconociendo a partir de los datos experimentales, que el mejor ajuste se obtenía por medio de Freundlich, lo que indicaría que el tinte orgánico tiene una alta afinidad por la organoarcilla.

Otros estudios efectuados sobre adsorción de tintes orgánicos sobre diferentes adsorbentes, como el trabajo de Tsai y col. (2005) quienes estudiaron la adsorción de colorante básico etil violeta sobre tierras de blanqueo provenientes de la industria de aceites comestibles, exponen que las isotermas ajustan correctamente a los modelos de Freundlich y de Langmuir, observando además que la capacidad de adsorción dependerá del pH, ya que a $\mathrm{pH}=3$ y $\mathrm{pH}=11$ se obtuvieron las mayores retenciones, como también de la temperatura, con lo cual el proceso de adsorción es de naturaleza endotérmica. Ignat y col., (2012) retuvieron rojo reactivo 3 y marrón directo 95, sobre un compuesto polisacárido lineal (quitosano), utilizando factiblemente los modelos de Freundlich y Langmuir, demostraron que la adsorción de éstos tintes es influenciada por el tiempo de contacto entre el adsorbente y la solución, el $\mathrm{pH}$, la temperatura y la adición de $\mathrm{NaCl}$, donde el ión $\mathrm{Na}^{+}$, produce un decrecimiento en la disociación de los colorantes, resultando esto en una disminución en la adsorción. Roulia y Vassiliadis (2008), retuvieron un colorante catiónico sobre arcilla y perlita, indicando que el efectivo ajuste por Langmuir demuestra una fuerte atracción adsorbente-adsorbato, y debido a la distribución homogénea de las cargas sobre la superficie de la arcilla, las moléculas de los colorantes incorporadas, producen agregados isotrópicos automontados. Šmelcerović y col. (2010), describen que en función de las características de las isotermas de Langmuir obtenidas, que el residuo de ceniza obtenido a partir de carbón es un decolorante efectivo de colorante quinónico Vat Blue 14. Por último, Espantaleón y col. (2003), en su investigación sobre remoción de colorantes y surfactantes 
no iónicos en aguas de desechos, sobre arcillas activadas con $\mathrm{H}_{2} \mathrm{SO}_{4}$; demostraron que las moléculas de colorante poseen una alta afinidad por los sitios activos en la bentonita ácida, reteniéndose casi en su totalidad, la adsorción de colorantes aniónicos con grupos sulfonato es en forma de monolámina, lo que se explica por la presencia de un exceso de protones probablemente adsorbidos en el proceso de activación ácida.

Luego de la reseña bibliográfica expuesta de retención de diversos colorantes sobre superficies variadas, es posible apreciar, que en la mayoría de los casos, los tintes poseen una interacción con la superficie de los adsorbentes, en monocapa, por lo que se obtienen altas afinidades adsorbato/adsorbente, lográndose en la mayoría de los casos una importante la remoción de los colorantes; en coincidencia con lo observado en la presente tesis.

Si bien la bibliografía informa sobre un amplio rango de valores de retención de tintes orgánicos por arcillas, los estudios exhiben resultados de adsorción de colorantes generales, sin realizar un análisis individual de cada grupo cromóforo presente en las diversas estructuras. De esta manera, la información sobre la temática que se plantea en la presente tesis, es relativamente novedosa.

\subsubsection{Comparación en la adsorción de los tintes $\mathrm{R}, \mathrm{O}$ e $\mathrm{Y}$}

Para una mejor interpretación de los resultados obtenidos en las isotermas de adsorción se exponen a continuación (Tabla 8.4.4) los valores de capacidad de adsorción de los diferentes grupos cromóforos analizados para cada uno de los colorantes.

Tabla 8.4.4. Comparación $\mathrm{Xm}$ de los ensayos So-R/O/Y y Zo-R/O/Y con los grupos azo (Y/O/R), naftaleno $(\mathrm{R} / \mathrm{O})$ y benceno $(\mathrm{O})$.

\begin{tabular}{c|c|c|c|c|c|c}
\hline \multirow{2}{*}{ Adsorbente } & \multicolumn{6}{c}{ Xm (mmol.g $\left.{ }^{-1}\right)$} \\
\cline { 2 - 7 } & \multicolumn{5}{|c|}{ AZO } & \multicolumn{2}{c}{ NAFTALENO } & BENCENO \\
\cline { 2 - 7 } & Y & R & O & R & O & O \\
\hline Zo & 0,278 & 0,120 & 0.113 & 0,196 & 0,210 & 0,173 \\
\hline So & 0,140 & 0,039 & 0,020 & 0,040 & 0,020 & 0,010 \\
\hline
\end{tabular}


Luego del análisis de las isotermas obtenidas para los distintos grupos cromóforos (azo, naftaleno y benceno) constituyentes en algunos casos de los colorantes R, O e Y, se aprecia que el grupo azo del colorante Y, posee la mayor capacidad de retención, ya sea para el adsorbente So como para Zo; mientras que éste cromóforo, para el caso de $\mathrm{R}$ y $\mathrm{O}$ muestra una diferencia significativa en las capacidades de retención de cada adsorbente, siendo los mayores valores de Xm los obtenidos en las experiencias con Zo, decreciendo para So. Para el caso de los grupo naftaleno en $\mathrm{R}$ y $\mathrm{O}$, las capacidades de remoción del sustrato Zo fueron similares; en tanto que nuevamente los valores Xm para So son considerablemente menores. Finalmente, para el caso del cromóforo benceno, analizado en el colorante $\mathrm{O}$, los valores de capacidad de adsorción se condicen con lo observado en los anteriores casos, es decir que el organoadsorbente Zo posee mayor capacidad que So en la remoción de éste grupo. Cabe destacar que los resultados anteriores se observan para concentraciones iguales a $125 \mathrm{mg} . \mathrm{L}^{-1}$ de los colorantes, y relaciones sólido/líquido desde 0,4 g.L $L^{-1}$ a 8 g.L. ${ }^{-1}$.

De acuerdo con lo descripto en el anterior párrafo, es posible determinar cómo orden de adsorción $\mathrm{Y}>>\mathrm{R} \geq \mathrm{O}$ para ambas organoarcillas (So y Zo).

El mencionado orden de remoción de tintes textiles, podría estar relacionado con la cantidad de carbonos presentes en la estructura de los colorantes, Tabla 8.4.5, donde a mayor contenido de carbonos (Umpuch y Jutarat, 2013), mayor es la adsorción.

Tabla 8.4.5. Cantidad de átomos presentes en las estructuras de los tintes Y, R y O.

\begin{tabular}{c|c|c|c|c|c|c|c}
\hline Colorante & $\mathbf{C}$ & $\mathbf{H}$ & $\mathbf{O}$ & $\mathbf{N}$ & $\mathbf{S}$ & $\mathbf{N a}$ & $\mathbf{C l}$ \\
\hline $\mathbf{Y}$ & 35 & 34 & 4 & 6 & --- & --- & 2 \\
\hline $\mathbf{O}$ & 16 & 10 & 7 & 2 & 2 & 2 & --- \\
\hline $\mathbf{R}$ & 18 & 14 & 8 & 2 & 2 & 2 & --- \\
\hline
\end{tabular}

En base a la Tabla 8.1.1 “Comparación estructural colorantes $R$, $O$ e $Y$ ”, donde se comparan las estructuras de los colorantes, y teniendo en cuenta el orden de adsorción en la totalidad de los ensayos; es posible sugerir que la mayor afinidad de ambas organoarcillas por el colorante $\mathrm{Y}$, además del contenido de carbonos que éste presenta, se deba a la presencia de dos grupos azoicos en la estructura del tinte. Si bien las diferencia en la 
remoción de los colorantes $\mathrm{R}$ y $\mathrm{O}$ no es significativa, la levemente mayor afinidad de las organobentonitas por R, puede deberse a la presencia de uno de los dos grupos auxocromo sulfónicos unido al cromóforo naftaleno, siendo el menos removido $\mathrm{O}$, quien posee sus dos grupos auxocromo (sulfonato) unidos al cromóforo naftaleno. Por lo tanto, la variación en la posición de uno de los grupos sulfonato, estaría influenciando la diferencia en el orden de adsorción de ambos adsorbentes. 


\subsection{Caracterización de los productos de adsorción}

Los productos de los ensayos de adsorción fueron caracterizados mediante técnicas analíticas, con la finalidad de estudiar las modificaciones que podrían haberse ocasionado durante el proceso de adsorción, como así también, obtener información que aporte al estudio del mecanismo de retención en ambas organoarcillas.

\subsubsection{Análisis por DRX. Espaciado interlaminar (d001)}

El estudio de la modificación en el espaciado interlaminar de los sólidos recuperados de los ensayos de adsorción de las soluciones coloreadas Y, O y R; con la organobentonita So, se realizó por medio de DRX, sobre las muestras orientadas y a ángulos hasta $16^{\circ} 2 \theta$. En la Figura 8.5.1, se presentan los espectros de difracción obtenidos. Para el adsorbente So $(2,22 \mathrm{~nm})$ el espaciado entre las láminas se vio modificado hacia valores superiores. Cuando los colorantes $\mathrm{O}, \mathrm{Y}$ ó R se encuentran presentes en la organobentonita se aprecia un aumento en el espaciado interlaminar $(2,31 \mathrm{~nm}$ a $2,34 \mathrm{~nm})$ y hasta un ensanchamiento del pico, indicando alteración del espaciado.

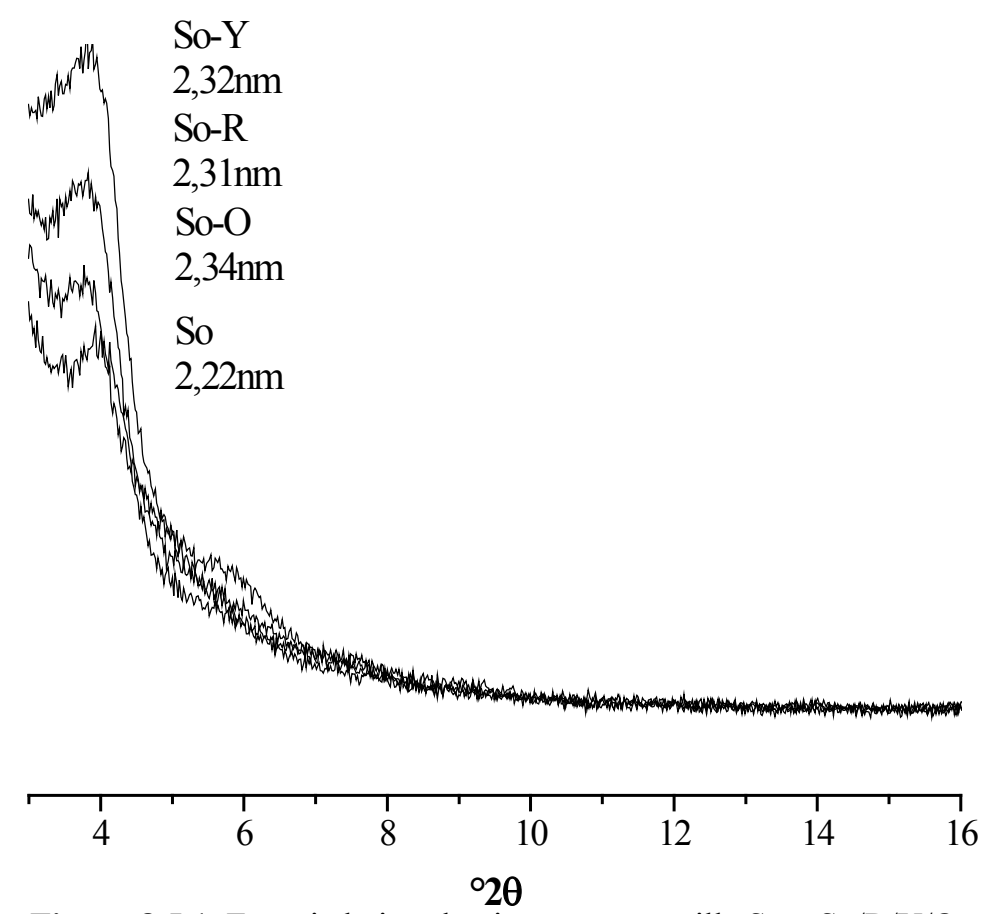

Figura 8.5.1. Espaciado interlaminar organoarcilla So y So/R/Y/O. 
La Figura 8.5.2 muestra los espaciados basales de la Zo con posterioridad a la retención de los colorantes $\mathrm{Y}, \mathrm{R}$ y $\mathrm{O}$. En éste caso también la presencia de los colorantes retenidos ha incrementado levemente el espaciado interlaminar de $1,91 \mathrm{~nm}$ correspondiente al Zo a valores de 1,97nm - 1,98nm luego de la retención.

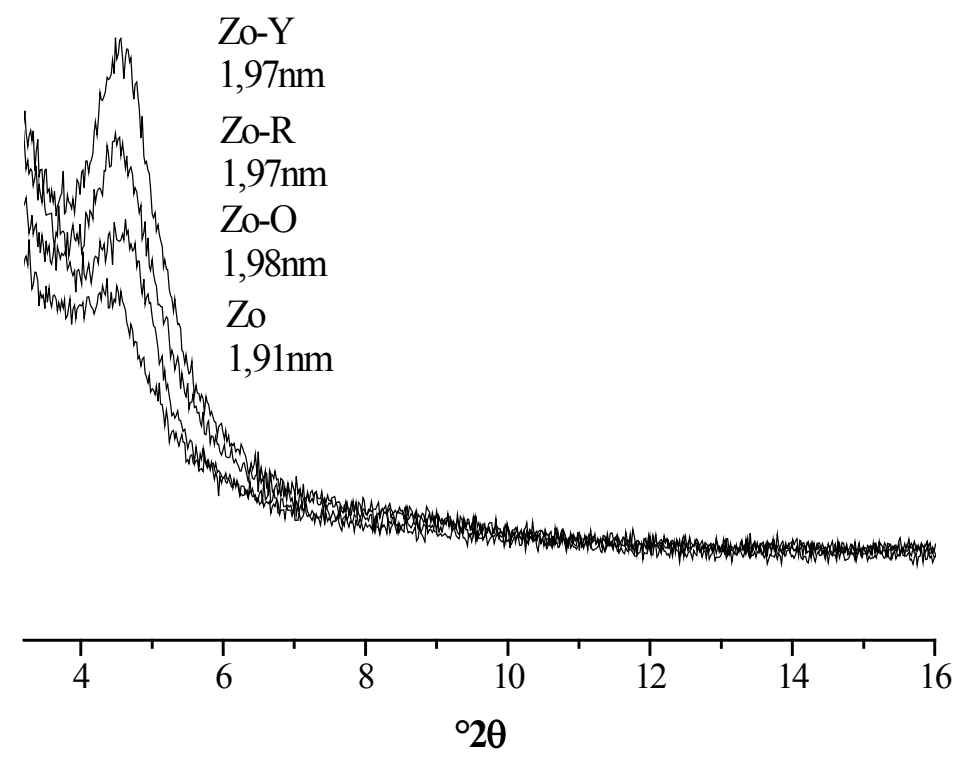

Figura 8.5.2. Espaciado interlaminar organoarcilla Zo y ZoR/Y/O.

\subsubsection{Análisis por ATD-TG}

La Figura 8.5.3 y Figura 8.5.4, muestran las pérdidas de masa obtenidas del análisis termogravimétrico para los adsorbentes orgánicos (Zo y So) y los mismos con los colorantes en estudio ( $\mathrm{Y}, \mathrm{R}$ y $\mathrm{O}$ ) ya retenidos, muestras denominadas Zo-Y/R/O y So$\mathrm{Y} / \mathrm{R} / \mathrm{O}$.

Son apreciables similares temperaturas de disminución de masa con respecto a las muestras sin el colorante, evidenciadas cada una de ellas a aproximadamente entre $100^{\circ} \mathrm{C}$ y $220^{\circ} \mathrm{C}$ para la deshidratación y entre $300^{\circ} \mathrm{C}$ y $730^{\circ} \mathrm{C}$, etapa que puede relacionarse con la descomposición del orgánico tanto presente en el surfactantes como el de los colorantes. 


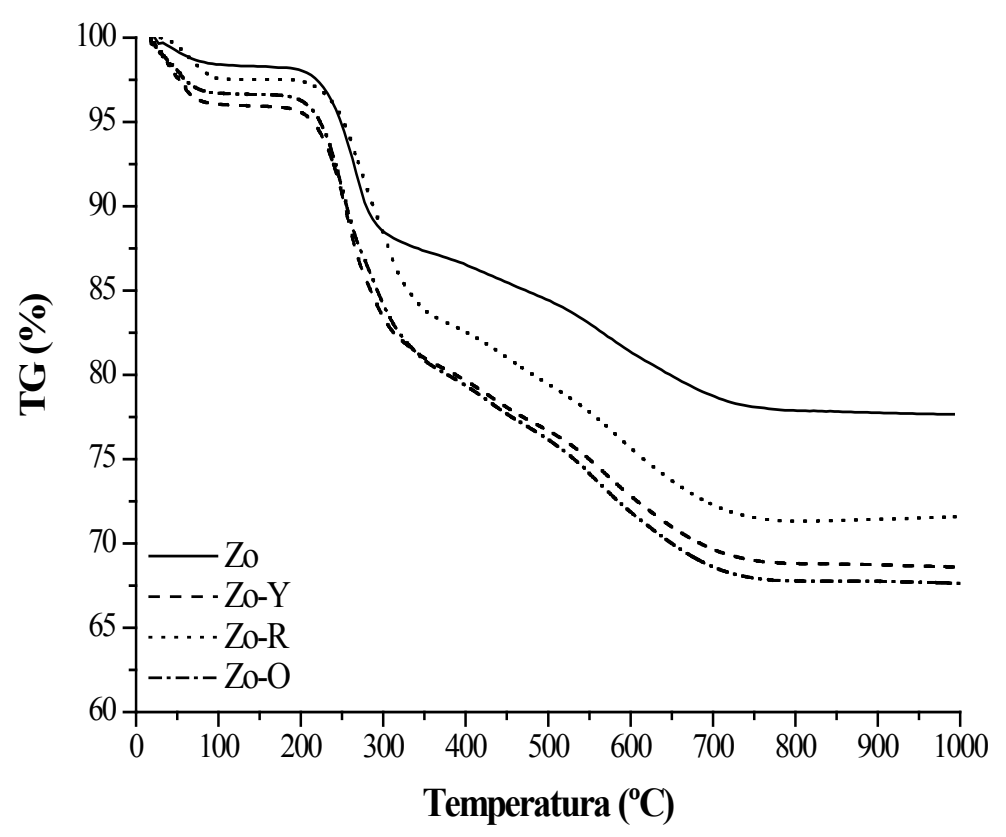

Figura 8.5.3. TG muestras $\mathrm{Zo}, \mathrm{Zo}-\mathrm{Y} / \mathrm{R} / \mathrm{O}$.

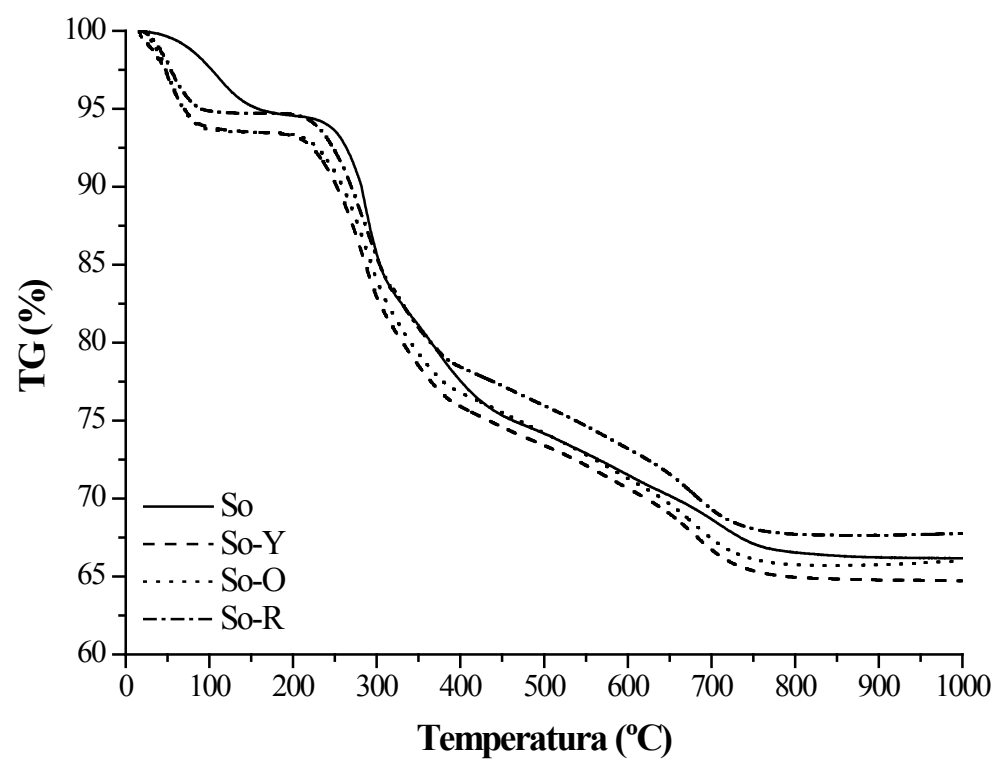

Figura 8.5.4. TG muestras So, So-Y/R/O.

En la Tabla 8.5.1, se muestran los valores de las pérdidas de masa por temperatura de los adsorbentes Zo y So con los colorantes R, O e Y retenidos. Las pérdidas en el rango de $25^{\circ} \mathrm{C}$ a $200^{\circ} \mathrm{C}$, son mayores para la muestra So $\left(5,37^{\circ} \mathrm{C}-6,75^{\circ} \mathrm{C}\right)$ respecto a la muestra $\mathrm{Zo}$ 
$(2,58-4,43)$ a la vez que se observa una tendencia a una mayor pérdida cuando se retuvo el tinte $\mathrm{Y}$, seguido de $\mathrm{O}$ y finalmente R. Es notable observar que esa mayor perdida por parte de So con los colorantes se produce a bajas temperaturas (Figura 8.5.4). Las pérdidas de masa en el rango de $250^{\circ} \mathrm{C}-750^{\circ} \mathrm{C} / 1000^{\circ} \mathrm{C}$ también marcan similar tendencia.

El indicar los valores de temperatura como $750^{\circ} \mathrm{C} / 1000^{\circ} \mathrm{C}$, se refiere a que prácticamente la diferencia entre $750^{\circ} \mathrm{C}$ y $1000^{\circ} \mathrm{C}$ en valores de masa, son despreciables, como se observa en la Figura 8.5.1. Sin embargo, lo más relevante se aprecia cuando las pérdidas de masa a lo largo de todo el rango de temperatura estudiado $\left(25^{\circ} \mathrm{C}-1000^{\circ} \mathrm{C}\right)$ de las organobentonitas (Zo y So) se comparan luego de la retención de los colorantes (Zo-R, ZoO, Zo-Y; So-R, So-O- So-Y) (Tabla 8.5.1). De esta manera la Zo con una pérdida de $22,34 \%$ aumenta a valores de entre 28,46 - 32,04\% luego de retener cada uno de los colorantes. Para el caso de la pérdida de masa de la So con los colorantes el incremento es relativamente bajo (de 33,82\% para So, a 36,52\% como máximo para posterior retención de los colorantes).

Tabla 8.5.1. Pérdidas de masa de los adsorbentes So-R/O/Y y Zo-R/O/Y.

\begin{tabular}{|c|c|c|c|c|c|c|}
\hline \multirow{2}{*}{$\begin{array}{c}\text { Temperatura } \\
\left({ }^{\circ} \mathbf{C}\right)\end{array}$} & \multicolumn{5}{|c|}{ Zérdida de masa (\%) } \\
& Zo-R & Zo-O & Zo-Y & So-R & So-O & So-Y \\
\cline { 2 - 7 } & 2,58 & 3,73 & 4,43 & 5,37 & 6,65 & 6,75 \\
\hline $25-200$ & 25,98 & 28,62 & 26,96 & 26,88 & 27,39 & 28,44 \\
\hline $201-750 / 1000$ & 28,56 & 32,35 & 31,39 & 32,25 & 34,04 & 36,52 \\
\hline Total & & 22,34 & & 33,82 & \\
\hline Total adsorbente & 6,22 & 10,01 & 9,05 & $-1,57$ & 0,22 & 1,47 \\
\hline Total colorante & & & & & \\
\hline
\end{tabular}

Finalmente, la Figura 8.5.5 y Figura 8.5.6, detallan los resultados DTA de las muestras Zo-Y/R/O y So-Y/R/O. 


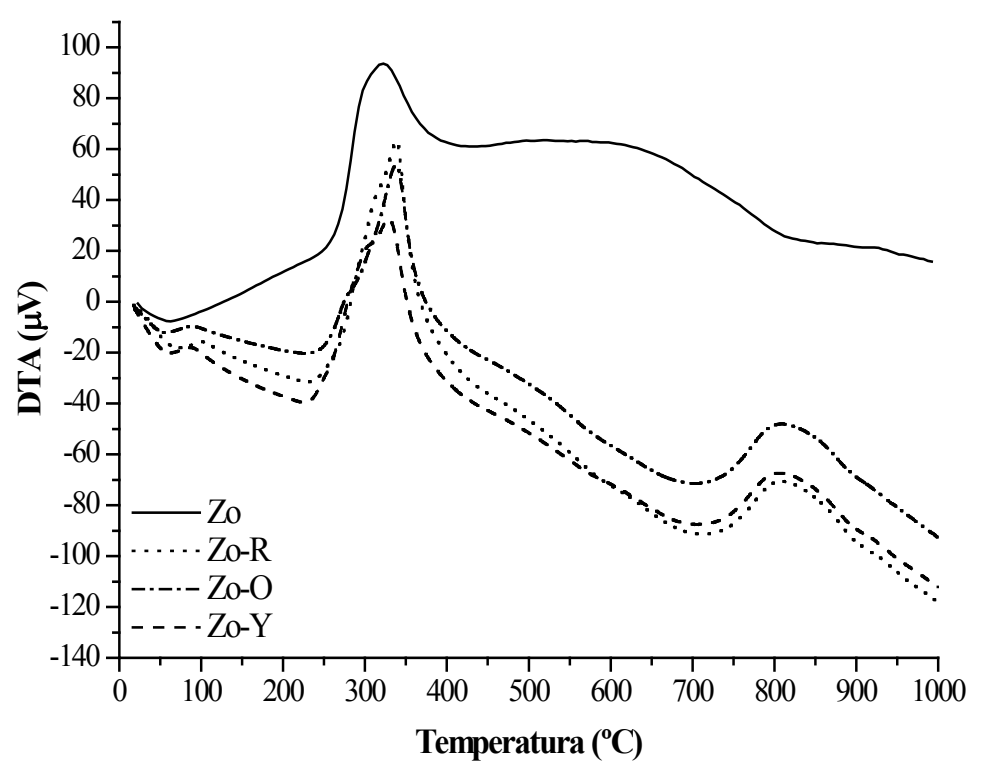

Figura 8.5.5. ATD muestras Zo, Zo-R/O/Y.

La Figura 8.5.5, muestra un pico exotérmico a $350^{\circ} \mathrm{C}$ relacionado con la eliminación del material orgánico tanto del surfactante como de los colorantes; a continuación se presenta un segundo pico endotérmico a $710^{\circ} \mathrm{C}$ asociado con la formación de carbono residual proveniente de la materia orgánica.

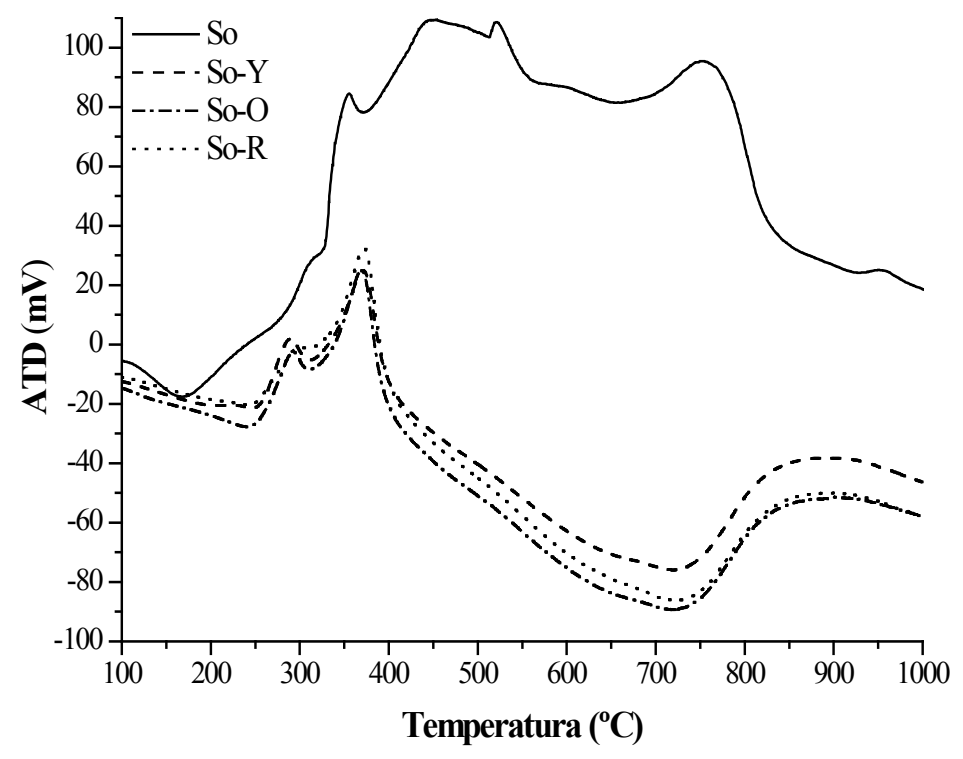

Figura 8.5.6. ATD muestras So, So-R/O/Y. 
A diferencia de la anterior, la Figura 8.5.6, correspondiente a la muestra So posterior a la retención de los colorantes muestra dos picos exotérmicos a $290^{\circ} \mathrm{C}$ y $350^{\circ} \mathrm{C}$ para las muestras con la carga de colorante adsorbido, éstos también provenientes de la materia orgánica tanto del $\mathrm{HDTMA}^{+}$como de los colorantes. Finalmente se observa el pico endotérmico atribuido a la eliminación de carbono residual.

\subsubsection{Análisis por IR}

Las muestras adsorbentes con la carga de los colorantes, también se analizaron por medio de ensayos en el infrarrojo.

En la Figura 8.5.7 se presenta las bandas en el IR de la organobentonita So luego de retener el colorante $\mathrm{R}$, en tanto que en la Tabla 8.5.3 se muestran los valores de número de onda y su correspondencia con el grupo asociado.

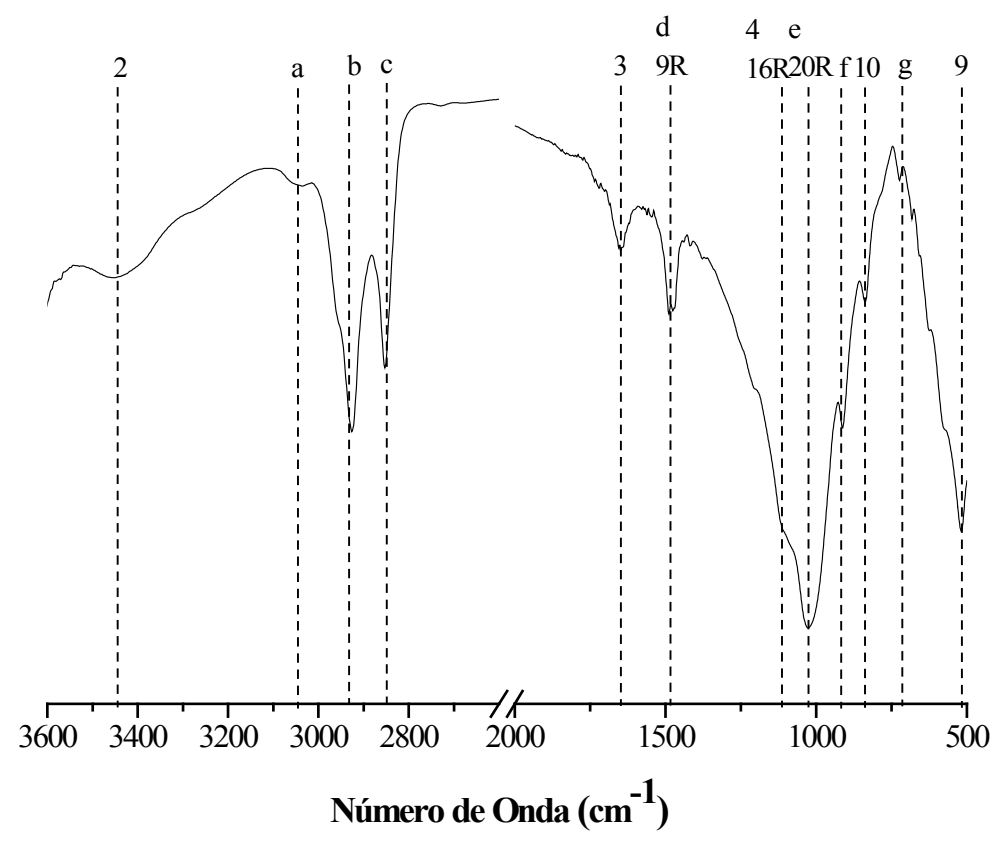

Figura 8.5.7. IR de la muestra So-R. 
Tabla 8.5.2. Bandas de absorción y grupos asociados de la muestra So-R.

\begin{tabular}{|c|c|c|}
\hline Bandas & Número de Onda $\left(\mathbf{c m}^{-1}\right)$ & Grupos Asociados \\
2 & 3452 & H-O-H Stretching del agua \\
a & 3051 & Stretching simétrico de la cabeza del grupo $\left(=\mathrm{CH}_{2}\right)$ \\
b & 2925 & $\mathrm{CH}_{3}-\mathrm{N}$ stretching simétrico del trimetil-amonio \\
c & 2852 & Stretching simétrico del metileno $\left(=\mathrm{CH}_{2}\right)$ \\
3 & 1647 & Bending del grupo H-O-H \\
\hline \hline d/9R & 1498 & N=N (R) y Stretching $-\mathrm{CH}_{3}$ \\
$4 / 16 \mathrm{R}$ & 1095 & Señal complementaria $(\mathrm{C}-\mathrm{C} ; \mathrm{C}-\mathrm{N}, \mathrm{C}-\mathrm{O})$ y stretching \\
$\mathrm{e} / 20 \mathrm{R}$ & 1029 & simétrico Si-O-Si \\
\hline $\mathrm{f}$ & 912 & Vibraciones del grupo SO ${ }_{3}{ }^{\mathrm{e}}$ e interacción orgánico- \\
7 & 838 & superficie siloxano \\
$\mathrm{g}$ & 723 & N-C vibración stretching asimétrico \\
$\mathrm{h}$ & 680 & Stretching Al-Fe ${ }^{+3}-\mathrm{OH}$ \\
8 & 518 & C-H Rocking del metileno $\left(=\mathrm{CH}_{2}\right)$ \\
\hline
\end{tabular}

La identificación numérica corresponde con las bandas pertenecientes a la esmectita; aquellas que se identifican con letras minúsculas son las pertenecientes al catión orgánico entre las láminas de la arcilla $\left(\mathrm{HDTMA}^{+}\right)$y las correspondientes a los colorantes se identifican con la nomenclatura del colorante. Es así que para el ensayo de adsorción So$\mathrm{R}$, se observan las vibraciones pertenecientes a la esmectita $\mathrm{S}$ y los grupos orgánicos del catión de amonio cuaternario, en éstas últimas se aprecia la banda del grupo azo del colorante R coincidente con el grupo metileno $\left(1498 \mathrm{~cm}^{-1}\right)$, bandas complementarias de las uniones C-C, C-N y C-O del tinte solapadas con el grupo Si-O-Si $\left(1095 \mathrm{~cm}^{-1}\right)$ y el grupo $\mathrm{SO}_{3}{ }^{\circ}$ de $\mathrm{R}$ con la señal de interacción de superficie siloxano/orgánico de So $\left(1029 \mathrm{~cm}^{-1}\right)$.

En la Figura 8.5.8, se observan los resultados de los ensayos IR realizados sobre el organoadsorbente So con el tinte $\mathrm{O}$ retenido en su estructura. 


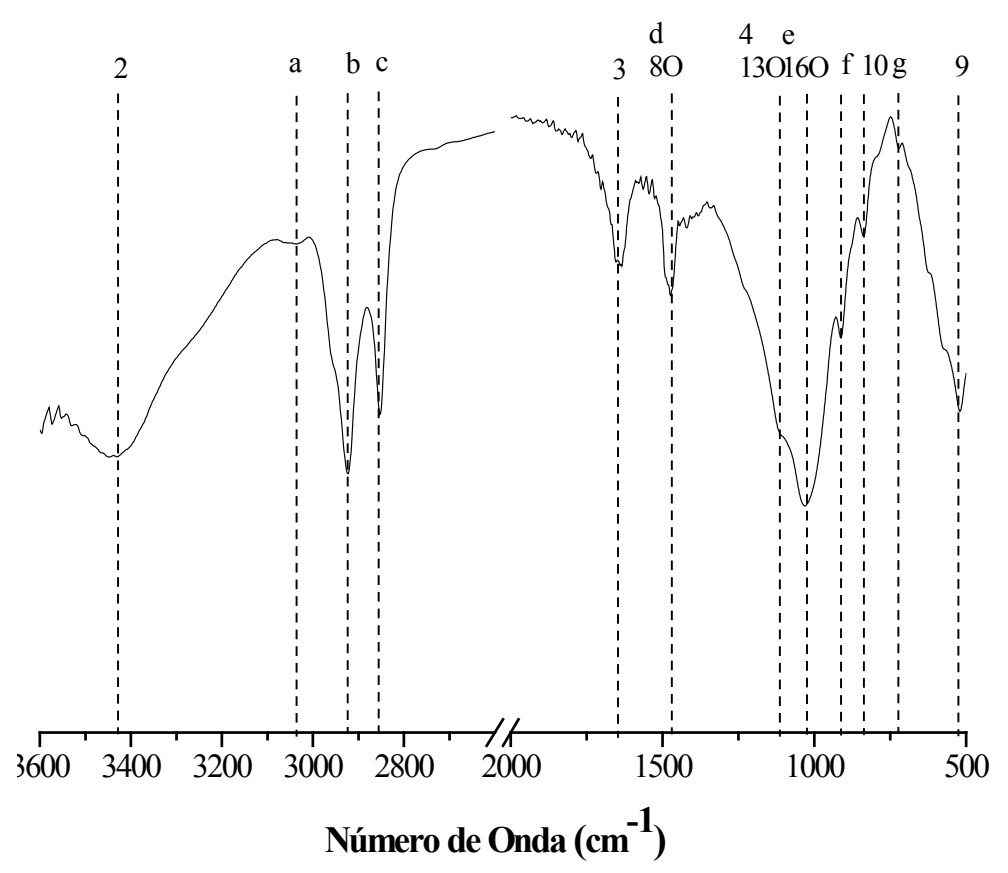

Figura 8.5.8. IR de la muestra So-O.

Tabla 8.5.3. Bandas de absorción y grupos asociados de la muestra So-O.

\begin{tabular}{|c|c|c|}
\hline Bandas & Número de Onda $\left(\mathrm{cm}^{-1}\right)$ & Grupos Asociados \\
\hline 2 & 3448 & H-O-H Stretching del agua \\
\hline a & 3039 & Stretching simétrico de la cabeza del grupo $\left(=\mathrm{CH}_{2}\right)$ \\
\hline $\mathrm{b}$ & 2921 & $\begin{array}{l}\text { Stretching simétrico de la cabeza del trimetil-amonio } \\
\qquad\left(\mathrm{CH}_{3}-\mathrm{N}\right)\end{array}$ \\
\hline $\mathrm{c}$ & 2652 & Stretching simétrico metileno $\left(=\mathrm{CH}_{2}\right)$ \\
\hline 3 & 1639 & Bending del grupo H-O-H \\
\hline $\begin{array}{l}\mathrm{d} / 8 \mathrm{O} \\
4 / 130\end{array}$ & $\begin{array}{l}1490 \\
1145\end{array}$ & $\begin{array}{c}\mathrm{N}=\mathrm{N} \text { y Scisoring del metileno }\left(=\mathrm{CH}_{2}\right) \\
\text { Señales complementarias }(\mathrm{C}-\mathrm{C}, \mathrm{C}-\mathrm{N} \text { y C-O }) \text { y } \\
\text { stretching longitudinal } \mathrm{Si}-\mathrm{O}-\mathrm{Si}\end{array}$ \\
\hline $\mathrm{e} / 16 \mathrm{O}$ & 1031 & $\begin{array}{c}\text { Vibración del } \mathrm{SO}_{3}{ }^{=} \text {e interacción orgánico-superficie } \\
\text { siloxano }\end{array}$ \\
\hline $\mathrm{f}$ & 912 & $\mathrm{~N}-\mathrm{C}$ vibración stretching asimétrico \\
\hline 10 & 840 & Stretching Al-Mg-OH \\
\hline $\mathrm{g}$ & 719 & C-H Rocking del metileno $\left(=\mathrm{CH}_{2}\right)$ \\
\hline 9 & 518 & Bending Si-O-Al \\
\hline
\end{tabular}


Las bandas de absorción pertenecientes a la muestra So-O se muestran en la Tabla 8.5.4; como se detalló anteriormente, las bandas identificadas con números arábigos corresponden a aquellas señales encontradas en el adsorbente natural y en el colorante $\mathrm{O}$ (diferenciadas éstas con la nomenclatura utilizada para cada colorante), siendo las reconocidas con letras minúsculas las señales provenientes del catión orgánico y la interacción de éste con las muestra natural (So). En el caso del ensayo de So con el tinte O, se encontraron señales vibracionales provenientes de éste se ubican a $1490 \mathrm{~cm}^{-1}, 1145 \mathrm{~cm}^{-1}$ y $1031 \mathrm{~cm}^{-1}$ de los grupos azo, señales $\mathrm{C}-\mathrm{C} / \mathrm{C}-\mathrm{O} / \mathrm{C}-\mathrm{N}$ y $\mathrm{SO}_{3}{ }^{2}$ respectivamente, solapadas con las bandas del grupo metileno, Si-O-Si e interacción superficie siloxano/orgánico, respetando el mismo orden.

El resultado del análisis IR de la muestra So-Y se observa en la Figura 8.5.9, el detalle de cada una de las bandas de absorción identificadas se presenta en la Tabla 8.5.5.

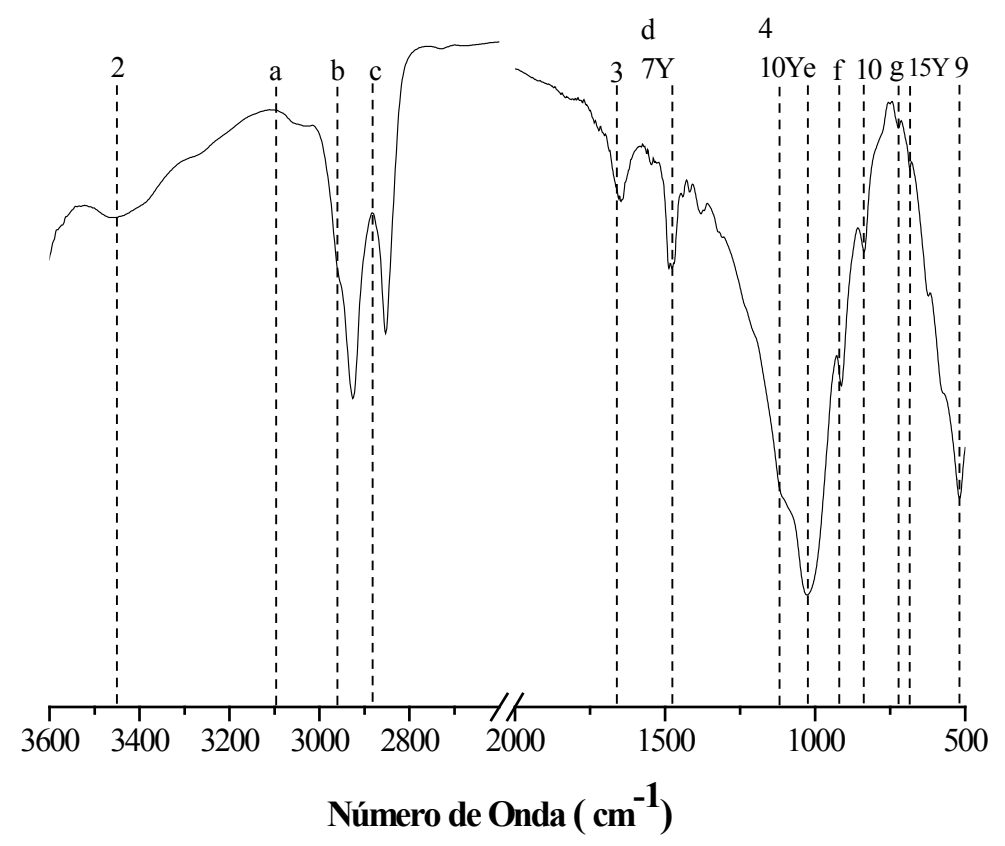

Figura 8.5.9. IR de la muestra So-Y. 
Tabla 8.5.4. Bandas de absorción y grupos asociados de la muestra So-Y.

\begin{tabular}{|c|c|c|}
\hline Bandas & Número de Onda $\left(\mathbf{c m}^{-1}\right)$ & Grupos Asociados \\
2 & 3463 & H-O-H Stretching del agua \\
$\mathrm{a}$ & 3054 & Stretching simétrico de la cabeza del grupo $\left(=\mathrm{CH}_{2}\right)$ \\
$\mathrm{b}$ & 2927 & $\mathrm{CH}_{3}-\mathrm{N}$ stretching simétrico del trimetil-amonio \\
$\mathrm{c}$ & 2852 & $\mathrm{C}-\mathrm{H}$ Stretching simétrico del grupo metileno $\left(=\mathrm{CH}_{2}\right)$ \\
3 & 1643 & Bending del grupo H-O-H \\
\hline $\mathrm{d} / 7 \mathrm{Y}$ & 1477 & Grupo azo y C-H Scisoring del grupo $=\mathrm{CH}_{2}$ \\
$4 / 10 \mathrm{Y}$ & 1112 & Cenales complementarias de los grupos $\mathrm{C}-\mathrm{C}, \mathrm{C}-\mathrm{N}$ y stretching longitudinal Si-O-Si \\
\hline \hline $\mathrm{e}$ & 1027 & Interacción orgánico-superficie siloxano \\
$\mathrm{f}$ & 912 & N-C vibración stretching asimétrico \\
10 & 838 & Stretching Al-Mg-OH \\
$\mathrm{g}$ & 725 & $\mathrm{C}-\mathrm{H}$ Rocking del metileno $\left(=\mathrm{CH}_{2}\right)$ \\
\hline $15 \mathrm{Y}$ & 690 & Stretching Cl-Ar \\
\hline 9 & 520 & Bending Si-O-Al \\
\hline
\end{tabular}

Como ya fue expuesto en los ensayos anteriores, se identificaron las señales características del adsorbente So, que se aprecian en los ensayos So-R y So-O. Para el caso de la retención de $\mathrm{Y}$, las bandas coincidentes con el tinte se encuentran a $1477 \mathrm{~cm}^{-1}$, $1112 \mathrm{~cm}^{-1}$ y $690 \mathrm{~cm}^{-1}$, correspondientes a los grupos azo $(\mathrm{N}=\mathrm{N})$, bandas complementarias de los grupos C-C, C-N y C-O, y finalmente vibraciones de la unión Cl-Ar, respectivamente.

La Figura 8.5.10, exhibe las bandas características del ensayo realizado sobre el adsorbente Zo y la disolución R. Como ya se observó en los ensayos efectuados sobre el sustrato So, se conservan las bandas de absorción de la organobentonita; la presencia del colorante se evidencia en las señales vibracionales de los grupos que se describen en la Tabla 8.5.6. 


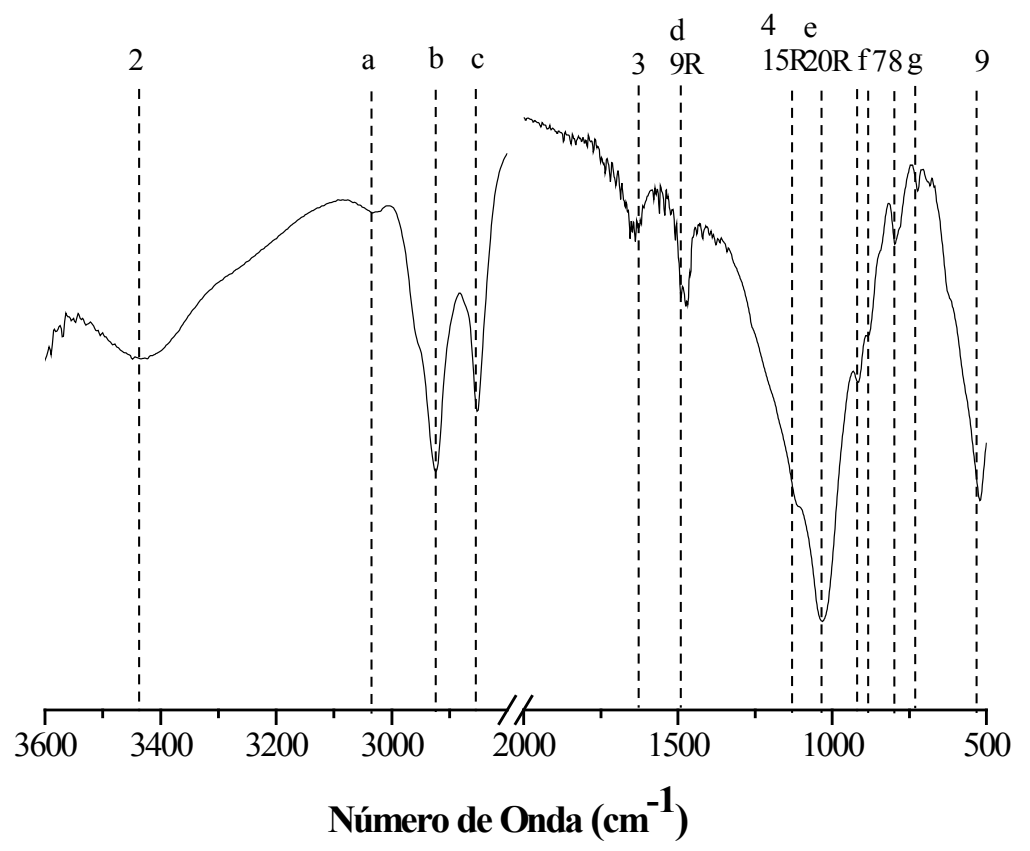

Figura 8.5.10. IR de la muestra Zo-R.

Tabla 8.5.5. Bandas de absorción y grupos asociados de la muestra Zo-R.

\begin{tabular}{|c|c|c|}
\hline Bandas & Número de Onda $\left(\mathrm{cm}^{-1}\right)$ & Grupos Asociados \\
\hline 2 & 3435 & H-O-H Stretching del agua \\
\hline a & 3029 & Stretching simétrico de la cabeza del grupo $\left(=\mathrm{CH}_{2}\right)$ \\
\hline $\mathrm{b}$ & 2924 & $\begin{array}{l}\text { Stretching simétrico de la cabeza del trimetil-amonio } \\
\qquad\left(\mathrm{CH}_{3}-\mathrm{N}\right)\end{array}$ \\
\hline $\mathrm{c}$ & 2852 & $\mathrm{C}-\mathrm{H}$ Stretching simétrico del grupo metileno $\left(=\mathrm{CH}_{2}\right)$ \\
\hline 3 & 1639 & Bending del grupo $\mathrm{H}-\mathrm{O}-\mathrm{H}$ \\
\hline$d / 9 R$ & 1475 & $\begin{array}{l}\text { Vibración del grupo azo y C-H Scisoring del grupo } \\
\qquad=\mathrm{CH}_{2}\end{array}$ \\
\hline $4 / 15 \mathrm{R}$ & 1118 & $\begin{array}{c}\text { Señal complementaria }(\mathrm{C}-\mathrm{C} ; \mathrm{C}-\mathrm{N}, \mathrm{C}-\mathrm{O}) \text { y stretching } \\
\text { longitudinal } \mathrm{Si}-\mathrm{O}-\mathrm{Si}\end{array}$ \\
\hline $\mathrm{e} / 20 \mathrm{R}$ & 1033 & $\mathrm{SO}_{3}=$ e interacción orgánico-superficie siloxano \\
\hline ff & 916 & N-C vibración stretching asimétrico \\
\hline 7 & 877 & Stretching Al- $-\mathrm{Fe}^{+3}-\mathrm{OH}$ \\
\hline 8 & 785 & Stretching del cuarzo (Si-O) \\
\hline g & 723 & $\mathrm{C}-\mathrm{H}$ Rocking del metileno $\left(=\mathrm{CH}_{2}\right)$ \\
\hline 9 & 520 & Bending Si-O-Al \\
\hline
\end{tabular}


Los grupos propios del colorante R se observan a números de onda de $1475 \mathrm{~cm}^{-1}$, $1118 \mathrm{~cm}^{-1}$ y $1033 \mathrm{~cm}^{-1}$ de las bandas azo $(\mathrm{N}=\mathrm{N})$, uniones $\mathrm{C}-\mathrm{C} / \mathrm{C}-\mathrm{N} / \mathrm{C}-\mathrm{O}$ y vibraciones del grupo $\mathrm{SO}_{3}{ }^{2}$; coincidentes con las absorciones de la organobentonita del grupo metileno, stretching Si-O-Si y las interacciones siloxano/orgánico.

Los ensayos Zo-O, Figura 8.5.11, en la que se aprecian las bandas de absorción, se encontraron grupos pertenecientes al colorante $\mathrm{O}$ a $1475 \mathrm{~cm}^{-1}, 1112 \mathrm{~cm}^{-1}$ y $1031 \mathrm{~cm}^{-1}$, de las señales del cromóforo azo $(\mathrm{N}=\mathrm{N})$, vibraciones complementarias de los grupos $\mathrm{C}-\mathrm{C} / \mathrm{C}-\mathrm{N} / \mathrm{C}$ $\mathrm{O}$ y las señales del grupo $\mathrm{SO}_{3}{ }^{=}$; de igual manera que en los espectros infrarrojos anteriores, las bandas de absorción del tinte fueron coincidentes con los grupos del adsorbente Zo, identificados para el metileno $\left(=\mathrm{CH}_{2}\right)$, interacción $\mathrm{Si}-\mathrm{O}$ y superficie siloxano/orgánico.

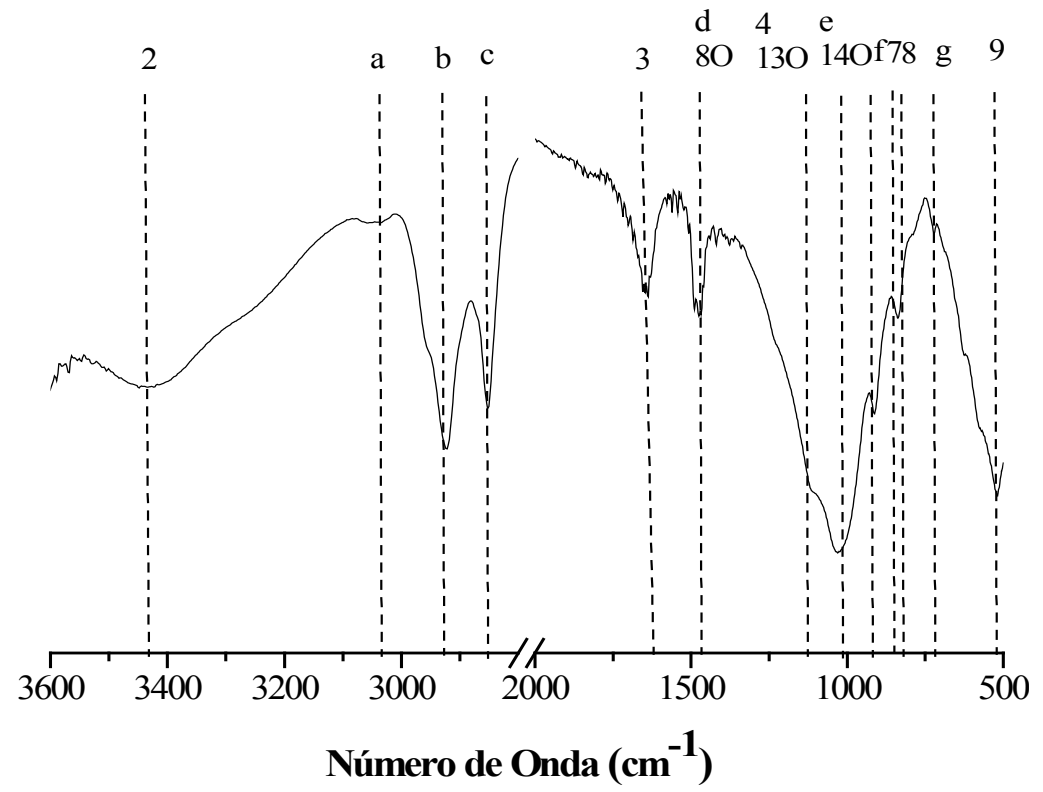

Figura 8.5.11. IR de la muestra Zo-O.

En la Tabla 8.5.7, se encuentran detalladas la totalidad de las vibraciones de los grupos de la esmectita, esmectita/HDTMA ${ }^{+}$y tinte, identificadas en los ensayos de adsorción del sustrato Zo y el colorante O. 
Tabla 8.5.6. Bandas de absorción y grupos asociados de la muestra Zo-O.

\begin{tabular}{|c|c|c|}
\hline Bandas & Número de Onda $\left(\mathrm{cm}^{-1}\right)$ & Grupos Asociados \\
\hline 2 & 3431 & H-O-H Stretching del agua \\
\hline $\mathrm{a}$ & 3045 & Stretching simétrico de la cabeza del grupo $\left(=\mathrm{CH}_{2}\right)$ \\
\hline $\mathrm{b}$ & 2923 & Stretching de la cabeza del grupo trimetil-amonio \\
\hline $\mathrm{c}$ & 2850 & C-H Stretching simétrico del grupo metileno $\left(=\mathrm{CH}_{2}\right)$ \\
\hline 3 & 1639 & Bending del grupo $\mathrm{H}-\mathrm{O}-\mathrm{H}$ \\
\hline $\mathrm{d} / 8 \mathrm{O}$ & 1471 & $\mathrm{~N}=\mathrm{N}$ y $\mathrm{C}-\mathrm{H}$ Scisoring del grupo $=\mathrm{CH}_{2}$ \\
\hline $4 / 130$ & 1112 & $\begin{array}{l}\text { Señales complementarias de los grupos C-C, C-N y } \\
\text { C-O y stretching longitudinal Si-O-Si }\end{array}$ \\
\hline $\mathrm{e} / 14 \mathrm{O}$ & 1031 & $\begin{array}{c}\text { Vibraciones } \mathrm{SO}_{3}=\text { e interacción orgánico-superficie } \\
\text { siloxano }\end{array}$ \\
\hline 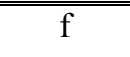 & 912 & "N-C vibración stretching asimétrico \\
\hline 7 & 844 & Stretching Al- $\mathrm{Fe}^{+3}-\mathrm{OH}$ \\
\hline 8 & 825 & Stretching del cuarzo Si-O \\
\hline $\mathrm{g}$ & 721 & C-H Rocking del metileno $\left(=\mathrm{CH}_{2}\right)$ \\
\hline 9 & 524 & Bending Si-O-Al \\
\hline
\end{tabular}

La Figura 8.5.12, y la Tabla 8.5.8, muestran las bandas y el detalle de cada grupo a las que pertenecen, que fueron identificadas en los ensayos con la organobentonita Zo y el tinte $\mathrm{Y}$.

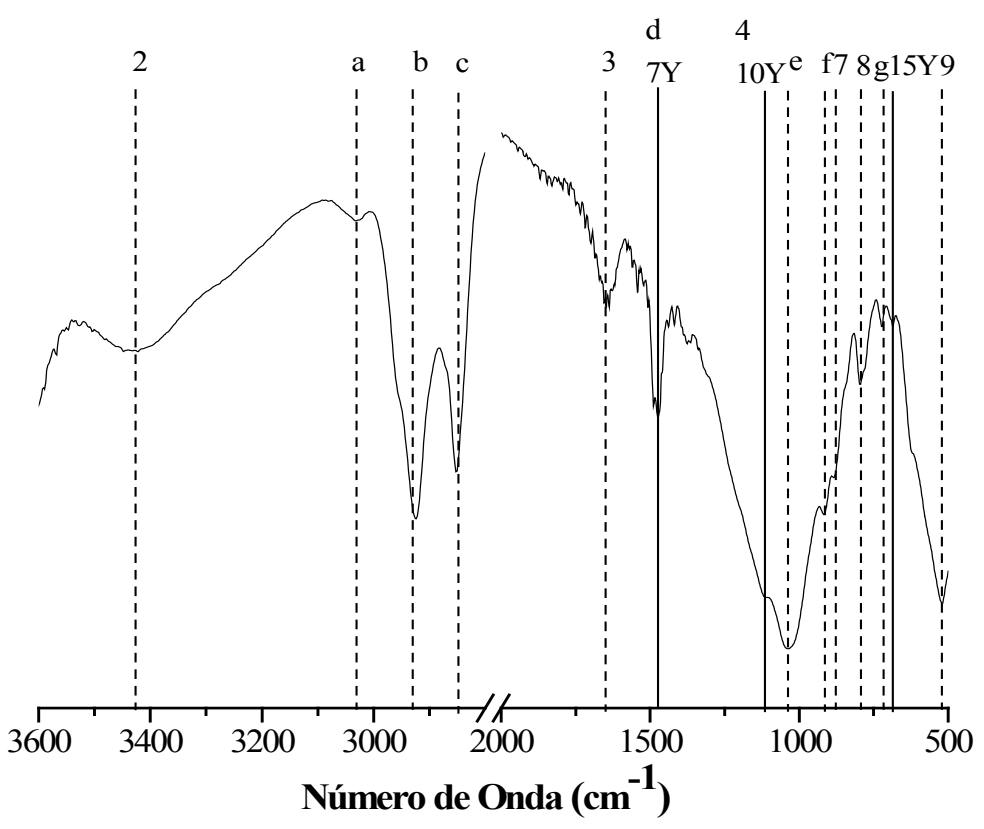

Figura 8.5.12. IR de la muestra Zo-Y. 
Tabla 8.5.7. Bandas de absorción y grupos asociados de la muestra Zo-Y.

\begin{tabular}{|c|c|c|}
\hline Bandas & Número de Onda $\left(\mathrm{cm}^{-1}\right)$ & Grupos Asociados \\
\hline 2 & 3431 & H-O-H Stretching del agua \\
\hline $\mathrm{a}$ & 3035 & Stretching simétrico del grupo $\left(=\mathrm{CH}_{2}\right)$ \\
\hline $\mathrm{b}$ & 2927 & Stretching simétrico del grupo trimetil-amonio \\
\hline $\mathrm{c}$ & 2852 & C-H Stretching simétrico del grupo metileno $\left(=\mathrm{CH}_{2}\right)$ \\
\hline 3 & 1648 & Bending del grupo $\mathrm{H}-\mathrm{O}-\mathrm{H}$ \\
\hline $\mathrm{d} / 7 \mathrm{Y}$ & 1477 & Grupo azo y scisoring del grupo $=\mathrm{CH}_{2}$ \\
\hline $4 / 10 Y$ & 1118 & $\begin{array}{c}\text { Señales complementarias de los grupos } \mathrm{C}-\mathrm{C}, \mathrm{C}-\mathrm{N} \text { y } \\
\text { C-O y stretching longitudinal Si-O-Si }\end{array}$ \\
\hline e & 1033 & Interacción orgánico-superficie siloxano \\
\hline $\mathrm{f}$ & 912 & $\mathrm{~N}-\mathrm{C}$ vibración stretching asimétrico \\
\hline 7 & 873 & Stretching $\mathrm{Al}-\mathrm{Fe}^{+3}-\mathrm{OH}$ \\
\hline 8 & 792 & Vibración del grupo Si-O en cuarzo \\
\hline $\mathrm{g}$ & 725 & C-H Rocking del metileno $\left(=\mathrm{CH}_{2}\right)$ \\
\hline $15 \mathrm{Y}$ & 686 & Stretching de la unión $\mathrm{Cl}-\mathrm{Ar}$ \\
\hline 8 & 520 & Bending Si-O-Al \\
\hline
\end{tabular}

Los grupos característicos del tinte $\mathrm{Y}$ se identificaron a $1477 \mathrm{~cm}^{-1}, 1118 \mathrm{~cm}^{-1} \mathrm{y}$ $686 \mathrm{~cm}^{-1}$; éstos pertenecen a las vibraciones del grupo azo $(\mathrm{N}=\mathrm{N})$, señales complementarias de $\mathrm{C}-\mathrm{C} / \mathrm{C}-\mathrm{N} / \mathrm{C}-\mathrm{O}$ y stretching del grupo $\mathrm{Cl}-\mathrm{Ar}$; en éstas, sólo las primeras dos bandas coinciden con grupos de la organoarcilla Zo, precisamente en los grupos metileno y las vibraciones del grupo $\mathrm{Si}-\mathrm{O}-\mathrm{Si}$; mientras que la señal del grupo clorobenceno (Cl-Ar) se aprecia como una nueva señal, de igual manera que se observó en los ensayos con el adsorbente So y éste mismo tinte.

De esta manera, las bandas de los colorantes identificadas en los organoadsorbentes So y Zo correspondieron a: vibraciones del grupo azo y señales complementarias de las uniones $\mathrm{C}-\mathrm{C} / \mathrm{C}-\mathrm{O} / \mathrm{C}-\mathrm{N}$ para $\mathrm{Y}, \mathrm{O}$ y $\mathrm{R}$; vibraciones de $\mathrm{SO}_{3}{ }^{=}$en los tintes $\mathrm{R}$ y $\mathrm{O}$, en tanto que la absorción del grupo Cl-Ar se presentó en el colorante Y.

Finalmente, los estudios por DRX, análisis térmico e infrarrojo de los colorantes en las organobentonitas permitieron inferir la presencia de los colorantes en los sólidos, ya 
sea por alteración del espaciado interlaminar, pérdidas de masa, y presencia de bandas características de los colorantes, respectivamente.

\subsubsection{Ensayos de Desorción}

Los ensayos de desorción realizados por los adsorbentes So-Y/O/R y Zo-Y/O/R, con agua destilada y analizados por UV-visible, se presentan a continuación en las Figuras 8.5.13 y 8.5.14.

Para el total de las experiencias (So-Y/R/O y Zo-Y/R/O), el contacto en agitación con agua destilada durante 24 horas, no logró desorber a los colorantes de las estructuras de las organobentonitas.

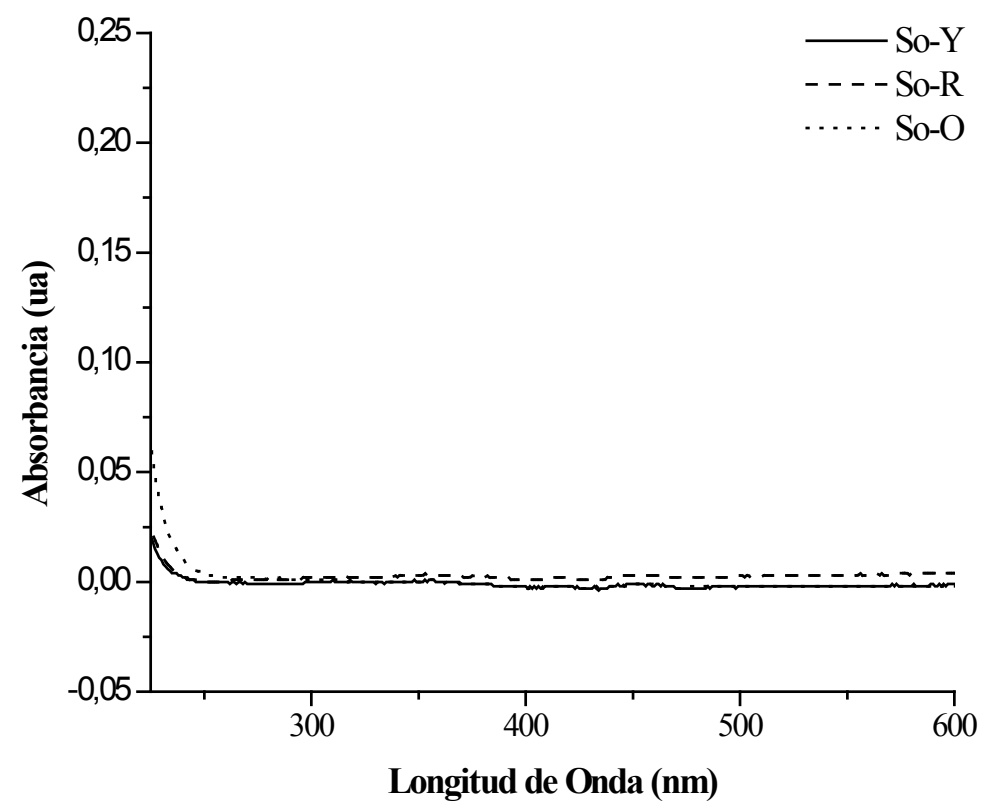

Figura 8.5.13. UV-vis. Ensayos de desorción sólido So-R/O/Y. 


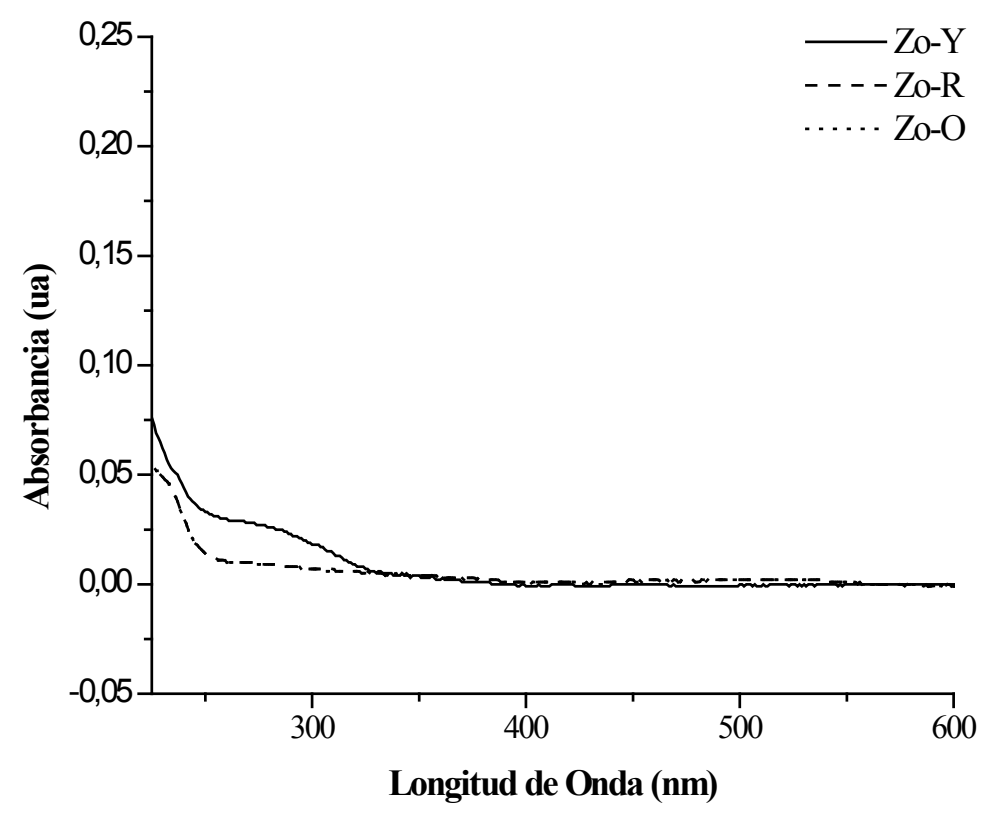

Figura 8.5.14. UV-vis. Ensayos de desorción sólido Zo-R/O/Y. 


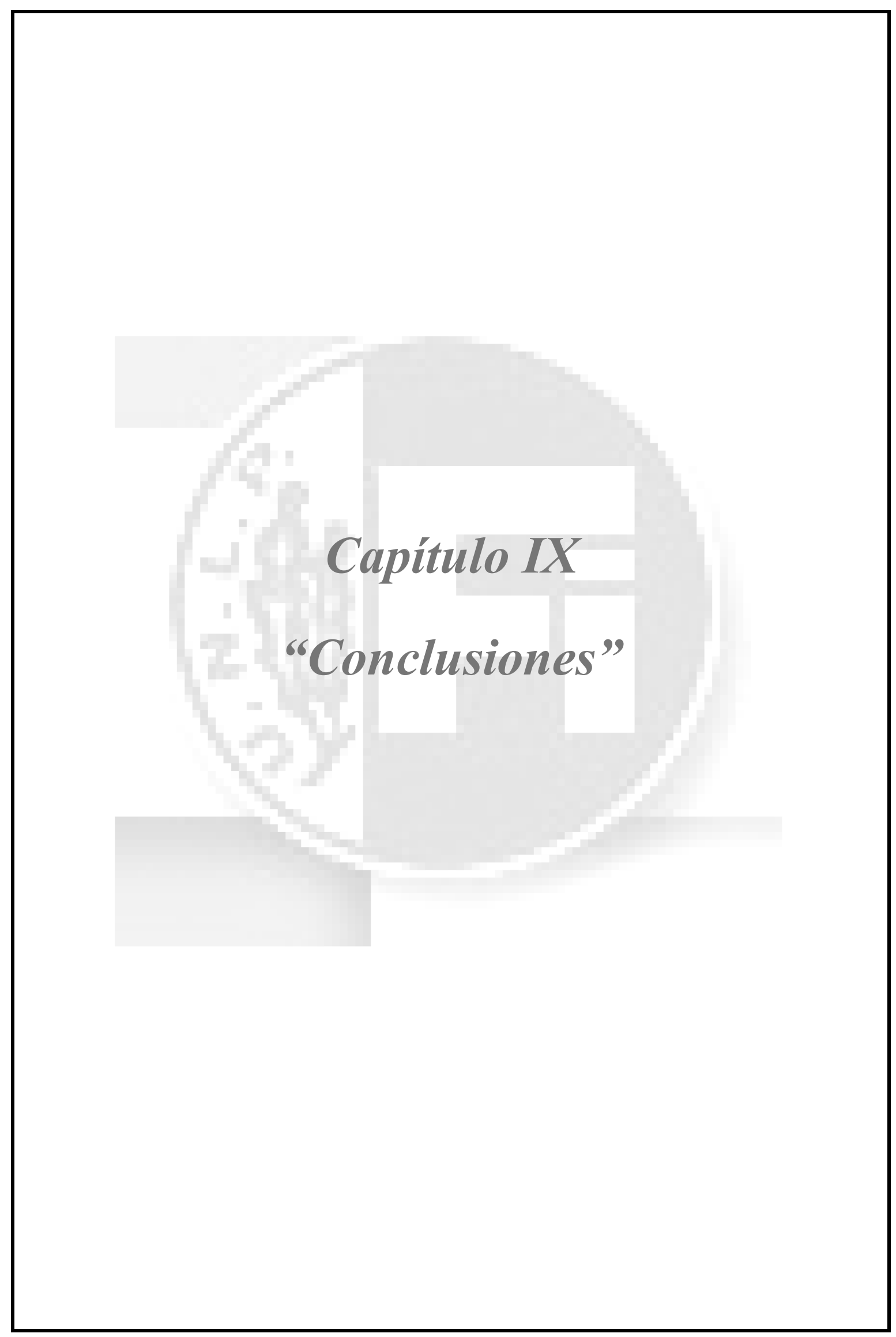





\section{CONCLUSIONES}

El estudio de evaluación sobre retención de colorantes textiles (Yelow GR, Orange G y Red Allura AC) por arcillas permitió arribar a las siguientes conclusiones:

\section{a) Relativo a la selección de arcillas}

a.1) Posterior a estudios previos de varias arcillas nacionales fueron seleccionadas dos bentonitas con diferentes características respecto al componente mineral arcilloso que las conforma. De esta manera una bentonita de la provincia de Neuquén (Z) y otra de San Juan (S) fueron seleccionadas debido fundamentalmente a que poseen diferente composición mineralógica y estructural.

De los diferentes ensayos de caracterización, efectuados sobre las bentonitas $\mathrm{S}$ y $\mathrm{Z}$, se concluye que la primera, $\mathrm{S}$, posee una mayor fracción de mineral arcilloso, presentando sólo cuarzo como mineral minoritario no arcilloso; mientras que la bentonita $\mathrm{Z}$ presenta una mayor variedad de minerales no arcillosos, siendo éstos: cuarzo, feldespato y yeso. Del análisis químico, mineralógico y térmico de las bentonitas, se reconoció que la $\mathrm{S}$ posee esmectita tipo montmorillonita; a diferencia de la $\mathrm{Z}$, en la que se determinó que se trata de una bentonita conformada por dos especies de esmectitas: montmorillonita y beidelita/nontronita.

a.2) Habiéndose confirmado que las arcillas naturales no demostraron capacidad de retención de los colorantes seleccionados, se procedió a realizar un tratamiento con sal de amonio cuaternario (catión orgánico HDTMA ${ }^{+}$) en base a las propiedades de los colorantes, fundamentalmente de carácter aniónico.

a.2.1) Posterior a la modificación de las bentonitas con el catión orgánico, pudo observarse una marcada diferencia entre ambas organobentonitas (So y Zo) desde el punto de vista del espaciado interlaminar, donde la So mostró un valor mayor respecto a la Zo. Esto significo que la disposición del catión orgánico entre las láminas del mineral arcilloso en la So fue diferente al del Zo. Así, el espaciado de la So fue 2,22 nm y en la organobentonita Zo 1,91 $\mathrm{nm}$. La variación interlaminar del adsorbente So, se corresponde con una disposición de la molécula orgánica tipo parafina; en tanto que, el espaciado 
entre las láminas en el adsorbente Zo, concuerda con una disposición tipo pseudotrilaminar.

a.2.2) La disminución del agua fisiadsorbida en la estructura de las organobentonitas So y Zo (confirmada por análisis termogravimetricos), se condice con la variación en la naturaleza hidrofílica natural de los minerales arcillosos, a organofílica en los sustratos orgánicos. Esto último, no es un punto menor, debido a que la afinidad por los compuestos orgánicos, creada a partir de la modificación de las bentonitas con la sal HDTMA-Br, posibilita la adsorción de compuestos de naturaleza orgánica sobre una estructura naturalmente organofóbica. La interacción entre las arcillas y el surfactante (catión orgánico seleccionado), además, se ve evidenciada en las bandas de absorción en el infrarrojo, donde se detectó modificación en la vibración de la banda stretching del agua $\left(\sim 3400 \mathrm{~cm}^{-1}\right)$ y la presencia de bandas características del HDTMA ${ }^{+}$, siendo una de las destacadas la banda ubicada a $3022 \mathrm{~cm}^{-1}$ del grupo $\mathrm{CH}_{3}-\mathrm{N}$ perteneciente al stretching simétrico de la cabeza del trimetilamonio.

De acuerdo con los cálculos efectuados, la cantidad retenida de orgánico equivalente a $\mathrm{HDTMA}^{+}$indicaría que So retuvo más, debido a su mayor capacidad de intercambio catiónico.

\section{b) Relativo a los colorantes}

b.1) Los colorantes seleccionados $\mathrm{Y}, \mathrm{O}, \mathrm{R}$ fueron caracterizados por IR y UVvisible. Cada uno de ellos presentó diferentes bandas de absorción de acuerdo con los grupos cromóforos y auxocromos que conforman su estructura química; es así que para el tinte $\mathrm{Y}$, se reconoció por UV-visible el grupo azoico a $400 \mathrm{~nm}$, y entre las principales bandas en el IR a $1456 \mathrm{~cm}^{-1}$ (stretching Ar$\mathrm{N}=\mathrm{N})$ y $688 \mathrm{~cm}^{-1}$ banda correspondiente al estiramiento del cloro-benceno. Para el caso de R, además de identificar el cromóforo azo a 496 nm, se detectó el grupo naftaleno a $316 \mathrm{~nm}$ y benceno a $215 \mathrm{~nm}$; y por ensayos IR las bandas a $874 \mathrm{~cm}^{-1}$ (sustituciones aromáticas triples), $981 \mathrm{~cm}^{-1}\left(\mathrm{SO}_{3}{ }^{=}\right)$y $1498 \mathrm{~cm}^{-1}$ $(\mathrm{N}=\mathrm{N})$. Finalmente, en el colorante $\mathrm{O}$ se caracterizaron los mismo tres grupos cromóforos y auxocromos encontrados en $\mathrm{R}$, ubicados éstos a $248 \mathrm{~nm}$ (benceno), $330 \mathrm{~nm}$ (naftaleno) y $485 \mathrm{~nm}$ (azo); en tanto que, en los resultados 
por IR, las bandas de absorción principales fueron las ubicadas a $788 \mathrm{~cm}^{-1}$ (sustituciones aromáticas triples), $981 \mathrm{~cm}^{-1}\left(\mathrm{SO}_{3}{ }^{=}\right)$y $1490 \mathrm{~cm}^{1}(\mathrm{~N}=\mathrm{N})$.

b2) Para el estudio efectuado en cada uno de los cromóforos que forman la estructura de los colorantes, se observó que no existen grandes diferencia entre ellos, sin embargo, para el caso particular del grupo naftaleno, constituyente de los colorantes $\mathrm{R}$ y $\mathrm{O}$, la presencia de los dos grupos auxocromos sulfonato asociados al cromóforo naftaleno, que conforma la estructura química del colorante $\mathrm{O}$, éstos se presentan unidos al naftaleno, mientras que en el tinte $\mathrm{R}$, uno de los sulfonatos está unido al naftaleno, en tanto que el restante se une al restante grupo aromático. Además el colorante $\mathrm{Y}$ posee dos grupos azo, a diferencia de $\mathrm{R}$ y $\mathrm{O}$, quienes solo contienen uno de este cromóforo.

\section{c) Relativo a las adsorciones}

c.1) Influencia del tipo de adsorbente (arcillas)

La mencionada variación en el espaciado d001 de las organobentonitas, en el apartado "Relativo al adsorbente" (a.2.1), que da información sobre la disposición de la molécula orgánica en la estructura esmectítica, afecta la adsorción de los tintes estudiados.

En los ensayos efectuados sobre las organoarcillas So y Zo, se observaron diferencias significativas al analizar los valores de la cantidad agregada de adsorbente a una misma concentración y cantidad de solución coloreada; es así que los mayores valores de retención se presentaron en las experiencias efectuadas sobre Zo, superando en cada uno de los colorantes retenidos el 98\% al agregar una cantidad de $2 \mathrm{~g}$ de adsorbente por cada $\mathrm{L}$ de solución coloreada. Para el sustrato So, los valores alcanzados fueron del 70\%; siendo muy inferior en las experiencias con las soluciones de $\mathrm{R}$ y $\mathrm{O}$, llegando a valores cercanos a $70 \%$ y $45 \%$, respectivamente. El orden de remoción fue $\mathrm{Y}>\mathrm{R}>\mathrm{O}$ tanto en los ensayos en sistema batch con el organoadsorbente Zo como con So.

c.2.) Isoterma de adsorción evaluando diferentes grupos cromóforos que constituyen a los colorantes estudiados. 
Los resultados de las experiencias de adsorción, efectuadas analizando cada uno de los grupos cromóforos y auxocromo que conforman los tintes $\mathrm{R}, \mathrm{O}$ e $\mathrm{Y}$; estudiados en la presente tesis, mostraron que el grupo cromóforo azo, común a los tres colorantes fue más fuertemente retenido por ambas organobentontias, con valores muy superiores por parte de la muestra Zo. La forma de las isotermas de adsorción se correspondió con las de tipo L2.

\section{d) Relativo a producto final adsorbente-adsorbato}

d.1) Los ensayos por IR de los productos obtenidos (organobentonitas con colorantes retenidos) demostraron presencia de bandas características pertenecientes a los colorantes retenidos. Esto significo efectividad en la capacidad de retención por parte del adsorbente organobentonita.

d.2) Las modificaciones en los análisis térmicos de los productos, también demostraron la existencia de colorantes en el sólido organobentonias posterior a las retenciones.

d.2) De los valores de espaciado entre láminas de los adsorbentes con colorantes en su estructura, obtenidos por DRX, fue posible concluir que los grupos orgánicos de los colorantes, estarían ubicados en la estructura del mineral de igual forma que el amonio cuaternario que modificó levemente el carácter de la arcilla primitiva (parafina en So y pseudotrilamina Zo).

\section{e) Relativo a las desorciones}

e.1) Las experiencias de desorción a las que se sometieron las organobentonitas So y Zo con los colorantes Y, O y R, demostraron que el contacto de ellas con agua destilada durante 24 horas no remueve a los tintes de su estructura.

e.2) Por medio de las desorciones es posible concluir que los productos de adsorción de las soluciones coloreadas en las organobentonitas estudiadas (So y Zo) son estables en solución acuosa, lo que se considera sumamente importante debido a la propiedad de eliminar sustancias peligrosas o mutar a moléculas carcinogénicas, que poseen los colorantes estudiados $(\mathrm{Y}, \mathrm{O}$ y R) al estar en contacto con el agua. 
Este trabajo de Tesis permitió concluir que:

- Colorantes aniónicos pueden ser removidos por arcillas bentoníticas constituidas por esmectitas modificadas con catión orgánico.

- La disposición del catión orgánico en el espaciado interlaminar de la esmectita, componente principal de la bentonita influye en la capacidad de retención de los colorantes.

- El colorante Yellow fue retenido con mayor facilidad debido a su contenido mayor en grupo azo respecto a los colorantes Red y Orange.

- Los grupos azo, naftaleno y benceno presentes en los colorantes fueron retenidos en forma similar por las arcillas orgánicas, donde solo el tipo de arcilla marca la diferencia.

- Los colorantes retenidos son estables en presencia de agua. 


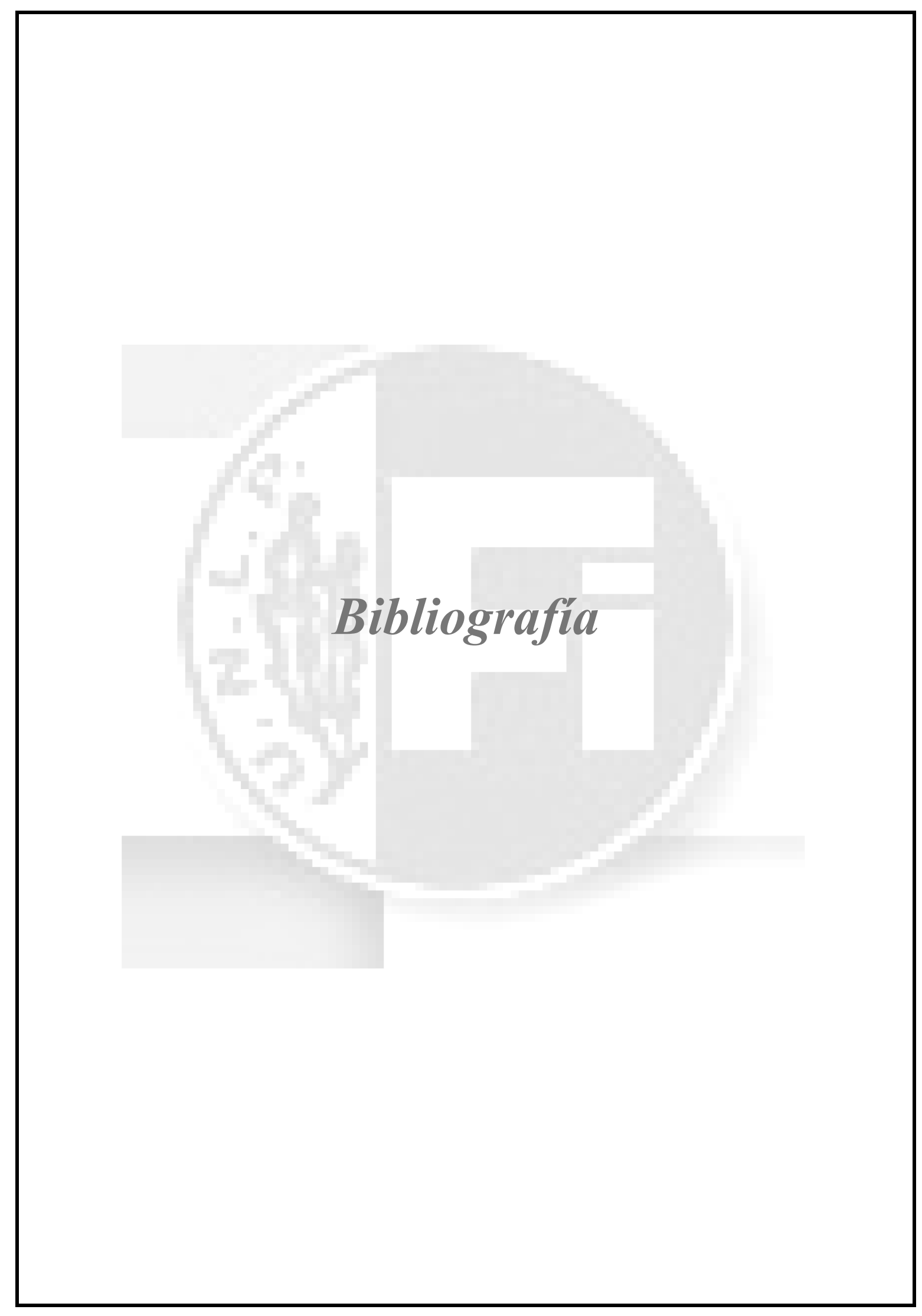





\section{BIBLIOGRAFIA}

Actualización de Informe de Impacto Ambiental (1997). Empresa MINARMCO S.A. Yacimiento 7 de Mayo y Júpiter. Dirección General de Minería. Expte No 2220/97.

Albanis, D.C.; Hela, T. A.; Sakellarides, D. G. \& Danis, T. M. (2000). Removal of dyes from aqueous solutions by adsorption on mixtures of fly ash and soil in batch and column techniques. Global Nest; The Int. J., Vol 2, N³, pp 237-244.

Allen, S. J. \& Koumanova, B. (2005). Decolourisation of water/wastewater using adsorption (review). Journal of the University of Chemical Technology and Metallurgy, 40, 3, pp175-192.

Alonso-Calderón, A. I. A.; Pérez-Curiel, J.; Montiel-Salinas, C.; Geissler, G.; ZayasPérez, M. T.; y Villegas-Rosas, M. L. O. (2008). Eliminación de fenol, 2-clorofenol y clorantes en aguas artificiales contaminadas y aguas residuales textiles utilizando a la peroxidada de chayote. Revista Latinoamericana de Recursos Naturales, 4(2); pp 278284.

Ambrogi, A.; Cardarelli, D. A. \& Eggers, R. (2003). Separation of natural colorants using a combined high-pressure extraction-adsorption process. Latin American Applied Research. 33; pp 323-326.

Anderson, M. A.; Trouw, F. R. \& Tam, C. N. (1999). Properties of water in calcium and hexadecyltrimethylammonium-exchanged bentonite. Clays and Clay Minerals, Vol. 47, $N^{o} 1 ;$ pp 28-35.

Andini, S.; Cioffi, R.; Montagnaro, F.; Psciotta, F.; Santoro, L. (2006). Simultaneous adsorption of chlorophenol and heavy metals ions on organophilic bentonite. Applied Clay Science, Volume 37, Issues 1-2, pp. 126-133.

Ayala, M. E.; Penuela Mesa, G. y Montoya, J. L. (2006). Procesos de membranas para el tratamiento de agua residual industrial con altas cargas de colorante Amarillo ácido 23. Revista Facultad de Ingeniería, Universidad de Antioquía, No 38; pp 53-63.

Baban, A.; Yediler, A. \& Ciliz, N.K. (2010). Integrated water management and CP implementation for wool and textile blend processes. Clean, Vol.38, No.1, pp. 84-90

Bailly, J.; Volzone, C.; Cantera, C. \& Greco A. (2011). Modified bentonites as adsorbents for Retailing anionic dyes used in tanning industry. XXXI IULTCS Congress. Paper E48.

Bhatt, A. S.; Sakari, P. L., Vasudevan, M.; Pawar, R. R.; Sudheesh, N., Bajaj, H. C. \& Mody, H. M. (2012). Adsorption of an anionic dye from aqueous medium by organoclays: equilibrium modelling, kinetic and thermodynamic exploration. The Royal Society Of Chemistry 2; pp 8663-8671.

Bishop, J. L.; Pieters, C. M.; Edwards, J.O. (1994). Infrared Spectroscopic Analysis on the nature of waterin montmorillonite. Clays and Clay Minerals, vol. 42, No, pp. 702716. 
Blackburn, J. W.; Cadena, F.; Cazares; Chattopadhyay, E. S.; Gullick, R. W.; Gray, D.; Johnston, C. T.; Sawhney, B. L.; Traina, S. \& Weber, W. (1996). Organic Pollutants in the enviroment. CMS Workshop Lectures. Volumen 8. The Clay Minerals Society.

Boyd, S. A.; Jaynes, W. F. (1992). Role of layer change in organic contaminant sorption by organo-clay. In layer charges characteristics of clay. Pre-meeting Workshop CMS and SSA. Minesota. University Katchewa, Saskatchewan, pp. 89-120.

Brindley G. W., Brown G. (1980). Crystal Structures of Minerals and their X-Ray Identification. Mineralogical Society. Monograph No. 5. Mineralogical Society and The Royal Society.

Cegarra Sánchez, J. (2010). Fisicoquímica de la tintura de las fibras acrílicas con colorantes catiónicos. Escuela Superior de Ingenieros Industriales de Tarrasa (España).

Censo Nacional Minero, Evaluación Estadística; Secretaría de Minería de la Nación, Fundación EMPREMIN; (2003-2004).

Ceyhan, Ö. \& Baybaş, D. (1999). Adsorption of some textile dyes by hexadecyltrimethylammonium bentonite; pp 193-200.

Chacón, J. M.; Leal, M. T.; Sánchez, M. \& Bandala, E. R. (2002). Tratamiento de agua residual proveniente de la industria textil mediante fotocatálisis solar. XXVIII Congreso Interamericano de Ingeniería Sanitaria y Ambiental, Cancún, México.

Colour Index. www.colour-index.com

Cowan CT and White D. (1958). The mechanism of exchange reactions occurring between sodium montmorillonite and various n-primpary aliphatic amine salts. Trans. Faraday Soci. 54, pp 691-697.

Cowan CT and White D. (1960). Adsorption by organo-clay complexe. Clays and Clay Minerals, 9, pp 458-467.

Cowan CT and White D. (1961). Adsorption by organo-clay complexe part 2. Clays and Clay Minerals, 10, pp 226-235.

Daraei, A. (2013). Treatment of Textile Waste Water with Organoclay. Iran J. Chemistry Engineering, Vol 32, No 2.

Dawood, S. \& Sen, T. K. (2014). Review on dye removal from its aqueous solution into alternative cost effective and non-conventional adsorbents. Journal of Chemical and Process Engineering.

Day, R. A.; Underwood, A. L. (1989). Química Analítica Cuantitativa. Editorial Prentice-Hall Hispanoamericana S.A., ISBN 968-880-124-0. Mexico.

Dos Santos, O. A.; Castelli, C. Z.; Oliveira, M. F.; Almeida Neto, Da Silva, A. F. \& Meuris, G. C. (2013). Adsorption of Synthetic Orange Dye Wastewater in organoclay. Chemical Engineering Transactions, 32, pp 307-312. 
Duman, O.; Tunç, S. \& Polat, T. G. (2015). Determination od adsorptive properties of expanded vermiculite for the removal of C. I. Basic Red 9 from aqueous solution: Kinetic, isotherm and thermodynamic studies. Applied Clay Science; pp 22-32.

Dye Manufacturing (1998). Pollution Prevention and Abatement Handbook. World Bank Group Effective.

Dye Manufacturing (2012).

EPA US; High Production Volume (HPV) Challenge Program. The HPV voluntary challenge chemical list. Robust summaries and test plans. 2-Naphthalenesulfonic acid, 6-hydroxy-5-[(2-methoxy-5-methyl-4-sulfophenyl)azo]disodium salt. Washington, DC: US EPA, Off. Prevent. Pest. Tox. Subst., Pollut. Prevent. Toxics. Available from, as of May 19, 2011: http://www.epa.gov/chemrtk/viewsrch.htm.

Espantaleón, A. G.; Nieto, J. A.; Fernández \& M.; Marsal, A. (2003). Use of activated clays in the renoval of dyes and surfactants from tannery waste Waters. Applied Clay Science 24; pp 105-110.

Estadística Dirección Provincial de Minería y Policía Minera de Neuquén, 2015.

Fungaro, D. A.; Bonely, S. I. (2012). Synthesis and characterization of zeolite from coal ashes modified by cationic surfactant. Cerâmica, vol. 58, $N^{o}$ 345, ISSN 0366-6913.

Giles C., MacEwan T.H., Nakhwa, S.N. and Smith, D. (1960). A system of classification of solution absortion Isotherms, and its use in diagnosis of adsorption mechanisms and in measurement of specific surface areas of solids. J. Chem. Soc. pp.3973-3993.

Gosh, D. \& Bhattacharyya, K. G. (2002). Adsorption of methylene blue on kaolinite. Applied Clay Science 20; pp 295-300.

Green, F.J. (1990). The Sigma-Aldrich Handbook of Stains, Dyes, and Indicators. Aldrich Chemical Company, Inc: Milwaukee, WI; pp 539.

Greene-Kelly, R. (1957). The montmorillonite minerals (smectites): in The Differential Thermal Investigation of Clays, R. C. Mackenzie, ed., Mineralogical Society, London, 140-164.

Grim R. E. (1962). Applied Clay Mineralogy. McGraw-Hill, New York, 422 pp.

Guerra R.; Pizone, J. A.; Soneyro, D. (2014). Producción de áridos en Argentina. Vial 102, pp. 44-47.

Guggenheim, S. y Martin R.T. (1995). Report. Definition of clay and clay mineral: Joint report of the AIPEA nomenclature and CMS nomenclature committees. Clay and Clays Minerals. 43, 2,pp 255-256.

Guia de Buena Prácticas Ambientales para la Industria Textile (2009). International Resources Group (IRG) y Centro Nacional de Producción más limpia en Honduras. Editorial AGA\&Asociados, Honduras. 
Hao, O. J.; Kim, H.; Chang, P. C. (2000). Decolourization of wastewater. Critical Reviews in Environmental Science and Technology, vol. 30, pp. 449-505.

Hedley, C. B.; Yuan, G. B \& Theng, K. G. (2007).Thermal analysis of montmorillonites modified with quaternary phosphonium and ammonium surfactants. Applied Clay Science 35; pp 180-188.

Hedley, C. B.; Yuan, G.; Theng, B. K. G. (2007). Thermal analysis of montmorillonites modified with quaternary phosphonium and ammonium surfactants. Applied Clay Science, vol. 35, Issues 3-4, pp. 180-188.

Hu, Q. H.; Haghseresht, F. S.; Qiao, Z.; Xu, Z. P.; Wilson, M. A. \& Max Lu., G. Q. Adsorption of Basic Red Dye on Bentonite Clay. Procedings of the $1^{a}$ Nanomaterials Conference, pp 18-20.

IARC. (1972). Monographs on the Evaluation of the Carcinogenic Risk of Chemicals to Humans. Geneva: World Health Organization, International Agency for Research on Cancer: (Multivolume work). Available at: http://monographs.iarc.fr/ENG/Classification/index.php p. V8; pp 182.

Ignat, M. E.; Dulman, V. \& Tinca, O. (2012). Reactive Red 3 and Direct Brown 95 dyes Adsorption onto Chitosan. Cellulose Chemistry and Technology, 46 (5-6), pp 357-367

Industrial Dyes. Chemistry, Properties, Applications (2003). Edited by Klaus Hunger. ISBN 3-527-30426-6, Germany.

Irwin, H. (1981). Activated carbon adsorption of organic from the aqueous phase. Ann Arbor Science, Michigan.

IUPAC (1997). Compendium of chemical terminology: the gold book. $2^{\circ}$ Edition Scientific Publications, Oxford.

Jamishidi, A.; Rafiee, M. \& Jahangiri-Rad, M. (2014). Adsorption Behavior of Reactive Blue 29 Dye on Modified Nanoclay, Trends in Appklied Sciences Research 9 (6): 30; pp 3-311; ISSN 1819-3579.

Jefferson Lopes, T. J.; Hess Gonçalves, O.; Barbosa Barros, R.; Rodrigues Capelli, F. C., Machado, R. A. F.; Novy Quadri, M. G. \& Bastos Quadri, M. (2005). Adsorption of natural dyes on clay fixed on Polymers. Brazilian Archives of Biology and Technology, Vol. 48 Special; pp 275-280.

Jenkins R. (1999). X-Ray Fluorescence Spectrometry, Vol. 152, 2nd Edition, ISBN 0471-29942-1, Ed. Wiley Inter Science, USA.

Johnston, C. T. (1996). Sorption of organic compounds on clay minerals: A surface functional group approach; In Shawney BL, (Ed.); CMS Workshop Lectures, Organic Pollutants in the Environment; Vol. 8; The Clay Minerals Society, Boulder, CO, USA; pp 2-44.

Juang, L. C.; Wang, C. C.; Lee, C. K. \& Hsu, T. C. (2007). Dyes Adsorption Onto Organoclay and MCM-41. J. Environ. Eng. Manage, 17(1); pp 29-38. 
Kaickhoff, S. \& Bailey G. W. (1973). Optical Absorption Spectra of clay minerals, Clays and Clay Minerals; Vol. 21; pp 59-70.

Kaya, A. \& Ören, A. H. (2005). Adsorption of zinc from aqueous solutions to bentonite. Journal of Hazardous Materials B125; pp 183-189.

Khodaeer, E. A. (2015). Removal of Direct 50 Dyes from Aqueous Solution Using Natural Clay and Organoclay Adsorbents. Baghdad Science Journal Vol.12 (1).

Kim, C. S.; Yates, D. M. \& Heaney, P. J. (1997). The layered sodium silicate magadiite: An analog to smectite for benzene sorption from water. Clays and clay minerals, Vol. 45, $N^{\circ}$ 6; $p p$ 881-885.

Kuppusamy, Ll. \& Briones, R. (1997). Tratamiento anaerobio del agua residual de la industria textil mediante un reactor tipo EGSB a escala laboratorio y piloto. XI Congreso Nacional de Ingeniería Sanitaria y Ciencias Ambientales, Zacatecas, México.

Lacin, O.; Bayrak, B.; Korkut, O. \& Sayan, E. (2005). Modeling of adsorption and ultrasonic desorption of cadmium (II) and zinc (II) on local bentonite. Journal of Colloid and Interface Science; pp 330-335.

Lagaly G., Beneke K., Weiss A. (1975). Magadiite and H-magadiite: I. Sodium magadiite and some of its derivatives. Am mineral 60. II H-magadiite and its intercalation compounds Am Mineral 60:642-658.

Lagaly, G. (1979). The "layers change" of regular interstratified 2:1 clay minerals. Clays and Clay Minerals, vol. 27, $N^{\circ} 1, \mathrm{pp} .1-10$.

Lagaly, G. (1982). Layer charge heterogeneity in vermiculites. Clays and Clay Minerals, vol. 30, $N^{o} 3$, pp. 215-222.

Lee, J. F.; Mortland, M. M.; Chiou, C. T.; Kile, D. E.; Boyd, S. A. (1989). Shapeselective adsorption of aromatic compounds from water by tetramethylammoniumsmectite. Journal Chemical Society Faraday Transactions, II, 85, pp. 2953-2962.

Lee, S. Y. \& Kim, S. J. (2002). Expansion of smectite by hexadecyltrimethylammonium. Clays and clay minerals, Vol. 50, $N^{o} 4$, pp 435-445.

Lian, L.; Guo, L.; Wang, A. (2009). Use of CaCl2 modified bentonite for removal of Congo Red dye from aqueous solutions. Desalination, vol. 249, Issues 2, pp. 797-801.

Lin, S. H.; Juang, R. S. \& Wang. Y. H. (2004). Adsorption of acid dye from water onto pristine and acid-activated clays in fixed beds. Journal of Hazardous Materials B 113; pp 195-200.

Lozano-Álvarez, J. A.; Jáuregui-Rincon, J.; Mendoza-Díaz, G.; Rodríguez-Vázquez, R. \& Frausto-Reyes, C. (2009). Study of sorption equilibrium of Biopolymers Alginic Acid and Xanthan with C. I. Disperse Yellow 54. Journal Mexican Chemistry Society, 53 (2), pp 59-70. ISSN 1870-249X. 
Machado, F. M.; Bergmann, C. P.; Lima, E. C.; Abedayo, M. A. \& Fagan, S. B. (2014). Adsorption of a Textile Dye from Aqueous Solutions by Carbon Nanotubes. Materials Research: 17 (Suppl. 1); pp 153-160.

Mackenzie, R.C. (1970). Differential thermal analysis. Fundamental aspects. Vol. I \& II. Academic Press. London and New York.

Madejová J., Komadel P. (2001). Baseline studies of the clay minerals society source Clays: infrared methods. Clays and Clays Minerals, 49, 5, pp 410432.

Madejová, H. (2003). FTIR techniques in clay minerals Studies. Review. Vibrational Spectroscopy 31; pp 1-10.

Mansilla, H. D.; Lizama, C.; Gutarra, A. y Rodríguez, J. (2001).Tratamiento de residuos líquidos de la industria de celulosa y textil. $N^{o} 13$.

Margulies, L.; Rozen, H.; Nir, S. (1988). Model for competitive adsorption of organic cations on clays. Clays and Clay Minerals, 36, pp. 270-276.

Markiewicz, M.; Mrozik, W.; Reywan, K. Thöming, J. Hupka, J. Jungnickel, C. (2013). Changes in zeta potential of imidazolium ionic liquids modified minerals. Implications for determining mechanism of adsorption. Chemosphere, vol. 90, pp. 706-712.

Martinez Stagnaro, S. Y.; Volzone, C. \& Rueda, M. (2012). Influence of Thermal Treatment on Bentonite Used as Adsorbent for $\mathrm{Cd}, \mathrm{Pb}, \mathrm{Zn}$ Retention from Mono-Solute and Poly-Solute Aqueous Solutions. Materials Research, 15(4), pp 1-5.

Mattson, J.; Mark, H.; Malbin, M. (1969). "Surface chemistry of active carbon: specific adsorption of phenols”. Journal Colloid and Interface Science, 31, 116-130.

Morales-Guzmán, F. y Melgoza-Alemán, R. M. (2009). “Tratamiento del Colorante Azo Rojo Directo 23 mediante Reactores Discontinuos Secuenciados Anaerobios/Aerobios". Información Tecnológica-Vol. 20 N¹; pp 73-82.

Mortland, M. M.; Shaobai, S. \& Boyd, S. A. (1986). Clay-organic complexes as adsorbents for phenol and chlorophenols. Clays and Clay Minerals, Vol. 34, No5, pp 581-585.

Multilateral Investment Guarantee Agency. Environmental Guidelines for Dye Manufacturing. Pp 363-366.

Newman, A.C.D. (1987). Chemistry of clays and clays minerals, Mineralogical Society, Monograph No. 6, ISBN 0-582-30114-9, Longman Scientific \& Technical, London, 480.

O'Neil, M. J. (ed.). (2006). The Merck Index - An Encyclopedia of Chemicals, Drugs, and Biologicals. Whitehouse Station, NJ: Merck and Co. Inc., pp 52.

Paiva, L. B.; Morales, A. R. \& Díaz, F. R. V. (2008). Argilas organofílicas: características, metodologías de preparação e técnicas de caracterização. Cerámica 54; pp 213-226. 
Parolo, M. E.; Pettinari, G. R.; Musso, T. B.; Sánchez-Izquierdo, M. P.\& Fernández, L. G. (2014). Characterization of organo-modified bentonite sorbents: The effect of modification conditions on adsorption performance. Applied Surface Science; pp 356363.

Petit, S.; Righi D.; Madejová, J.; Decarreau, A. (1999). Interpretation of the infrared $\mathrm{NH}_{4}{ }^{+}$spectrum of the $\mathrm{NH}_{4}{ }^{+}$-clays: application to the evaluation of the layer charge. Clays and Clay Minerals, vol. 34, pp. 543-549.

Robinson, T.; McMullan, G.; Marchant, R. \& Nigam, P. (2001). Remediation of dyes in textile effluent: a critical review on current treatment technologies with a proposed alternative. Bioresource Technology, vol.77, pp.247-255

Roulia, M. \& Vassiliadis, A. A. (2008). Sorption characterization of a cationic dye retained by clays and perlite. Microporous and Mesopouros Materials 116; pp 732-740.

Sánchez, N.; Vazquez, M. y Torresi, R. (2010). Degradación y adsorción del colorante AZO RR239 en solución acuosa, por partículas de hierro "zero-valente" a nanoescala, inmovilizadas sobre aserrín. Revista Facultad de Ingeniería Universidad Antioquía, $N^{\circ} 55$; pp 18-25.

Sanz Tejedo, A. La industria de los colorantes y pigmentos., http://www.eii.uva.es/organica/qoi/tema-11.php.

Serratosa JM., Rausell-Colom JA., Sanz J. (1984). Charge density and its distribution in phyllosilicates: Effect on the arrangement and reactivity of adsorbed species. $J$ Mol. Catal. 27, pp 223-234.

Sheng, G.; Xu, S.; Boyd, S. A. (1996). Mechanism(s) Controlling Sorption of Neutral Organic Contaminants by Surfactant-Derived and Natural Organic Matter. Environment Science Technology, 30, pp. 1553-1557.

Šmelcerović, M.; Đorđević, D.; Novaković, M. \& Mizdraković, M. (2010). Decolorization of a textile vat dye by adsorption on waste ash. J. Serb. Chem. Soc. 75 (6) JSCS-4013. University of Niš, Faculty of Technology, Bulevar oslobođenja 124, 16000 Leskovac, Serbia; pp 855-872.

Smith, J. A.; Jaffe, P. R. (1991).Comparison of tetracholomethane sorption to an alkiylammonium clay and an alkyldiammonium clay. Environment Science Technology, vol. 25 (12), pp. 2054-2058.

Smith, J. A.; Jaffe, P. R. (1994). Benzene transport through landfill liners containing organophilic bentonite. Journal Environmental Enginnering, 120, pp. 1559-1577.

Solís-Oba, M.; Eloy-Juárez, M.; Teutli, M.; Nava J. L. \& González, I. (2009). Comparisons advanced techniques for the treatment o fan indigo model solution: electro incineration, Chemicals coagulation and enzymatic. Revista Mexicana de Ingeniería Química, Vol. 8, $N^{o} 3$; pp 275-282. 
Soloman, P.A.; Basha, C.A.; Ramamurthi, V.; Koteeswaran, K. \& Balasubramanian, N. (2009). Electrochemical degradation of Remazol Black B dye effluent. Clean, Vol.37, No.11, pp.889-900.

Sparks D.L. (1995).Ion exchange processes. Chapter 6 in Environmental soil chemistry. Academic press. New York. pp 141-158.

Sun Kou, M. R.(2004). Procesos para el tratamiento de las aguas residuales en plantas galvánicas y metalúrgicas. Estructplan On Line.

Suteu, D.; Zaharia, C.; Bilba, D.; Muresan, A. (2009). Muresan, R. \& Popescu, A. Decolorization wastewaters from the textile industry - physical methods, chemical methods. Industria Textil, Vol.60, No.5, pp.254-263.

Tahir, S. S. \& Rauf, N. (2004). Removal of Fe(II) from the wastewater of a galvanized pipe manufacturing industry by adsorption onto bentonite clay. Journal of Environmental Management 73; pp 285-292.

Temuujin, J.; Jadambaa, T.; Burmaa, G. (2004). Erdenechimeg, S.; Amarsanaa, J. \& MacKenzie, K. J. D. Characterisation of acid activated montmorillonite clay from Tuulant (Mongolia). Ceramics International 30; pp 251-255.

Theng, B. K. G.; Greenland, D. J; Quirck, J. P. (1967). Adsorption of alkylammonium cation by montmorillonite. Clays and Clay Minerals, 7: pp. 1-17.

Tsai, W. T.; Chang, C. Y.; Ing, C. H. \& Chang, C. F. (2004). Adsorption of dyes from aqueous solution on activated bleaching earth. Journal of Colloid and Interface Science; pp 72-78.

Tuesta, E. G.; Vivas, M.; Sun, R. y Gutarra, A. (2005). Modificación química de arcillas y su aplicación en la retención de colorantes. Revista Sociedad Química Perú 71; N¹; pp 26-36.

UK Food Guide, a British food additives website. Last retrieved 20 May 2007.

Umpuch, C. (2015) Removal of Yellow 20 dye from aqueous solution using organo-rice straw: Characteristic, Kinetic and Equilibrium studies. Enginnering Journal, Vol. 19 Issue 2; pp 59-69.

Umpunch, C.; Jutarat, B. (2013). Adsorption of organic dyes from aqueous solution by surfactant modified corn straw. International Journal Enginnering of Chemical and Applications, vol. 4, $N^{o}$ 3, pp. 134-139.

Valldeperas, J.; Lis, M. J.; Carrillo, F. y Navarro, J. A. (2005)Interpretación de las isotermas de absorción de colorantes. Trabajo de Divulgación, Boletín Intexter (U.P.C.), $N^{o} 127$.

Van der Zee, J. (2002). Heathing the patient: a promising approach?. Review Annals of Oncology, vol. 13, pp. 1173-1184. 
Venaruzzo, J. L.; Volzone, C.; Rueda, M. L. \& Ortiga, J. (2002). Modified bentonitic clay minerals as adsorbents of $\mathrm{CO}, \mathrm{CO}_{2}$ and $\mathrm{SO}_{2}$ gases; Microporous and Mesoporous Materials 56(1); pp 73-80.

Vimonses, V.; Jin, B. \& Chow, C. W. K. (2010) Insight into removal kinetic and mechanisms of anionic dye by calcined clay materials and lime. Journal of Hazardous Materials; pp 420-427.

Vorhees C.V., Butcher, R. E.; Brunner, R. L.; Wootten, V.; Sobotka, T. J. (1983). Developmental toxicity and psychotoxicity of $F D$ and $C$ red dye No. 40 (allura red $A C$ ) in rats. Toxicology; 28(3):207-17.

Xie, W., Gao, Z., Lui, K., Pan, W., Vaia, R., Hunter, D., Singh, A. (2001a), Thermal characterization of organically modified montmorillonite. Thermochimica acta, 367368, 339-350.

Xu S., Boyd S.A. (1995) Cationic Surfactarrt sorption to a Vermiculite Subsoil via hydrophobic Boding. Environ. Sci. Technol. 29, pp 312-320.

Yariv S., Lahav N., Lancher M. (1976) NOTE. On the mechanism of staining montmorillonite by benzidine. Clays and Clay Minerals, Vol. 24, pp. 5152.

Yonni, F.; Fasoli, H.; Giai, M. y Álvarez, H. (2008) Estudio de la biodegradabilidad y ecotoxicidad sobre colorantes textiles. Higiene y Sanidad ambiental, Vol. 8; pp 331334.

Zaharia C. \& Suteu, (2006) D. Textile Organic Dyes - Characteristics, Polluting Effects and Separation/Elimination Procedures from Industrial Effluents - A Critical Overview. Technical University of Iasi, Faculty of Chemical Engineering and Environmental Protection, Romania.

Zaharia, C.; Suteu, D.; Muresan, A. (2009) Muresan, R. \& Popescu, A. Textile wastewater treatment by homogenous oxidation with hydrogen peroxide. Environmental Engineering and Management Journal, Vol.8, No.6, pp.1359-1369.

Zhu, L.; Su, Y. (2002). Benzene vapour sorption by organobentonites from ambient air. The Clay Minerals Society, 50 (4). 



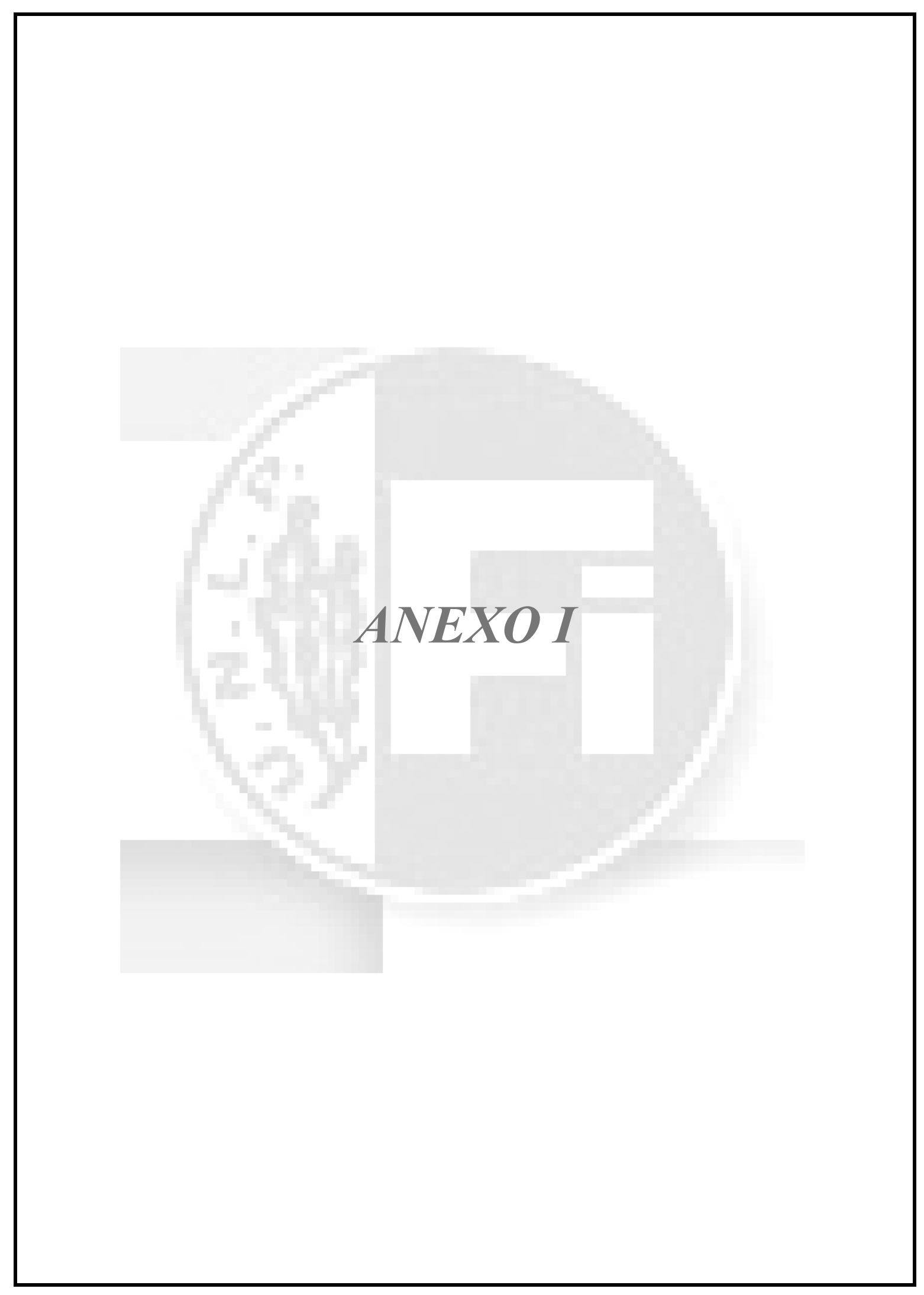




\section{CURVAS DE CALIBRACIÓN DE COLORANTES}

Las curvas de calibración de los colorantes en estudio fueron realizadas por medio de la lectura de soluciones de concentración conocida en un equipo UV-visible PG-Instruments modelo T60, Imagen A.1.

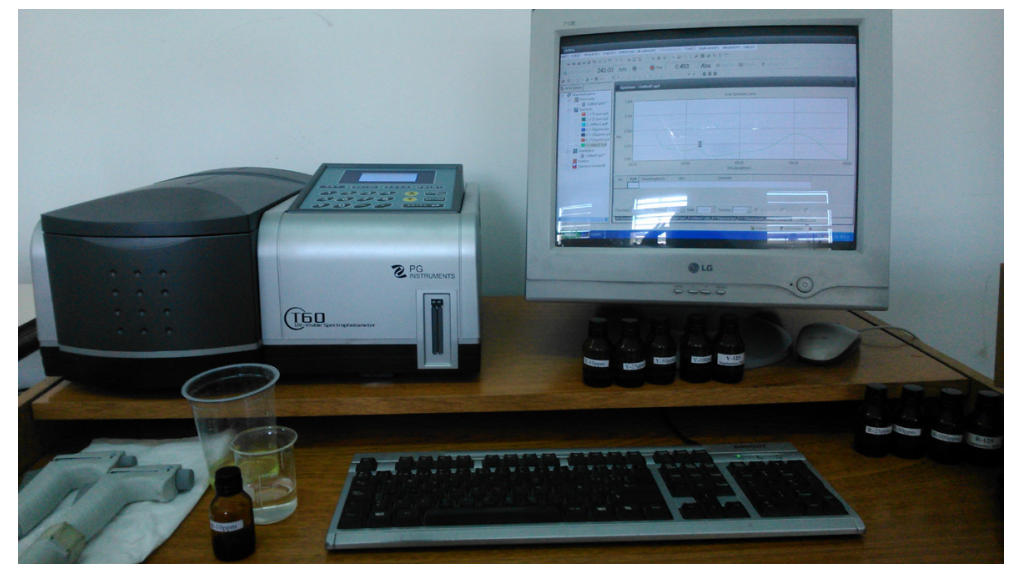

Imagen A.1. Espectómetro UV-visible PG Instruments Mod. T60

\section{Curva de calibración Yellow GR}

Para la cuantificación del colorante Yellow GR se efectuaron curvas de calibración, con soluciones de concentración conocida, comprendidas entre $10 \mathrm{mg} . \mathrm{L}^{-1} \mathrm{y}$ $125 \mathrm{mg} \cdot \mathrm{L}^{-1}$. La curva de calibración obtenida Figura A.1., se realizó cuantificando el grupo cromóforo azo a 400nm de longitud de onda.

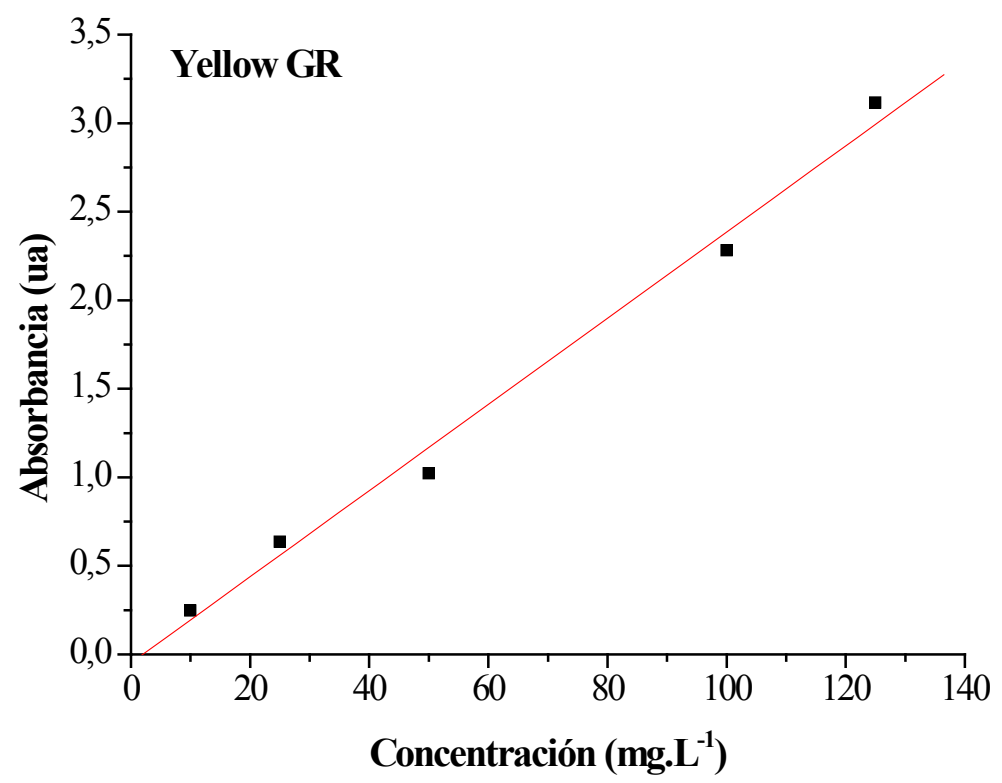

Figura A.1. Curva de Calibración Yellow GR $\lambda=400 \mathrm{~nm}$ 


\section{Curva de calibración Red Allura AC}

Para la cuantificación del colorante Red Allura AC se efectuaron curvas de calibración, con soluciones de concentración conocida, comprendidas entre $10 \mathrm{mg} . \mathrm{L}^{-1} \mathrm{y}$ $125 \mathrm{mg} \cdot \mathrm{L}^{-1}$.

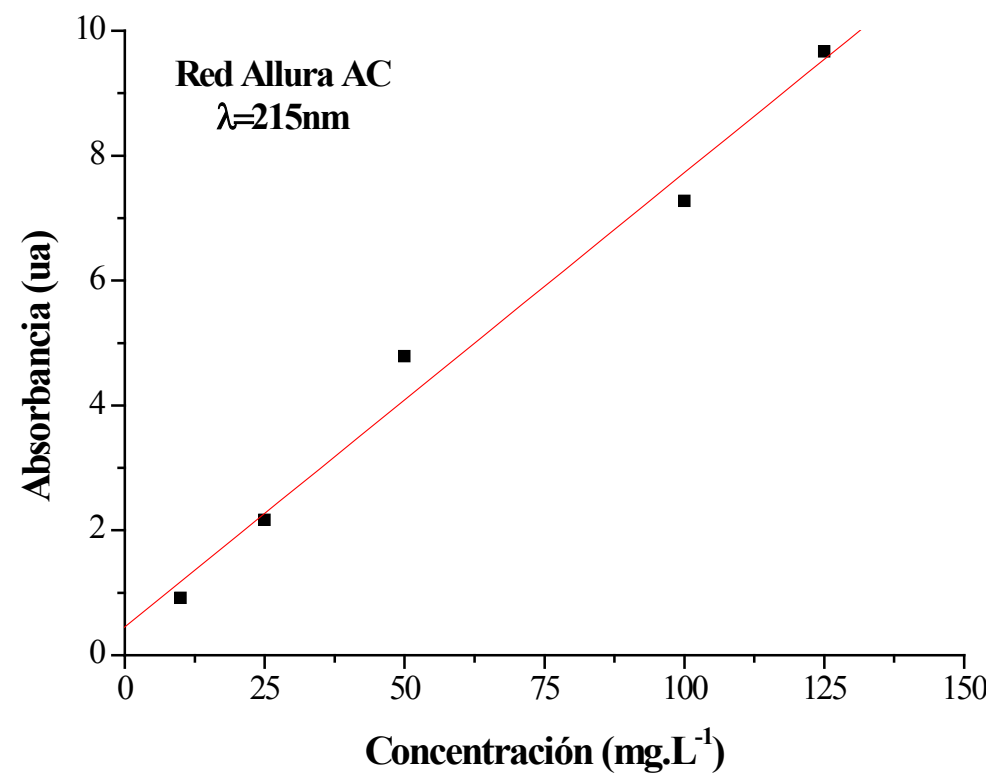

Figura A.2. Curva de Calibración Red Allura AC $\lambda=215 \mathrm{~nm}$

Las curvas de calibración, obtenidas de los espectros UV-visible, se efectuaron diferenciando entre los grupos ubicados a $215 \mathrm{~nm}$ (p-metil,p-metoxibenceno) Figura A.2., 316nm (naftol) Figura A.3. y 496 (azo) Figura A.4.

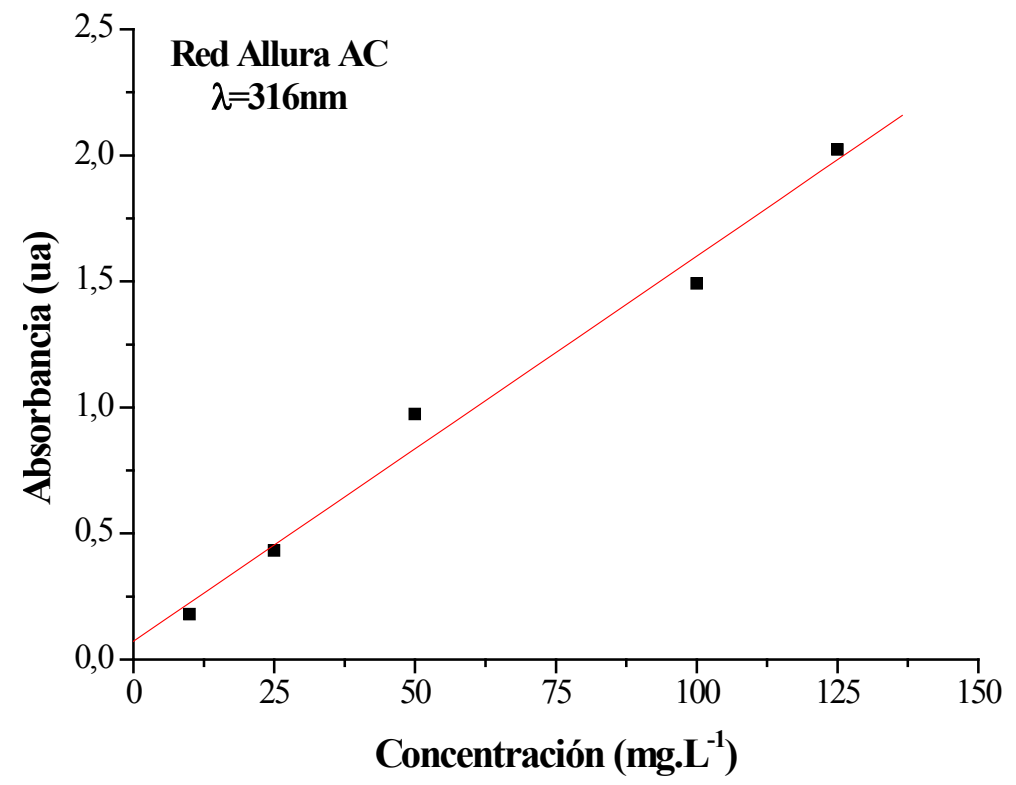

Figura A.3. Curva de Calibración Red Allura AC $\lambda=316 \mathrm{~nm}$ 


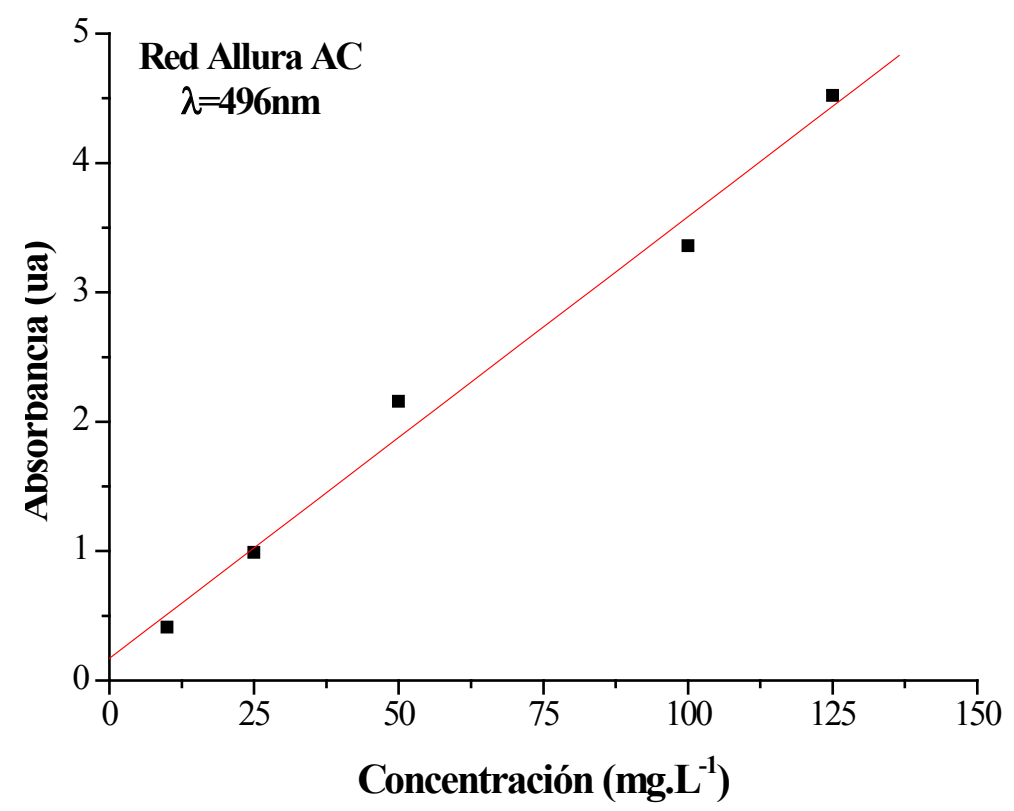

Figura A.4. Curva de Calibración Red Allura AC $\lambda=496 \mathrm{~nm}$

\section{Curva de calibración Orange G}

Para la cuantificación del colorante Orange $G$ se efectuaron curvas de calibración, con soluciones de concentración conocida, comprendidas entre $10 \mathrm{mg} . \mathrm{L}^{-1} \mathrm{y}$ $125 \mathrm{mg} . \mathrm{L}^{-1}$; diferenciando los espectros UV-visible obtenidos a $248 \mathrm{~nm}$ (benceno) Figura A.5., 330nm (naftol) Figura A.6., y 485nm (azo) Figura A.7.

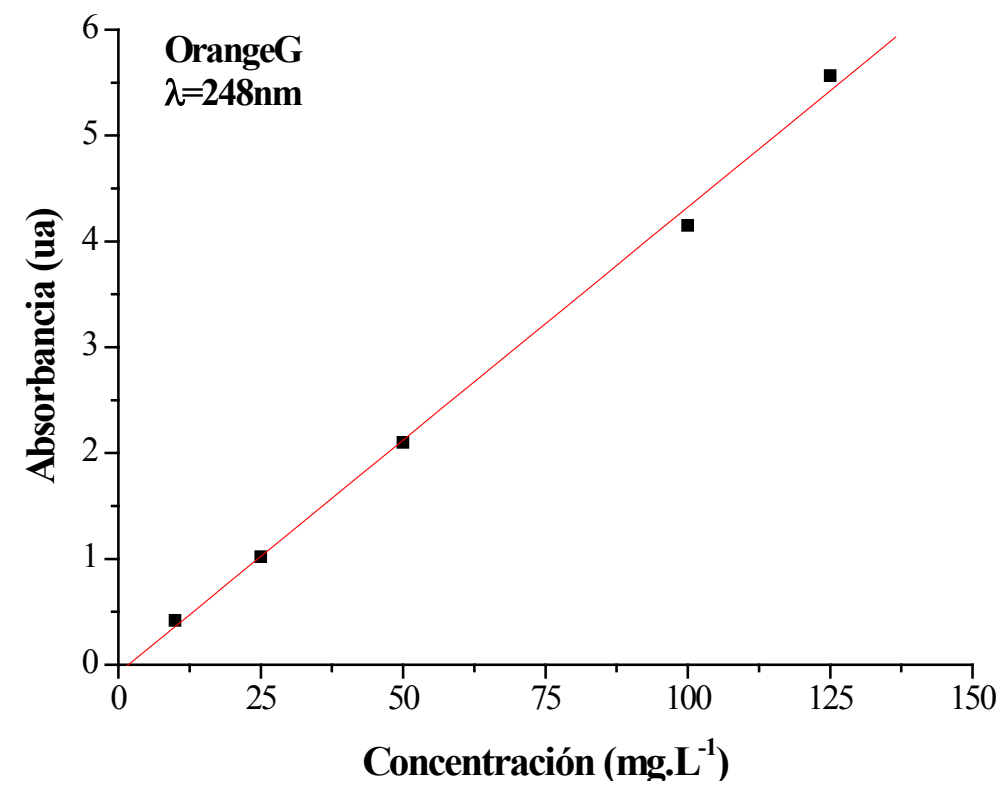

Figura A.5. Curva de Calibración Orange $\mathrm{G} \lambda=248 \mathrm{~nm}$ 


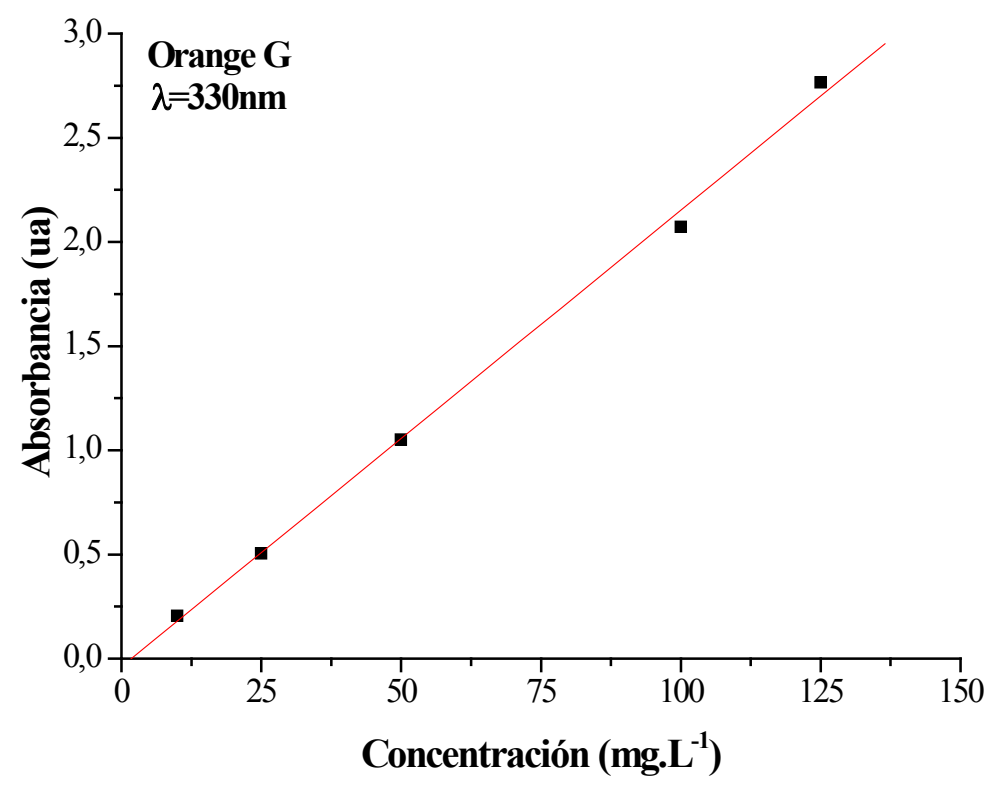

Figura A.6. Curva de Calibración Orange G $\lambda=330 \mathrm{~nm}$

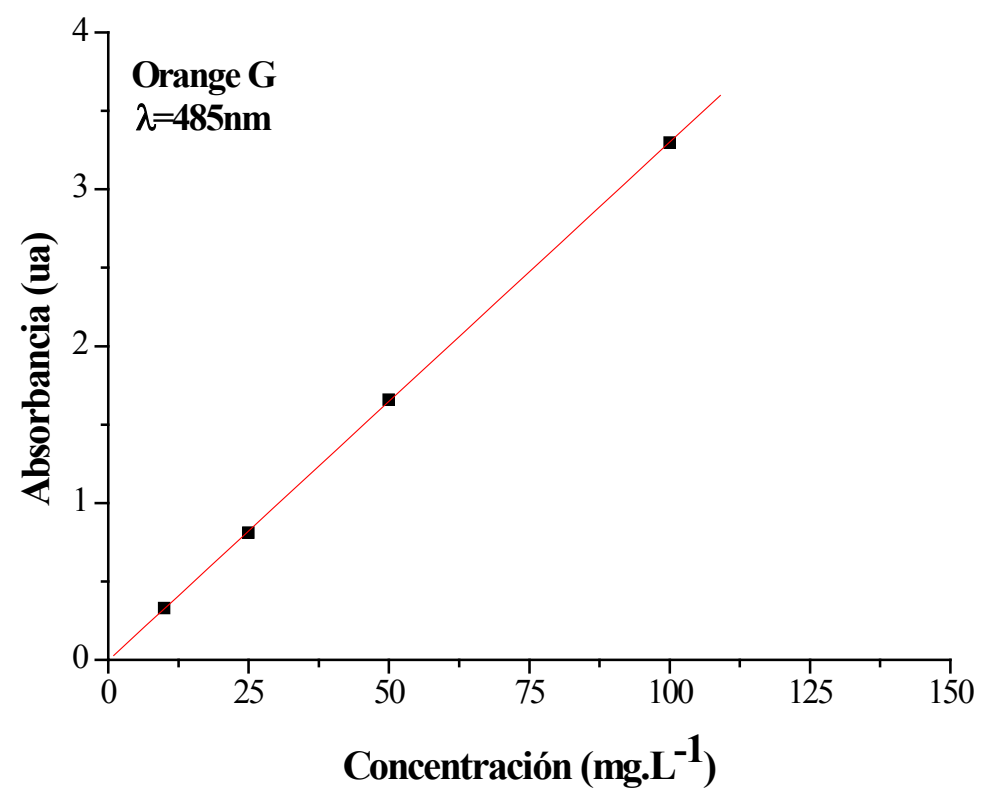

Figura A.7. Curva de Calibración Orange G $\lambda=485 \mathrm{~nm}$ 



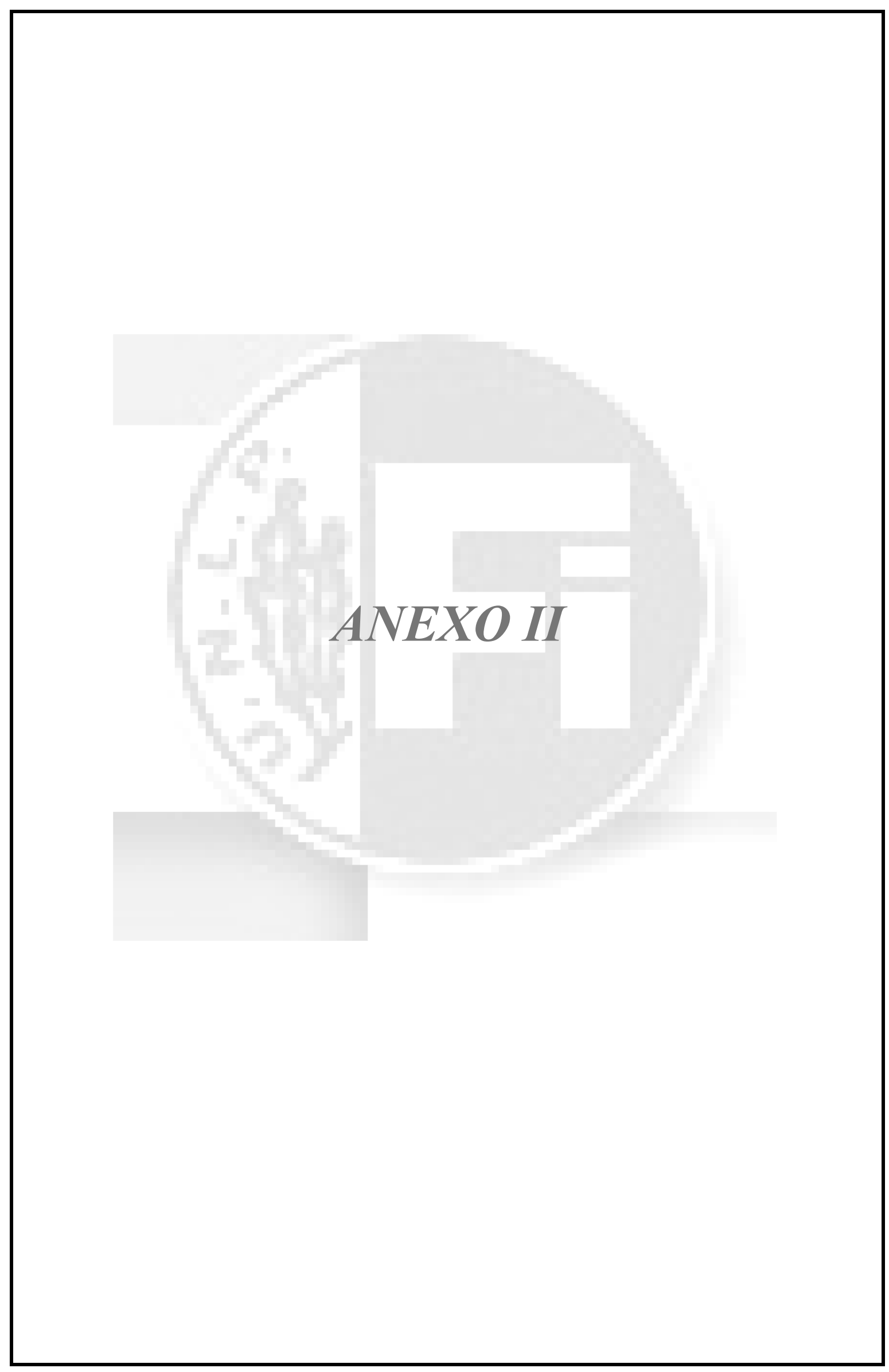


ADSORPTION OF DYES ON A TEXTILE INDUSTRYCLAY

MINERALNATURAL AND CHEMICAL TREATED ${ }^{1}$

\author{
Susana Y. Martinez Stagnaro ${ }^{1}$, Cristina Volzone ${ }^{2}$, Lucas Huck ${ }^{2}$ \\ ${ }^{1}$ Asentamiento Universitario Zapala, Facultad de Ingeniería, Universidad Nacional del Comahue, 12 de \\ Julio y Rahue, (8340), Zapala, Neuquén, Argentina \\ ${ }^{2}$ Centro de Tecnología de Recursos Minerales y Cerámica - CETMIC (CICPBA, CCT CONICET La \\ Plata) C.C. 49, Cno. Centenario y 506, (1897) M. B. Gonnet, Buenos Aires, Argentina
}

\begin{abstract}
The textile industry is among the main activities generating toxic waste. These come from environment processes releasing large amounts of organic and inorganic material together with compounds capable of imparting color. Paper published in recent years relating to the remediation of these effluents, show results from treatment with various oxidants, solvent extraction reverse, osmosis, electrochemical oxidation, coagulation and biological treatments. While the before mentioned processes are effective in removing contaminants, most of them are expensive and sometimes the end of treatment, sludge originate create and additional problem of pollution.

This paper analyzes the behavior of a natural bentonite and intercalated with an organic substance in the adsorption phenomenon. The textile dyes were selected Allura Red and GR Yellow. Tests were conducted at room temperature in batch system, contacting the solids with the dyes in aqueous solutions concentration $50 \mathrm{mg} . \mathrm{L}^{-1}$. The adsorptions were assessed the dye before and after contact with the solid using UVvisible spectrophotometer.
\end{abstract}

Keywords: Dye, adsorption, bentonite.

\footnotetext{
${ }^{1}$ XI Jornadas Argentinas de Tratamiento de Minerales, Neuquén, Argentina (2012), ISBN 978-987-604311-3, pp 433-438.
} 
REMEDIACIÓN AMBIENTAL DE SOLUCIONES ACUOSAS CON CARGAS

DE COLORANTES PROVENIENTES DE LA INDUSTRIA TEXTIL EMPLEANDO ADSORBENTES BENTONÍTICOS ${ }^{2}$

\author{
Martinez Stagnaro, S. ${ }^{1}$, Volzone, C. ${ }^{2}$, Huck, L. ${ }^{2}$ \\ ${ }^{1}$ Asentamiento Universitario Zapala, Facultad de Ingeniería, Universidad Nacional del Comahue, 12 de \\ Julio y Rahue, (8340), Zapala, Neuquén, Argentina \\ ${ }^{2}$ Centro de Tecnología de Recursos Minerales y Cerámica - CETMIC (CICPBA, CCT CONICET La \\ Plata) C.C. 49, Cno. Centenario y 506, (1897) M. B. Gonnet, Buenos Aires, Argentina
}

Las aguas de desechos derivadas de los diferentes procesos llevados a cabo en el teñido de fibras naturales o sintéticas de la industria textil, poseen un alto contenido de sustancias nocivas para el medioambiente tales como: metales pesados y moléculas orgánicas provenientes comúnmente, de los colorantes manipulados en el proceso. Estos contaminantes poseen una alta toxicidad, particularmente las estructuras orgánicas que componen los tintes, como los cromóforos, conservan la capacidad de transformarse en subproductos, cuya naturaleza depende de los grupos funcionales de los cuales se conformaba la molécula original, pudiendo resultar en compuestos nitrosos, sulfurosos y azo entre otros. La peligrosidad de éstos contaminantes, teniendo en cuenta la escasa y en ocasiones nula estrategia de pretratamiento de desechos, motivan el presente trabajo. La bibliografia cientifica referida al tratamiento de estos contaminantes, hace referencia a metodologías de remediación que en ocasiones son costosas y de difícil acceso para las pequeñas y medianas industrias del rubro textil, por lo cual, es necesario desarrollar procesamientos que sean económicos, fáciles de implementar y eficientes. En el presente trabajo se aplicará el fenómeno de adsorción como tratamiento descontaminante, utilizando un adsorbente natural de fácil extracción y abundante en la naturaleza denominado bentonita, el cual fue modificado químicamente con el objetivo de incrementar la capacidad de retención. Los colorantes estudiados fueron Naranja GR, Negro GN y Marrón Africano, todos solubles en agua y con estructuras moleculares diferentes. Los ensayos se realizaron en sistema batch a temperatura ambiente durante 24 horas, controlando el fenómeno de adsorción con la lectura de las soluciones sobrenadantes realizadas con un espectrómetro UV-visible.

Palabras Claves: Colorantes, Adsorción, Textil, Bentonita.

\footnotetext{
${ }^{2}$ SETAC 2012. Buenos Aires, Argentina.
} 


\title{
APROVECHAMIENTO DE MINERALES ARCILLOSOS PARA LA
}

ADSORCIÓN DE COLORANTE RED ALLURA. EVALUACIÓN DE LA

CAPACIDAD DE RETENCIÓN MODIFICANDO SU ESTRUCTURA QUÍMICA Y TIEMPO DE CONTACTO ${ }^{3}$

\author{
Susana Y. Martinez Stagnaro ${ }^{1}$; Cristina, Volzone ${ }^{2}$; Lucas, Huck ${ }^{2}$ \\ ${ }^{1}$ Asentamiento Universitario Zapala, Facultad de Ingeniería, Universidad Nacional del Comahue, 12 de \\ Julio y Rahue, (8340), Zapala, Neuquén, Argentina \\ ${ }^{2}$ Centro de Tecnología de Recursos Minerales y Cerámica - CETMIC (CICPBA, CCT CONICET La \\ Plata) C.C. 49, Cno Centenario y 506, (1897) M. B. Gonnet, Buenos Aires, Argentina.
}

Los minerales arcillosos son ampliamente utilizados para diversas aplicaciones: carga de pintura, terminación de pozos de petróleo, incluso en la industria farmacéutica y cosmética, sin embargo, el presente trabajo tiene como objetivo el aprovechamiento de estos para la remediación de efluentes contaminados con carga de colorantes orgánicos. Si bien los materiales del grupo de las arcillas ya han sido estudiados en el campo de la remediación ambiental, para la remoción de cationes metálicos, gases etc. los estudios inherentes a tintes de naturaleza orgánica son muy escasos. Las aguas de desechos de industrias que utilizan grandes cantidades de colorantes, como lo son las empresas textiles, pueden contener compuestos tóxicos que al estar en solución poseen la capacidad de migrar fácilmente y alcanzar grandes extensiones, generando consecuencias nocivas en los seres vivos. Por lo expuesto, se estudiarán dos bentonitas provenientes de las provincias de Neuquén y San Juan antes y después de ser modificadas químicamente mediante tratamiento, contactando las mismas con el colorante Red Allura. Las pruebas fueron efectuadas en sistema batch con agitación, a tiempos de contacto de 1, 5, 10, 24 y 72 horas. Los resultados obtenidos a partir de la interpretación de los espectros $U V$-visibles del colorante y el sobrenadante de cada uno de los experimentos, permitieron conocer el comportamiento de los adsorbentes en contacto con la molécula del tinte en función de los tiempos.

Palabras Claves: Colorantes, adsorción, arcillas orgánicas.

\footnotetext{
${ }^{3}$ ATACER 2013. Olavarría, Buenos Aires, Argentina.
} 


\title{
ADSORCIÓN DE COLORANTE TEXTIL YELLOW GR EMPLEANDO UNA
} ESMECTITA NATURAL Y TRATADA CON HDTMA ${ }^{4}$

\author{
S. Martinez Stagnaro ${ }^{(1)}{ }^{*}$, C. Volzone $^{(2)}$. L. Huck ${ }^{(2)}$ \\ ${ }^{(1)}$ Asentamiento Universitario Zapala, Facultad de Ingeniería, Universidad Nacional del Comahue, 12 de \\ Julio y Rahue, (8340), Zapala, Neuquén, Argentina \\ ${ }^{(2)}$ Centro de Tecnología de Recursos Minerales y Cerámica - CETMIC (CICPBA, CCT CONICET La \\ Plata) C.C. 49, Cno. Centenario y 506, (1897) M. B. Gonnet, Buenos Aires, Argentina \\ E-mail*: syms.05@hotmail.com
}

Durante el proceso de tinción de las fibras pueden generarse descargas de igualadores, dispersantes, antiespumantes, estabilizadores de pH, secuestrantes de dureza y colorantes [1], se estima que del 10 al 20\% de los tintes empleados, son arrojados en las aguas de desecho [2]. Estas sustancias, encargadas de impartir el color a las fibras, son muy solubles en agua, persistentes y de baja degradabilidad. Además, los cromóforos que constituyen sus estructuras, son potenciales formadores de aminas aromáticas tóxicas, y en algunos casos pueden producir mutaciones a especies altamente dañinas [2,3]. Con la finalidad de minimizar los efectos adversos de éstos compuestos, se trató una solución de colorante textil denominado Yellow GR, compuesto por grupos cromóforos tipo azo $(-N=N-)$, con un mineral esmectítico. Los ensayos fueron realizados sobre el sustrato natural y modificado orgánicamente con HDTMA, con una relación sólido/líquido de $1 \%$ en agitación y temperatura ambiente durante un rango de tiempo de 1 a 72 horas, con el objetivo de evaluar la cinética en el fenómeno de adsorción y relacionar el mecanismo de retención de acuerdo a la modificación estructural del mineral.

Palabras clave: Adsorción, Colorante, Esmectita.

\footnotetext{
${ }^{4}$ SAASA 2013, San Luis, Argentina.
} 


\title{
EVALUACIÓN DEL USO DE NANOARCILLA PARA LA ELIMINACIÓN DE COLORANTES UTILIZADOS EN LA INDUSTRIA TEXTIL ${ }^{5}$
}

\author{
Martinez Stagnaro, S.*1 ${ }^{1}$ Volzone, C. ${ }^{2}$, Huck, L. ${ }^{2}$ \\ 1 Asentamiento Universitario Zapala, Facultad de Ingeniería, Universidad Nacional del Comahue, 12 de \\ Julio y Rahue, (8340), Zapala, Neuquén, Argentina \\ 2 Centro de Tecnología de Recursos Minerales y Cerámica - CETMIC (CICPBA, CCT CONICET La \\ Plata) C.C. 49, Cno. Centenario y 506, (1897) M. B. Gonnet, Buenos Aires, Argentina. \\ *syms.05@hotmail.com
}

Palabras Claves: Colorantes, Adsorción, Textil, Nanoarcilla.

\section{RESUMEN}

Los colorantes comúnmente empleados en la industria textil presentan estructuras resonantes con una distribución de valencias, dentro de una molécula compleja, que determina el color del tinte. Este coloreado es producido por cromóforos capaces de retener radiaciones en el rango UV-visible. Además de impartir color, éstos compuestos, al ser despedidos en el medioambiente, pueden ocasionar serios problemas en la biota debido a que sus productos de biodegradación pueden ser una fuente de sustancias tóxicas tales como aminas, las que se generan a partir de los grupos cromóforos tipo azo característicos en la mayoría de los colorantes. Los tratamientos desarrollados actualmente para la eliminación de color y resíduos peligrosos provenientes de estos materiales son complejos y costosos, por ésta razón las industrias que los utilizan carecen de plantas de tratamiento de desperdícios generados durante la etapa de tinción. El estudio que se presenta tiene como objetivo analizar el comportamento de minerales arcillosos como materiales adsorbentes de sustancias colorantes utilizadas en la indústria textil. Las muestras seleccionadas para los ensayos de retención fueron los tintes comercialmente conocidos como: Naranja GR, Negro GN y Marrón Africano. El material utilizado como adsorbente fue una arcilla bentonítica en su estado natural y luego de ser modificada como un catión orgánico, generalmente llamada nanoarcilla, para aumentar el grado de retención de los colorantes. La retención de los colorantes fue evaluado por mediciones en el espectro UV-visible empleando un equipo HP-8354.

Keywords: Dyes, Adsorption, Textile, Nanoclay.

\footnotetext{
${ }^{5} 13^{\circ}$ Congreso Internacional en ciencia y tecnología de Metalurgia y Materiales 2013. Puerto Iguazú, Misiones, Argentina.
} 
TRATAMIENTO DE RETENCIÓN DE UN COLORANTE UTILIZADO EN LA INDUSTRIA TEXTIL (YELLOW GR) POR ARCILLA ORGÁNICA ${ }^{6}$

\author{
S. Y. Martinez Stagnaro ${ }^{1}$, L. A. Muldon ${ }^{1}$ C. Volzone ${ }^{2}$ \\ 1- Asentamiento Universitario Zapala, Facultad de Ingeniería, Universidad Nacional del Comahue, 12 de \\ Julio y Rahue, (8340), Zapala, Neuquén, Argentina. syms.05@hotmail.com \\ 2- Centro de Tecnología de Recursos Minerales y Cerámica- CETMIC (CCT CONICET La Plata- \\ CICPBA) C.C. 49, Cno Centenario y 506, (1897) M. B. Gonnet, Buenos Aires, Argentina.
}

\title{
RESUMEN
}

Gracias a los estudios efectuados durante las últimas décadas, es de amplio conocimiento el potencial de los materiales arcillosos en el campo de la adsorción. Se han efectuados estudios de retención de gases, soluciones con contenidos de diversos cationes, e incluso mezclas de ellos; como también se han modificado los materiales adsorbentes mediante métodos físicos, químicos y físico-químicos con la finalidad de aumentar la capacidad de adsorción de ellos. Si bien los mecanismos de tratamiento de contaminantes son similares, las variaciones en el comportamiento, ya sea de los adsorbentes como de los adsorbatos es variado, y el éxito del tratamiento radica en el conocimiento y entendimiento de éstos. Este trabajo propone el ensayo de una solución del tinte textil Yellow GR, de naturaleza orgánica y con un tamaño de molécula considerablemente grande; con un mineral arcilloso modificado. Para esto se empleó una bentonita Argentina tratada con HDTMA-Br. Las condiciones experimentales fueron: relación sólido/líquido en el rango de 2-50mg de adsorbente/10ml solución $Y$ de concentración $250 \mathrm{mg} . \mathrm{L}^{-1}$; durante 24 horas a temperatura ambiente. Se obtuvieron muestras de la solución sobrenadante y el sustrato adsorbente para ser analizadas por $U V$-visible, IR y DRX. Los resultados conseguidos de la interpretación de los análisis, indicarían en un principio que el adsorbente orgánico, preparado a partir de una arcilla modificada, posee una mayor capacidad de retención de éste tipo de molécula, mientras que la natural no presenta gran afinidad por la misma.

PALABRAS CLAVES: adsorción, colorante, arcilla orgánica.

\footnotetext{
${ }^{6}$ X Encontro Brasileiro sobre Adsorção. Guarujá-SP-Brasil, Abril 2014.
} 


\title{
USO DE ORGANO-BENTONITA PARA LA REMOCIÓN DEL COLORANTE
} TEXTIL ORANGE GR ${ }^{7}$

\author{
Susana Y. Martínez Stagnaro ${ }^{1}$, Carla Musso Perulán ${ }^{1}$, Luis A. Muldón ${ }^{1}$, Joaquín Cornejo ${ }^{1}$, Alejandra \\ Fuentes $^{1}$, Cristina Volzone ${ }^{2}$ \\ ${ }^{1}$ Asentamiento Universitario Zapala, Facultad de Ingeniería, Universidad Nacional del Comahue, 12 de \\ Julio y Rahue, (8340), Zapala, Neuquén, Argentina- syms.05@hotmail.com \\ ${ }^{2}$ Centro de Tecnología de Recursos Minerales y Cerámica- CETMIC (CICPBA, CCT CONICET La \\ Plata) C.C. 49, Cno Centenario y 506, (1897) M. B. Gonnet, Buenos Aires, Argentina
}

\section{RESUMEN}

El mineral arcilloso denominado esmectita es el componente principal de la bentonita. Posee una gran variedad de usos, entre ellos su empleo como adsorbente natural de contaminantes, característica que proviene principalmente de su reducido tamaño de partícula (gran área superficial) y alta capacidad de intercambio catiónico y bajo costo. El estudio que se propone tiene como objetivo evaluar el comportamiento de retención de la bentonita y órgano-bentonita frente a un colorante textil denominado Orange GR, una molécula orgánica compleja, constituida por variados grupos funcionales. Debido al carácter hidrofilico de la arcilla natural la misma fue modoficada con un orgánico para llevar a ser organofilica. De esta manera la arcilla orgánica fue preparada a partir del intercambio con un catión orgánico conocido como hexadeciltrimetilamonio (HDTMA). La bentonita natural y la orgánica fueron contactadas con solución del colorante Orange GR de concentración 250ppm. Los sólidos obtenidos de los ensayos se caracterizaron por análisis en el Infrarrojo y Difracción de Rayos $X$. La retención del colorante por los sólidos fue evaluada por diferencia en las medidas en el UV-visible de las soluciones colorantes antes y después del contacto con cada sólido. Los resultados indicaron retenciones del colorante del 90\% sobre la órgano-bentonita, mientras que el estudio efectuado con el sólido natural no llegó a retener más de $8 \%$ del tinte textil.

Palabras Clave: Adsorción, organo-bentonita, colorante textil, orange gr.

\section{Tópico: Simposio. Materiales porosos nanoestructurados}

\footnotetext{
${ }^{7}$ XII JATRAMI 2014. San Luis, Argentina.
} 
APLICACIÓN DE UN MATERIAL NANOARCILLOSO COMO POSIBLE ADSORBENTE DEL TINTE RED ALLURA ${ }^{8}$

\author{
Martínez Stagnaro, S. Y. ${ }^{a^{*}}$, Ortiga J. ${ }^{b}$, Gallegos, N. ${ }^{c}$, Volzone C. ${ }^{b}$ \\ ${ }^{a}$ Asentamiento Universitario Zapala, Facultad de Ingeniería, Universidad Nacional del Comahue, 12 de \\ Julio y Rahue, Zapala (8340), Neuquén, Argentina \\ ${ }^{\mathrm{b}}$ Centro de Tecnología de Recursos Minerales y Cerámica- CETMIC (CICPBA, CCT CONICET La \\ Plata) C.C. 49, Cno Centenario y 506, (1897) M. B. Gonnet, Buenos Aires, Argentina \\ ${ }^{\mathrm{C}}$ Centro de Investigación y Desarrollo en Ciencias Aplicadas CINDECA - Facultad de Ingeniería. UNLP, \\ calle 47 No 257, (1900) La Plata, Argentina *syms.05@hotmail.com
}

\title{
A B S T R A C T
}

Generally, clay minerals have a great capacity to retain pollutants of various types; this is due to its natural characteristics, mainly from its small particle size, which gives a large surface area. Notwithstanding this, the adsorption of the organic molecule used as a textile dye (Allura Red) tested in this study on the interface of a clay material, is hampered by the hydrophilic nature of the substrate. This property can be changed by specific organophilic clay treatments done. In this study a clay mineral was modified with an organic cation known as hexadecyltrimethylammonium (HDTMA ${ }^{+}$) and later used as adsorbent dye. Retention assays to test the ability of the solid were performed by contacting for 24 hours, different amounts of organoclay, also called, Nanoclay with a solution at 250mg. $L^{-1}$. The analysed solid/liquid ratio was in the range of 0,2 to $5 \mathrm{mg} \cdot \mathrm{L}^{-1}$. Analysis by $U V$-visible spectrophotometry allowed quantification of the amount of dye retained while by instrumental techniques such as X-Ray Diffraction (XRD) and Infrared spectrophotometry (IR) were studies solid. 
ELIMINACIÓN DE COLORANTE RED ALLURA POR BENTONITA Y ORGANOBENTONITA ${ }^{9}$

\author{
S. Y. Martinez Stagnaro ${ }^{\mathrm{a}}$, J. Cornejo ${ }^{\mathrm{a}}$, A. Fuentes ${ }^{\mathrm{a}}$, L. A. Muldon ${ }^{\mathrm{a}}$, N. Gallegos ${ }^{\mathrm{b}}$, C. Volzone ${ }^{\mathrm{c}}$
}

${ }^{\text {a }}$ Asentamiento Universitario Zapala, Facultad de Ingeniería, Universidad Nacional del Comahue, 12 de Julio y Rahue, (8340), Zapala, Neuquén, Argentina. syms.05@hotmail.com

${ }^{\mathrm{b}}$ Centro de Investigación y Desarrollo en Ciencias Aplicadas CINDECA - Facultad de Ingeniería. UNLP, calle $47 \mathrm{~N}^{\circ}$ 257, (1900) La Plata, Argentina.

${ }^{\mathrm{c}}$ Centro de Tecnología de Recursos Minerales y Cerámica, CIC-CONICET La Plata, Argentina. Cno. Centenario y 506, (1897) M.B.Gonnet, Prov.de Buenos Aires, Argentina.

El método de adsorción de diversos contaminantes, empleando minerales arcillosos, es una de las técnicas más factibles de utilizar a la hora de la remediación de efluentes contaminados. La factibilidad del proceso radica principalmente en el bajo costo de los materiales adsorbentes, por ser abundantes en la naturaleza, y sus características naturales: reducido tamaño de partícula, capacidad de intercambio catiónico y elevada superficie especifica. Sin embargo, aquellos efluentes contaminados con tintes coloreados orgánicos provenientes de diversas industrias (textil, alimenticia, plásticos, papel, entre otras) suelen no ser retenidos por las arcillas naturales debido a su naturaleza hidrofilica. Ésta problemática podría solucionarse si se realiza un tratamiento de intercambio de iones inorgánicos por orgánicos, que modifiquen las propiedades superficiales naturales de la arcilla, dando origen a lo que se conoce como organoarcilla. La remoción de tintes de naturaleza orgánica es una problemática que crece día a día debido a la falta de controles ambientales en las aguas de desechos, originadas por industrias cada vez más abundantes debido al creciente consumo de productos manufacturados (papel, plásticos, textiles, cueros, gomas, etc.). Los colorantes orgánicos usados para impartir color a los productos, tienen la particularidad de ser muy solubles en agua y, debido a que, generalmente, tienen estructuras aromáticas complejas, son biológicamente no degradables y presentan alta estabilidad y toxicidad, representando una inminente amenaza ambiental.

Es por lo expuesto que el objetivo del presente trabajo es evaluar el empleo de una bentonita y una organobentonita, en la remoción del tinte orgánico Red Allura, por medio de ensayos de adsorción.

Los sólidos adsorbentes y la solución coloreada a retener fueron estudiados empleando técnicas analiticas instrumentales de Difracción de Rayos X (DRX), Espectrometría Infrarroja (IR), Análisis Térmico Termogravimétrico (TG) y Espectrometría UV-visible.

Se efectuaron experiencias de adsorción del colorante con una concentración inicial de $250 \mathrm{mg} . \mathrm{L}^{-1}$, en sistema batch, a temperatura ambiente, durante 24 horas, variando las relaciones sólido/líquido; transcurrido éste tiempo se extrajeron alícuotas del sobrenadante para su cuantificación, recuperando los sólidos previa eliminación de la solución no retenida, mediante reiterados lavados con agua destilada. Los datos obtenidos indicarían una adsorción favorable del colorante en estudio por la organobentonita.

Palabras clave: Adsorción, Organobentonita, Red Allura, Remediación.

\title{
Tópico: 22. Materiales nanoestructurados.
}

\footnotetext{
9 II Congreso Internacional de Ciencia y Tecnología Ambiental / II Congreso Nacional de la Sociedad Argentina de Ciencia y Tecnología Ambiental. Buenos Aires, Argentina (2015).
} 
Tesis Doctoral: Susana Y. Martinez Stagnaro "Evaluación sobre el uso de arcillas para la adsorción de colorantes utilizados en la industria textil"

\title{
RETENCIÓN DE TINTE ORGÁNICO TEXTIL YELLOW GR SOBRE
}

\section{NANOARCILLAS ${ }^{10}$}

\author{
Martinez Stagnaro S. Y. ${ }^{\mathrm{a} *}$, Fuentes A. ${ }^{\mathrm{a}}$, Cornejo J. ${ }^{\mathrm{a}}$, Casé A. M. ${ }^{\mathrm{a}}$, Volzone C. ${ }^{\mathrm{b}}$ \\ ${ }^{a}$ Asentamiento Universitario Zapala, Facultad de Ingeniería, Universidad Nacional del Comahue, 12 de Julio y Rahue, (8340), \\ Zapala, Neuquén, Argentina. \\ ${ }^{b}$ Centro de Tecnología de Recursos Minerales y Cerámica- CETMIC (CICPBA, CCT CONICET La Plata) C.C. 49, Cno Centenario \\ y 506, (1897) M. B. Gonnet, Buenos Aires, Argentina.
}

syms.05@hotmail.com

\begin{abstract}
A B S T R A C T
The textile industry employs during the staining step of fibers from various sources, a variety of chemical compounds and is also a major consumer of water [1]. Within the variety of products that use this industry are dyes, and they are the cause of the environmental problems with the greatest impact on people, as they may contain in its various structures, both heavy metals as well, aromatics or amines, able to mutate into highly carcinogenic species [2]. According to the cationic or anionic nature of the dyes, clays are capable of adsorbing molecules in their natural state or, sometimes, after appropriate treatment, to facilitate the retention of one or another type of molecule [3.4]. For these reasons, in this paper, the results obtained in the treatment of a textile dye colored with Yellow GR (Y), with two clay minerals (S and Z) from different regions of Argentina solution are discussed, modified by a simple exchange of inorganic cations by organic cations of quaternary ammonium known as hexadecyl-trimethyl-ammonium-bromide (HDTMA), transforming them into organo-clays also called nano-clays in certain cases. The solids were subjected to tests of X-ray diffraction (XRD), Differential Thermal Analysis-Thermogravimetric (TG-DTA) and infrared spectroscopy (IR), in order to know the effects of exchange on the mineral structure. The adsorption tests were performed in batch system at room temperature, modifying the solid / liquid ratio for 24 hours, at which equilibrium according to previous work is reached [5]. After the experience of the supernatant solution samples they were extracted to be quantified by UV-visible spectroscopy content unadsorbed dye. Studies in the nanoclays prepared from natural bentonites our country shed encouraging results regarding retention Yellow GR dye.
\end{abstract}

Keywords: Nano-clay, Yellow GR, Adsorption.

${ }^{10} 15^{\circ}$ Congreso Internacional de Metalurgia y Materiales, CONAMET/SAM 2015. Concepción, Chile (2015). 


\title{
REMOCIÓN DE COLORANTES ORGANICOS POR ADSORCIÓN SOBRE BENTONITA Y ORGANOBENTONITA ${ }^{11}$
}

\author{
Susana Y. Martínez Stagnaro ${ }^{(1)} *$, Alejandra Fuentes ${ }^{(1)}$, Joaquín Cornejo $^{(1)}$ y Cristina Volzone $^{(2)}$ \\ (1) Asentamiento Universitario Zapala, Facultad de Ingeniería, Universidad Nacional del Comahue, 12 de \\ Julio y Rahue, (8340), Zapala, Neuquén, Argentina.syms.05@hotmail.com \\ (2) Centro de Tecnología de Recursos Minerales y Cerámica- CETMIC (CICPBA, CCT CONICET La \\ Plata) C.C. 49, Cno Centenario y 506, (1897) M. B. Gonnet, Buenos Aires, Argentina.
}

\section{RESUMEN}

La adsorción de contaminantes en las distintas industrias para atenuar los efectos dañinos en el ambiente, es una de las alternativas actuales de descontaminación. Debido a las propiedades adsorbentes provenientes de las características fisicoquímicas, y con la finalidad de minimizar los costos en el tratamiento propuesto, en concordancia con lo expuesto por Juang et. al., 2007; se empleó como adsorbente un mineral arcilloso esmectítico, componente principal de las rocas bentoníticas, identificado como $S$. El presente trabajo pretende analizar el fenómeno de adsorción de la bentonita mencionada, como alternativa en la retención de contaminantes orgánicos de la industria textil, como asi también reconocer los grupos funcionales mas afines de los adsorbatos frente a los adsorbentes. Es por lo expuesto que se realizaron estudios de adsorción de soluciones coloreadas con los colorantes Yellow GR (Y) y Orange G(O), debido a la naturaleza aniónica de estos tintes, y a las características naturales de la bentonita, se plantea un tratamiento con una sal orgánica bromuro de hexadeciltrimetilamonio (HDTMABr), para aumentar la capacidad de retención de orgánicos, por medio de la modificación del carácter iónico del mineral, según lo propuesto por Lagaly,1982; material adsorbente identificado como So. Para el desarrollo de éste estudio, se efectuaron ensayos en sistema batch a temperatura ambiente durante 24 horas. La cuantificación del colorante retenido se realizó por medio de un equipo UV-visible, mientras que el estudio de los sólidos antes y después de la retención se efectuó empleando equipos de Difracción de Rayos $X$, Infrarrojo y Análisis Térmico Diferencial y Termogravimétrico. Los resultados obtenidos demuestran que el tratamiento de los adsorbentes con HDTMA-Br aumenta considerablemente la capacidad de adsorción de ambos colorantes, como fue observado en trabajos anteriores; evidenciando además una mayor afinidad por el colorante Orange $G$.

11 International Congress of Science and Technology of Metallurgy and Materials, SAM - CONAMET 2013 
EVALUATE THE USE OF NANOCLAY FOR THE REMOVAL OF DYES

\title{
USED IN THE TEXTIL INDUSTRY ${ }^{12}$
}

\author{
Martinez Stagnaro, S. ${ }^{a} ;$ Volzone, C. ${ }^{b} \&$ Huck, L. ${ }^{b}$ \\ ${ }^{a}$ Asentamiento Universitario Zapala, Facultad de Ingeniería, Universidad Nacional del Comahue, 12 de Julio y Rahue, (8340), \\ Zapala, Neuquén, Argentina \\ ${ }^{b}$ Centro de Tecnología de Recursos Minerales y Cerámica- CETMIC (CICPBA, CCT CONICET La Plata) C.C. 49, Cno Centenario \\ y 506, (1897) M. B. Gonnet, Buenos Aires, Argentina
}

\begin{abstract}
The dyes commonly used en the textile industry has structural resonant valence distribution, within a complex molecule, which determines the color of the dyes. The coloring is produced by chromospheres holding radiation in UV-visible range. Besides coloring, these compounds to be found in waste water and cause serious problems in living organism, because their biodegradation products may be a source of toxic substances such as amines, which are generated from the characteristic azo chromospheres groups in most of the dyes. Current treatments for color removal from hazardous waste from these materials are complex and costly, for this reason the industries that use no waste treatment plants generated during the staining step. The present study aims to analyze the comportments of clay minerals as adsorbents for dyes used in the textile industry. The dyes used in this work are commercially known as: Orange GR, Black GN an African Brown. Nanoclay obtained by bentonite clay treated with organic cation was used as adsorbent for dyes retentions. The retention of the dyes was evaluated by measurements in the UV-visible spectrum by using an equipment model HP-8354.
\end{abstract}

(C) 2014 The Authors. Published by Elsevier Ltd.

Selection and peer-review under responsibility of the scientific committee of SAM - CONAMET 2013.

${ }^{12}$ Procedia Materials Science, Vol. 8 (2015), 586-591, ISSN: 2211-8128. 


\title{
ANÁLISIS ESTRUCTURAL DE UNA BENTONITA TRATADA CON UNA SAL DE AMONIO Y SU APLICACIÓN COMO ADSORBENTE DE COLORANTES $\operatorname{AZOICOS}^{13}$
}

\author{
Susana Y. Martínez Stagnaro ${ }^{(1,2) *}$, Alejandra Fuentes ${ }^{(3)}$, Joaquín Cornejo ${ }^{(3)}$ y Cristina Volzone ${ }^{(4)}$ \\ (1) Universidad Nacional del Comahue, CONICET, FAIN, AUZa, 12 de Julio y Rahue, (8340), \\ Zapala, Neuquén, Argentina. \\ (2) Universidad Nacional de La Plata, Facultad de Ingeniería, calle $47 N^{\circ}$ 257, (1900), La Plata, \\ Buenos Aires, Argentina. \\ (3) Universidad Nacional del Comahue, Facultad de Ingeniería, Asentamiento Universitario \\ Zapala, 12 de Julio y Rahue, (8340), Zapala, Neuquén, Argentina \\ (4) Centro de Tecnología de Recursos Minerales y Cerámica-CETMIC (CICPBA, CCT \\ CONICET La Plata) C.C. 49, Cno Centenario y 506, (1897) M. B. Gonnet, Buenos Aires, \\ Argentina. \\ *Correo Electrónico:syms.05@hotmail.com
}

\section{RESUMEN}

La adsorción de contaminantes en las distintas industrias para atenuar los efectos dañinos en el ambiente, es una de las alternativas actuales de descontaminación. Debido a las propiedades adsorbentes de algunas arcillas provenientes de sus características fisicoquimicas, y con la finalidad de minimizar los costos en el tratamiento propuesto se empleó como materia prima arcillosa una bentonita, abundante en nuestro país. El presente trabajo analiza el fenómeno de adsorción de colorantes azoicos, utilizados de la industria textil, por una bentonita tratada con sal de amonio. Como la capacidad de adsorción no solo depende del adsorbente sino de la sustancia a adsorber, el tratamiento anteriormente mencionado origina una estructura nano en el componente arcilloso de la bentonita (esmectita) ocasionando una mayor capacidad de retención de ciertas moléculas orgánicas. Los colorantes azoicos utilizados fueron el Yellow $G R(Y)$ y el Orange $G(O)$, en tanto que como adsorbente se utilizó una bentonita nacional tratada con la sal orgánica bromuro de hexadecil-trimetil-amonio (HDTMA-Br). Para el desarrollo del estudio, se efectuaron ensayos de adsorción en sistema batch a temperatura ambiente durante 24 horas. La cuantificación de los colorantes retenidos se realizó por medidas en el espectro UV-visible, mientras que el estudio estructural del adsorbente antes y después de la retención se efectuó empleando equipos de Difracción de Rayos X, Infrarrojo y Análisis Térmico Diferencial-Termogravimétrico. Los resultados obtenidos indicaron un cambio estructural entre las láminas del componente mineral arcilloso de la bentonita utilizada, luego del tratamiento con el amonio y retención de los colorantes. Por medio de las isotermas de adsorción se observo una retención efectiva de ambos colorantes, sin embargo, los valores alcanzados en la capacidad de retención, presentan diferencias que pueden ser atribuidas a los grupos funcionales que conforman la estructura de las distintas moléculas.

\section{TÓPICO DEL CONGRESO O SIMPOSIO: T22}

PRESENTACIÓN (ORAL O PÓSTER): $P$ (póster)

\footnotetext{
${ }^{13}$ Congreso Internacional de Metalúrgia y Materiales, $16^{\circ}$ SAM-CONAMET, Córdoba, Argentinas (2016).
} 